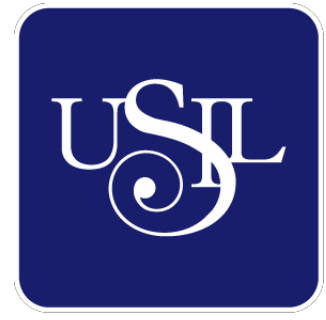

UNIVERSIDAD

SAN IGNACIO

DE LOYOLA

FACULTAD DE CIENCIAS EMPRESARIALES

Carrera de Gestión Ambiental Empresarial

\title{
PROPUESTA DE GUÍA DE GESTIÓN AMBIENTAL PARA LA UNIVERSIDAD SAN IGNACIO DE LOYOLA
}

Tesis para optar el Título Profesional de Licenciado en Gestión Ambiental Empresarial

\section{LUIGGI ANTHONY BALLARDO EVANGELISTA}

Asesor:

Susana Rocío Tejada Matos

Lima - Perú

2018 
EPÍGRAFE.

"La educación científica de los jóvenes es al menos tan importante, quizá incluso más, que la propia investigación".

Glenn Theodore Seaborg 


\section{Dedicatoria.}

A mi madre, quien siempre me alentó en mi camino; a mis hermanas, quienes siempre me sacan una sonrisa. 


\section{AGRADECIMIENTOS.}

Al finalizar esta investigación, a la cual dedique mucho esfuerzo; debo agradecer a quienes hicieron posible este sueño de titulación.

En primer lugar, agradecer a Dios por permitir que usted y yo podamos leer esta Tesis. En segundo lugar, agradecer a mi familia, en especial a mi Madre, quien siempre me aconsejó e hizo hasta lo imposible para hacer de mí un profesional. Quiero expresar también mi mayor agradecimiento a mis tíos Max y Carmen, por preocuparse siempre de su sobrino.

Mención aparte para Mimi, mi querida abuelita; quien partió hace muy poco y viene iluminándome desde entonces.

Finalmente, como olvidar a mis colegas de la Autoridad Nacional del Agua y del Programa de las Naciones Unidas para el Desarrollo, quienes alentaron siempre a este servidor. 


\section{ÍNDICE.}

1. INTRODUCCIÓN

2. PROBLEMA DE INVESTIGACIÓN 17

$\begin{array}{ll}\text { 2.1 Planteamiento del problema } & 17\end{array}$

$\begin{array}{ll}2.2 \text { Formulación del problema } & 18\end{array}$

2.3 Justificación de la investigación 19

3. OBJETIVOS E HIPOTESIS 21

$\begin{array}{ll}3.1 \text { Objetivo general } & 21\end{array}$

3.2 Objetivos específicos $\quad 21$

$\begin{array}{ll}3.3 \text { Hipótesis } & 21\end{array}$

4. LIMITACIONES 22

5. MARCO REFERENCIAL 23

5.1 Definiciones, conceptos y abreviaturas 23

$\begin{array}{ll}5.2 \text { Antecedentes } & 29\end{array}$

$\begin{array}{ll}\text { 5.3 Marco Teórico } & 31\end{array}$

$\begin{array}{ll}\text { 5.3.1 Universidad sostenible } & 31\end{array}$

5.3.2 Política e instrumentos de gestión ambiental - Sector Educación 44

5.3.3 Guía de gestión ambiental: Beneficios e implementación - Sector Educación

5.3.4 Sistema de Gestión Ambiental - Sector Educación 47

5.3.5 Diagnóstico Ambiental - Sector Educación 52

5.3.6 Educación Ambiental - Sector Educación 53

5.3.7 Participación de partes interesadas - Sector Educación 58

5.3.8 Descripción de la Universidad y su gestión ambiental 59

5.3.8.1 La Universidad San Ignacio De Loyola - USIL 59

5.3.8.2 Gestión Ambiental USIL $\quad 60$

5.4 Marco Legal - Normatividad Principal $\quad 64$

5.4.1 Pacto Mundial de la Naciones Unidas 64

5.4.2 Política Nacional del Ambiente 65

5.4.3 Política Nacional de Educación Ambiental 66

5.4.4 ISO 14001: Gestión Ambiental 67

5.4.5 ISO 26000: Responsabilidad Social 67 
5.4.6 Ley de Recursos Hídricos - Ley Nº 29338

5.4.7 Ley de Gestión Integral de Residuos Sólidos - DL N¹278 69

5.4.8 Ley de Promoción del Uso Eficiente de la Energía - Ley №27345 69

6. MÉTODO

$\begin{array}{ll}6.1 \text { Tipo de Investigación } & 71\end{array}$

6.2 Diseño de Investigación $\quad 71$

$\begin{array}{ll}6.3 \text { Categorías de análisis } & 73\end{array}$

$\begin{array}{ll}6.4 \text { Muestra } & 74\end{array}$

6.5 Instrumentos de Investigación $\quad 74$

6.6 Procedimiento de recolección de Datos $\quad 76$

7. DIAGNÓSTICO AMBIENTAL USIL

7.1 Política de Seguridad y Salud Ocupacional, Ambiente y RRSS 78

7.2 Análisis del Contexto Organizacional USIL $\quad 79$

7.3 Análisis del Liderazgo USIL $\quad 82$

7.4 Análisis de la Planificación Ambiental USIL 83

7.5 Análisis del Control y Seguimiento de aspectos ambientales significativos 83

7.6 Análisis del Soporte Institucional USIL $\quad 84$

7.7 Análisis de la Evaluación de Desempeño Ambiental USIL 90

$\begin{array}{ll}\text { 7.8 Matriz de Procesos - USIL } & 91\end{array}$

7.9 Diagnóstico de Aspectos e Impactos Ambientales USIL 92

7.9.1 Metodología del Diagnóstico Ambiental 92

7.9.2 Matriz resumen de aspectos ambientales significativos 95

8. PROPUESTA DE GUÍA DE GESTIÓN AMBIENTAL USIL 97

8.1 Propuesta de Sistema de Gestión Ambiental USIL 98

8.1.1 Contexto de la Organización 99

8.1.1.1 Comprensión de la organización y su contexto 95

8.1.1.2 Comprensión de las necesidades y expectativas de las partes interesadas 103

8.1.1.3 Delimitación del alcance de la Guía de Gestión Ambiental 104

8.1.2 Liderazgo: Comité de Gestión Ambiental USIL 105

8.1.2.1 Estructura del Comité de Gestión Ambiental 105

8.1.2.2 Modelo de Política de Gestión Ambiental USIL 107 
8.1.2.3 Funciones y responsabilidades - Comité de Gestión Ambiental

8.1.2.3.1 Funciones y responsabilidades - Presidente $\quad 110$

8.1.2.3.2 Funciones y responsabilidades - Gerente $\quad 110$

8.1.2.3.3 Funciones y responsabilidades - Directores $\quad 112$

8.1.2.3.4 Funciones y responsabilidades - Repr. Postgrado 113

8.1.2.3.5 Funciones y responsabilidades - Presidente Estudiantil 113

8.1.2.4 Consejo Estudiantil de Gestión Ambiental 114

8.1.2.4.1 Estructura Consejo Estudiantil de Gestión Ambiental

8.1.2.4.2 Integrantes Consejo Estudiantil de Gestión Ambiental

8.1.2.4.3 Proceso electoral de integrantes y Presidente del Consejo Estudiantil de Gestión Ambiental 117

8.1.3 Planificación Ambiental USIL 119

8.1.3.1 Estructura Plan Operativo Ambiental universitario 121

8.1.4 Control y seguimiento de aspectos ambientales significativos 123

8.1.5 Soporte Institucional 124

8.1.5.1 Recursos 124

8.1.5.2 Comunicación 126

8.1.5.3 Información documentada $\quad 127$

8.1.6 Evaluación de Desempeño 128

8.1.6.1 Seguimiento, medición, análisis y evaluación 128

$\begin{array}{ll}\text { 8.1.6.2 Auditoria interna } & 131\end{array}$

8.2 Educación Ambiental Universitaria USIL 132

8.2.1 Educación Ambiental en la currícula universitaria USIL 134

8.2.2 Capacitación de integrantes del Sistema de Gestión Ambiental USIL138

8.2.2.1 Lineamientos para capacitación de alumnos 139

8.2.2.2 Lineamientos para capacitación de profesores y personal administrativo 140

8.2.3 Voluntariado y Servicio Social Ambiental 141

$\begin{array}{ll}\text { 9. ENCUESTA - ESCALA LIKERT } & 143\end{array}$

9.1 Definición de la problemática 144

9.2 Selección de Expertos 144

9.3 Encuesta Likert 150 
10. RESULTADOS 151

10.1 Presentación de Resultados 151

10.2 Discusión 156

10.3 Conclusiones 158

10.4 Recomendaciones 159

11. REFERENCIAS BIBLIOGRÁFICAS 160

12. ANEXOS 165 


\section{INDICE DE FIGURAS.}

Figura 01: Universidades que cumplen con indicadores - RAI Perú.

Figura 02: Universidades que cumplen los indicadores de Gestión Ambiental.

Figura 03: Universidades que cumplen los indicadores de Gestión Ambiental (2).

Figura 04: Universidades que cumplen los indicadores de Formación.

Figura 05: Universidades que cumplen los indicadores de Extensión.

Figura 06: Universidades que cumplen los indicadores de Extensión (2).

Figura 07: Universidades que cumplen los indicadores de Investigación.

Figura 08: Universidades que cumplen los indicadores de Investigación (2).

Figura 09: Evolución de la certificación ISO 14001 - Sector educación 2000 - 2017.

Figura 10: Número de organizaciones certificadas con SGA en el Perú.

Figura 11: Fuentes de Información de Problemas Ambientales en México.

Figura 12: Universidad San Ignacio de Loyola - La Molina.

Figura 13: Producción Residuos Sólidos USIL - 2015.

Figura 14: Política de Seguridad, Salud, Medio Ambiente y Responsabilidad Social USIL, 2015.

Figura 15: Organigrama Unidad Ambiental USIL.

Figura 16: Fotografía - Unidad de Ambiente, Seguridad, Salud y Responsabilidad Social - USIL

Figura 17: Fotografía de la Unidad de Ambiente, Seguridad, Salud y Responsabilidad Social - USIL (2)

Figura 18: Mapa de procesos USIL.

Figura 19: Contexto de la Organización - USIL.

Figura 20: Grupos de Interés USIL.

Figura 21: Expectativas de las partes interesadas.

Figura 22: Organigrama del Sistema de Gestión Ambiental USIL.

Figura 23: Propuesta de Política Integrada USIL.

Figura 24: Organigrama del Consejo Estudiantil de Gestión Ambiental.

Figura 25: Distribución de Información Documentada - Formato digital. 
Figura 26: Organigrama académico USIL.

Figura 27: Encuesta "Guía de Gestión Ambiental USIL".

Figura 28: Registro de Plan de Tesis 26/10/2017 - INFOSIL.

Figura 29: Aprobación de Plan de Tesis "Guía de Gestión Ambiental para la Universidad San Ignacio de Loyola".

Figura 30: Aprobación a modificaciones realizadas en el marco de la investigación - Lic. Susana Tejada.

Figura 31: Solicitud de aprobación a modificaciones en el marco de la investigación.

Figura 32: Acciones estrategias y metas priorizadas 2017 - 2022. PLANEA.

Figura 33: Carta de validación de matriz de identificación de aspectos e impactos ambientales.

Figura 34: Acta de creación, conformación y funcionamiento del Comité de Sostenibilidad USIL.

Figura 35: Estructura de la Unidad Ambiental, Social, Seguridad y Salud Ocupacional USIL.

Figura 36: Carta de consentimiento informado - Jefa Unidad Seguridad, Salud, Medio Ambiente y Responsabilidad Social USIL.

Figura 37: Correo electrónico Secretaria del Rector.

Figura 38: Encuesta Vicepresidenta de Responsabilidad Social.

Figura 39: Carta Consentimiento Informado Vicepresidenta Responsabilidad Social.

Figura 40: Encuesta Vicerrectora de Investigación y Desarrollo.

Figura 41: Carta de Consentimiento Informado Decano de la Faculta de Ciencias Empresariales - Director de la carrera de Gestión Ambiental.

Figura 42: Correo del Decano de la Facultad de Ciencias Empresariales - Director de la carrera de Gestión Ambiental - Vicerrector Académico.

Figura 43: Encuesta Coordinador Académico de la carrera de Gestión Ambiental.

Figura 44: Carta de Consentimiento Informado Coordinador Académico de la carrera de Gestión Ambiental.

Figura 45: Correo electrónico a la Directora de Ingeniería Ambiental - Solicitud de llenado de encuesta.

Figura 46: Encuesta Coordinador Académico de la carrera de Ingeniería Ambiental.

Figura 47: Carta de Consentimiento Informado Coordinador Académico de la carrera de Ingeniería Ambiental.

Figura 48: Encuesta Coordinador Académico de la carrera de Ingeniería del Agua.

Figura 49: Carta de Consentimiento Informado Coordinador Académico de la carrera de Ingeniería del Agua. 


\section{INDICE DE TABLAS.}

Tabla 01: Universidades peruanas encuestadas RAI Perú.

Tabla 02: Certificación de SGA a nivel mundial 2013 -2017.

Tabla 03: Ejes Estratégicos - Plan Nacional de Educación Ambiental 2017 - 2022

Tabla 04: Matriz de Identificación de Aspectos e Impactos Ambientales.

Tabla 05: Matriz de Fortalezas, Oportunidades, Debilidades y Amenazas (FODA)

Tabla 06: Matriz de Identificación de Aspectos e Impactos Ambientales (2).

Tabla 07: Matriz final de identificación de aspectos e impactos ambientales.

Tabla 08: Planificación Ambiental USIL 2017.

Tabla 09: Planificación Ambiental USIL 2017- Capacitaciones efectuadas.

Tabla 10: Planificación Ambiental USIL 2017- Eventos realizados.

Tabla 11: Estructura del Plan Operativo Ambiental Universitario.

Tabla 12: Matriz de control operacional de aspectos ambientales significativos identificados.

Tabla 13: Matriz de monitoreo y medición de aspectos ambientales significativos identificados.

Tabla 14: Estructura del curso "Fundamentos del Desarrollo Sostenible".

Tabla 15: Criterios para selección de Panel de Expertos.

Tabla 16: Tabla resumen de resultados - Categoría de análisis.

Tabla 17: Tabla resumen de resultados - Categoría de análisis (2).

Tabla 18: Tabla resumen de resultados - Categoría de análisis (3).

Tabla 19: Tabla resumen de resultados - Categoría de análisis (4).

Tabla 20: Tabla resumen de resultados - Categoría de análisis (5).

Tabla 21: Tabla resumen de resultados - Categoría de análisis (6).

Tabla 22: Evolución cantidad de empresas certificación ISO 14001 - Nivel Mundial.

Tabla 23: Relación entre categoría de análisis y premisas.

Tabla 24: Matriz de identificación de impactos ambientales - Procesos Estratégicos 
Tabla 25: Matriz de identificación de aspectos e impactos ambientales - Procesos Estratégicos (2).

Tabla 26: Resumen de Aspectos e Impactos Ambientales - Procesos Estratégicos.

Tabla 27: Matriz de identificación de aspectos e impactos ambientales - Procesos Principales.

Tabla 28: Matriz de identificación de aspectos e impactos ambientales - Procesos Principales (2).

Tabla 29: Matriz de identificación de aspectos e impactos ambientales - Procesos Principales (3).

Tabla 30: Resumen de Aspectos e Impactos Ambientales - Procesos Principales.

Tabla 31: Matriz de identificación de aspectos e impactos ambientales - Procesos de apoyo.

Tabla 32: Matriz de identificación de aspectos e impactos ambientales - Procesos de apoyo (2).

Tabla 33: Resumen de Aspectos e Impactos Ambientales - Procesos de apoyo.

Tabla 34: Matriz de identificación de aspectos e impactos ambientales - Procesos de evaluación.

Tabla 35: Resumen de Aspectos e Impactos Ambientales - Procesos de evaluación

Tabla 36: Matriz de identificación de aspectos e impactos ambientales - Procesos tercerizados.

Tabla 37: Matriz de identificación de aspectos e impactos ambientales - Procesos tercerizados (2).

Tabla 38: Resumen de Aspectos e Impactos Ambientales - Procesos tercerizados.

Tabla 39: Comunicación interna.

Tabla 40: Ficha de observaciones - Auditoría.

Tabla 41: Estructura de Informe final de Auditoría.

Tabla 42: Criterios para la selección del panel de expertos.

Tabla 43: Tabla resumen de resultados - Categoría de análisis.

Tabla 44: Tabla resumen de resultados - Categoría de análisis (2).

Tabla 45: Tabla resumen de resultados - Categoría de análisis (3).

Tabla 46: Tabla resumen de resultados - Categoría de análisis (4).

Tabla 47: Tabla resumen de resultados - Categoría de análisis (5).

Tabla 47: Tabla resumen de resultados - Categoría de análisis (6).

Tabla 48: Matriz de consistencia. 


\section{RESUMEN.}

La presente Tesis tiene por objetivo conocer el grado de acuerdo de las autoridades y expertos en materia ambiental de la Universidad San Ignacio de Loyola (USIL) en relación a la propuesta de Guía de Gestión Ambiental como herramienta que contribuirá al cumplimiento de los compromisos ambientales establecidos en la Política Integrada de la universidad.

En este sentido, como primera etapa, se ha procedido a desarrollar un Diagnóstico Ambiental con la finalidad de conocer los aspectos e impactos ambientales que genera la universidad; y analizar la gestión ambiental actual de la misma.

Como segunda etapa, se elaboró una propuesta de Guía de Gestión Ambiental que incluye las siguientes partes: (i) Propuesta de Sistema de Gestión Ambiental; y, (ii) Educación ambiental.

Asimismo, se han expuesto indicadores, conceptos teóricos sobre gestión ambiental, elementos del contexto internacional de gestión ambiental en el ámbito educacional, experiencias internacionales y legislación nacional vigente relacionada al tópico.

Mientras que, como tercera etapa, se realizaron encuestas, usando la escala de medición Likert, con la finalidad de conocer el grado de acuerdo de autoridades y expertos en materia ambiental USIL, en relación al diseño e implementación de la propuesta de Guía de Gestión Ambiental.

Finalmente, se analizan los resultados obtenidos con el método precedente y se determina el grado de acuerdo de autoridades y expertos en materia ambiental de la universidad, en relación al diseño e implementación de la propuesta de Guía de Gestión Ambiental; instrumento que contribuirá al cumplimiento de los compromisos ambientales establecidos en la Política Integrada de la universidad. 


\begin{abstract}
.
The objective of this thesis is to know the degree of agreement of the authorities and experts in environmental matters of the University San Ignacio de Loyola (USIL) in relation to the proposal of Environmental Management Guide as a tool that will contribute to the fulfillment of the established environmental commitments in the Integrated Politics of the university.

In this sense, as a first stage, we have proceeded to develop an Environmental Diagnostic in order to know the environmental aspects and impacts generated by the university; and analyze the current environmental management of the same.

As a second stage, a proposal for an Environmental Management Guide was prepared, which includes the following parts: (i) Proposal for an Environmental Management System; and, (ii) Environmental education.

Likewise, indicators, theoretical concepts on environmental management, elements of the international context of environmental management in the educational field, international experiences and current national legislation related to the topic have been exposed.

While, as a third stage, surveys were conducted, using the Likert scale of measurement, in order to know the degree of agreement of authorities and environmental experts USIL, in relation to the design and implementation of the proposal of Environmental Management Guide.

Finally, the results obtained with the previous method are analyzed and the degree of agreement of authorities and experts in environmental matters of the university is determined, in relation to the design and implementation of the proposal of Environmental Management Guide; tool that will contribute to the fulfillment of the environmental commitments established in the Integrated Policy of the university.
\end{abstract}




\section{INTRODUCCIÓN.}

El intenso desarrollo tecnológico de las últimas décadas se ha visto acompañado por la creciente insostenibilidad entre las relaciones del sistema productivo y ecosistemas del planeta; así como el progresivo incremento de los posibles riesgos de las formas de vida; incluyendo en funcionamiento de la biosfera. Todo ello ha dado lugar a riesgos ambientales con carácter global, los cuales poseen conexiones locales no siempre evidentes, que generan conflictos sociales y resultan complicado de afrontar desde las políticas tradicionales (Espluga y Prades, 2015).

La inadecuada gestión de los recursos del planeta, tendría efectos negativos en los periodos actuales, así como en periodos futuros; lo cual podría limitar las posibilidades de desarrollo de las generaciones siguientes (Enkerlin Hoeflich, 1997).

En la actualidad, bajo un contexto de cambio climático, las organizaciones a nivel mundial muestran preocupación por reducir, cada vez más, sus impactos ambientales, dado que, en un mundo tan competitivo, mejorar el desempeño ambiental de las organizaciones representa una necesidad latente (Rodríguez Córdova, 2014).

El Perú, no es ajeno a esta tendencia mundial, y gran cantidad de las organizaciones privadas e instituciones públicas, buscan gestionar, de forma eficiente, sus impactos ambientales; dado que la nula gestión de estos puede representar una amenaza a nivel organizacional (Fernández y Vitora, 1997).

El establecimiento de políticas ambientales corporativas permite brindar principios y lineamientos para orientar la toma de decisiones y lograr resultados óptimos en materia ambiental en el accionar de la empresa (Formoso, 2011). En tal sentido, los aspectos e impactos ambientales en organizaciones se gestionan a partir del uso y aplicación de Políticas e instrumentos de gestión ambiental diseñados a la medida de las mismas.

El diseño de instrumentos de gestión ambiental, tales como Guías de Gestión Ambiental o Sistemas de Gestión Ambiental, buscan identificar, analizar, controlar y gestionar los impactos ambientales dentro de las organizaciones, con la finalidad de transformar su gestión en una ventaja competitiva (Pinillo y Fernández, 2011).

Actualmente, las organizaciones buscan el diseño e implementación de instrumentos de gestión ambiental debido a que son herramientas que permiten la consecución de resultados enmarcados en la política corporativa. Asimismo, marcan la dirección 
organizacional de las acciones a realizar y representan sistemas estructurados que incluyen la estructura organizativa - corporativa, planificación, procesos, operaciones, recursos y responsabilidades para llevar a cabo, mantener y revisar los objetivos ambientales de la organización (ISO, 2016).

El diseño de instrumentos de gestión ambiental, tales como Guías de Gestión Ambiental Corporativas, es una estrategia netamente de negocios, la cual permite agregar valor a quien la aplique, crear una diferenciación positiva ante la competencia, mejorar la relación con los grupos de interés y crear buena imagen corporativa (Pinillo y Fernández, 2011).

Una organización social y ambientalmente responsable debe identificar y mitigar los impactos ambientales que genera su actividad productiva o de servicios (Sánchez, 2010). Debido a la limitada fiscalización y supervisión en materia ambiental que se tiene en el país, la mitigación y prevención ante pasivos ambientales no está internalizada en la población, y mucho menos en las organizaciones (SPDA, 2010).

En el contexto educativo, las universidades peruanas vienen realizando esfuerzos para la incorporación de la perspectiva ambiental en sus políticas institucionales. En este sentido, el estudio "Incorporación de la perspectiva ambiental en universidades peruanas", determinó que 19 universidades peruanas (11 privadas y 8 públicas) presentaban la perspectiva ambiental en su política institucional; sin embargo, en la mayoría de casos, esta referencia era superficial (Cárdenas, 2014). Por otro lado, de forma contradictoria, buscan crear un nuevo perfil de estudiante, el cual no será ajeno al impacto social y ambiental que sus actividades generen. Esto representa la doble moral ambiental universitaria (Triguera, 2011).

Las organizaciones del sector educación a nivel mundial, dígase universidades públicas o privadas, en su gran mayoría, presentan políticas de gestión ambiental y realizan diversas acciones bajo el contexto de educación ambiental universitaria (Martínez, 2008). Sin embargo, gran cantidad de estas acciones no se interrelacionan o no están alineadas a los principios de la política ambiental de la organización, ni contribuyen a la consecución de objetivos plasmados en esta, esto quiere decir que estas acciones realizadas, pese a ser adecuadas, pueden estar aisladas.

La ausencia de instrumentos de gestión ambiental en universidades dificulta la conexión entre actividades y políticas, dado que estos son la plataforma sobre la cual se realizan actividades alineadas a los principios de la política, con el objetivo de cumplir las metas institucionales previamente establecidas (Alba, 2006). 


\section{PROBLEMA DE INVESTIGACIÓN.}

\subsection{Planteamiento del Problema.}

La Universidad San Ignacio de Loyola (USIL), en su Reporte de Sostenibilidad 2015, presenta su Política de Seguridad, Salud Ocupacional y Medio Ambiental (Política Integrada), en la que se compromete a:

- Identificar los aspectos ambientales significativos y gestionarlos eficientemente para proteger el medio ambiente.

- Exigir que proveedores, contratistas, trabajadores directos, trabajadores autónomos y personas bajo modalidad formativa laboral cumplan con las normas aplicables de seguridad, salud ocupacional y medio ambiente.

- Revisar y analizar periódicamente los resultados del Sistema de Gestión en Seguridad, Salud y Medio Ambiente, propiciando así la mejora continua del sistema para lograr la excelencia mundial.

- Garantizar la compatibilidad o la integración del Sistema de Gestión de la Seguridad, Salud y Medio Ambiente con los otros sistemas de gestión de la Organización.

- Identificar y garantizar el cumplimiento de los requisitos y obligaciones legales en materia de Medio Ambiente, así como los asumidos voluntariamente por la Organización.

- Diseñar y desarrollar planes de capacitación, entrenamiento y sensibilización para todos los colaboradores en temas ambientales.

- Garantizar la participación de los trabajadores y sus representantes en el Sistema de Gestión de Medio Ambiente de la Organización.

La Política Integral USIL, dictamina los principios y lineamientos para orientar la toma de decisiones y lograr resultados óptimos en materia ambiental. Actualmente, USIL desarrolla actividades e iniciativas ambientales en sus campus universitarios, tal y como se evidencia en el Reporte de Sostenibilidad USIL 2015; sin embargo, estas actividades requieren estar interrelacionadas entre sí; de forma tal que contribuyan al cumplimiento de los compromisos ambientales establecidos en su Política Integrada. 
La Gestión Ambiental en USIL no cuenta en la actualidad con un instrumento de gestión ambiental que permita establecer parámetros, estrategias, reglas y lineamientos para la realización de actividades y procesos consecuentes que estén alineados a los objetivos institucionales y acciones estratégicas establecidas en la Política Integrada de la universidad.

Los instrumentos de gestión ambiental en universidades, llámese Guías de Gestión Ambiental o Sistemas de Gestión Ambiental, permiten desarrollar y cumplir los objetivos institucionales enmarcados en la Política de Gestión Ambiental de la universidad (Vallaeys, 2008).

Según la norma internacional ISO 14001 - Gestión Ambiental (2015), las políticas y principios por los cuales se rige una institución u organización son dictaminados siempre por los altos funcionarios, alta dirección, autoridades o expertos en la temática; dado que son ellos quienes direccionan el futuro y fijan las metas de las organizaciones. USIL, al ser una institución educativa, cuenta con autoridades y expertos en materia ambiental, y son estos los que dictaminan los compromisos ambientales establecidos en la Política Integrada USIL y velan por su cumplimiento.

Estas autoridades, asesorados por expertos, son creadores de la Política Integrada USIL, la cual incluye el componente ambiental. Asimismo, como tomadores de decisión; deben evaluar la necesidad de implementar a futuro una Guía de Gestión Ambiental, como instrumento que contribuya al cumplimiento de compromisos ambientales establecidos en la Política Integrada USIL.

\subsection{Formulación del Problema.}

¿Qué tan de acuerdo están las autoridades y expertos en materia ambiental de la Universidad San Ignacio de Loyola en relación al diseño e implementación de la propuesta de Guía de Gestión Ambiental, instrumento que contribuirá al cumplimiento de los compromisos ambientales establecidos en la Política Integrada de la universidad? 


\subsection{Justificación de la investigación.}

Se estima conveniente el análisis del presente caso de estudio, debido a que la Universidad San Ignacio de Loyola no cuenta en la actualidad con un instrumento de gestión ambiental que establezca criterios, lineamientos y estrategias unificadas para la ejecución de actividades y procesos que contribuyan al cumplimiento de los objetivos ambientales organizacionales y acciones estratégicas establecidas en la Política Integrada de la universidad.

La implementación de instrumentos de gestión ambiental en organizaciones, contribuyen al cumplimiento de los objetivos institucionales ambientales; siempre y cuando estos instrumentos se alineen a la Política organizacional. En este sentido, el diseño e implementación de un instrumento de gestión como la Guía de Gestión Ambiental USIL, permitirá obtener información y datos en cuanto al origen y efectos de los impactos generados por la acción, decisión u omisión de la universidad. Por otro lado, la presente Guía es un instrumento para la toma de decisiones, la cual facilitará el desarrollo de estrategias para el logro de los objetivos establecidos por la Universidad San Ignacio de Loyola.

Las autoridades USIL, asesorados por expertos en materia ambiental, son quienes deben velar por el cumplimiento de los compromisos ambientales establecidos en la Política Integrada; y deben dictaminar la necesidad de implementar a futuro una Guía de Gestión Ambiental, como instrumento que contribuya al cumplimiento de los compromisos ambientales establecidos en la Política mencionada. Es preciso mencionar que esta propuesta de Guía de Gestión Ambiental, representa la base de un instrumento de gestión perfectible, el cual busca mejorar el desempeño ambiental de la organización.

La presente investigación permite conocer el grado de acuerdo de autoridades y expertos en materia ambiental de la universidad, en relación al diseño e implementación de un instrumento de gestión que contribuya a la mejora de procesos y permita presentar un atributo diferenciador frente a la competencia. Asimismo, este instrumento permite gestionar adecuadamente los recursos, identificar y proponer medidas de mitigación ante los aspectos e impactos ambientales significativos diagnosticados; $y$, finalmente, representa un instrumento que influye en la imagen corporativa de la institución educativa, debido a que forma profesionales con enfoque ambiental, reforzando su compromiso de responsabilidad social. Para conocer el 
grado de acuerdo de autoridades y expertos, se ha previsto realizar encuestas, usando la escala de medición Likert.

La necesidad de contar con un instrumento de gestión ambiental es poseer una herramienta o plataforma en la cual se detalle explícitamente el accionar de la universidad, es decir, una herramienta (documento guía) que alinee todas las acciones de la universidad con el cumplimiento de los compromisos institucionales.

Esta propuesta de Guía de Gestión Ambiental (instrumento de gestión ambiental) es capaz de orientar acciones del personal administrativo, docentes y alumnos a través de reglamentos, lineamientos, dispositivos técnicos y medidas de control seguimiento, con la finalidad de contribuir al cumplimiento de los compromisos ambientales establecidos Política Integrada de la universidad. Es decir, la Guía representa un instrumento para la toma de decisiones.

La Guía de Gestión Ambiental USIL tiene como base un diagnóstico ambiental institucional, el cual permite identificar y categorizar los aspectos e impactos ambientales originados en las instalaciones de la universidad. Asimismo, otorga una vista actual de la gestión ambiental en la universidad, propone medidas estratégicas para mitigar los impactos significativos identificados; y, plantea la Propuesta de Sistema de Gestión Ambiental (Capítulo I) que incluye lo siguiente:

1. Contexto de la organización: Determinación de partes interesadas, así como sus expectativas y necesidades en relación con la organización.

2. Liderazgo: Compromiso institucional y funciones del personal.

3. Planificación Ambiental: Planificación de la gestión ambiental en la universidad.

4. Control y Seguimiento de Aspectos Ambientales Significativos: Instrumento e instrucciones para el control y seguimiento de impactos ambientales significativos diagnosticados.

5. Soporte Institucional: Recursos institucionales, comunicación interna - externa y gestión de la documentación.

6. Evaluación del Desempeño: Evaluación del accionar ambiental de la universidad, a través de instrumentos para el control, seguimiento y establecimiento de auditorías, en un periodo de tiempo determinado de acuerdo al alcance establecido.

Finalmente, incluye un capítulo de Educación ambiental, donde se proponen estrategias para capacitar - sensibilizar a la comunidad universitaria. 


\section{OBJETIVOS E HIPÓTESIS.}

\subsection{Objetivo General.}

- Conocer el grado de acuerdo de las autoridades y expertos en materia ambiental de la Universidad San Ignacio de Loyola en relación al diseño e implementación de la propuesta de Guía de Gestión Ambiental, instrumento que contribuirá al cumplimiento de los compromisos ambientales establecidos en la Política Integrada de la universidad.

\subsection{Objetivos Específicos.}

- Desarrollar el Diagnóstico Ambiental de la universidad con el objetivo de mostrar una vista actual de la gestión ambiental en la universidad e identificar aspectos e impactos ambientales significantes y priorizarlos.

- Diseñar una propuesta de Guía de Gestión Ambiental que incluya los siguientes instrumentos de gestión ambiental: (i) Propuesta de Sistema de Gestión Ambiental; y, (ii) Educación ambiental.

- Realizar encuestas, usando la escala de medición Likert, para conocer el grado de acuerdo de autoridades y expertos en materia ambiental de la universidad, en relación al diseño e implementación de la propuesta de Guía de Gestión Ambiental, instrumento que contribuirá al cumplimiento de los compromisos ambientales establecidos en la Política Integrada de la universidad.

\subsection{Hipótesis.}

Pese a que la investigación es netamente cualitativa descriptiva, se ha establecido una hipótesis de trabajo. Según Carlos Muñoz Razo, en su libro "Como elaborar y asesorar una investigación de Tesis" segunda edición, año 2011; manifiesta lo siguiente para el establecimiento de hipótesis en investigaciones cualitativas: "Si bien se establece una hipótesis de trabajo, ésta no necesariamente se comprueba con datos de medición numérica o con interpretación estadística. Sin embargo, con los resultados obtenidos es posible interpretar y explicar la realidad estudiada".

La hipótesis de trabajo es la siguiente: Las autoridades y expertos en materia ambiental de la Universidad San Ignacio de Loyola están de acuerdo con el diseño e implementación de la propuesta de Guía de Gestión Ambiental, instrumento que contribuirá al cumplimiento de los compromisos ambientales establecidos en la Política Integrada de la universidad. 


\section{LIMITACIONES.}

Con fecha 26 de octubre 2017, se registra el Plan de Tesis "Guía de Gestión Ambiental para la Universidad San Ignacio de Loyola" (Anexo $\mathbf{N}^{\circ}$ 01: Registro de Plan de Tesis), el mismo que fue aprobado el 24 de noviembre 2017 (Anexo N 02: Aprobación de Plan de Tesis).

En este sentido, en el mencionado Plan consta el diseño de la propuesta de Guía, así como la aplicación del método Delphi, con la finalidad de conocer el grado de acuerdo autoridades y expertos en materia ambiental de la universidad en relación al diseño e implementación de la propuesta de Guía de Gestión Ambiental.

En el desarrollo de la presente investigación, se modificó el método Delphi por la aplicación de encuestas mediante el uso de la escala de medición Likert; lo cual no representa modificación en la consecución del objetivo de la investigación. La modificación radica en que el método Delphi requiere que un individuo efectúe una encuesta dos o más veces con la finalidad de reducir la dispersión de opiniones. Esto representa una limitación dado que las autoridades y expertos en materia ambiental de la universidad disponen de reducido tiempo para el análisis de la propuesta de "Guía de Gestión Ambiental" y posterior desarrollo de encuestas.

Esta modificación, cuenta con el aval técnico de la asesora de la presente investigación designada por la universidad, Lic. MBA. PhD(c) Susana Tejada (Anexo No 03: Aprobación a las modificaciones realizadas en el marco de la investigación" Anexo N 04: Solicitud de aprobación a modificaciones - Bach. Luiggi Ballardo). Asimismo, en el anexo precitado, constan modificaciones en cuanto al título y objetivo de la investigación en relación a lo establecido en el Plan de Tesis.

Posterior a las modificaciones indicadas, el desarrollo de la presente investigación contó con las limitaciones siguientes:

- Según el organigrama USIL, existe un número limitado de autoridades y expertos en materia ambiental en la universidad.

- Existen cargos que son ocupados por un mismo profesional, lo cual reduce el número de autoridades y expertos en materia ambiental a encuestar.

- Autoridades y expertos en materia ambiental de la universidad no disponen de tiempo necesario para el análisis de un instrumento de gestión ambiental; y posterior llenado de encuestas. 


\section{MARCO REFERENCIAL.}

\subsection{Definiciones, conceptos y abreviaturas.}

\section{Definiciones:}

Para el propósito de este Informe de Tesis, se utilizan las siguientes definiciones extraídas de la norma internacional ISO 14001:2015, debido a que es la metodología más utilizada en términos de certificación en gestión ambiental. Las definiciones son las siguientes:

- Sistema de Gestión Ambiental:

Parte del sistema de gestión usada para gestionar aspectos ambientales, cumplir requisitos legales y otros requisitos, y abordar los riesgos y oportunidades.

- Política Ambiental:

Intenciones y dirección de una organización, relacionadas con el desempeño ambiental, como las expresa formalmente su alta dirección.

- Instrumento de Gestión Ambiental:

Instrumento que permite la implementación, aplicación y reglamentación de la Política Ambiental. Los instrumentos de gestión ambiental como herramientas decisorias están basados en disciplinas que proveen de información rigurosa, sistemática y validada por medio de investigaciones que buscan reducir al mínimo el error de una decisión.

- Objetivo Ambiental:

Objetivo establecido por la organización, coherente con su Política Ambiental.

- Organización:

Persona o grupo de personas que dirige y controla una organización al más alto nivel.

- Medio Ambiente:

Entorno en el cual una organización opera, incluidos el aire, el agua, el suelo, los recursos naturales, la flora, la fauna, los seres humanos y sus interrelaciones.

- Aspecto Ambiental:

Elemento de las actividades, productos o servicios de una organización que interactúa, o puede interactuar, con el medio ambiente. 
- Impacto Ambiental:

Cambio en el medio ambiente, ya sea adverso o beneficioso, como resultado total o parcial de los aspectos ambientales de una organización.

- Requisito:

Necesidad o expectativa establecida, generalmente implícita u obligatoria.

- Riesgo:

Efecto de la incertidumbre.

- Ciclo de Vida:

Etapas consecutivas e interrelacionadas de un sistema de producto (o servicio), desde la adquisición de materia prima o su generación a partir de los recursos naturales hasta la disposición final del mismo.

- Proceso:

Conjunto de actividades interrelacionadas o que interactúan, las cuales transforman las entradas en salidas.

- Acción Correctiva:

Acción para eliminar la causa de una no conformidad y evitar que vuelva a ocurrir.

- Auditoria:

Proceso sistemático, independiente y documentado para obtener las evidencias de auditoria y evaluarlas de manera objetiva con el fin de determinar el grado en el que se cumplen los criterios auditables.

- Mejora Continua:

Actividad recurrente para mejorar el desempeño en la organización.

- Eficacia:

Grado en el que se realiza las actividades planificadas y se logran los resultados planificados o esperados.

- Indicador:

Representación medible de la condición o el estado de las operaciones, la gestión, o las condiciones.

- Medición:

Proceso para determinar un valor. 


\section{Conceptos:}

Asimismo, en el contexto de la presente investigación, se utilizan los conceptos siguientes:

\section{- Desarrollo Sostenible:}

Según el Informe Brundtland, 1987, el desarrollo sostenible es el desarrollo que satisface las necesidades de la generación presente sin comprometer la capacidad de las generaciones futuras para satisfacer sus propias necesidades". Esta interpretación es tridimensional; dado que considera tres dimensiones: dimensión económica, dimensión social y dimensión ambiental.

\section{- Responsabilidad Social:}

El Libro Verde de la Unión Europea, define la Responsabilidad Social Empresarial cómo concepto por el cual las empresas deciden contribuir voluntariamente a mejorar la sociedad y a preservar el medio ambiente. A través suyo, las empresas se conciencian del impacto de su acción sobre todos y expresan su compromiso de contribuir al desarrollo económico, a la vez que, a la mejora de la calidad de vida de los trabajadores y sus familias, de la comunidad local donde actúan y de la sociedad en su conjunto (Eur-lex.europa.eu, 2017).

\section{- Responsabilidad Social Universitaria:}

La Responsabilidad Social Universitaria (RSU) es el compromiso de la universidad ante las exigencias éticas de orientar sus actividades hacia el desarrollo sostenible, considerando el impacto ambiental y social que puedan tener estas.

La Responsabilidad Social Universitaria exige, desde una visión holística, articular las diversas partes de la institución en un proyecto de promoción social de principios éticos y de desarrollo social equitativo y sostenible, para la producción y transmisión de saberes responsables y la formación de profesionales ciudadanos igualmente responsables (Francois Vallaeys, 2014).

Para efectos de esta investigación, se utilizará el concepto de responsabilidad social como un contrato social de la universidad hacia la sociedad, propuesto por Vallaeys:

"Tú, Sociedad, me garantizas autonomía y recursos, y yo, Universidad, te doy (1) más Democracia a través de la formación de estudiantes y ciudadanos responsables, (2) más Ciencia responsable, lúcida y abierta a la solución de los problemas sociales de la humanidad, y (3) mejor Desarrollo equitativo, innovador y sostenible, con profesionales competentes y comprometidos (Francois Vallaeys, 2014). 


\section{- Gestión Ambiental:}

Según el Glosario de Términos sobre Medio Ambiente de la UNESCO y del Programa Internacional de Educación Ambiental del PNUMA, la Gestión Ambiental se define como la etapa central en el proceso de ordenamiento ambiental, puesto que consiste propiamente en las decisiones sobre qué maniobras realizar, cómo realizarlas, en qué plazos y en último término, en la selección paso a paso de las opciones posibles y más adecuadas en el proceso de desarrollo.

\section{- Universidad con enfoque ambiental:}

Las Universidades tienen una responsabilidad social y por esta razón, deben promover patrones de desarrollo que sean compatibles con un ambiente seguro, un balance ecológico, la conservación de la biodiversidad, ya que tienen la posibilidad de capacitar una comunidad en habilidades de sostenibilidad y que ésta es un gran potencial para el presente y para las metas propuestas en este campo a mediano y largo plazo (Viebahn, 2002).

Como lo expresa José Sarukhan (1998), "las Universidades deben extender sus responsabilidades a la formación de personas libres y universales, capaces de pensar, decidir y actuar por sí mismas, críticas y autocríticas, dueñas de libertad interior, social, política, ambiental, sin prejuicios ni sectarismos, siendo ésta, su responsabilidad con la comunidad".

"En una sociedad, la enseñanza superior es a la vez uno de los motores de desarrollo económico y uno de los polos de la educación a lo largo de la vida. (...). Son en primer lugar las universidades las que agrupan el conjunto de las funciones tradicionales asociadas al progreso y la transmisión del saber: investigación, innovación, enseñanza y formación, educación permanente (...) cooperación internacional. Todas estas funciones pueden contribuir al desarrollo sostenible. En su condición de centros autónomos de investigación y creación del saber, las universidades pueden ayudar a resolver algunos problemas de desarrollo que se plantean a la sociedad" (Delors et al., 1996: 149-150).

\section{- Sociedad Sostenible:}

Una sociedad sostenible será aquella en que todos los aspectos de la vida cívica y personal sean compatibles con el desarrollo sostenible y todas las dependencias públicas, en todos los niveles de gobierno, trabajen aunadas para avanzar hacia ese tipo de sociedad (UNESCO, 1997). 


\section{- Estrategia organizacional:}

Refiere a la creación, implementación y evaluación de las decisiones dentro de una organización, sobre la cual se busca la consecución de objetivos a largo plazo. En este sentido, debe contar con un plan estratégico. Los procesos de gestión estratégica (formulación, implementación, ejecución y control) deben funcionar de forma integrada y sistémica, con la finalidad de lograr los objetivos propuestos (Castellanos y Cruz, 2014).

La estrategia organizacional concibe a la organización como un todo. Se enfoca al alcance y asignación de recursos, dado que el diseño e implementación de la presente estrategia proviene desde el más alto nivel organizacional. En este sentido, a nivel organizacional, se busca el análisis del entorno; así como la formulación de la misión, visión y objetivos, incluyendo una perspectiva a largo plazo.

\section{- Estrategia Corporativa Ambiental:}

Referida al plan que tiene por finalidad la mitigación de impactos sobre el ambiente ocasionados por el accionar de una organización. Para la integración del ambiente en la estrategia corporativa de una organización se debe implementar tres factores: (i) Misión: Se debe integrar el componente ambiental de forma transversal en la organización; (ii) Objetivos: La consecución de objetivos debe considerar la gestión de los impactos ambientales; y, (iii) Análisis estratégico: Se debe integrar el componente ambiental en la negociación, análisis interno y externo de la organización, análisis de la competencia, valor agregado, rentabilidad, cadena de valor, recursos y capacidades (ESAN, 2016)

La estrategia ambiental corporativa debe poseer aspectos tales como: (i) evitar actividades riesgosas al entorno natural (minimizar riesgos ambientales); (ii) promover la participación ambiental (concientizar); y, (iii) evitar y prevenir la contaminación.

La implementación de estrategias ambientales a nivel corporativo permite la optimización de recursos, fortalecimiento de políticas de responsabilidad social, creación de valor agregado, incremento en la percepción de la imagen organizacional, ingreso a nicho de mercado y empresas que consideren el componente ambiental, entre otros. 


\section{Abreviaturas.}

Adicionalmente, en el marco de la presente investigación, se utilizan las abreviaturas siguientes:

USIL: Universidad San Ignacio de Loyola.

RS: Responsabilidad Social.

RSU: Responsabilidad Social Universitaria.

SGA: Sistema de Gestión Ambiental.

CGA: Comité de Gestión Ambiental.

CEGA: Consejo Estudiantil de Gestión Ambiental.

LMP: Límite Máximo Permisible.

ECA: Estándar de Calidad Ambiental.

EPS-RS: Empresa Prestadora de Servicios de Residuos Sólidos.

ISO: International Organization for Standardization.

MINAM: Ministerio del Ambiente del Perú

MINEDU: Ministerio de Educación del Perú.

UNESCO: Organización de las Naciones Unidas para la Educación, Ciencia y Cultura PNUMA: Programa de las Naciones Unidas para el Medio Ambiente.

PNUD: Programa de las Naciones Unidas para el Desarrollo. 


\subsection{Antecedentes.}

A nivel mundial, la implementación de instrumentos de gestión ambiental, tales como Guías de Gestión Ambiental a nivel de universidades, viene forjándose camino gracias a los grandes beneficios que trae consigo.

En Europa, precisamente en España, en el año 2007, la Universidad de Murcia estableció el Programa de Gestión Ambiental de Campus Sostenible, en la cual planteaba distintos objetivos como: (i) La conservación de espacios verdes como fuente de biodiversidad; (ii) La correcta gestión de residuos, tanto en exterior como en interior; (iii) Optimización del uso de recursos; (iv) Impulsar el uso de energías renovables en el campus; (v) Gestionar el agua a través del uso de tecnologías verdes; (vi) Mejorar la calidad ambiental de las instalaciones; (vii) La movilidad sostenible, apoyada en transportes alternativos; (viii) Educación ambiental del colectivo universitario; (ix) La mejora del entorno y los servicios ambientales; y, (x) Impulsar iniciativas de desarrollo sostenible en nuestros Campus (Um.es, 2017).

El Vicerrectorado de Economía e Infraestructura de la Universidad de Murcia, con la finalidad de realizar actividades orientadas al cumplimiento de los objetivos institucionales enmarcados en el Programa, decidió, en el año 2012, diseñar la Guía de Gestión Ambiental de Campus Sostenible de la Universidad de Murcia. Esta guía enfatiza en los retos que posee la universidad e iniciativas que propicia esta para la consecución de sus objetivos, en aras de poseer campus sostenibles.

Por otro lado, en el año 2013, Rut Abraín Sánchez, juntamente con Pilar Piñeiro y Sergio Ramos, investigadores de la Universidad de Vigo, investigaron el siguiente caso de estudio: "Sistemas de Gestión Ambiental como instrumento de Gestión Ambiental en las universidades españolas". El alcance de la investigación fueron todas las universidades españolas que contaban con permisos para desempeñarse, ya sean estas públicas o privadas. La técnica usada fue la encuesta y el instrumento, el Cuestionario.

El estudio confirmó que, de las 79 universidades estudiadas, 23 de estas cuentan con un instrumento de gestión ambiental. Para efectos de este caso de estudio se definió un Manual de Sistema de Gestión Ambiental como un instrumento de gestión. Esto se traduce a que el $29 \%$ de las universidades en España cuentan con instrumento de gestión ambiental. 
Asimismo, la Universidad Politécnica de Valencia (UPV), en el año 1999, redacta y aprueba su Política Ambiental. El año 2007, tras no lograr cumplir con sus compromisos, decide modificarla y permite la creación de un instrumento de gestión ambiental denominado "Manual para la implementación de un sistema de gestión ambiental" (Consejo de gobierno UPV, 2010). En este sentido, la UPV se comprometió a mantener su sistema de gestión ambiental homologado al Reglamento Europeo de Ecogestión y Ecoauditoría (EMAS) y a la norma UNE EN ISO 14001, los cuales establecen objetivos ambientales exigentes, accesibles al público, controlando los progresos de forma continua, elaborando declaraciones ambientales anuales, que serán públicas, y difundiéndolas tanto a la universidad como al resto de la sociedad (UPV.es, 2007).

En Perú, existen universidades que poseen instrumentos de gestión ambiental que funcionan como plataformas para el cumplimiento de compromisos institucionales. Estos instrumentos marcan la dirección de actividades en materia de gestión ambiental de la universidad; así como de sus grupos de interés. Pese a esto, ninguna universidad peruana, ha implementado o certificado un Sistema de Gestión Ambiental (SGA). No obstante, existen investigaciones que dan a conocer propuestas de implementación de SGA; sin embargo, estas propuestas se limitan a facultades individuales, mas no a campus universitarios.

Este es el caso de la Pontificia Universidad Católica del Perú (PUCP), la cual cuenta con propuestas de implementación de SGA en sus distintas facultades. Una de estas para la Facultad de Ciencias e Ingeniería, elaborada por María del Carmen Joaquín Laguna en 2007. Asimismo, la Universidad Nacional Mayor de San Marcos (UNMSM), cuenta con una propuesta de "Guía para la Implementación de un Instrumento de Gestión Ambiental para el Centro de Información y Control Toxicológico (CICOTOX) de la Facultad de Farmacia y Bioquímica", cuyas autoras fueron Patricia Cabrera Melgar y Gabriela Loyola Cajahuaringa en 2007. En ambos casos de estudio se elaboró un diagnóstico ambiental como línea base, el cual sirvió como insumo sustancial para el diseño de la Guía de implementación del instrumento de gestión (SGA). A partir de estas investigaciones, en todos los casos de estudio, se concluye que es necesario el diseño e implementación de un instrumento de gestión capaz de unificar y orientar las acciones ambientales de las instituciones educativas con la finalidad de cumplir objetivos institucionales. 


\subsection{Marco Teórico.}

\subsubsection{Universidad Sostenible.}

Las universidades deben aspirar a ser sostenibles. Una universidad sostenible es aquella que no depende de los recursos que le puedan proporcionar otros, cuyo desarrollo (actividad) no impacta de forma relevante al medio ambiente; y que posea una comunidad universitaria (estudiantes, directivos, profesores y trabajadores) social y ambientalmente responsable (Benayas, 2004).

En otra definición, una universidad sostenible es un ente socialmente responsable con relación a los temas de salud, bienestar humano y ecológico. Busca la generación de conocimientos sociales y ambientales (Cole, 2003).

Las universidades, aquellas responsables y conscientes de su misión social, deben aspirar ser un espacio de formación para la búsqueda de la excelencia académica y el compromiso (misión individual) social. A partir de este punto, se viene trabajando la sostenibilidad ambiental, como pilar para la conseguir el equilibro de la comunidad.

Este último término de sostenibilidad se viene concibiendo desde los años 1970; a partir de la Declaración de Estocolmo donde se anunció la necesidad de incluir la sostenibilidad en la educación superior. Asimismo, fue en esta conferencia donde por primera vez se reconoció la estrecha relación entre hombre y medio ambiente para hablar sobre el concepto de sostenibilidad (UNESCO, 1972).

A partir de este acontecimiento, se vienen suscitando iniciativas para el fomento de la sensibilidad ambiental entre el alumnado universitario, con el objetivo de sensibilizar sobre la necesidad de proteger y respetar la naturaleza, de forma tal que tengamos un mejor futuro a corto, mediano y largo plazo.

Si consideramos a las universidades como ciudades pequeñas, con el detalle de que es aquí donde emerge el conocimiento, surge la siguiente afirmación elaborada por Goran Olof Wall, profesor de la universidad de Tecnología Chalmers - Suecia: "La ventaja es que en la Universidad las cosas se hacen basadas en el conocimiento, en la ciencia, en la investigación, y no se cometerían errores innecesarios o típicos que se cometen en desarrollos de este tipo. Esto haría que toda la ciudad se interesara en los resultados que tuviera la Universidad y la metodología sería la misma, ya que los problemas de la Universidad son los mismos de la ciudad, aunque en una escala diferente" (Wall, 2008). 
En los últimos 20 años, algunas universidades vienen internalizando el concepto de sostenibilidad, algunas solo al nivel de apertura de maestrías o especializaciones relacionados al tópico; y otras, imitables, han diseñado e implementado sus propias políticas ambientales con el objetivo de transformarse a un campus sostenible (Caride, 2006). Muchas universidades de Europa, Estados Unidos, Canadá, Australia, Asia y América del Sur empiezan a reconocer su responsabilidad con relación al medio ambiente. A modo de ejemplo, algunas hablan de transformar sus campus en campus sostenibles, otras hablan de edificaciones inteligentes y eco amigables; y, finalmente, otras hablan del término eco universidades.

Estas tendencias, algunas más ambiciosas que otras, siguen 3 principios o directrices fundamentales de la sostenibilidad en universidades:

(i) Implementación de un Sistema de Gestión Ambiental.

Los sistemas de gestión ambiental otorgan un enfoque sistémico para las actividades ambientales en las universidades. Logra mejorar procesos donde discrimina los aspectos e impactos ambientales significativos y los que no lo son. Plantea objetivos, mejora el desempeño ambiental y fortalece la responsabilidad de la comunidad universitaria con el ambiente.

(ii) Participación Pública y Responsabilidad social.

Esta directriz hace referencia a la relación entre la universidad con la comunidad (stakeholders). Las universidades deben ser modelos positivos para la sociedad y deben aunar esfuerzos con ella. Sus acciones deben ser ejemplos de justicia, responsabilidad social y ambiental, paz, defensa de derechos humanos y sociales.

(iii) Enseñanza e investigación sostenible.

La enseñanza debe abrir nuevos campos de investigación y promocionar el trabajo interdisciplinario, siendo éste una de las herramientas más fuertes de trabajo en estos temas (Lourdel et al., 2005).

Estas directrices o principios vienen siendo adoptadas por diversas universidades, algunas muy prestigiosas a nivel global. Por ejemplo, existen universidades sostenibles, las cuales tienen en su interior centros de sostenibilidad ambiental desde donde se desarrollan las estrategias mencionadas (Herremans et al., 2000). 
La Universidad de Stanford, a través de su iniciativa "Stanford sobre el Medio Ambiente y Sostenibilidad" ha tomado como reto el asegurar que las generaciones actuales y futuras puedan vivir bien en el planeta. El Instituto de Medio Ambiente de Stanford, "Woods" crea programas de investigación estratégica diseñados para abordar los principales desafíos de sostenibilidad que enfrenta el planeta. Woods reúne a los mejores académicos de Stanford y otras instituciones académicas y los conecta con líderes prominentes del gobierno, organizaciones no gubernamentales y empresas para desarrollar soluciones prácticas a problemas del mundo real (Universidad de Stanford, 2017).

La universidad de Cambridge integra un programa denominado "EcoCampus", el cual busca contribuir en la sostenibilidad de las instituciones de educación superior a través de la implementación de sistemas de gestión ambiental bajo la metodología ISO 14001. Este programa consta de 4 fases de certificación: Bronce, Plata, Oro y Platino (The Cambridge Green Challengue, 2017).

Actualmente, la universidad posee la certificación Plata, dado que logró lo siguiente:

- Comprometer a la alta gerencia a mejorar el desempeño ambiental del campus.

- Realizar un diagnóstico de impactos ambientales de sus operaciones y servicios.

- Identificar las leyes ambientales que debe cumplir la universidad.

- Desarrollar un Visión, Política y estrategia de sostenibilidad que los identifique.

Asimismo, vienen uniendo esfuerzos para adjudicarse la certificación "Oro", motivo por el cual buscan lo siguiente:

- Identificar funciones y responsabilidades del personal en relación con el SGA.

- Capacitar al personal, cuando sea necesario, para garantizar la competencia.

- Desarrollar procedimientos operacionales para controlar las actividades que podrían tener un efecto sobre el medio ambiente.

- Desarrollar procedimientos para prevenir o minimizar los impactos ambientales.

En Europa, existen universidades pioneras en la temática de la sostenibilidad ambiental y desarrollo sostenible; entre las que destacan las Universidades de Murcia, de Vigo, de Alicante y la Universidad Autónoma de Madrid. 
Por otro lado, en América Latina, Brasil lidera el cambio de paradigma de la sostenibilidad. Actualmente viene trabajando en la dinámica de modelar los ambientes universitarios y en la generación de cambio de actitud de la comunidad universitaria. En efecto, si la comunidad universitaria vive en una cultura de protección ambiental desde sus edificios hasta sus opciones de alimentación, cambiará su forma de actuar frente al medio (Oliveira, 2006).

A modo de ejemplo, según el estudio "Prácticas de Gestión Ambiental en las universidades brasileras" realizado por Raquel Engelman Machado; Edi Madalena Fracasso; Patricia Tometich; y, Luis Felipe Nascimento; de un universo total de 192 Universidades brasileñas (MEC, 2012) y con una muestra simple de 75 Universidades; se concluyó que el 25,3\% tiene Sistema de Gestión Ambiental (SGA) implementado; el $20 \%$ está en fase de implementación y el 54,7\% no tiene sistema. Esto quiere decir que el $45,3 \%$ de universidades brasileras han desarrollado o vienen desarrollando un SGA.

Es válido recalcar que la sostenibilidad se asocia al crecimiento económico basado en justicia social y en el buen manejo de los recursos. Las Universidades son consideradas empresas y para que una organización o empresa sea sostenible, requiere conservación y buen uso de sus recursos (Elizabete et al., 2005).

La necesidad de tener en un futuro cercano mayor cantidad de universidades que tiendan a la sostenibilidad es que estas organizaciones tienen la capacidad de gestar el cambio mental que requieren las sociedades para su desarrollo. Las universidades actuales vienen adaptando el concepto de responsabilidad social, razón por la cual vienen promoviendo patrones de desarrollo cada vez más ambientales.

Como lo expresa José Sarukhan (1998), "las Universidades deben extender sus responsabilidades a la formación de personas libres y universales, capaces de pensar, decidir y actuar por sí mismas, críticas y autocríticas, dueñas de libertad interior, social, política, ambiental, sin prejuicios ni sectarismos, siendo ésta, su responsabilidad con la comunidad".

En el Perú, la Red Ambiental Interuniversitaria (RAI - Perú), promovida y facilitada por la Dirección General Educación, Cultura y Ciudadanía Ambiente (DGECCA) del Ministerio del Ambiente (MINAM), desarrolló, durante el año 2014, el reporte siguiente: "Incorporación de la Perspectiva Ambiental en las Universidades Peruanas", el cual tuvo por objetivo explorar el nivel de incorporación de la perspectiva ambiental en las funciones sustantivas de las distintas universidades 
peruanas; así como orientar el camino de estas para mejorar su desempeño ambiental (José Martín Cárdenas, 2014).

Para el desarrollo del reporte se elaboró una encuesta con 32 ítems (indicadores), los cuales se dividían en 4 temáticas; siendo la primera de ellas "Gestión Ambiental"; la segunda de ellas "Formación"; la tercera "Extensión" y la cuarta, "Investigación".

Estas encuestas fueron remitidas a 74 universidades a nivel nacional, a las cuales se les dio un plazo de 45 días calendario entre los meses de abril y junio del año 2014, para que fueran respondidas y adjunten la evidencia de cada respuesta.

Las encuestas respondidas por las universidades fueron analizadas en relación a las evidencias adjuntadas, revisión de sitios web oficiales y en algunos casos, consultas directas a las universidades. En este sentido, en caso las universidades marquen "SÍ" a algunas respuestas (ítem) y no hayan adjuntado la evidencia respectiva, esta respuesta será considerada como "No". Es importante precisar que la encuesta no presenta escalas de intervalo, solo se muestra si la universidad cumple o no cumple con los ítems. Estos ítems son los siguientes:

\section{A. Gestión Ambiental:}

1. Incorporación de la perspectiva ambiental en el quehacer de la universidad como un lineamiento de la política institucional.

2. Existencia de política ambiental de la universidad.

3. Existencia de un plan o programa ambiental institucional.

4. Existencia de una unidad, oficina o servicio de carácter técnico - administrativo con dedicación exclusiva para los temas de ambiente (Comité Ambiental, Oficina de Asuntos Ambientales, otros).

5. Asignación presupuestal para el desarrollo de proyectos y acciones ambientales.

6. Involucramiento de docentes, estudiantes y administrativos en el diseño e implementación de la política ambiental de la universidad.

7. Existencia de un plan específico, eje estratégico o línea de acción ambiental sobre agua, que incluya aspectos de ahorro en agua, sanidad para consumo humano, riego y gestión de aguas residuales.

8. Existencia de un plan específico, eje estratégico o línea de acción ambiental para el uso eficiente de energía, que incluya alumbrado, climatización y energías renovables. 
9. Existencia de un plan específico, eje estratégico o línea de acción ambiental sobre reducción del uso de papel.

10. Existencia de un plan específico, eje estratégico o línea de acción ambiental para la minimización, recogida selectiva y manejo adecuado de los residuos sólidos.

11. Existencia de un plan específico, eje estratégico o línea de acción ambiental sobre la gestión de zonas verdes y la promoción de la biodiversidad.

12. Inclusión de criterios ambientales en la planificación urbanísticas del campus, oficina o sede universitaria.

\section{B. Formación:}

13. Mención expresa a las actividades de formación en la política ambiental de la universidad.

14. Incorporación de competencias ambientales básicas en los planes de estudios de las distintas carreras profesionales.

15. Incorporación de alguna materia específica, optativa u obligatoria centrada en contenidos ambientales en los planes de estudio de las distintas carreras profesionales.

16. Incorporación de la perspectiva ambiental como área de especialización o fase terminal, hacia los últimos semestres de las licenciaturas.

17. Incorporación de contenidos o referencias ambientales en los cursos ya existentes de las distintas carreras profesionales.

18. Oferta de programas de grado o pregrado (carreras profesionales) específicos sobre ambiente.

19. Oferta de programas de postgrado (Especializaciones, Maestrías o Doctorado) específicos sobre ambiente.

20. Oferta de programa de educación continua en temas ambientales (diplomados, cursos, seminarios o talleres, entre otros).

\section{Extensión:}

21. Existencia de un plan específico, eje estratégico o línea de acción de responsabilidad socio ambiental formalmente aprobado.

22. Existencia de programas de extensión para contribuir a la solución de problemas ambientales en comunidades (proyectos socio ambientales).

23. Participación permanente en procesos públicos y sociales (a escala nacional, regional o local), en materia ambiental (CAR, CAM, Comisiones Multisectoriales, Grupos Técnicos u otros). 
24. Existencia de programas y proyectos de difusión en temas ambientales dentro de la universidad y hacia los distintos sectores de la sociedad.

25. Existencia de un programa de voluntariado ambiental universitaria formalmente establecido.

26. Prestación de servicios profesionales en materia ambiental dirigido a distintos sectores de la sociedad.

27. Participación en redes universitarias nacionales e internacionales con enfoque ambiental.

\section{Investigación:}

28. Mención expresa a la investigación y transferencia de tecnología en la política ambiental de la universidad.

29. Existencia de grupo de investigación específico sobre ambiente formalmente constituido.

30. Existencia de estrategias para fomentar la realización de investigaciones ambientales (subvenciones, concursos, otros).

31. Inclusión de criterios ambientales en la aprobación de proyectos de investigación de la universidad.

32. Existencia de estrategias para incentivar la utilización de la universidad y del campus en la realización de investigaciones sobre temas ambientales.

A continuación, se detallan las 37 universidades que respondieron la encuesta durante el tiempo de 45 días establecidos. Estas 37 universidades son la muestra del estudio, donde se incluyen universidades públicas y privadas de todo el país. 


\section{Tabla 01}

\section{Universidades peruanas encuestadas RAI Perú}

\begin{tabular}{|c|c|c|c|}
\hline & Universidad & Categoría & Región \\
\hline 1 & Universidad César Vallejo & Privada & La Libertad \\
\hline 2 & Universidad Privada Antenor Orrego & Privada & La Libertad \\
\hline 3 & Universidad Antonio Ruiz de Montoya & Privada & Lima \\
\hline 4 & Universidad Marcelino Champagnat & Privada & Lima \\
\hline 5 & Universidad Peruana de Ciencias e Informática & Privada & Lima \\
\hline 6 & Universidad Católica Los Ángeles de Chimbote & Privada & Ancash \\
\hline 7 & Universidad Peruana Unión & Privada & Lima \\
\hline 8 & Universidad de Lima & Privada & Lima \\
\hline 9 & Universidad José Carlos Mariátegui & Privada & Moquegua \\
\hline 10 & Universidad de San Martín de Porres & Privada & Lima \\
\hline 11 & Universidad Femenina del Sagrado Corazón & Privada & Lima \\
\hline 12 & Universidad Continental & Privada & Junín \\
\hline 13 & Universidad Andina Néstor Cáceres Velásquez & Privada & Puno \\
\hline 14 & Universidad Ricardo Palma & Privada & Lima \\
\hline 15 & Universidad Tecnológica de los Andes & Privada & Apurímac \\
\hline 16 & Universidad Católica San Pablo & Privada & Arequipa \\
\hline 17 & Universidad Privada Antonio Guillermo Urrelo & Privada & Cajamarca \\
\hline 18 & Universidad Le Cordon Bleu & Privada & Lima \\
\hline 19 & Universidad Peruana Los Andes & Privada & Junín \\
\hline 20 & Universidad Alas Peruanas & Privada & Lima \\
\hline 21 & Pontificia Universidad Católica del Perú & Privada & Lima \\
\hline 22 & Universidad Privada San Juan Bautista & Privada & Lima \\
\hline 23 & Universidad Nacional del Centro del Perú & Pública & Junín \\
\hline 24 & Universidad Nacional de Ingeniería & Pública & Lima \\
\hline 25 & Universidad Nacional Hermilio Valdizán & Pública & Huánuco \\
\hline 26 & Universidad Nacional Federico Villareal & Pública & Lima \\
\hline 27 & Universidad Nacional del Callao & Pública & Lima \\
\hline 28 & Universidad Nacional Toribio Rodríguez de Mendoza de Amazonas & Pública & Amazonas \\
\hline 29 & Universidad Nacional de Huancavelica & Pública & Huancavelica \\
\hline 30 & Universidad Nacional de Trujillo & Pública & La Libertad \\
\hline 31 & Universidad Nacional de Santa & Pública & Ancash \\
\hline 32 & Universidad Nacional Amazónica de Madre de Dios & Pública & Madre de Dios \\
\hline 33 & Universidad Nacional Santiago Antúnez de Mayolo & Pública & Ancash \\
\hline 34 & Universidad Nacional Mayor de San Marcos & Pública & Lima \\
\hline 35 & Universidad Nacional de Jaén & Pública & Cajamarca \\
\hline 36 & Universidad Nacional de San Martín & Pública & San Martín \\
\hline 37 & Universidad Nacional Jorge Basadre Grohmann & Pública & Tacna \\
\hline
\end{tabular}

Fuente: Red Ambiental Interuniversitaria - Perú, 2014. 
El reporte "Incorporación de la Perspectiva Ambiental en las Universidades Peruanas" arrojó los resultados siguientes:

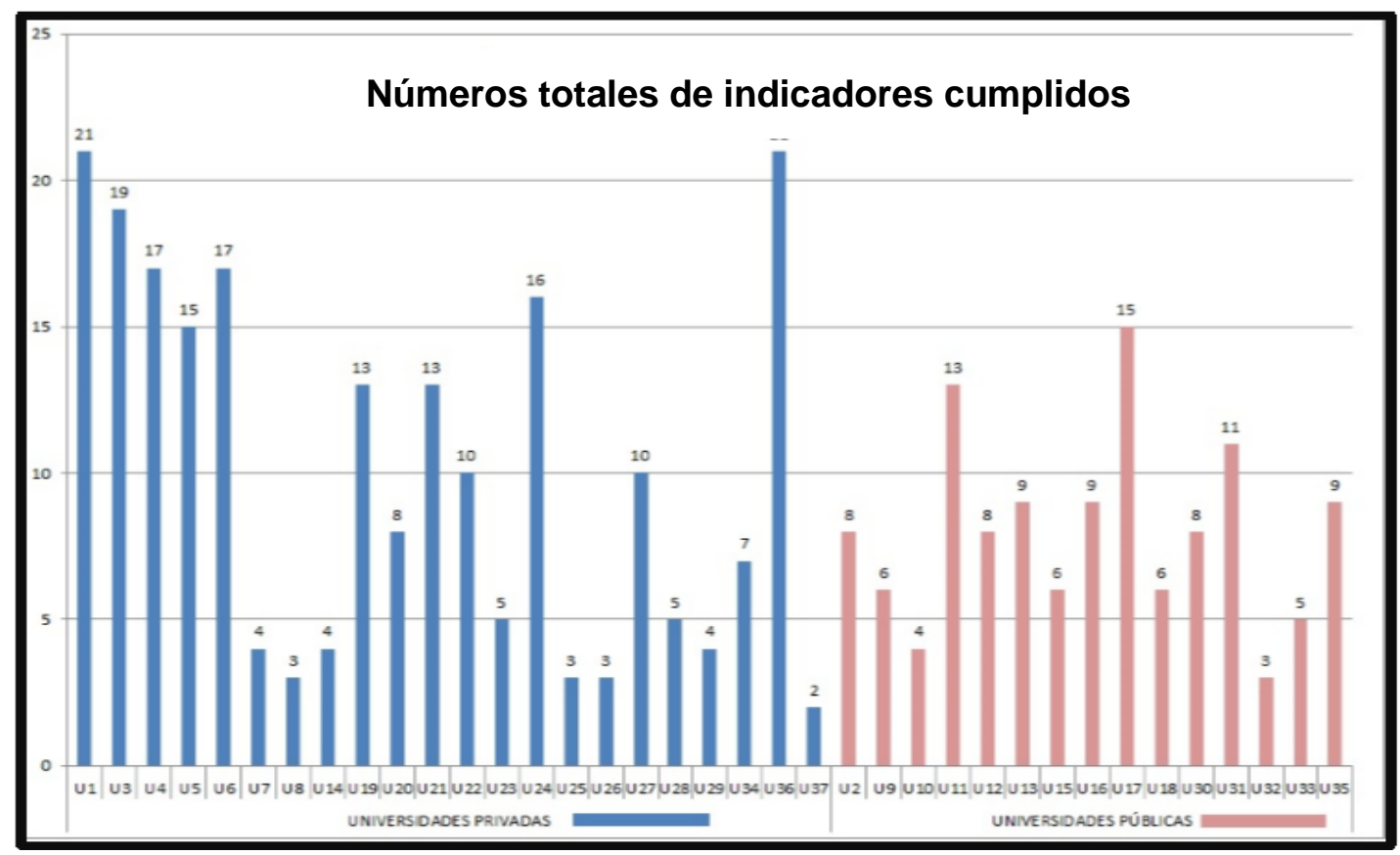

Figura 01: Universidades que cumplen con indicadores. Fuente: RAI - Perú, 2014.

Con 21 indicadores cumplidos y debidamente evidenciados, la Universidad Nacional de San Martín (Departamento de San Martín - Perú) lidera el ranking; mientras que, con 2 indicadores, la Universidad Jorge Basadre (Departamento de Tacna - Perú) es la más relegada. Por otro lado, 7 universidades privadas cumplen con 15 indicadores o más (la mitad de 32 indicadores); sin embargo, solo una universidad pública logra pasar esta brecha.

\section{Indicador - Gestión Ambiental:}

En lo que respecta a las acciones de la universidad para disminuir su impacto ambiental, la mayoría de universidades tiene un cumplimiento bajo. 11 universidades manifiestan contar con una línea de acción sobre gestión de residuos (9 privadas y 2 públicas), 9 han incluido criterios ambientales en la planificación urbanísticas del campus (6 privadas y 3 públicas) y 8 cuentan con una línea de acción sobre agua (6 privadas y 2 públicas).

Asimismo, tan solo 8 universidades (6 privadas y 2 públicas) tienen Política Ambiental; y tan solo 2 privadas reciben presupuesto para el accionar ambiental de la organización. 
Finalmente, de los 12 indicadores de gestión evaluados, los cuatro primeros lugares le corresponden a una universidad pública (Universidad Nacional de San Martín) y tres particulares. Por otro lado, 9 universidades (5 públicas y 4 particulares) no cumplen con algún indicador.

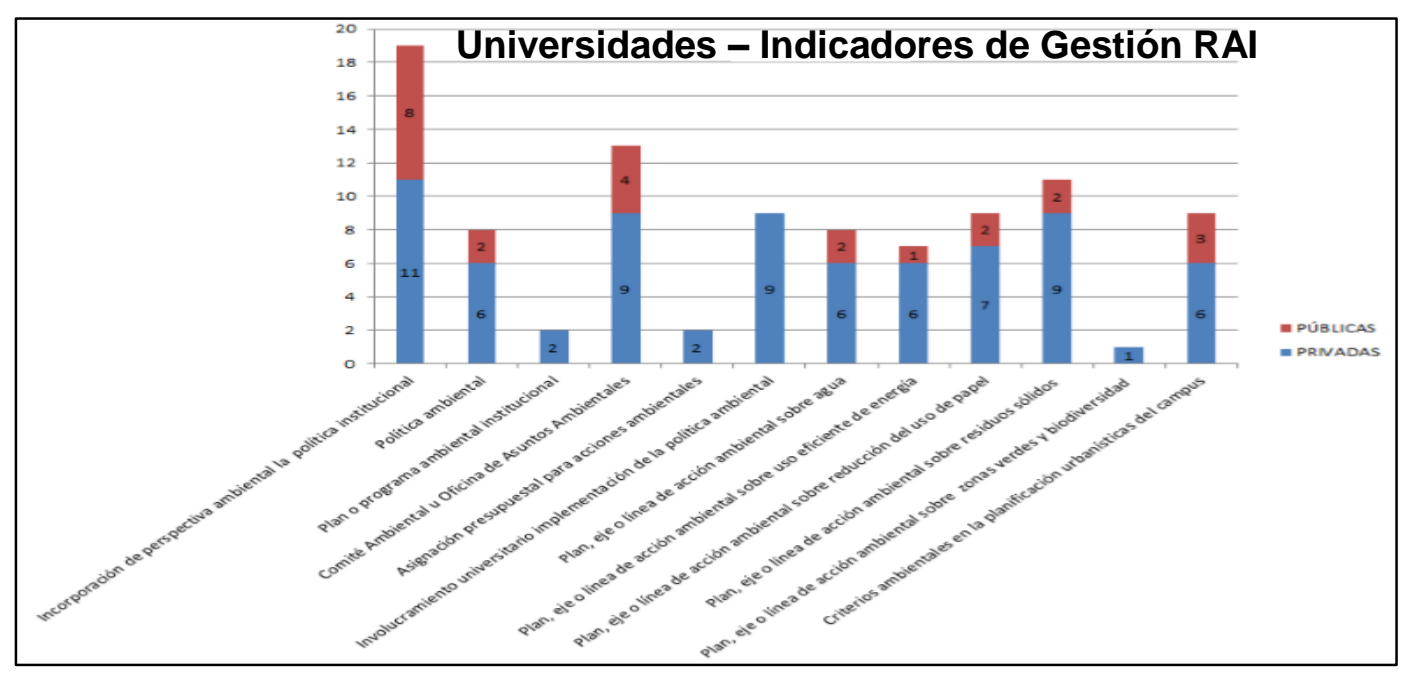

Figura 02: Universidades que cumplen con indicadores de Gestión Ambiental. Fuente: RAI-Perú, 2014

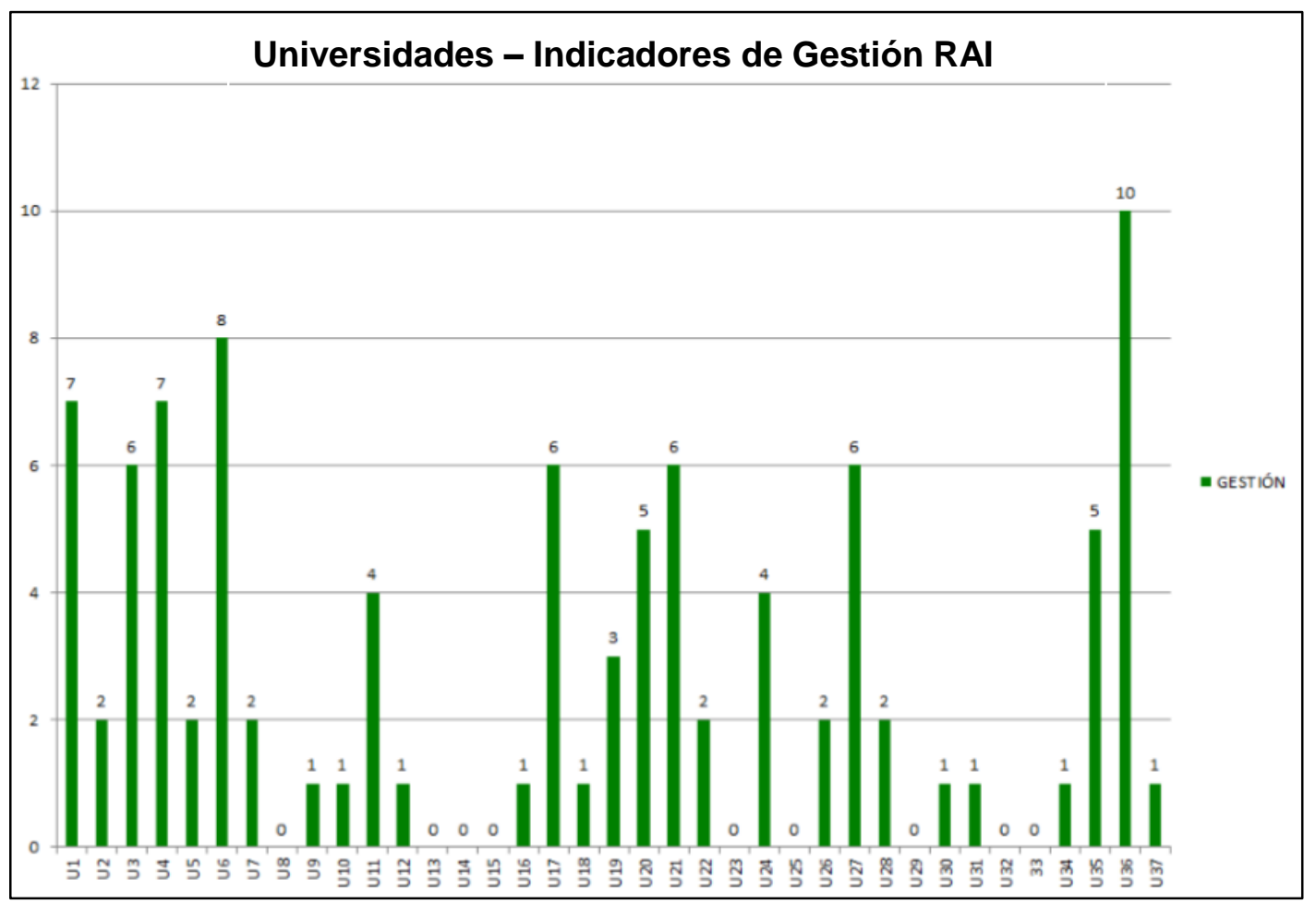

Figura 03: Universidades que cumplen con indicadores de Gestión Ambiental Fuente: RAI-Perú 


\section{Indicador - Formación:}

En relación al indicador de formación, sólo 8 universidades hacen mención a las actividades de formación en sus políticas ambientales ( 6 privadas y 2 publicas), 13 señalan la incorporación de competencias ambientales básicas en los planes de estudio de las distintas carreras profesionales (12 privadas y 1 pública), 16 han incorporado una materia centrada en contenidos ambientales en los planes de estudio de las distintas carreras profesionales (14 privadas y 2 públicas), 23 ofrecen cursos de grado o pregrado sobre ambiente (10 privadas y 13 públicas), y 22 programas de postgrado en materia ambiental (9 privadas y 13 públicas). Puede ver el total de resultados en la figura siguiente (RAI, 2014).

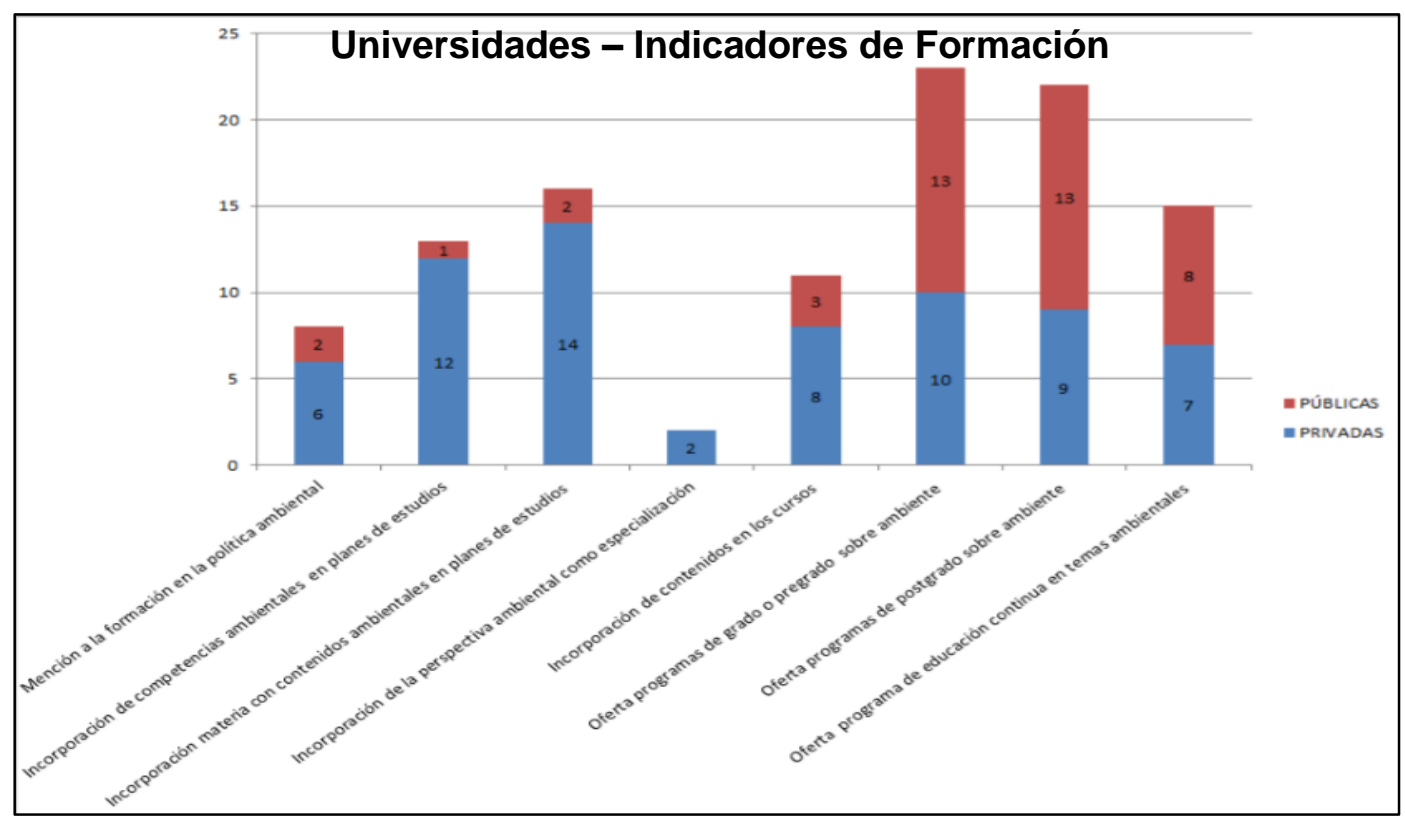

Figura 04: Universidades que cumplen los indicadores de Formación. Fuente: RAI - Perú, 2014

\section{Indicador - Extensión:}

En relación al indicador de extensión, solo tres universidades (privadas todas) mencionan contar con un plan de responsabilidad socio ambiental aprobado. Asimismo, 20 universidades señalan participar permanentemente y de manera institucional en procesos públicos y sociales en materia ambiental; 6 de las 37 universidades cuentan con voluntariado ligado a medio ambiente.

Finalmente, de los 7 indicadores de extensión, solo una universidad nacional alcanza 6 de estos (Universidad Nacional de San Martín); y 3 universidades presenta un cumplimiento nulo (Universidad Peruana Unión - Departamento de Lima; Universidad Nacional Federico Villarreal - Departamento de Lima; y Universidad Hermilio Valdizan - Departamento de Huánuco). 


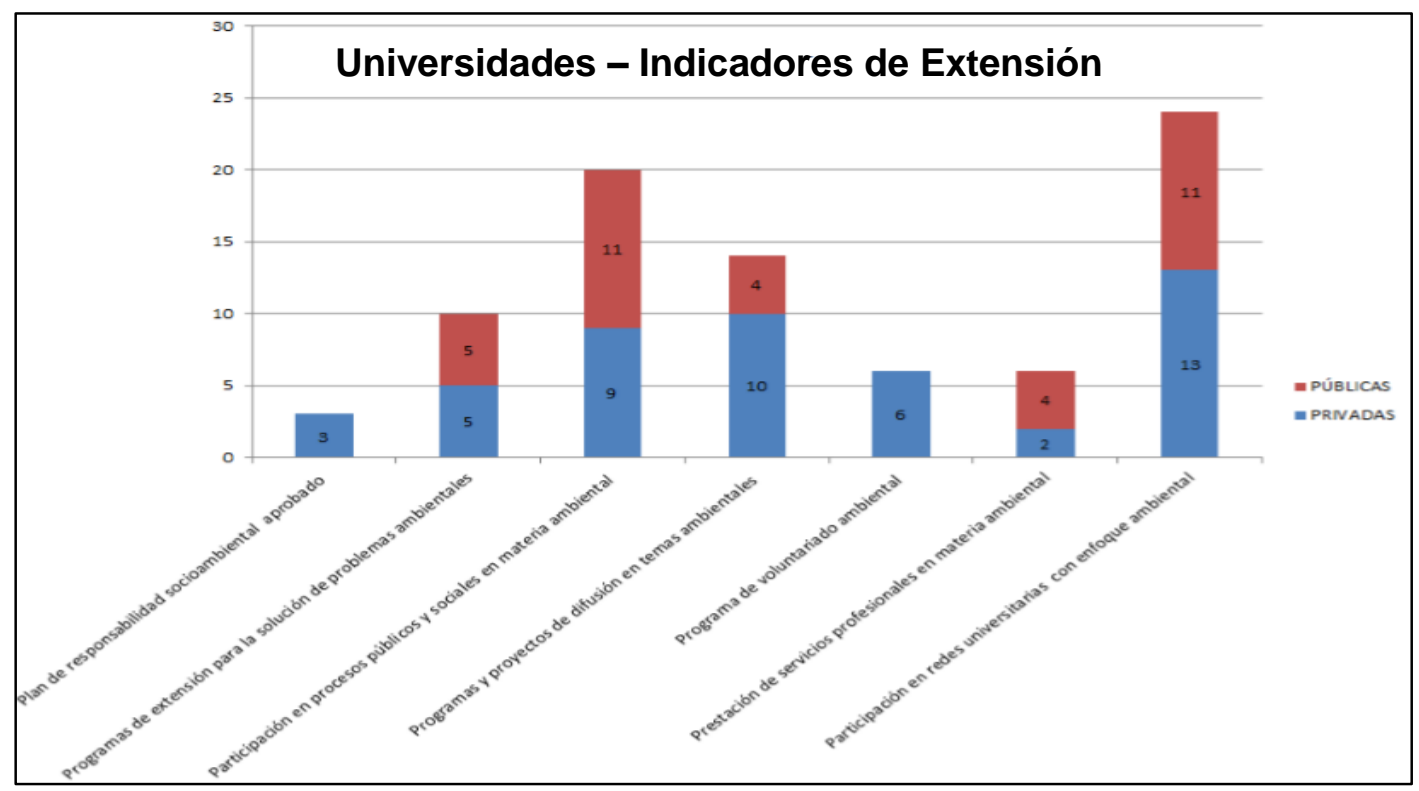

Figura 05: Universidades que cumplen los indicadores de Extensión. Fuente: RAI - Perú, 2014

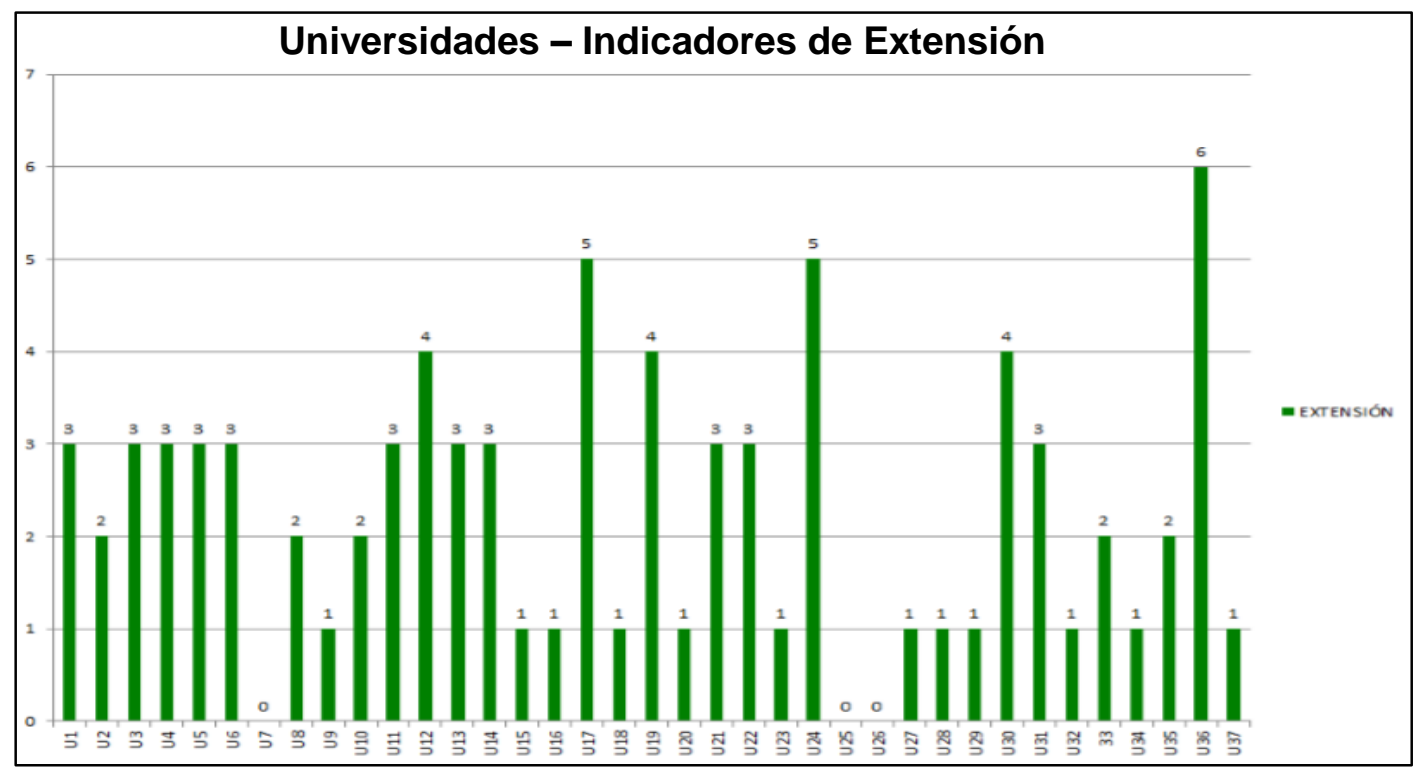

Figura 06: Universidades que cumplen los indicadores de Extensión. Fuente: RAI - Perú, 2014

\section{Indicador - Investigación:}

En relación al indicador investigación, se logró visualizar que 6 de las 37 universidades mencionan la palabra investigación en su política ambiental; 6 universidades (4 privadas y 2 públicas) aplican criterios ambientales para la aprobación de proyectos de investigación; y, 12 universidades cuentan con un grupo de investigación constituido. 


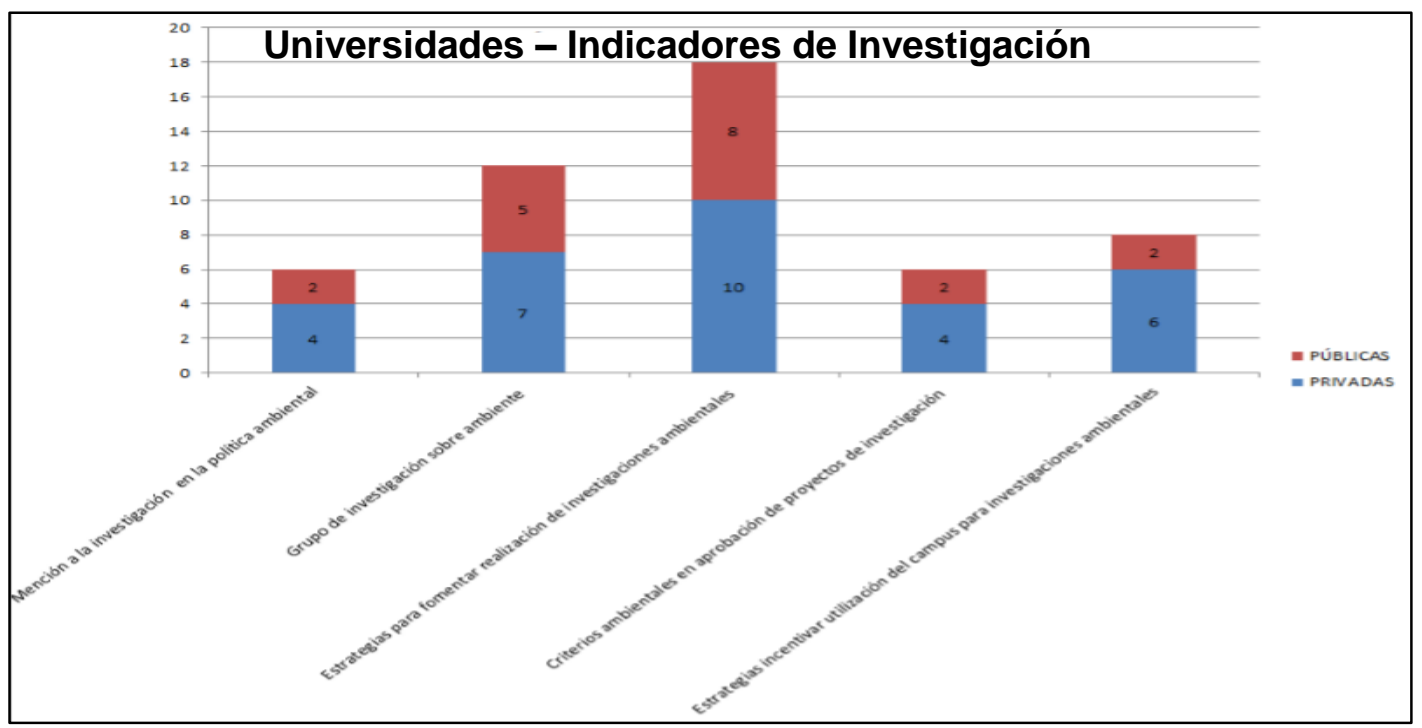

Figura 07: Universidades que cumplen los indicadores de Investigación. Fuente: RAI - Perú, 2014

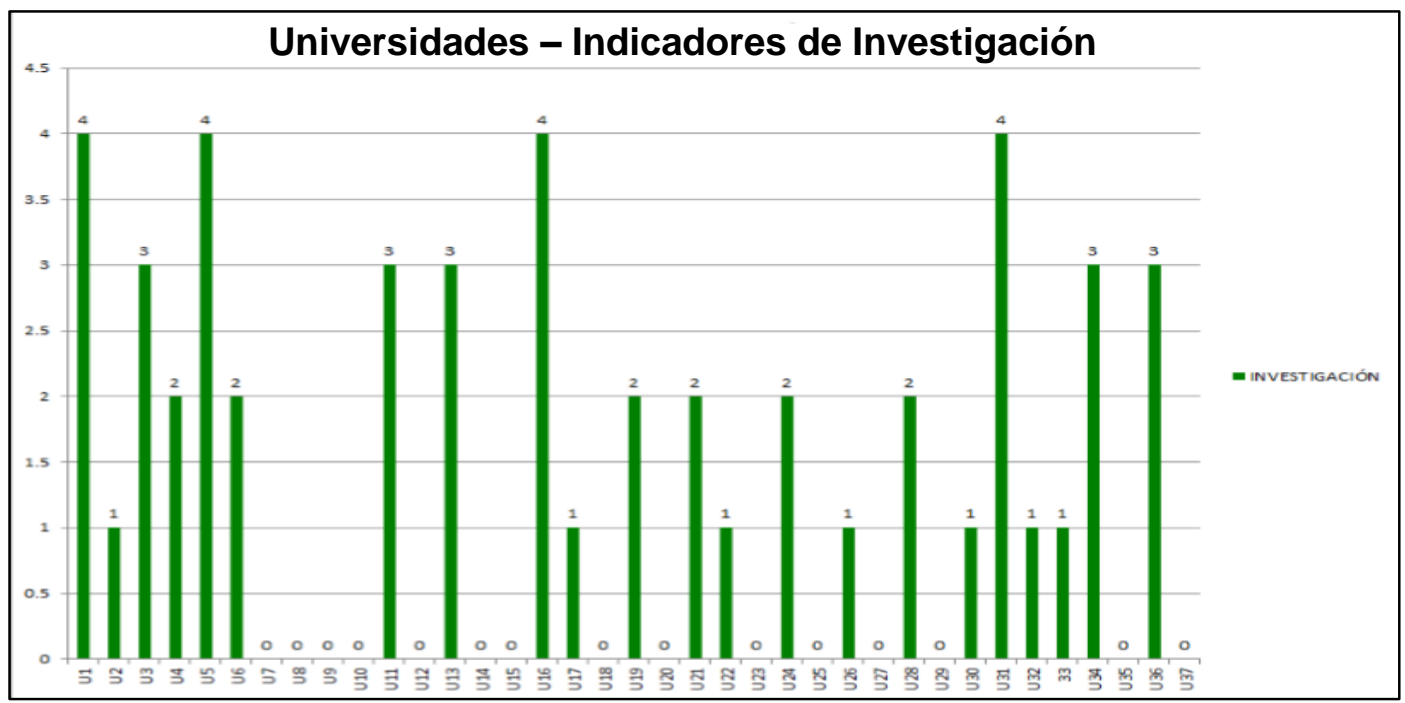

Figura 08: Universidades que cumplen los indicadores de Investigación. Fuente: RAI - Perú, 2014

A modo de conclusión, no existen universidades en el país que hayan alcanzado el umbral de sostenibilidad. Por el momento, no existe universidad peruana sostenible; sin embargo, existen indicios y primeros pasos.

Por otro lado, en el marco del Sistema Nacional de Gestión Ambiental del Perú, se establece la Política Nacional del Ambiente, la cual incluye lineamientos de política sobre "Cultura, educación y ciudadanía ambiental", los cuales buscan, entre otras cosas, el fomento de la responsabilidad socio-ambiental y la eco eficiencia por parte de familias, empresas e instituciones; incluyendo el sector educativo (Política Nacional del Ambiente, 2009). En este sentido, el país presenta un marco regulatorio ambiental sobre el cual las universidades deberán enmarcarse y desarrollar acciones en favor de la educación y del ambiente. 


\subsubsection{Política e Instrumentos de Gestión Ambiental - Sector Educación.}

En la actualidad, los centros de educación - independientemente del nivel al que se aboquen - generan impactos directos e indirectos al medio ambiente. Esta afirmación incluye a las universidades; las cuales son consideradas pequeñas ciudades, dada su extensión (área), población (cantidad de personas) y actividades que se realizan en su interior. Son precisamente estos factores los que impactan directa o indirectamente en el medio ambiente. Las universidades son estructuras complejas, debido a son espacios de encuentro de numerosas culturas, estilos y experiencias de vida. Asimismo, presentan grandes diferencias entre los mismos estudiantes, facultades y comunidad universitaria, lo que lleva a repensar las decisiones a tomar dentro del sistema (Cohen, 1986).

Las universidades vienen adaptando el enfoque de sostenibilidad (dimensión económica, social y ambiental). Empiezan a internalizar sus problemáticas y desarrollan estrategias para la resolución de las mismas; lo cual permite la internalización de los principios "sustentabilidad" y "desarrollo" (Riojas, 2000).

La conferencia de Tbilisi - Georgia, del año 1997, en su Informe Final anuncia lo siguiente: "las universidades en su calidad de centros de investigación, de enseñanza y de formación de personal calificado de un país deben dar cada vez mayor cabida a la investigación sobre educación ambiental y a la formación de expertos en educación formal y no formal" (UNESCO, 1978).

Esta afirmación de la UNESCO crea un nuevo objetivo para las universidades, el cual es aprovechar eficientemente los recursos con la finalidad de crear un campus ambientalmente sostenible. Esto quiere decir que las universidades deben ser instituciones preocupadas en reducir y mitigar responsablemente los impactos que generan sus actividades, decisiones u omisiones. Asimismo, deberán crear sus propias Políticas Institucionales Ambientales, las cual deberán servir como modelo para otras instituciones de la ciudad o de otros países.

Este cambio en la historia educativa fue promovido por diversos gobiernos, movimientos estudiantiles, grupos ambientales y ONG. Este apoyo ha permitido que, a partir del Informe Final de la UNESCO en Tbilisi, diversas instituciones educativas en el mundo hayan formulado Políticas Ambientales con la finalidad de mitigar sus impactos y establecer directrices de gestión (Newman, 2006). 
La Política Ambiental, tal y como se conoce hoy en día se gestó durante las décadas del 60 y 70, principalmente en Europa y USA. Desde décadas pasadas, este concepto es considerado como un nuevo campo o una nueva sección de la política convencional, la cual nace en los países "desarrollados" o industrializados, como una reacción al daño ambiental originado por la actividad humana.

Pero solo como sección particular, la Política Ambiental es un Novum (una novedad, un nuevo componente), que en los años setenta, en los países industrializados tomó una conformación institucional y que provee con una nueva palabra al idioma político (González, 2005).

Las políticas son el conjunto de objetivos, principios, criterios y orientaciones generales para la protección del medio ambiente de una sociedad particular. Esas políticas se ponen en marcha mediante una amplia variedad de instrumentos y planes. Distinguir entre políticas, instrumentos y planes es necesario para efectos analíticos y prescriptivos, pero estas tres dimensiones se encuentran con frecuencia fundidas en la práctica y diferenciarlas no es tarea fácil (Manuel Rodríguez, 2007).

Las políticas pueden tener como objetivo la protección de un determinado ecosistema, el fortalecimiento de la capacidad de actores, o a compensar su débil posición frente a otros actores (ej. en relación con algunos de los oponentes de una determinada acción). También pueden estar dirigidas a incidir en factores del contexto como: el mejoramiento de las condiciones para la generación y apropiación social de la información, la transformación de ciertas condiciones políticoinstitucionales; las condiciones socioeconómicas y tecnológicas (ej. desarrollo de nuevas tecnologías limpias, e innovaciones de tecnologías de final del tubo) (Fiorino, 1995; OCDE, 1997; Janicke y Weidner, 1997).

Por otro lado, los instrumentos de gestión ambiental son herramientas decisorias basadas en disciplinas que proveen de información rigurosa, sistemática y validada por medio de investigaciones que buscan reducir al mínimo el error de una decisión (Rosalba Thomas, 2015).

Los instrumentos de gestión ambiental se dividen 3 categorías. La primera es la Evaluación de Impacto Ambiental (Diagnóstico), proceso de advertencia temprana, a través de la cual se identifican, mitigan y controlan los impactos negativos derivados de la aplicación de políticas, planes, programas, proyectos y actividades. Este instrumento opera sobre la lógica de incorporar la dimensión ambiental a los 
proyectos de inversión o acciones que alteren significativamente algún componente ambiental (BID, 2010).

El segundo instrumento de gestión ambiental es el Sistema de Gestión Ambiental, el cual es un proceso, el cual permite planear, revisar, implementar y mejorar todas las actividades, procedimientos, procesos y acciones llevadas a cabo en una organización en materia ambiental; de tal forma que se cumpla con la legislación vigente, las políticas ambientales y con los objetivos organizacionales.

El tercer instrumento de gestión ambiental es la Educación Ambiental. Para la Dirección de Educación Ambiental México, es un proceso de formación que permite la toma de conciencia de la importancia del medio ambiente, promueve en la ciudadanía el desarrollo de valores y nuevas actitudes que contribuyan al uso racional de los recursos naturales y a la solución de los problemas ambientales que enfrentamos en nuestras ciudades (DEA, 2017).

Para la presente Tesis, se crearán los 3 instrumentos de gestión y serán compilados en un documento llamado: "Propuesta de Guía de Gestión Ambiental USIL".

\subsubsection{Guía de Gestión Ambiental: Beneficios e implementación - Sector Educación.}

Las Guías de Gestión Ambiental son instrumentos a implementarse para el cumplimiento de las Políticas inmersas en los Sistemas de Gestión Ambiental de cualquier organización e institución, entre ellas, el sector educativo.

Las Guías de Gestión Ambiental, en general, proponen lineamientos, estrategias, herramientas, procedimientos y mecanismos que deben ser implementados para la mejora continua de la gestión ambiental en la organización. Asimismo, las guías en mención, funcionan como instrumentos para la toma de decisiones, dado que su implementación permite prever y reducir impactos ambientales negativos. Asimismo, proponen estrategias para su identificación; mejoran la imagen corporativa; contribuyen al logro de la eficiencia y al cumplimiento de la normativa vigente en materia ambiental; y alinean la realización de acciones en el marco de la Política Ambiental de la organización y del Sistema de Gestión Ambiental; entre otros.

En el caso del sector educativo, específicamente en las universidades, las guías tienen los mismos efectos; sin embargo, se adiciona el componente de educación ambiental, formación de profesionales y responsabilidad social. Las universidades, al 
implementar instrumentos de gestión ambiental, aspiran a convertirse en universidades sostenibles (Cole, 2003).

Adicionalmente, implementar una guía de gestión ambiental como parte del Sistema de Gestión Ambiental de una universidad para lograr el cumplimiento de la Política ambiental de la misma, permite formar profesionales social y ambientalmente responsables. Esta implementación se basa en la toma de decisiones al más alto nivel, dado que compromete a la organización en sí, y no a las personas individuales.

Actualmente en el Perú, las universidades en su mayoría no presentan instrumentos de gestión ambiental; y ninguna de estas cuenta con una certificación internacional de gestión ambiental. Asimismo, las Políticas Ambientales de las universidades peruanas no están articuladas con las actividades que estas desempeñan, lo cual dificulta sustancialmente la implementación de sistemas de gestión ambiental.

Finalmente, las Guías de Gestión Ambiental, como instrumentos de gestión ambiental para universidades, deben contar mínimamente con (i) una línea base o diagnóstico que permita conocer la realidad actual, planificar a futuro y establecer metas; (ii) propuesta de lineamientos para el establecimiento del sistema de gestión ambiental; y, (iii) debe integrar la educación ambiental en la comunidad universitaria.

\subsubsection{Sistema de Gestión Ambiental - Sector Educación.}

Las Políticas Ambientales de las universidades deben integrar la participación de la comunidad. Esta última, no referida como objeto destinatario; sino logrando mentalizar, transformar, socializar e implicar a la comunidad con nuevas éticas y epistemologías que ayudarán a colocarnos en el trayecto de la sensibilidad y racionalidad ambiental (Leff, 2004).

Hoy, cuando la temática ambiental no es variable pasajera, las empresas independientemente al rubro que pertenezcan - han visto por conveniente integrar la gestión ambiental como herramienta de mejora de competitividad y oportunidad ante nuevos mercados. En países desarrollados y en los que aún se encuentran en vías de desarrollo, las empresas vienen realizando acciones a favor del medio ambiente; inclusive, vienen creando organizaciones encargadas de implantar políticas y prácticas en desarrollo sostenible (Latorre, 1996).

En este sentido, existen dos vertientes en materia de gestión ambiental corporativa:

- Por un lado, los mecanismos establecidos por el Gobierno o Estado para que el precio de los bienes y servicios posean costo económico y ambiental, pensado en 
términos de sostenibilidad de los recursos (Brugger, 1993). Por ejemplo: (i) tasas retributivas, (ii) tasas compensatorias; y, (iii) licencias ambientales.

- Por otro lado, se encuentran las acciones propias de la empresa, la cual tiende a la eco eficiencia, mediante la mejora organizacional, uso de tecnologías, gestión de recursos; permitiendo una mejora ambiental y económica. Esto se traduce que la gestión ambiental no es solo la mejora ecológica de la empresa; sino que repercute en la concepción de la empresa, generar ingresos y ser rentable.

Para la mejora de la gestión ambiental corporativa, al transcurrir de los años, se han formulado modelos para mejorar el comportamiento ambiental de las empresas, siendo el más utilizado y reconocido a nivel mundial el Sistema de Gestión Ambiental de la Organización Internacional de Estandarización (ISO), ISO 14000.

La Organización Internacional de Estandarización (ISO), a través de la ISO 14000, busca dar el enfoque ambiental a la estructura organizacional, prácticas, procesos procedimientos y recursos de las empresas. La ISO 14000 es una normativa internacional voluntaria y certificable (auditable); además es la más conocida en el mundo dada su adaptación a distintos tipos de regulaciones.

La gestión ambiental de una empresa, en el marco de la ISO 14000, permite estudiar internamente el accionar ambiental de la organización. Asimismo, permite desarrollar sistemas ambientales con el objetivo de agregar valor a la compañía y satisfacer las necesidades de esta, stakeholders y regulaciones del propio lugar.

Las universidades pueden ser vistas como empresas o ciudades pequeñas. El crecimiento en términos de regulaciones ambientales también afecta su accionar; motivo por el cual hoy en día las universidades buscan hacerse cargo de sus impactos, acciones u omisiones relacionados al medio ambiente. En este contexto, el sector educación a nivel mundial, viene adaptándose a la implementación de sistemas de gestión ambiental.

Como ejemplo claro y digno de imitar, universidades europeas y estadounidenses han avanzado en sus modelos de gestión ambiental porque han creado, al interior de sus instituciones, entes totalmente independientes y del más alto nivel jerárquico, encargados de planificar, organizar e implementar labores de gestión ambiental.

A modo de resumen, un modelo (sistema) de gestión ambiental propio de una universidad debe contemplar lo siguiente:

- Reconocimiento y compromiso por parte de la Alta Dirección de la Universidad. 
- Identificación de aspectos e impactos ambientales.

- Desarrollo de una Política Ambiental propia.

- Establecer objetivos ambientales medibles y acordes a la Política Ambiental.

- Diseñar mecanismos para evaluación y mejora continua.

- Asignar recursos para la implementación del modelo de gestión.

- Planificar y diseñar, participativamente, las actividades ambientales en la organización.

- Concientizar a la comunidad universitaria.

- Establecer responsables de la implementación y monitoreo del sistema.

El último reporte de ISO (The ISO Survay of Management System Estandar Certification) del año 2017, señala que durante ese año 362610 organizaciones fueron certificadas a nivel mundial, lo cual representó un crecimiento del $1.05 \%$ respecto al 2016, donde el número de certificaciones alcanzó los 346 147; y un crecimiento del 1.13\% respecto al año 2015 donde se alcanzó 319496 organizaciones certificadas. En este sentido, se visibiliza la tendencia en la implementación y certificación de sistemas de gestión ambiental en todos los sectores, siendo los de mayor crecimiento: construcción, fabricación de metales y equipos eléctricos - ópticos (Ver Tabla 02).

Respecto al sector educación a nivel mundial y basándonos en las estadísticas de ISO - 2017 (Ver Figura 09), podemos observar que, desde el año 2000 hasta el año 2017, existe tendencia positiva de los centros educativos a implementar sistemas de gestión ambiental. Es válido mencionar que este crecimiento es sostenido anualmente; sin embargo, no presenta, entre los años analizados, un crecimiento exponencial. 


\section{Tabla 02}

Certificación de SGA a nivel mundial 2013 -2017

\begin{tabular}{|c|c|c|c|c|c|c|}
\hline Código & $\begin{array}{l}\text { Sector Industrial certificado } \\
\text { con ISO } 14001\end{array}$ & 2013 & 2014 & 2015 & 2016 & 2017 \\
\hline 1 & Agricultura y Pesca & 2467 & 2215 & 2408 & 2149 & 2396 \\
\hline 2 & Minería y extracción & 2532 & 2520 & 2548 & 2674 & 2429 \\
\hline 3 & $\begin{array}{l}\text { Productos comestibles, } \\
\text { bebidas y tabaco. }\end{array}$ & 6890 & 7219 & 6842 & 6693 & 6402 \\
\hline . & . & . & . & $\cdot$ & $\cdot$ & $\cdot$ \\
\hline$\cdot$ & $\cdot$ & . & $\cdot$ & $\dot{.}$ & : & $\dot{.}$ \\
\hline$\cdot$ & $\cdot$ & $\cdot$ & $\cdot$ & $\cdot$ & $\cdot$ & $\cdot$ \\
\hline 37 & Educación & 905 & 781 & 688 & 829 & 689 \\
\hline 38 & Salud y Trabajo social & 1008 & 1018 & 899 & 1145 & 1071 \\
\hline 39 & Otros servicios sociales & 6344 & 7679 & 6799 & 6905 & 4404 \\
\hline & TOTAL & 240891 & 254108 & 267971 & 314405 & 275776 \\
\hline
\end{tabular}

Fuente: ISO, 2017 / Ver Cuadro completo en Anexo $\mathbf{N}^{\circ} \mathbf{0 5}$.

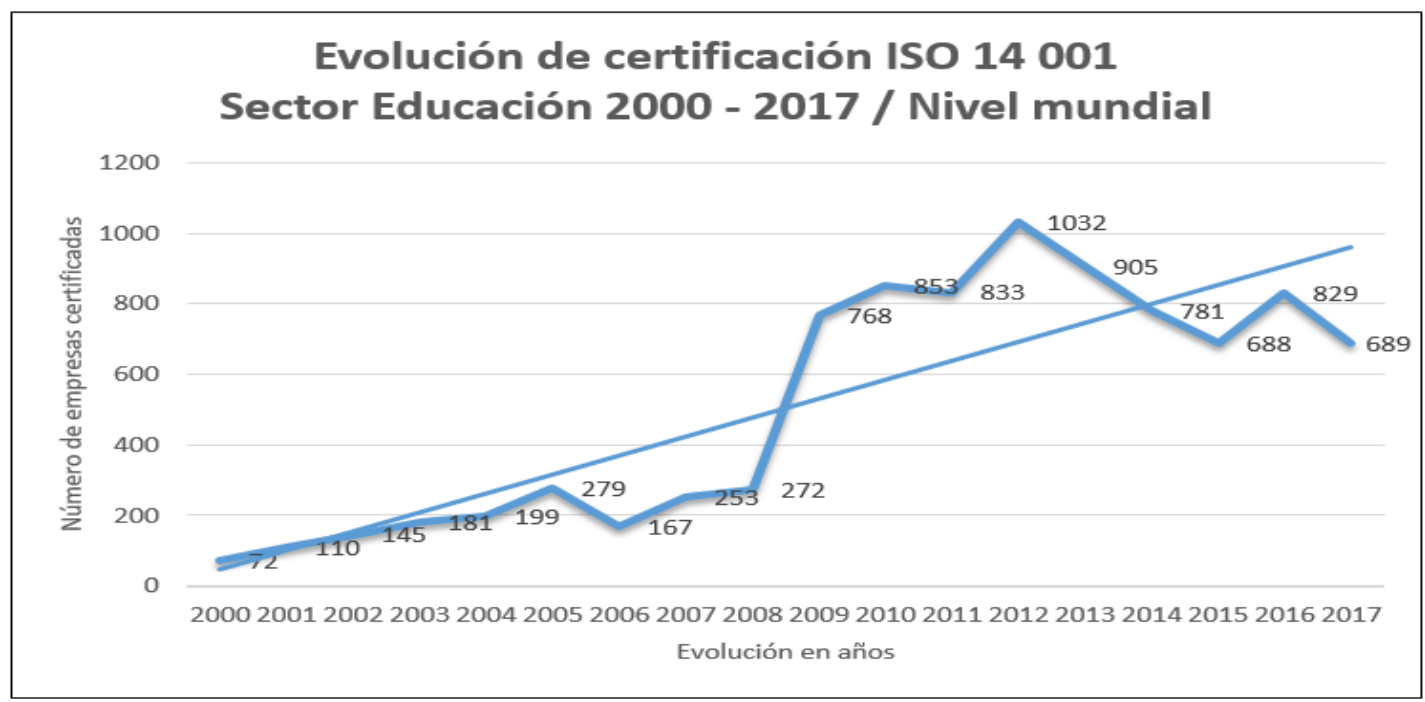

Figura 09: Evolución certificación ISO 14001 - Sector educación 2000 - 2017 / Nivel mundial. Fuente: Elaboración propia (ISO, 2017).

Por otro lado, ISO en el año 2017, reportó que 499 organizaciones contaban con un Sistema de Gestión Ambiental certificado e implementado en el Perú (Fuente, ISO 2017). En la Figura10, se visualiza la evolución cuantitativa de organizaciones con SGA en el Perú desde el año 2000 al 2017. 


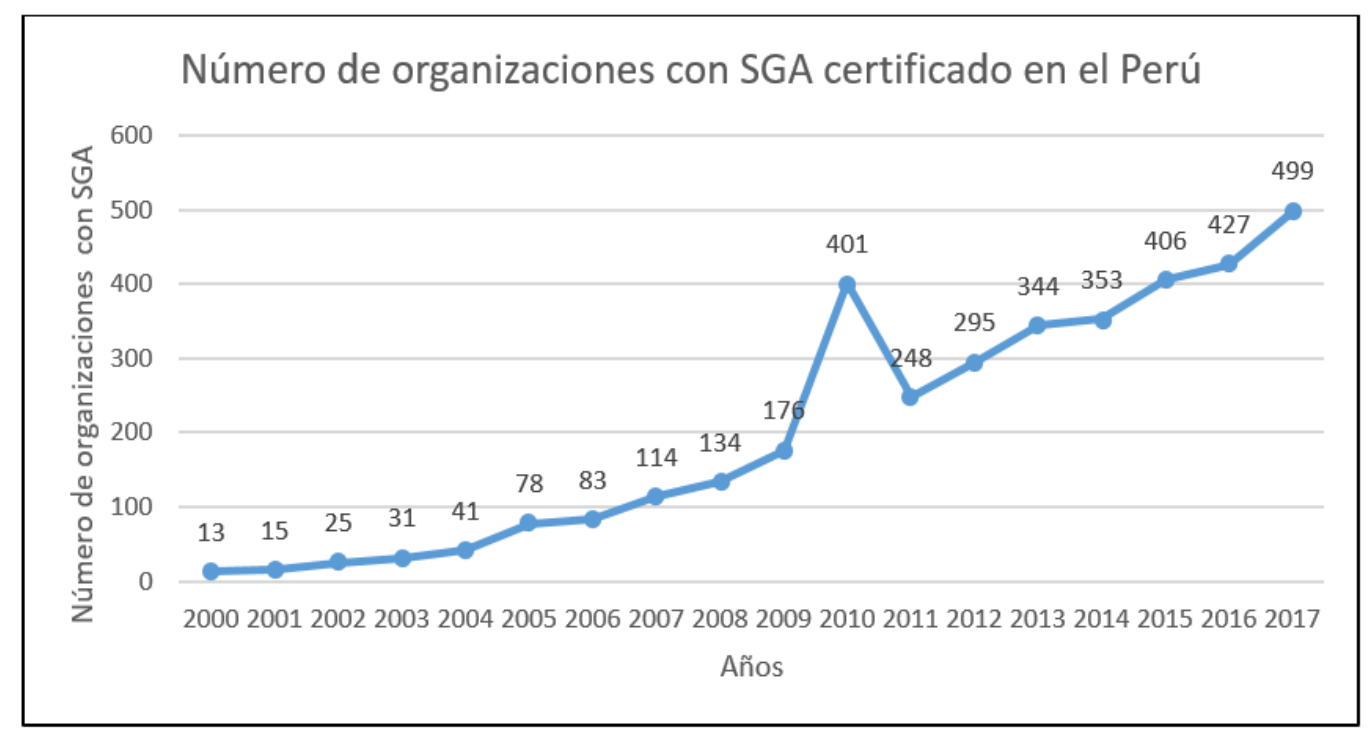

Figura 10: Evolución de organizaciones en el Perú con SGA 2000 - 2017. Fuente: Elaboración propia (ISO, 2017).

La implementación de Sistemas de Gestión Ambiental durante los últimos 17 años, en el Perú, viene en aumento y marca una tendencia. A modo de ejemplo, durante el año 2014, el sector Extractivo y Minería obtuvo la mayor cantidad de certificaciones en SGA (55), en segundo lugar, se ubicó el sector Transporte y Comunicaciones con 43 certificaciones; y, en tercer lugar, el sector Construcción con 28 certificaciones. Coincidentemente el sector Minería y Construcción son los que mayor impacto ambiental generan en nuestro territorio; a su vez originan conflictos sociales y ambientales. La gran brecha entre estos sectores y los restantes es la normativa vigente, las exigencias sociales por parte de las comunidades y stakeholders; y finalmente: El Mercado.

En el Perú, el sector educación es uno de los sectores que menos implementa SGA en sus organizaciones; dado que existe el sesgo que estos sistemas integrados son exclusivamente para sectores productivos o industriales. Una de las organizaciones educativas que ha implementado y certificado su SGA es el Centro de Negocios de la Pontificia Universidad Católica del Perú - CENTRUM, el cual posee un SGA aplicable al diseño, desarrollo y procesos de gestión de los programas: Doctorado, Maestría, Professional in Business Administration, Diplomaturas, Cursos de educación ejecutiva y programas confeccionados a requerimientos del cliente, en las distintas modalidades a nivel local. Con la implementación de este sistema, CENTRUM ha logrado alcanzar y cumplir con la legislación legal e industrial; reducir sus multas, mejorar la competitividad de la organización, ahorro de costos por un 
mejor uso de los recursos y mayor conciencia en el manejo de los aspectos e impactos ambientales (CENTRUM - Reconocimiento Internacional, 2015).

En un contexto global, donde los consumidores cada día están más informados, son más críticos y exigentes; la implementación de sistemas que optimicen recursos, que generen menor daño e impacto ambiental; creen conciencia y respeto hacia nuestro entorno, se ha vuelto, más que una tendencia, una necesidad. La implementación de sistemas de gestión ambiental contribuye a la consecución de los objetivos organizacionales, dado que, desde su esencia, es una estrategia de negocios.

\subsubsection{Diagnóstico Ambiental - Sector Educación.}

El diagnóstico ambiental es un instrumento técnico, que puede ser efectuado por un proyecto, institución u organización, obra e industria; el cual tiene por objetivo determinar las acciones correctivas necesarias para mitigar los impactos ambientales negativos diagnosticados.

El diagnóstico ambiental, independientemente al sector en el cual se aplique, está constituido por un conjunto de estudios, análisis y propuestas de actuación y seguimiento que abarcan un determinado territorio, en un periodo establecido.

El diagnóstico ambiental se diferencia del inventario ambiental por la propuesta de solución a los problemas diagnosticados; así como por incluir un sistema de parámetros con los cuales evaluar, medir y controlar los problemas encontrados.

En el caso específico de las universidades, los diagnósticos ambientales contribuyen al reconocimiento de los impactos ambientales significativos y no significativos. Por otro lado, muestra transparencia ante la comunidad universitaria.

El diagnóstico ambiental representa el punto de partida de la gestión ambiental de la universidad; dado que es partir de este punto que se puede planificar actividades a futuro y establecer metas alcanzables.

Finalmente, el diagnóstico ambiental se enmarca bajo el concepto de responsabilidad social universitaria, dado que la gestión de los impactos diagnosticados representa la responsabilidad de la organización ante los mismos. Toda universidad debería responsabilizarse por los impactos ambientales generados por sus acciones, decisiones y omisiones. Este es el primer paso para lograr el concepto de universidad sostenible. 


\subsubsection{Educación Ambiental - Sector Educación.}

"La educación ambiental es el proceso de reconocer valores y clarificar conceptos con el objeto de desarrollar habilidades y actitudes necesarias para comprender y apreciar las interrelaciones entre el hombre, su cultura y sus entornos biofísicas. La educación ambiental incluye también la práctica en la toma de decisiones y la auto formulación de un código de conducta sobre los problemas que se relacionan con la calidad ambiental" (I.U. C.N., Nevada).

Para la Dirección de Educación Ambiental de la Secretaría de Medio Ambiente de México, la Educación Ambiental representa un proceso formativo que permite conocer la importancia real del ambiente. Asimismo, promueve y desarrolla actitudes y valores que contribuyan al uso racional de los recursos naturales y a la posible solución de problemas ambientales que enfrenta la sociedad.

La Educación Ambiental fortalece el respeto por todas las formas de vida y los derechos humanos. Contempla al ser humano como parte del ecosistema, desechando el concepto antropocentrista, el cual situaba al hombre como eje del sistema natural.

La Conferencia Intergubernamental sobre Educación Ambiental, organizada por Organización de las Naciones Unidas para la Educación, Ciencia y Cultura (UNESCO) y el Programa de las Naciones Unidas para el Medio Ambiente (PNUMA), en 1977 en Tbilisi - Georgia, aprobaron los siguientes propósitos y principios orientadores para la Educación Ambiental.

\section{Propósitos o metas:}

a) Promover conciencia e interés por la interdependencia económica, social, política y ecológica en los sectores urbanos y rurales.

b) Proporcionar a cada persona la oportunidad de adquirir conocimientos, valores, actitudes, compromisos y habilidades para proteger y mejorar el medio ambiente.

c) Crear nuevos patrones de conducta hacia el medio ambiente para los individuos, grupos y la sociedad como un todo.

\section{Categorías de los objetivos:}

Ayudar a los grupos sociales y a los individuos a:

a) Adquirir conciencia hacia el ambiente y sus problemas asociados (Conciencia). 
b) Poseer experiencias y adquirir conocimientos básicos sobre el medio ambiente y sus problemas (Conocimientos).

c) Adquirir valores y sentimientos de preocupación por el medio ambiente, así como la motivación para participar en el mejoramiento y protección ambiental (Actitudes).

d) Adquirir destrezas en la identificación y resolución de problemas ambientales (Habilidades).

e) Gozar la oportunidad de comprometerse activamente a favor de la resolución de los problemas ambientales (Participación).

\section{Contexto Internacional de la Educación Ambiental:}

La Secretaría de Medio Ambiente (SEDEMA) del estado mexicano es el espacio creado especialmente con el objetivo de democratizar la Política Ambiental Mexicana. Esta entidad busca otorgar información sobre el medio ambiente del Estado de México; así como difundir acciones para su protección y conservación (Secretaría del Medio Ambiente México, 2017).

SEDEMA, a través de la Dirección de Concertación y Participación Ciudadana, realiza distintas actividades como conferencias, talleres, cursos y exposiciones con la finalidad de promover la participación de los sectores (público, social y privado) en las tareas de prevención, protección, conservación y remediación del medio natural.

Asimismo, busca fomentar y fortalecer hábitos para la nueva cultura ambiental; de forma tal que se pueda revertir o corregir los hábitos o actitudes que han dañado en el pasado al medio ambiente. Por otro lado, busca incorporar en la sociedad la idea que con el paso del tiempo y manteniendo nuestros hábitos - actitudes (comportamiento) que perjudican al medio ambiente, estaremos perdiendo la oportunidad de disfrutar una mejor calidad de vida hoy y a futuro (Programa de Educación Ambiental de la Secretaría del Medio Ambiente México).

Según el estudio Green at fifteen - PISA 2016, realizado por la Organización para la Cooperación y Desarrollo Económico (OCDE); el 64,8\% de los estudiantes mexicanos (escolares y universitarios) reciben información sobre educación ambiental en aulas, siendo el principal medio. Por otro lado, el 39,86\% de la información proviene a través de los medios de comunicación masivos tales como Tv, radio y periódicos. Entre los problemas ambientales más destacados por los 
estudiantes se encuentran deforestación, escasez de agua, extinción de flora y fauna; y, contaminación del aire (Green at fifteen - OCDE).

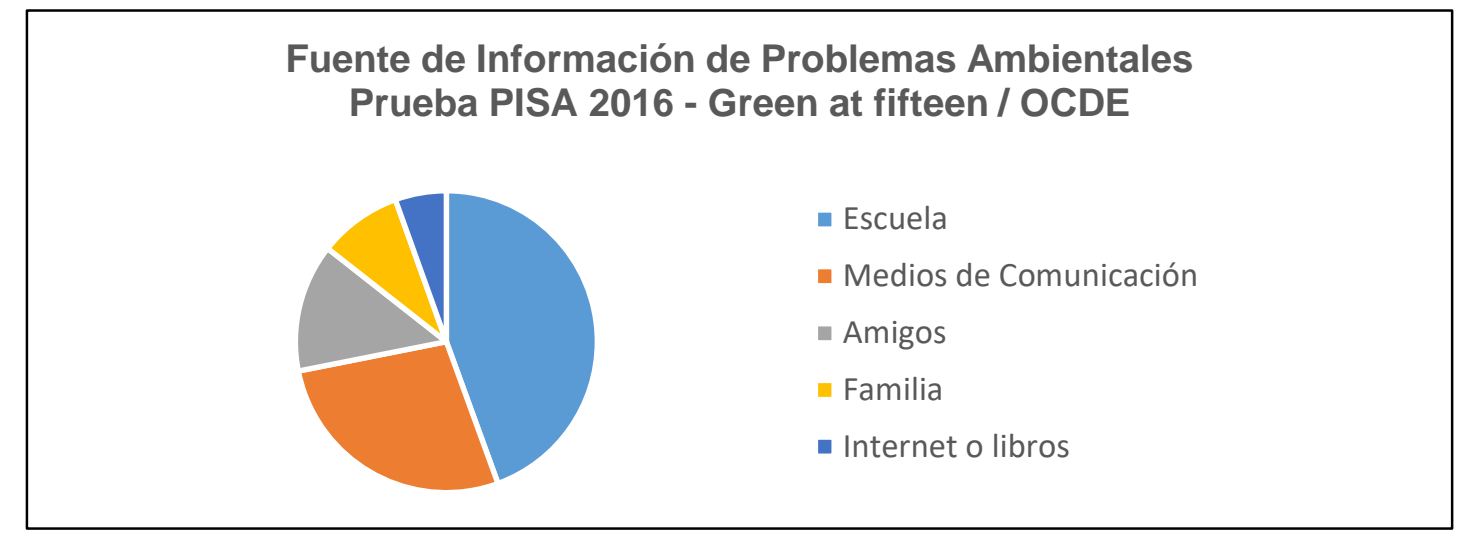

Figura 11: Fuentes de Información de Problemas Ambientales en México. Fuente: Elaboración Propia basado en la Prueba PISA 2016 - Green at fifteen.

\section{Contexto Nacional de la Educación Ambiental:}

En el Perú, el Ministerio de Medio Ambiente y el Ministerio de Educación, son los encargados de dar cumplimiento a la Política Nacional de Educación Ambiental a nivel nacional. Esta Política posee un instrumento de gestión, que la implementa de forma coordinada, multisectorial y descentralizada; denominado Plan Nacional de Educación Ambiental 2017 - 2022 (PLANEA). El Plan Nacional de Educación Ambiental posee el siguiente objetivo general: "Desarrollar la educación y la cultura ambiental orientadas a la formación de una ciudadanía ambientalmente responsable y una sociedad peruana sostenible, competitiva, inclusiva y con identidad" (PLANEA - Ministerio de Medio Ambiente del Perú).

Asimismo, posee los siguientes objetivos específicos:

- Asegurar el enfoque ambiental con enfoque intercultural y de género en el Sistema Educativo, en sus diferentes etapas, niveles, modalidades y formas.

- Desarrollar una cultura ambiental con enfoque intercultural y de género en el quehacer público y privado nacional.

- Incorporar el enfoque intercultural, de género y de derechos humanos, así como la inclusión social en los procesos y recursos de la educación, comunicación e interpretación ambiental.

- Formar una ciudadanía ambiental con enfoque intercultural y de género, informada y plenamente comprometida en el ejercicio de sus deberes y derechos ambientales y, en su participación en el desarrollo sostenible. 
- Garantizar la accesibilidad pública de la información ambiental, así como la investigación en educación y cultura ambiental con enfoque intercultural y de género.

El Plan Nacional de Educación Ambiental (PLANEA), en su matriz Acciones Estratégicas y Metas Priorizadas 2017- 2022; presenta Ejes Estratégicos (EE), los cuales incluyen Objetivos Estratégicos (OE).

Los Ejes mencionados; así como los Objetivos, se relacionan dada sus características. Esta relación se presenta a continuación:

\section{Tabla 03}

Ejes Estratégicos - Plan Nacional de Educación Ambiental 2017 - 2022

\begin{tabular}{|c|c|}
\hline Ejes Estratégicos (EE) & Objetivos Estratégicos (OE) \\
\hline \multirow{2}{*}{$\begin{array}{l}\text { EE1. Competencias de la comunidad educativa } \\
\text { para estilos de vida saludables y sostenibles. }\end{array}$} & $\begin{array}{l}\text { OE1. Comunidades Educativas con capacidad } \\
\text { para transversalizar el enfoque ambiental e } \\
\text { implementar proyectos educativos ambientales } \\
\text { y ambientales comunitarios. }\end{array}$ \\
\hline & $\begin{array}{l}\text { OE2. Estudiantes se apropian de prácticas } \\
\text { ambientales que contribuyen a generar un } \\
\text { entorno local y global saludable y sostenible. }\end{array}$ \\
\hline $\begin{array}{l}\text { EE2. Compromiso ciudadano para el desarrollo } \\
\text { sostenible }\end{array}$ & $\begin{array}{l}\text { OE3. Ciudadanos y ciudadanas cumplen } \\
\text { deberes y ejercen derechos ambientales. }\end{array}$ \\
\hline $\begin{array}{l}\text { EE3. Compromisos institucionales para el } \\
\text { desarrollo sostenible y sociedades sostenibles. }\end{array}$ & $\begin{array}{l}\text { OE4. Instituciones y organizaciones públicas, } \\
\text { privadas y sociedad civil adoptan prácticas } \\
\text { ambientales responsables. }\end{array}$ \\
\hline
\end{tabular}

Fuente: Plan Nacional de Educación Ambiental 2017 - 2022.

Asimismo, el presente Plan contempla el desarrollo de una ruta estratégica para cada Objetivo Estratégico (OE) - perteneciente a un Eje Estratégico (EE). Para efectos de la presente investigación, se detalla a continuación el Eje Estratégico 1; debido a que se relaciona con la Educación Ambiental impartida en la comunidad educativa, es decir colegios, universidades e institutos. Caso contrario como son el Eje 2, el cual aplica la Educación Ambiental el ciudadano; y el Eje 3; el cual centra sus objetivos en las instituciones y organizaciones públicas y privadas.

Dentro del Eje Estratégico 1, se encuentran dos objetivos estratégicos. Siendo el primero de ellos la transversalización del enfoque ambiental y el apoyo a proyectos ambientales comunitarios; mientras que, el segundo se refiere a la contribución de los estudiantes a la generación de un entorno local / global saludable y sostenible. 
Este último OE se alinea a los objetivos del presente Informe de Tesis, dado que la Guía de Gestión Ambiental USIL incluye la Educación Ambiental como instrumento para fomentar y fortalecer hábitos para la nueva cultura ambiental de los estudiantes universitarios bajo un enfoque de responsabilidad social, pilar institucional USIL.

En este contexto, el PLANEA propone la Ruta Estratégica para el cumplimiento exitoso del Objetivo Estratégico 2, el cual se alinea a la presente investigación (Anexo N06: Ruta Estratégica del PLANEA - Objetivo Estratégico 2).

\section{Estrategia 2.1:}

Fortalecer los diseños curriculares y proyectos educativos a nivel nacional, regional, local e institucional, así como las acciones complementarias que refuercen el manejo sostenible de los recursos naturales y la educación de los estudiantes.

La presente estrategia, a través de la ruta estipulada, busca aprovechar los espacios naturales y culturales con fines pedagógicos; de forma que se cree conciencia ambiental en los estudiantes. Asimismo, estipula la implementación de Tecnologías de Información y Comunicación (TIC) en el desarrollo de la educación ambiental.

\section{Estrategia 2.2:}

Promover e incentivar redes y/o voluntariados; así como comités ambientales y otros tipos de organización estudiantil que promuevan la educación ambiental y estilos de vida sostenibles y saludables.

La presente estrategia busca crear grupos estudiantiles/voluntariados/comités ambientales que promuevan estilos de vida sostenibles y saludables. Asimismo, una vez conformados los mismos, podrán ser capacitados y coordinar con organizaciones de la sociedad civil e instituciones públicas y privadas. Finalmente, se difundirán las acciones más relevantes y se buscará sostener en el tiempo estas agrupaciones.

\section{Estrategia 2.3:}

Promover la participación de los estudiantes en eventos y espacios de difusión de experiencias exitosas en temas ambientales, tales como concursos, congresos, foros, festivales, seminarios y ferias.

La presente estrategia busca promover la participación de los colectivos ambientales; así como crear espacios para el intercambio de opiniones en la temática ambiental.

Finalmente, busca alentar la elaboración de proyectos de buenas prácticas ambientales, los cuales serán reconocidos por su logro. 


\subsubsection{Participación de partes interesadas - Sector Educación.}

En términos sencillos, la participación es estar presentes de forma activa en los procesos que nos preocupan e interesan porque este es un derecho fundamental de las personas y de la colectividad (Delpiano, 2003).

Asimismo, para participar adecuadamente, según el principio 10 de la Declaración de Rio sobre medio ambiente y desarrollo 1992, debe tenerse en cuenta tres elementos: (i) acceso a la información; (ii) acceso a la justicia; y (iii) derecho a participar.

Sin embargo, dentro de las organizaciones; y entre estas, las universidades, se requiere como paso fundamental la identificación de las partes interesadas, con la finalidad de conocer sus expectativas y necesidades. En este sentido, las universidades presentan algunas partes interesadas descritas a continuación:

- Gobierno: Toda organización está sujeta a las regulaciones establecidas por el Gobierno, entre ellas las regulaciones ambientales. El no cumplimiento de las mismas puede ocasionar sanciones.

- Accionistas: Los inversores buscan la generación de ingresos; motivo por el cual la gestión adecuada del medio ambiente permitirá reducir el riesgo de sanciones y multas; así como, reducción de costos por eficiencia en el uso de recursos.

- Alumnos: El grupo de interés más relevante para una universidad; dado que el desarrollo profesional y humano del mismo es el objetivo de la organización educativa. Asimismo, su participación es importante en el modelo de gestión ambiental de las universidades.

- Colaboradores: Las universidades poseen colaboradores de la parte administrativa y docentes, gracias a quienes la organización es capaz de aplicar el modelo de formación profesional y desarrollar el conjunto de servicios que complementan el desarrollo de los educandos. En cuanto a la temática ambiental, los colaboradores deben integrar el sistema de gestión ambiental, dado que su contribución permitirá alcanzar los objetivos ambientales de la organización.

- Proveedores: Los proveedores son los encargados de proveer insumos y servicios necesarios para el accionar de la universidad. La selección de proveedores debe poseer un criterio de compromiso ambiental, dado que las acciones de los mismos, pueden favorecer o perjudicar la imagen organizacional. 
- Comunidad: La sociedad en general representa una parte interesada; dado que el compromiso de una institución educativa es formar profesionales que puedan contribuir a futuro con el desarrollo de la sociedad. En este sentido, las universidades deben formar profesionales son responsabilidad social y ambiental.

La participación de los grupos de interés, en especial de los alumnos, es importante para el accionar ambiental de las instituciones educativas. En este sentido, las universidades vienen fomentando la educación ambiental entre la comunidad universitaria y empiezan a integrar al alumno dentro de las actividades ambientales de la universidad.

Conocer la percepción y la conducta de la comunidad universitaria, fomentar la participación del alumno, docentes, colaboradores y tomadores de decisión en temas ambientales y sensibilizar a las partes interesadas, representa un reto para el establecimiento de modelos de gestión ambiental en universidades.

\subsubsection{Descripción de la Universidad y su Gestión Ambiental.}

\subsubsection{La Universidad San Ignacio de Loyola - USIL.}

La Universidad San Ignacio de Loyola es una universidad peruana privada, cuenta con sedes en Estados Unidos, China y Paraguay. Fundada el año 1996 por el Economista y Político Raúl Diez Canseco Terry. USIL, como comúnmente es llamada, cuenta con 35 carreras profesionales en 8 facultades; promueve la formación bilingüe y se aboca a la gestión empresarial (usil.edu.pe, 2018).

En materia ambiental, la universidad cuenta con la Unidad Ambiental, Social y de Seguridad y Salud Ocupacional USIL, la cual se encarga de implementar, vigilar y hacer cumplir los programas y planes propuestos para las actividades realizadas en cada una de las instalaciones de la universidad, permitiendo el cumplimiento de la legislación nacional y requerimientos exigidos por las entidades financieras, referidos a los aspectos ambientales, sociales, seguridad y salud ocupacional (USIL, 2016).

Asimismo, es la primera universidad peruana en obtener una Certificación LEED (Leadership in Energy and Environmental Design). Esta es un importante reconocimiento internacional por la sostenibilidad en la infraestructura del Campus Almirante Grau - Pabellones B y C (USIL, 2016). La construcción de estos pabellones se efectuó con el financiamiento del Banco Interamericano de Desarrollo (BID). En este contexto se creó el Comité de Sostenibilidad (Anexo $\mathrm{N}^{\circ}$ 09), integrado por ejecutivos de la alta dirección quienes tienen como principal objetivo dar soporte a la 
implementación de los Planes de Gestión Ambiental y Social, así como al Sistema de Seguridad y Salud Ocupacional que permiten el fortalecimiento y posicionamiento como una organización sostenible (usil.edu.pe, 2018).

Finalmente, USIL cuenta con cuatro pilares, los cuales buscan fomentar el desarrollo de emprendedores capaces de lograr su progreso personal en un marco más amplio, de una manera socialmente responsable, contribuyendo a través de sus actividades al desarrollo del país, un Perú moderno que participa con confianza y dinamismo de la economía global. Estos pilares son: 1) Emprendimiento, 2) Investigación, 3) Globalización y 4) Responsabilidad Social (USIL, 2016).

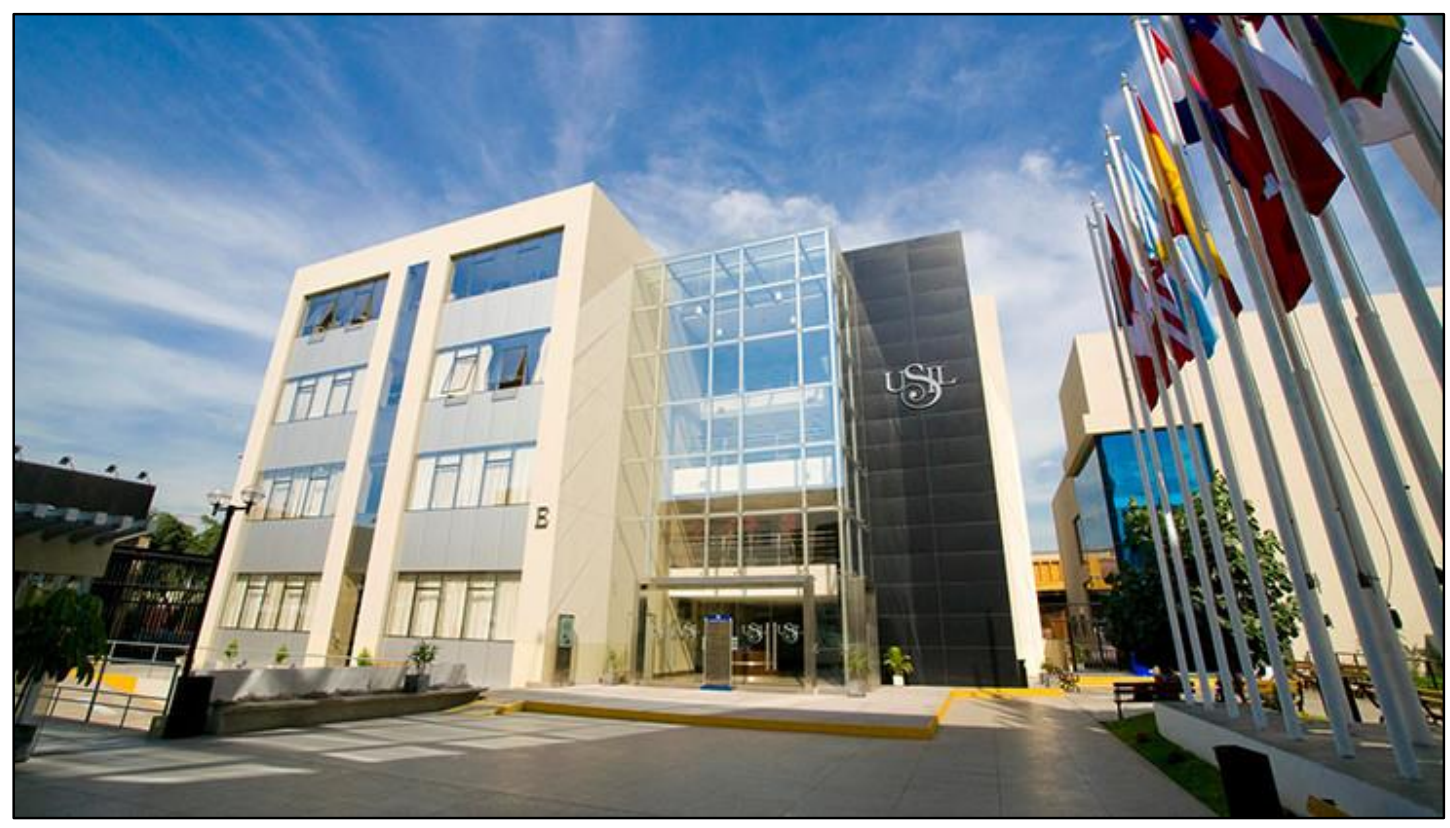

Figura 12: Universidad San Ignacio de Loyola - La Molina. Fuente: USIL.

\subsubsection{Gestión Ambiental USIL.}

La universidad San Ignacio de Loyola posee como principio fundamental la preservación del medio ambiente en todas sus actividades (Reporte de Sostenibilidad USIL, 2015). Es en este contexto que la universidad viene implementando acciones estratégicas que permiten la optimización de los recursos naturales; en aras de convertirse a una universidad sostenible. Estas acciones estratégicas, que constan en el Reporte de Sostenibilidad USIL 2015, son:

- Garantizar que todas las nuevas edificaciones cumplan con los requerimientos ambientales para lograr la obtención de la Certificación LEED (Leadership in Energy and Environmental Design) y mejorar progresivamente las edificaciones existentes bajo los estándares LEED. 
- Fortalecer las medidas de eco eficiencia en la institución, con el soporte de las carreras de Gestión Ambiental Empresarial e Ingeniería Ambiental.

- Desarrollar cultura de consumo sostenible y buenas prácticas en oficina.

- Reducir el consumo de agua y energía eléctrica en todas las operaciones.

Asimismo, la universidad se compromete, a través de su Política de Seguridad, Salud Ocupacional y Medio Ambiente, a cumplir con lo siguiente:

- Identificar los aspectos ambientales significativos y gestionarlos eficientemente para proteger el medio ambiente.

- Exigir su cumplimiento a los proveedores, contratistas, trabajadores directos, trabajadores autónomos y personas bajo modalidad formativa.

- Revisar y analizar periódicamente los resultados del Sistema de Gestión en Seguridad, Salud y Medio Ambiente, propiciando así la mejora continua del sistema para lograr la excelencia mundial.

- Garantizar la compatibilidad o la integración del Sistema de Gestión de la Seguridad, Salud y Medio Ambiente con los otros sistemas de gestión de la Organización.

- Identificar y garantizar el cumplimiento de los requisitos y obligaciones legales en materia de Medio Ambiente, así como los asumidos voluntariamente por la Organización.

- Diseñar y desarrollar planes de capacitación, entrenamiento y sensibilización para todos los colaboradores en temas ambientales.

- Garantizar la participación de los trabajadores y sus representantes en el Sistema de Gestión de Medio Ambiente de la Organización.

En este sentido, USIL ha previsto como objetivo estratégico el Fortalecimiento del Compromiso Institucional con el Medio Ambiente. Para lograr lo anunciado, viene desarrollando progresivamente las siguientes actividades, las cuales constan en el Reporte de Sostenibilidad USIL 2015:

- Generar estudios de impacto ambiental para todas sus nuevas edificaciones asumiendo compromisos específicos para cada sede. 
- Implementar mejoras en equipos, suministros y materiales que garanticen el cuidado del medio ambiente.

- Garantizar el manejo adecuado de residuos sólidos en todas las operaciones, implementando para ello programas de reciclaje en todas las sedes USIL.

- Implementar mejoras en los sistemas de agua, energía, sistemas que permitan ahorros en los consumos.

- Cambios de tecnología y de materiales que sean más amigables con el medio ambiente, tales como cambio de gases efecto invernadero en los sistemas de refrigeración y cambio por materiales de limpieza que sean ecológicamente amigables.

- Implementación de monitoreo de Calidad de Agua y Aire que permitan alinear las operaciones con la normatividad ambiental correspondiente.

En el contexto de impactos ambientales por consumo de energía y agua, USIL busca la optimización de los mencionados recursos. A modo de ejemplo, en el año 2015, la universidad consumió 6.35 millones de kW.h de energía eléctrica (9.4\% más en comparación al año 2014). Este resultado, pese a ser mayor que el año previo, denoto un ahorro potencial, dado que existió nueva infraestructura al servicio de los alumnos y se registró un aumento de la población estudiantil. Este nivel de consumo significó 313.7 kW.h por alumno (Reporte de Sostenibilidad USIL, 2015).

Para el caso específico de consumo de agua, el año 2015, la universidad utilizó $77,165.17 \mathrm{~m} 3$ provenientes de la red de agua potable y de aguas subterráneas estas últimas en la sede Pachacamac (Reporte de Sostenibilidad USIL, 2015). En el marco del uso eficiente del agua en la universidad, se tomaron las siguientes medidas según el Reporte de Sostenibilidad USIL 2015:

- Cambio de los inodoros convencionales por los de doble descarga.

- Colocación de dispositivos para evitar descargas innecesarias de agua.

- Grifería con mecanismos de ahorro.

- Difusión de comunicaciones virtuales e impresas para concientizar alumnos, colaboradores y visitantes.

- Entrega de toma todos para colaboradores en conmemoración a días festivos de conservación ambiental. 
- Concurso y actividades para alumnos y colaboradores durante el Día Mundial del Agua; y Día Internacional del Medio Ambiente.

Asimismo, en materia de residuos sólidos, la universidad produjo más de 829 toneladas de residuos en el año 2015. Estos residuos son manejados por Plan de Manejo de Residuos Sólidos que posee la universidad y aplica en forma integral, abarcando la segregación, gestión y disposición final de los residuos.

\begin{tabular}{|l|c|}
\hline Entidad Aliada / Evento & Peso en kg \\
\hline Residuos Comunes & 805,916 \\
\hline Residuos Peligrosos & 6,900 \\
\hline Residuos Reciclados - Papel & 16,522 \\
\hline Total & $\mathbf{8 2 9 , 3 3 9}$ \\
\hline
\end{tabular}

Figura 13: Producción Residuos Sólidos USIL - 2015. Fuente: Reporte de Sostenibilidad USIL, 2015 Finalmente, es importante destacar que la universidad es firmante del Pacto Mundial de las Naciones Unidas; documento en el cual se establecen 10 principios en materia de derechos humanos, medio ambiente, trabajo y lucha contra la corrupción. En este sentido, la universidad se compromete a cumplir con los siguientes principios en materia ambiental:

- Principio 7: "Las empresas deberán mantener un enfoque preventivo que favorezca el medio ambiente".

- Principio 8: "Las empresas deben fomentar las iniciativas que promuevan una mayor responsabilidad ambiental".

- Principio 9: "Las empresas deben favorecer el desarrollo y la difusión de las tecnologías respetuosas con el medioambiente". 


\subsection{Marco Legal - Normatividad Principal.}

\subsubsection{Pacto Mundial de las Naciones Unidas.}

Instrumento de Naciones Unidas, presentado en el Foro Económico Mundial del año 1999. Es la mayor iniciativa voluntaria de responsabilidad social empresarial del mundo; dado que cuenta con 13000 entidades firmantes en más de 170 países.

Tiene por finalidad transformar el mercado mundial a través del potenciamiento del sector privado con tendencia a la sostenibilidad. Por este motivo, posee 10 principios relacionados a los tópicos de derechos humanos, trabajo, medio ambiente y lucha contra la corrupción. Asimismo, posee dos objetivos principales. El primero, incorporar los 10 principios en actividades empresariales de todo el mundo; mientras que el segundo es canalizar las acciones en apoyo de los objetivos más amplios de las Naciones Unidas, incluyendo los Objetivos de Desarrollo Sostenible.

A continuación, se nombran los 10 principios divididos en los cuatro tópicos mencionados:

\section{Derechos Humanos:}

- Principio № 1: Apoyar y respetar la protección de los derechos humanos.

- Principio № 2: No ser cómplice de abusos de los derechos.

\section{Ámbito Laboral:}

- Principio № 3: Apoyar los principios de la libertad de asociación y sindical y el derecho a la negociación colectiva.

- Principio № 4: Eliminar el trabajo forzoso y obligatorio.

- Principio № 5: Abolir cualquier forma de trabajo infantil.

- Principio № 6: Eliminar la discriminación en materia de empleo y ocupación.

\section{Medio Ambiente:}

- Principio № 7: Las empresas deberán mantener un enfoque preventivo que favorezca el medio ambiente.

- Principio № 8: Las empresas deben fomentar las iniciativas que promuevan una mayor responsabilidad ambiental.

- Principio № 9: Las empresas deben favorecer el desarrollo y la difusión de las tecnologías respetuosas con el medio ambiente. 


\section{Anti-Corrupción:}

- Principio № 10: Las empresas e instituciones deberán trabajar contra la corrupción en todas sus formas, incluidos extorsión y soborno.

Se ha considerado la inclusión del Pacto Mundial de las Naciones Unidas como parte del Marco legal y normativo de la presente investigación, dado que la Universidad se encuentra suscrita al presente convenio y está comprometida con el cumplimiento de los principios establecidos. Este compromiso se puede evidenciar claramente en el Reporte de Sostenibilidad de la universidad.

\subsubsection{Política Nacional del Ambiente.}

Principal instrumento de gestión ambiental para el logro de la implementación del desarrollo sostenible en el Perú. Su elaboración, se basó en la Declaración de Río sobre el Medio Ambiente y Desarrollo, los Objetivos del Milenio formulados por la Organización de las Naciones Unidas, y demás tratados y declaraciones internacionales suscritos por el Estado Peruano en materia ambiental.

Basándose en la integración y relación de aspectos sociales, económicos y ambientales de las políticas públicas, y la satisfacción de necesidades de generaciones actuales y futuras; la Política Nacional del Ambiente representa un instrumento de cumplimiento obligatorio, debido a que orienta las actividades públicas y privadas en el país.

Por otro lado, la Política Nacional del Ambiente establece la base para la formulación del Plan Nacional de Acción Ambiental, la Agenda Nacional de Acción Ambiental y otros instrumentos de gestión pública ambiental en el marco del Sistema Nacional de Gestión Ambiental (Política Nacional del Ambiente, 2009).

En conclusión, la Política Nacional del Ambiente es un instrumento para el proceso estratégico del desarrollo del país, constituyendo la base para la conservación del ambiente, propiciando y asegurando el uso sostenible, responsable, racional y ético de los recursos naturales y del medio que lo sustenta, para contribuir al desarrollo integral, social, económico y cultural del ser humano, en permanente armonía con su entorno (Política Nacional del Ambiente, 2009).

Se ha considerado la inclusión de la Política Nacional de Ambiente en el marco legal de la presente investigación, dado que es el instrumento técnico y normativo que orienta las actividades públicas y privadas del país; esto incluye al sector educación en su nivel superior (universitario). 


\subsubsection{Política Nacional de Educación Ambiental.}

Instrumento de gestión ambiental que establece objetivos, lineamientos de política, metas y resultados esperados tanto en la formación; así como en el fortalecimiento, de capacidades de la ciudadanía para lograr el desarrollo sostenible ambiental nacional. Surgió como producto de un proceso participativo y de consulta liderado por los sectores Educación y Medio Ambiente, con la activa participación de entidades del sector público y la sociedad civil (Política Nacional de Educación Ambiental, 2012).

El gobierno, a través de los Ejes Estratégicos de la Gestión Ambiental, priorizó fortalecer la ciudadanía, la comunicación y educación ambiental, siendo un primer paso la aprobación de la Política Nacional de Educación Ambiental y su respectivo plan de implementación.

Según la Ley General del Ambiente, en su Artículo N 127.1, manifiesta que la educación ambiental es un proceso educativo integral, que genera conocimientos, actitudes, valores y prácticas en las personas, para que desarrollen sus actividades en forma ambientalmente adecuada, contribuyendo al desarrollo sostenible de nuestro país. Mientras que, en el Artículo № 127.1 de la mencionada Ley estipula que el cumplimiento de la Política Nacional de Educación Ambiental es obligatorio para los procesos de educación y comunicación desarrollados por entidades que tengan su ámbito de acción en el territorio nacional.

Asimismo, busca desarrollar la educación y cultura ambiental orientada a la formación de una ciudadanía ambientalmente responsable. En este sentido, el quinto objetivo específico de la Política Nacional de Educación Ambiental busca asegurar la accesibilidad pública de la información ambiental, así como la investigación en educación y cultura ambiental. En adición, el lineamiento № 10 "Educación superior universitaria y no universitaria", busca desarrollar el enfoque ambiental en la formación profesional, la investigación, proyección social y en la gestión institucional de las entidades de educación superior universitaria y no universitaria.

Se ha considerado la inclusión de la Política Nacional de Educación Ambiental en la presente investigación, debido a que busca la generación y fortalecimiento de conocimientos, valores y actitudes en favor del desarrollo sostenible. Además, representa el marco normativo sobre el cual la universidad debe implementar la educación ambiental en el desarrollo profesional de los estudiantes; así como, presenta lineamientos para la promoción de la investigación y cultura ambiental. 


\subsubsection{ISO 14001: Gestión Ambiental.}

La certificación ISO 14001 tiene por objetivo otorgar soporte a la aplicación de un Plan de Manejo Ambiental en instituciones u organizaciones, ya sean públicas o privadas. Fue creada por la Organización Internacional para Normalización (International Organization for Standardization - ISO), una red internacional de institutos de normas nacionales que trabajan en alianza con los gobiernos, la industria y representantes de los consumidores (ISO, 2015).

La aplicación de las normas internacionales ISO, incluyendo la 14 001, es de carácter voluntario; y han sido uniformizadas para su aplicación en todos los sectores existentes en la industria global (ISO, 2015). En este sentido, existen instituciones educativas de nivel superior (universitaria) que apuestan por la implementación de esta normativa internacional mediante el diseño y aplicación de Planes o Guías de Gestión Ambiental, que incluyan Sistemas de Gestión Ambiental.

La aplicación de esta normativa internacional en una organización busca reducir los impactos ambientales, creando de esta forma beneficios internos al mejorar el uso de recursos. La principal limitación con ISO 14001 es que no hay requisitos específicos. Esto quiere decir que una empresa con metas muy ambiciosas y una con metas más modestas, pueden ser certificadas por igual (Organización de las Naciones Unidas para la Alimentación y la Agricultura - FAO, 2015).

Se ha considerado la inclusión de esta normativa internacional en el marco legal del presente Informe de Tesis dado que brinda lineamientos para la mejora del desempeño ambiental de las organizaciones, entre ellas las universidades. Asimismo, su implementación puede representar una ventaja competitiva, promover la eficiencia en la asignación de recursos y mejorar la imagen corporativa.

\subsubsection{ISO 26000: Responsabilidad Social.}

La norma internacional ISO 26000 es una guía en Responsabilidad Social. Su diseño fue concebido para acoplarse a todo tipo de organización (pública o privada), en países desarrollados; así como en economías en transición. Esta norma contribuirá en el esfuerzo de operar la organización de forma socialmente responsable, característica que hoy es exigida por la población. Asimismo, esta normativa posee guías voluntarias, no establece requisitos; motivo por el cual, a diferencia de las ISO 14001 o ISO 9 001, no es certificable (ISO, 2010). 
La medición del desempeño integral de una organización, hoy en día, incluye el desempeño ambiental y social de la misma. En la actualidad, las organizaciones empiezan a reconocer la importancia de proteger y conservar los ecosistemas saludables. Asimismo, hoy más que antes, las organizaciones están sometidas a un escrutinio cada vez mayor por parte de sus diversas partes interesadas (ISO 26000, s.f., párr. 8).

El desempeño de una organización en materia de responsabilidad social, como su desempeño real (incluyendo el ambiental) pueden influir, entre otras cosas en: (i) su ventaja competitiva; (ii) reputación; (iii) capacidad para atraer y retener a trabajadores o miembros de la organización, clientes o usuarios; (iv) mantener la motivación, compromiso y productividad de los empleados; (v) percepción de los inversionistas, propietarios, donantes, patrocinadores y la comunidad financiera, y, (vi) las relaciones con empresas, gobiernos, medios de comunicación, proveedores, organizaciones pares, clientes y la comunidad donde opera (ISO 26000, s.f., párr. 9).

Se ha considerado la inclusión de esta normativa internacional en responsabilidad social dado que la Universidad San Ignacio de Loyola, promueve la práctica de la Responsabilidad Social, uno de sus pilares institucionales, entre los miembros de su comunidad universitaria. Finalmente, USIL busca generar una cultura organizacional responsable en un campus sostenible y formar profesionales socialmente responsables, a través de experiencias formativas que contribuyan al desarrollo del país y del mundo (Responsabilidad Social USIL, 2015).

\subsubsection{Ley de Recursos Hídricos - Ley № 29338.}

La Autoridad Nacional del Agua (ANA) regula el uso y gestiona los recursos hídricos en el país, comprende aguas superficiales, subterráneas, continental y los bienes asociados a esta. Asimismo, otorga licencias de uso y aprovechamiento de agua (Ley de Recursos Hídricos, Ley №29338).

Las actividades propias de USIL hacen uso de agua potable y alcantarillado. La universidad, en su sede Pachacamac hace uso de aguas subterráneas (Reporte de Sostenibilidad USIL - Optimización de la Energía y el Agua, 2015), motivo por el cual se estima conveniente el marco legal de la presente Ley. 


\subsubsection{Ley de Gestión Integral de Residuos Sólidos - DL №1278.}

El Ministerio del Ambiente, ente rector en materia ambiental en el Perú, a través del Decreto Legislativo N 1278, promulga la "Ley de Gestión Integral de Residuos Sólidos; derogando de esta forma la Ley N² 27314, "Ley General de Residuos Sólidos". La Ley de Gestión Integral de Residuos Sólidos [Ley], sostiene tres pilares de acción: (i) Reducir residuos como primera prioridad; (ii) eficiencia en el uso de los materiales; y, (iii) residuos visto como recursos y no como amenaza.

Esta nueva Ley representa una oportunidad para mejorar el servicio y la gestión de residuos sólidos en el país; así como incentiva la minimización en la producción de los mismos. Por otro lado, define a los residuos sólidos como aquellas sustancias, productos o subproductos en estado sólido o semisólido de los que su generador dispone, o está obligado a disponer, en virtud de lo establecido en la normatividad nacional o de los riesgos que causan a la salud y el ambiente, para ser manejados a través de un sistema que incluya, según corresponda, las siguientes operaciones o procesos: (i) Minimización de residuos; (ii) Segregación en la fuente; (iii) Reaprovechamiento; (iv) Almacenamiento; (v) Recolección; (vi) Comercialización; (vii) Transporte; (viii) Tratamiento; (ix) Transferencia; y, (x) Disposición final (Ley de Gestión Integral de Residuos Sólidos, Decreto Legislativo №1278).

Se estima conveniente la inclusión del marco legal de la Ley General de Residuos Sólidos en el presente Informe de Tesis dado que, las actividades ejecutadas por USIL generan residuos sólidos, los cuales, mediante el Plan de Manejo de Residuos Sólidos, son gestionados hasta su disposición final (Reporte de Sostenibilidad USIL - Gestión de Residuos, 2015).

\subsubsection{Ley de Promoción del Uso Eficiente de la Energía - Ley N²7345.}

El Ministerio de Energía y Minas es la autoridad competente del Estado para la promoción del uso eficiente de la energía. En este sentido, se promulgó la "Ley de Promoción del Uso Eficiente de la Energía" [Ley], Ley № 27345; con la finalidad de asegurar el suministro de energía, proteger al consumidor, fomentar la competitividad de la economía nacional y reducir el impacto ambiental negativo del uso y consumo de los energéticos. Asimismo, posee un Reglamento, aprobado por Decreto Superno № 053-2007-EM; el cual busca emitir normas reglamentarias para la mejor aplicación de la citada norma legal (Ley de Promoción del Uso Eficiente de la Energía, Ley $N^{\circ}$ 27345). 
La mencionada Ley, promueve la cultura del uso eficiente de la energía y coordina con las universidades del país el desarrollo de cursos de pre y post grado en eficiencia energética. Se estima conveniente la inclusión del marco legal de la Ley precitada en la presente investigación dado que, la universidad busca la optimización de la energía en sus instalaciones, a través de la implementación de nueva tecnología, y promueve su uso eficiente (Reporte de Sostenibilidad USIL - Gestión de Residuos, 2015). 


\section{MÉTODO.}

\subsection{Tipo de Investigación.}

Según el nivel de complejidad del estudio y el tipo de análisis al que se somete la información recolectada, se concluye la realización de una investigación descriptiva de análisis cualitativo, dado que se observa y describe el estado actual de la gestión ambiental en la Universidad San Ignacio de Loyola (fenómeno particular holístico); y con la información obtenida, se diseña una propuesta de Guía de Gestión Ambiental (instrumento de gestión ambiental) que contribuirá al cumplimiento de los compromisos ambientales establecidos en la Política Integrada de la universidad.

Finalmente, se realizarán encuestas, usando la escala de medición Likert, con la finalidad de conocer el grado de acuerdo de autoridades y expertos en materia ambiental de la universidad, en cuanto a la necesidad de implementar la Guía de Gestión Ambiental propuesta.

La presente investigación es cualitativa dado que cuenta con las siguientes características.

Una manera de expresar la peculiaridad de los métodos cualitativos frente a los cuantitativos es la de reconocer como tales a aquellos modos de investigar en los que se den las cinco características siguientes o, al menos, alguna de ellas: su objetivo es la captación y reconstrucción de significado, su lenguaje es básicamente conceptual y metafórico, su modo de captar la información no es estructurado sino flexible y desestructurado, su procedimiento es más inductivo que deductivo y la orientación no es particularista y generalizadora sino holística y concretizadora (Ruiz, 2003: 23).

La presente investigación estudia un fenómeno particular (estado actual de la gestión ambiental en la universidad) y no busca la generalización de sus resultados a una población determinada.

\subsection{Diseño de Investigación.}

Con la finalidad de cumplir con el objetivo general de la presente investigación se establecieron 03 etapas presentadas a continuación:

A. Elaboración del Diagnóstico Ambiental USIL.

1. Recopilación de información de las actividades en materia ambiental que viene desarrollando la universidad, con la finalidad de conocer el estado actual de la gestión ambiental en USIL. Este paso es la base para el diseño y desarrollo del 
Diagnóstico Ambiental Institucional y de los 2 instrumentos de gestión planeados: Propuesta de Sistema de Gestión Ambiental; y, Educación ambiental.

2. Identificación de los procesos estratégicos, principales, de apoyo y de evaluación que ejecuta la universidad para lograr la enseñanza educativa. Asimismo, se revisa información correspondiente a la Política Ambiental y recursos actuales que posee la universidad para el desarrollo eficiente de la gestión ambiental.

3. Identificación y descripción de aspectos e impactos ambientales generados por procesos previamente identificados dentro del ámbito de la universidad. Como resultado, se obtiene la línea base ambiental de la universidad. Después, los impactos son categorizados, con el apoyo de la Unidad de Seguridad, Salud Ocupacional y Medio Ambiente de la universidad, utilizando una Matriz de categorización de impactos ambientales, la cual permite diferenciar impactos significativos y no significativos. Los impactos significativos son de utilidad para siguientes pasos, dado que se proponen estrategias para gestionarlos.

4. Revisión de documentación existente en materia de: 1) Contexto de la organización; 2) Liderazgo; 3) Planificación; 4) Control y Seguimiento; 5) Soporte Institucional; 6) Evaluación de desempeño. Como parte del Diagnóstico Ambiental USIL, se analiza cada uno de los componentes numerados. Los pasos 1 ; 2 ; 3 y 4, tienen como producto el Diagnóstico Ambiental USIL. Asimismo, esta información recopilada, sumada al diagnóstico de aspectos e impactos ambientales priorizados, permite el diseño de la propuesta de Sistema de Gestión Ambiental para la universidad.

B. Diseño de propuesta de Guía de Gestión Ambiental.

5. Diseño de instrumentos e instructivos para contribuir en la mitigación de impactos ambientales significativos. Asimismo, se analiza el contexto de la organización, se determinan funciones para todos los actores de la universidad, se proponen mecanismos de control, se diseñan lineamientos para la gestión ambiental universitaria, se establecen medidas de prevención y se crean indicadores de avance hacia el cumplimiento de compromisos ambientales establecidos en la Política Integrada. Este paso tiene por objetivo mejorar la gestión ambiental en la universidad, así como contribuir al cumplimiento de los objetivos establecidos en la Política. Con este paso finaliza el diseño de la propuesta de Sistema de Gestión Ambiental para la universidad.

6. Educación ambiental. Se proponen estrategias para capacitar y sensibilizar a la comunidad universitaria. 
7. Se procede a unir los 02 instrumentos de gestión ambiental diseñados (propuesta de sistema de gestión ambiental y educación ambiental) y se integran en la propuesta de Guía de Gestión Ambiental de USIL.

C. Medición del grado de acuerdo de autoridades y expertos.

8. Elaboración de encuesta usando la escala de medición Likert, tomando en consideración las siguientes categorías de análisis:

- Guía de Gestión Ambiental: Beneficios e implementación.

- Gestión Ambiental actual USIL.

- Participación de partes interesadas.

- Propuesta de Sistema de Gestión Ambiental.

- Educación Ambiental.

9. Selección de autoridades y expertos en materia ambiental de la universidad que serán encuestados. Esta selección se realizará en base a los criterios siguientes:

- Relación con la temática ambiental USIL.

- Toma de decisiones en materia ambiental.

- Acceso a la información ambiental USIL.

- Disponibilidad y predisposición.

10. Aplicación de encuestas y evaluación de resultados obtenidos con la finalidad de conocer el grado de acuerdo de las autoridades y expertos en materia ambiental de la Universidad San Ignacio de Loyola en relación al diseño e implementación de la propuesta de Guía de Gestión Ambiental, instrumento contribuirá al cumplimiento de los compromisos ambientales establecidos en la Política Integrada de la universidad.

\subsection{Categorías de análisis.}

El presente caso de estudio presenta las categorías de análisis siguientes:

\section{Guía de Gestión Ambiental: Beneficios e implementación.}

Análisis de beneficios de la implementación de la Guía de Gestión Ambiental (instrumento de gestión ambiental) en la universidad.

\section{Gestión Ambiental actual USIL.}

Análisis de la gestión ambiental actual en la universidad. 


\section{Participación de partes interesadas.}

Análisis de la participación actual del alumnado y tomadores de decisión en el accionar ambiental de la universidad.

\section{Propuesta de Sistema de Gestión Ambiental.}

Análisis de la implementación de la propuesta de sistema de gestión ambiental para la universidad.

\section{Educación Ambiental.}

Análisis de la implementación de las propuestas del capítulo de "Educación Ambiental" de la Guía de Gestión Ambiental.

En el Anexo $\mathbf{N}^{\circ} \mathbf{0 7}$, se presenta las categorías de análisis distribuidas en la encuesta.

\subsection{Muestra.}

La presenta investigación, al ser cualitativa descriptiva, no posee una muestra establecida. Asimismo, estudia un fenómeno particular y no busca la generalización de sus resultados a una población determinada.

\subsection{Instrumentos de Investigación.}

Norma Internacional de Gestión Ambiental ISO 14 001:2015 - Instrumento 1.

La presente investigación utiliza la normativa internacional ISO 14 001:2015, dado que es una normativa netamente de gestión ambiental; es decir, va ligada al enfoque empresarial - corporativo. Esta norma brinda los lineamientos y principios para el diseño de la propuesta de Guía de Gestión Ambiental USIL; la cual contribuirá al cumplimiento de los compromisos ambientales establecidos en la Política Integrada de la universidad.

Matriz de priorización de aspectos e impactos ambientales - Instrumento 2.

Para la elaboración del diagnóstico ambiental se ha formulado y creado (autoría propia) la Matriz de Identificación de Aspectos e Impactos Ambientales, la cual ha sido validada por un especialista en sistemas integrados de gestión. (Anexo $\mathbf{N}^{\circ} \mathbf{0 8}$ : Carta de Validación de Matriz de Identificación de Aspectos e Impactos Ambientales). La matriz representa una herramienta de sistematización de información en base al diagnóstico ambiental a realizarse. 


\section{Tabla 04}

Matriz de Identificación de Aspectos e Impactos Ambientales

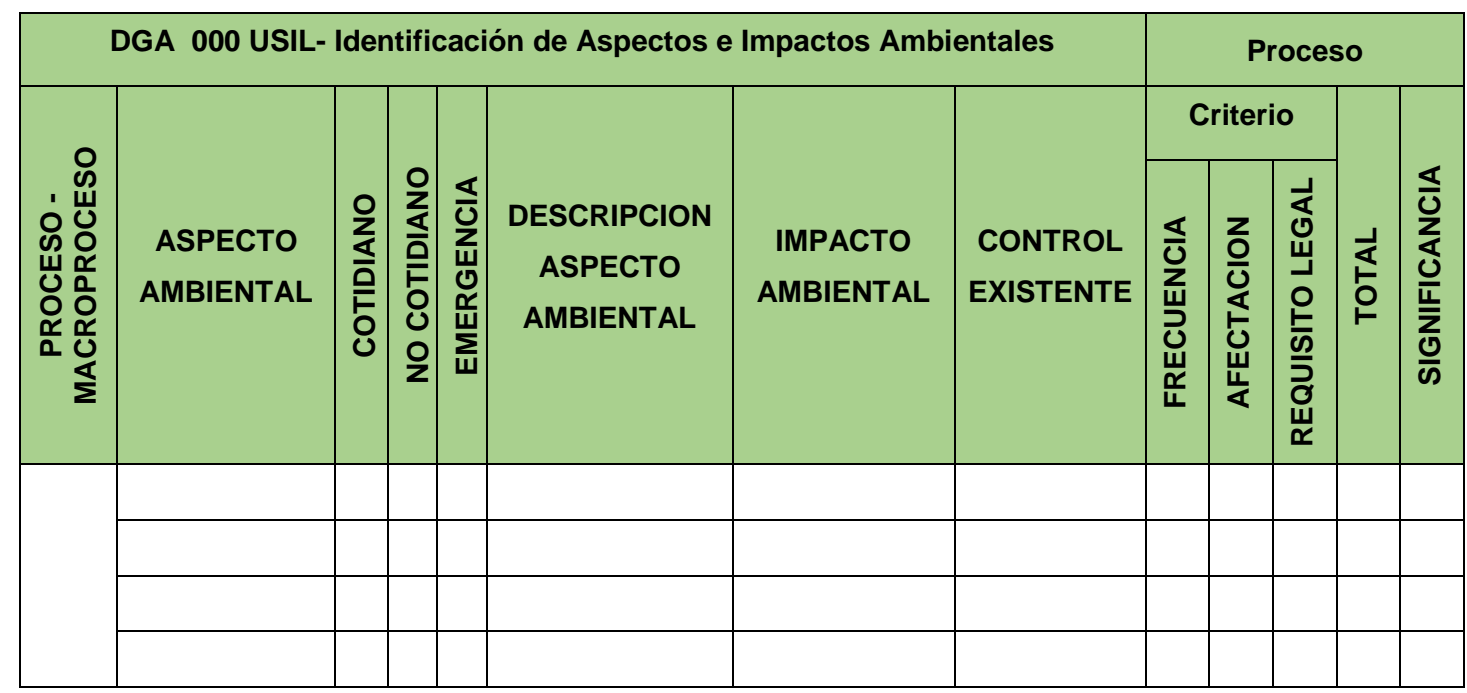

Fuente: Elaboración propia.

El procedimiento para el uso de la matriz es explicado en el acápite: Metodología del Diagnóstico Ambiental. Asimismo, se detalla cada criterio de evaluación.

\section{Encuesta usando escala Likert - Instrumento 3.}

La escala de Likert es una escala de medición utilizada por investigadores con la finalidad de evaluar y conocer opiniones y actitudes de un individuo. Asimismo, sirve para efectuar mediciones y conocer el grado de conformidad del individuo hacia algo determinado. Este método afirma que la fuerza e intensidad de la opinión o experiencia es lineal; motivo por el cual tiene como límites el "Totalmente desacuerdo" y el "Totalmente de acuerdo". Estos niveles pueden variar en sus escalas. Para efectos de la presente investigación, se utilizarán 5 escalas, siendo una de ellas el valor neutro. Se ha optado por la aplicación de esta técnica dado que:

- Representa una escala sencilla de aplicar y diseñar.

- Es uno de los métodos más usados por investigadores para conocer la opinión sobre un determinado tópico.

- Ofrece niveles para graduar la opinión de los encuestados.

- Es una técnica amigable de contestar para los encuestados. 


\subsection{Procedimiento de Recolección de datos.}

La recolección de datos para esta investigación representa un hito importante; debido a la realización, como primera etapa, de un diagnóstico ambiental en las instalaciones de la Universidad San Ignacio de Loyola; como segunda etapa, el diseño de una propuesta de Sistema de Gestión Ambiental; y como tercera etapa, un diagnóstico de Educación Ambiental en la universidad. Los procedimientos para la realización del diagnóstico, Sistema de Gestión Ambiental y Educación Ambiental (recolección de datos) se llevarán a cabo de acuerdo con la siguiente metodología:

1. Solicitud de información: El diagnóstico ambiental y los capítulos propuesta de Sistema de Gestión Ambiental; y Educación Ambiental, requieren información institucional validada. Por este motivo se procede a solicitar dicha información a las áreas y responsables competentes. Esta solicitud se da personalmente o vía correo electrónico.

2. Análisis de los datos: En este paso se analiza la información proporcionada por la universidad, en relación a los tres rubros nombrados. Se evalúa su conveniencia o se descarta según sea el caso.

3. Sistematización de datos: Habiéndose analizado los datos obtenidos para los tres productos (Diagnóstico ambiental; Sistema de Gestión Ambiental y Educación Ambiental) se procede a sistematizar la información e integrarla en la propuesta de Guía de Gestión Ambiental para la universidad.

4. Encuesta usando escala Likert: Se presenta una encuesta (escala Likert) a cada una de las autoridades o expertos en materia ambiental que trabajen en la universidad, con la finalidad de conocer el grado de acuerdo en relación al diseño e implementación de la Guía de Gestión Ambiental, instrumento que contribuirá al cumplimiento de los compromisos ambientales establecidos en la Política Integrada de la universidad. Las autoridades y expertos USIL serán seleccionados mediante el uso de criterios.

5. Sistematización de cuestionarios: Se analizan los datos recolectados en las encuestas y se presentan los resultados de las mismas. 


\section{DIAGNÓSTICO AMBIENTAL USIL.}

En el marco de la presente investigación, se elaboró un diagnóstico ambiental, donde se identifican aspectos e impactos ambientales que generan las acciones, decisiones u omisiones de la universidad; en sus campus universitarios Campus Fernando Belaunde Terry y Almirante Grau.

En este sentido, se elaboró una matriz de identificación de aspectos e impactos ambientales (validada por un especialista) para los Campus mencionados, con la finalidad de priorizar impactos ambientales en base a criterios de afectación, frecuencia y requisitos legales. La priorización mencionada se efectuó en estrecha coordinación con la Unidad de Seguridad, Salud, Medio Ambiente y Responsabilidad Social USIL.

El Diagnóstico Ambiental realizado permitió formular estrategias para la mitigación de impactos significantes diagnosticados; así como, identificar oportunidades y potenciar las buenas prácticas que viene implementado la universidad. En adición, el presente diagnóstico ambiental permite conocer la actual Política Integrada de Seguridad, Medio Ambiente, Salud Ocupacional y Responsabilidad Social; el mapa de procesos institucional; así como los recursos actuales que presenta la Unidad de Medio Ambiente para implementar una correcta gestión ambiental.

Asimismo, el mencionado diagnóstico incluye el análisis del contexto organizacional de la universidad (social, económico y ambiental); análisis del liderazgo en materia ambiental de la universidad; análisis de la planificación actual de la universidad en materia ambiental; análisis del control y seguimiento de aspectos ambientales diagnosticados significativos; análisis del soporte institucional que posee el componente ambiental en la universidad; $y$, análisis de la evaluación del desempeño actual ambiental de la universidad.

Finalmente, la importancia de la coordinación entre el tesista y la Unidad de Medio Ambiente, recae en que la presente investigación busca contribuir al cumplimiento de los compromisos ambientales establecidos en la Política Integrada de la universidad. 
7.1 Política de Seguridad, Salud, Medio Ambiente y RRSS USIL.

La Universidad San Ignacio de Loyola, mediante la Vicepresidencia de Responsabilidad Social, durante el año 2015, propuso la Política de Seguridad, Salud, Medio Ambiente y Responsabilidad Social, Política Integrada. A continuación, se presenta la Política mencionada:

\section{Política de Seguridad, Salud, Medio Ambiente y Responsabilidad Social}

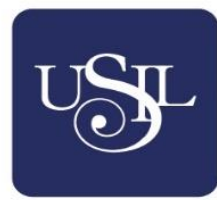

La Universidad San Ignacio de Loyola, cuyo objetivo es la formación de profesionales competentes y emprendedores, con Responsabilidad Social y con plena capacidad para desenvolverse nacional e internacionalmente; tiene como principio fundamental la Seguridad, Salud Ocupacional y preservación del Medio Ambiente en todas sus actividades para ello se compromete a cumplir con las siguientes políticas:

- Proteger la seguridad y salud de todos los miembros de la Organización mediante la identificación, revisión e implementación de objetivos, metas, programas y planes orientados a la prevención de lesiones, dolencias, accidentes e incidentes de trabajo, y enfermedades ocupacionales.

- Identificar los aspectos ambientales significativos de nuestras operaciones y gestionarlos eficientemente para proteger el medio ambiente.

- Identificar y garantizar el cumplimiento de los requisitos y obligaciones legales en materia de Seguridad, Salud Ocupacional y Medio Ambiente, así como los asumidos voluntariamente por la Organización.

- Diseñar y desarrollar planes de capacitación, entrenamiento y sensibilización para todos los colaboradores en materia de Seguridad, Salud Ocupacional y Medio Ambiente.

Exigir que los proveedores, contratistas, trabajadores directos, trabajadores autónomos y personas bajo modalidad formativa laboral cumplan con las normas aplicables de seguridad y salud ocupacional y medio ambiente.

- Revisar y analizar periódicamente los resultados del Sistema de Gestión en Seguridad, Salud y Medio Ambiente, propiciando así la mejora continua del sistema para lograr la excelencia mundial.

Garantizar la participación de los trabajadores y sus representantes en todos los elementos del Sistema de Gestión de la Seguridad, Salud y Medio Ambiente de la Organización.

- Garantizar la compatibilidad o la integración del Sistema de Gestión de la Seguridad, Salud y Medio Ambiente con los otros sistemas de gestión de la Organización.

- Implementar y desarrollar planes de Salud Ocupacional dentro de la Organización.

10 de agosto, 2015
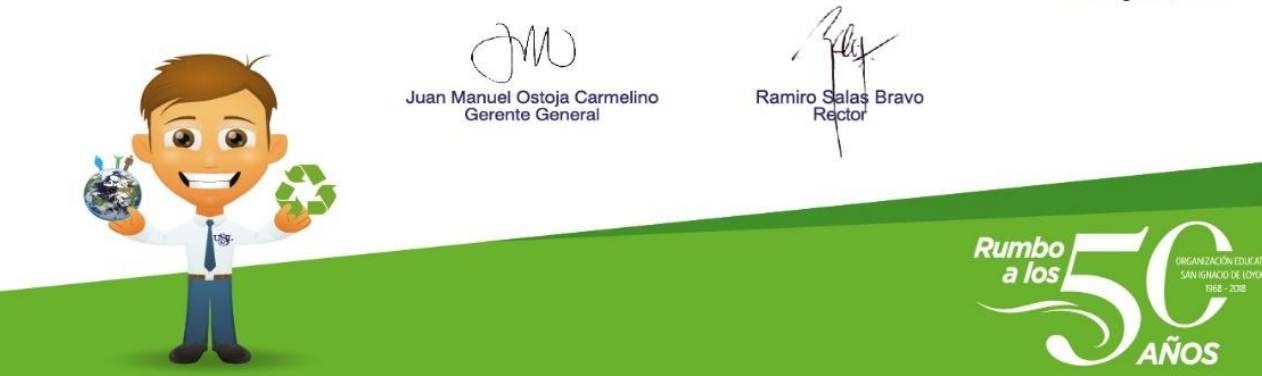

Figura 14: Política de Seguridad, Salud, Medio Ambiente y Responsabilidad Social USIL, 2015. 


\subsection{Análisis del Contexto Organizacional USIL.}

La Universidad San Ignacio de Loyola cuenta con un posicionamiento de mercado estable, conseguido a través de los años, en el ámbito educativo del país; el mismo que puede verse afectado positiva o negativamente por factores internos y externos que repercuten en el accionar de la universidad. En este sentido, con el fin de analizar el contexto organizacional de la universidad, se elabora la presente "Matriz de Fortalezas, Oportunidades, Debilidades y Amenazas (FODA)".

\section{Tabla 05}

Matriz de Fortalezas, Oportunidades, Debilidades y Amenazas (FODA).

\begin{tabular}{|c|c|}
\hline Factores críticos positivos (Fortaleza) & Aspectos positivos (Oportunidad) \\
\hline $\begin{array}{l}\text { - F1: Graduados con enfoque de } \\
\text { responsabilidad social y emprendimiento. } \\
\text { - F2: Calidad de infraestructura. } \\
\text { - F3: Procesos técnicos y administrativos de } \\
\text { calidad. } \\
\text { - F4: Convenios internacionales con } \\
\text { universidades reconocidas. } \\
\text { - F5: Centro de Investigación USIL. } \\
\text { - F6: Responsabilidad Social como pilar } \\
\text { organizacional. } \\
\text { - F7: Plana docente de calidad. } \\
\text { - F8: Diversidad en oferta de carreras } \\
\text { profesionales y programas de posgrado. } \\
\text { - F9: Diversidad de culturas, experiencias y } \\
\text { realidades del alumnado universitario. } \\
\text { - F10: Oferta de carreras con enfoque } \\
\text { empresarial o de gestión. } \\
\text { - F11: Certificación de edificio sostenible. } \\
\text { - F12: Adecuada gestión de residuos sólidos. } \\
\text { - F13: Institución con prestigio a nivel } \\
\text { nacional e internacional. } \\
\text { - F14: Doble grado académico. } \\
\text { - F15: Clases en inglés y virtuales. }\end{array}$ & $\begin{array}{l}\text { - O1: Demanda nacional de capacitación, } \\
\text { investigación y extensión social. } \\
\text { - O2: Posicionamiento y prestigio de la } \\
\text { universidad a nivel nacional e internacional. } \\
\text { - O3: Nuevas metodologías de educación. } \\
\text { - O4: Demanda laboral en nichos específicos. } \\
\text { - O5: Acceso a créditos bancarios. } \\
\text { - O6: Incremento de la sensibilización } \\
\text { ambiental por parte de la sociedad. } \\
\text { - O7: Tecnología para eficiencia de procesos. } \\
\text { - O8: Tendencia a campus sostenibles. } \\
\text { - 09: Incentivos para la investigación. }\end{array}$ \\
\hline Factores críticos (Debilidades) & Aspectos negativos (Amenazas) \\
\hline $\begin{array}{l}\text { - D1: Capacidad de infraestructura limitada } \\
\text { respecto a la cantidad de alumnos } \\
\text { ingresantes. } \\
\text { - D2: Juventud de la universidad frente a } \\
\text { competidores. } \\
\text { - D3: Falta de diagnóstico de impactos } \\
\text { ambientales. } \\
\text { - D4: Inexistencia de espacios para la toma de } \\
\text { decisiones en materia ambiental. } \\
\text { - D5: Débil integración de la comunidad } \\
\text { universitaria en las actividades ambientales. } \\
\text { - D6: Ausencia de instrumentos de gestión } \\
\text { ambiental que contribuyan al cumplimiento } \\
\text { de objetivos organizacionales. } \\
\text { - D7: Débil capacitación en materia ambiental } \\
\text { a la comunidad universitaria. }\end{array}$ & $\begin{array}{l}\text { - A1: Nueva regulación en materia educativa. } \\
\text { - A2: Universidades de poca calidad ofrecen } \\
\text { programas "engañosos" al mercado. } \\
\text { - A3: Crecimiento de infraestructura a nivel } \\
\text { institucional de universidades competidoras. } \\
\text { - A4: Creciente oferta de educación a } \\
\text { distancia y semipresencial. } \\
\text { - A5: Mayor fiscalización y regulación } \\
\text { ambiental. } \\
\text { - A6: Falta de oportunidades laborales e } \\
\text { investigación. } \\
\text { - A7: Oferta de servicios educativos a bajo } \\
\text { costo por parte de la competencia. } \\
\text { - A8: Masificación de profesionales. } \\
\text { - A9: Estrategia "Multisedes" de } \\
\text { competencia en el sector. }\end{array}$ \\
\hline
\end{tabular}

Fuente: Elaboración propia. 
En base al análisis organizacional de la universidad, se establecen las presentes estrategias:

- Estrategia 01: Impartir educación a distancia aprovechando el uso de tecnologías (F15; O3; A7; A4).

- Estrategia 02: Crear una asignatura de educación ambiental y responsabilidad, la cual sea obligatoria y transversal a todas las carreras universitarias (F1; F6; F8; O6; A1).

- Estrategia 03: Apertura de nuevas carreras que demande el mercado laboral actual y futuro (F10; F8; O2; O4).

- Estrategia 04: Promover e incentivar la investigación en la comunidad universitaria (F7; F5; O9; O1; D3).

- Estrategia 05: Ampliar la infraestructura universitaria bajo el enfoque de construcciones sostenibles (F2; F6; F11; O5; O8; D1; A3; A9).

- Estrategia 06: Sensibilizar y capacitar a la comunidad universitaria en materia ambiental (F8; D7; A5; O3; D5).

- Estrategia 07: Fortalecer los convenios institucionales con universidades extranjeras de prestigio (F4; O2; A8).

- Estrategia 08: Integrar al "ambiente" dentro de los grupos de interés de la universidad (F6; F8; O6; O8; A5; D3; D4).

- Estrategia 09: Uso de nuevas tecnologías para la mejora de procesos en campus universitarios (F6; F11; O8; O7).

- Estrategia 10: Fortalecimiento de convenios institucionales con entidades bancarias que brinden financiamiento a alumnos (O5; A7; F9).

- Estrategia 11: Apertura de nuevas sedes a nivel nacional e internacional (F13; O2; O5; A9; A3; D1).

- Estrategia 12: Fortalecer y difundir las carreras ligadas a la temática ambiental que la universidad ofrece (F8; F10; O2; O4; O6).

- Estrategia 13: Identificación y gestión de impactos ambientales en procesos y actividades universitarias (F3; F12; D3; D6; A5). 
- Estrategia 14: Creación de espacios integrales y participativos para la planificación ambiental en la universidad (D6; D5; D4; A5).

- Estrategia 15: Creación e implementación de instrumentos de gestión ambiental que contribuyan al cumplimiento de los objetivos organizacionales y a la mejora del desempeño ambiental de la universidad (D6; A5).

Finalmente, dado el objetivo de la presente investigación, se priorizan las estrategias ambientales identificadas:

- Estrategia Ambiental 01: Crear una asignatura de educación ambiental y responsabilidad, la cual sea obligatoria y transversal a todas las carreras universitarias (F1; F6; F8; O6; A1).

- Estrategia Ambiental 02: Ampliar la infraestructura universitaria bajo el enfoque de construcciones sostenibles (F2; F6; F11; O5; O8; D1; A3; A9).

- Estrategia Ambiental 03: Fortalecer y difundir las carreras ligadas a la temática ambiental que la universidad ofrece (F8; F10; O2; O4; O6).

- Estrategia Ambiental 04: Uso de nuevas tecnologías para la mejora de procesos en campus universitarios (F6; F11; 08; O7).

- Estrategia Ambiental 05: Identificación y gestión de impactos ambientales en procesos y actividades universitarias (F3; F12; D3; D6; A5).

- Estrategia Ambiental 06: Creación de espacios integrales y participativos para la planificación ambiental en la universidad (D6; D5; D4; A5).

- Estrategia Ambiental 07: Sensibilizar y capacitar a la comunidad universitaria en materia ambiental (F8; D7; A5; O3; D5).

- Estrategia Ambiental 08: Creación e implementación de instrumentos de gestión ambiental que contribuyan al cumplimiento de objetivos organizacionales y a la mejora del desempeño ambiental de la universidad (D6; A5).

- Estrategia Ambiental 09: Integrar al "ambiente" dentro de los grupos de interés de la universidad (F6; F8; O6; O8; A5; D3; D4). 


\subsection{Análisis del Liderazgo en USIL.}

En materia ambiental, la universidad cuenta con un Comité de Sostenibilidad (Anexo N 09: Acta de creación, conformación y funcionamiento del Comité de Sostenibilidad USIL), el mismo que no se encuentra activo. La Unidad Ambiental, Social, Seguridad y de Salud Ocupacional de la universidad, es la que lidera el desempeño ambiental de la corporación, es decir, también tiene a su cargo el desempeño ambiental de la universidad.

La precitada Unidad tiene por objetivo la implementación del Sistema de Gestión en Medio Ambiente, Responsabilidad Social y de Seguridad y Salud Ocupacional en la universidad con la finalidad de identificar riesgos, prevenir accidentes y enfermedades laborales, garantizar la conservación del medio ambiente y mantener un adecuado relacionamiento con nuestros grupos de interés (Unidad Ambiental,

\section{Social, Seguridad y Salud Ocupacional USIL, 2016).}

En el marco del presente diagnóstico se identificaron dos grupos estudiantiles, provenientes de las carreras de Gestión Ambiental e Ingeniería Ambiental, que vienen realizando actividades en materia ambiental en la universidad. Sin embargo, estos grupos estudiantiles no intervienen ni son representados en la toma de decisiones ambiental de la universidad. Es decir, la universidad y el alumnado de la misma, necesitan un mecanismo de coordinación en aras de contribuir a la gestión ambiental universitaria.

Este último comentario hace referencia a que el principal stakeholder de la universidad, es el alumnado, y es este quien debería intervenir con opinión; dado que la universidad cuenta con dos carreras especializadas en la temática, en la planificación ambiental de la universidad.

Finalmente, se ha reconocido voluntad y trabajo en materia ambiental en la universidad, con una oportunidad de mejorar en la coordinación entre autoridades y comunidad universitaria, con la finalidad de unir esfuerzo, empoderar a la comunidad universitaria y cumplir con los compromisos ambientales establecidos en la Política Integrada de la universidad. 


\subsection{Análisis de la Planificación Ambiental USIL.}

La universidad, a través de la Unidad Ambiental, Social, Seguridad y Salud Ocupacional, viene desarrollando diversas acciones en materia ambiental en la universidad; entre las cuales destaca el monitoreo de la gestión de la calidad de aire, ruido, agua y aguas residuales; campañas para la gestión de residuos; utilización de energías limpias; capacitaciones dirigidas a colaboradores, docentes y contratistas; así como la realización de eventos, charlas y talleres de sensibilización e intercambio de información en materia ambiental; entre otras.

Asimismo, en el marco del diagnóstico se identificó que la planificación ambiental se construye a partir de la opinión de autoridades universitarias; cuando la planificación ambiental en una institución educativa formadora como es la universidad, debería integrar al estudiante como agente decisor desde la etapa de planificación.

La universidad, según el Reporte de Sostenibilidad 2015, en el Capítulo Cultura USIL, en el acápite Sostenibilidad, no considera el medio ambiente como grupo de interés. Esta postura dificulta la planificación en materia ambiental en la universidad, así como el desempeño ambiental de la misma. Existen autores como Mark Starik, Nardia Haigh y Andrew Griffiths que consideran al medio ambiente como stakeholder dado que afecta y es afectado por las actividades de una organización, esto en referencia a la "Teoría de los Grupos de Interés" (1984) de Edward Freeman.

Los autores precitados basan su teoría en lo siguiente: (i) El entorno natural es una parte vital del entorno empresarial; (ii) el concepto de stakeholder es más amplio que las consideraciones humanas/políticas/económicas; (iii) el entorno natural se puede incorporar fácilmente en los procesos de gestión de los interesados; y, (iv) la inclusión del medio ambiente aporta un enfoque holístico, orientado a valores, enfocado y estratégico para la gestión de las partes interesadas (Starik, 1995).

\subsection{Análisis del Control y Seguimiento de aspectos ambientales significativos.}

La universidad, como se mencionó en el numeral precitado, realiza monitoreo de calidad de agua, agua residual, aire y ruido. Asimismo, implementa las metodologías y cumple con lo estipulado en la normatividad vigente.

En el marco del presente diagnóstico, se consultó con la Unidad Ambiental, Social, Seguridad y Salud Ocupacional, sobre la realización de un diagnóstico ambiental que permita conocer los aspectos e impactos ambientales que son originados por la acción, decisión u omisión por parte de la universidad. El mencionado diagnóstico 
estaría planificado, mas no ha sido ejecutado a la fecha. En este sentido, la comunidad universitaria, en su mayoría, desconoce los aspectos e impactos ambientales en los que incurren sus acciones. Este desconocimiento se traduce en falta de sensibilización y cuidado hacia el medio ambiente; lo que repercute en el desempeño ambiental de la universidad.

\subsection{Análisis del Soporte Institucional USIL.}

Actualmente la universidad, a través de su Vicepresidencia de Responsabilidad Social, posee una "Unidad Ambiental, Social, Seguridad y Salud Ocupacional". Esta unidad es el ente ejecutor responsable de implementar el Sistema de Gestión en Medio Ambiente, Responsabilidad Social, Seguridad y Salud Ocupacional de la universidad (Anexo $\mathbf{N}^{\circ}$ 10: Estructura de la Unidad de Ambiente, Social, Seguridad y Salud ocupacional USIL).

Asimismo, permite el cumplimiento de la normativa vigente y de aquellos requerimientos de instituciones relacionadas con USIL referente a aspectos medioambientales, de responsabilidad social, seguridad y salud ocupacional (Unidad

\section{Ambiental, Social, Seguridad y Salud Ocupacional USIL, 2016).}

Por otro lado, presenta los objetivos específicos siguientes:

- Proteger la seguridad y salud de todos los miembros de la USIL mediante la identificación, revisión e implementación de objetivos, metas, programas y planes orientados a la prevención de lesiones, dolencias, accidentes e incidentes de trabajo, y enfermedades ocupacionales.

- Identificar los aspectos ambientales significativos de nuestras operaciones y gestionarlos eficientemente para proteger el medio ambiente y evitar impactos en sus grupos de interés.

- Identificar y garantizar el cumplimiento de los requisitos y obligaciones legales en materia de Medio Ambiente, Responsabilidad Social y de Seguridad y Salud Ocupacional; así como los asumidos voluntariamente por USIL.

- Diseñar y desarrollar planes de capacitación; entrenamiento y sensibilización para todos los miembros en materia de Medio Ambiente y de Seguridad y Salud Ocupacional.

- Exigir que los miembros cumplan con las normas aplicables en materia de Medio Ambiente, Responsabilidad Social y de Seguridad y Salud ocupacional. 
- Revisar y analizar periódicamente los resultados del Sistema de Gestión en Medio Ambiente. Responsabilidad Social y de Seguridad y Salud Ocupacional. propiciando así la mejora continua del sistema para lograr la excelencia mundial.

- Garantizar la participación de los trabajadores, sus representantes y sus grupos de interés en todos los elementos del Sistema de Gestión en Medio Ambiente; Responsabilidad Social y de Seguridad y Salud Ocupacional.

- Garantizar la compatibilidad o la integración del Sistema de Gestión en Medio Ambiente, Responsabilidad Social y de Seguridad y Salud Ocupacional con los otros sistemas de gestión de la Organización.

- Implementar y desarrollar planes de Salud Ocupacional dentro de USIL.

- Medidas de prevención, control y/o mitigación de impactos ambientales y sociales que pudieran generarse durante el desarrollo de las actividades y en la ejecución de proyectos.

- Implementar sistemas de monitoreo de proyectos que permitan mitigar y compensar los riesgos.

- Identificar e implementar las demás medidas, planes e instrumentos que la normativa en Seguridad y Salud en el Trabajo señale.

La Unidad Ambiental, Social, Seguridad y Salud Ocupacional USIL posee el organigrama siguiente:

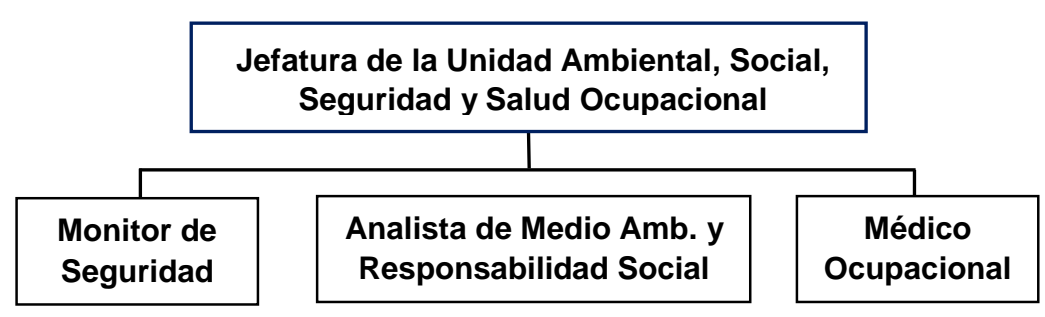

Figura 15: Organigrama Unidad Ambiental USIL. Fuente: USIL.

En una entrevista con la Analista de Medio Ambiente de la Unidad en mención, manifestó que cuentan, al año 2018, con los recursos siguientes:

- Infraestructura: La Unidad cuenta con dos ambientes amoblados con escritorios y sillas ergonómicas. Ambos ambientes son eficientes en cuanto al espacio. El primer ambiente es ocupado por la Jefatura de la Unidad, mientras que el segundo es ocupado por los profesionales restantes. Finalmente, pese a la eficiencia en el 
espacio, ante una situación de sismo, se evidencia la dificultad en el desplazamiento, dado el estrecho espacio del corredor interno.

- Recursos Humanos: Actualmente la Unidad cuenta con tres profesionales y una responsable, haciendo un total de 4 profesionales. Estos profesionales son especialistas en las labores que desempeñan.

- Recursos económicos: La Unidad recibe presupuesto para la ejecución del Programa Anual. No se tiene mayores datos del presupuesto.

- Recursos tecnológicos: La Unidad cuenta con 5 computadoras y celulares corporativos.

- Otros: La unidad cuenta con mobiliario básico para su accionar; escritorios, sillas ergonómicas y útiles de oficina; sin embargo, no cuenta con adecuada ventilación.

A continuación, se presentan fotografías del mes de enero 2018 de la unidad:

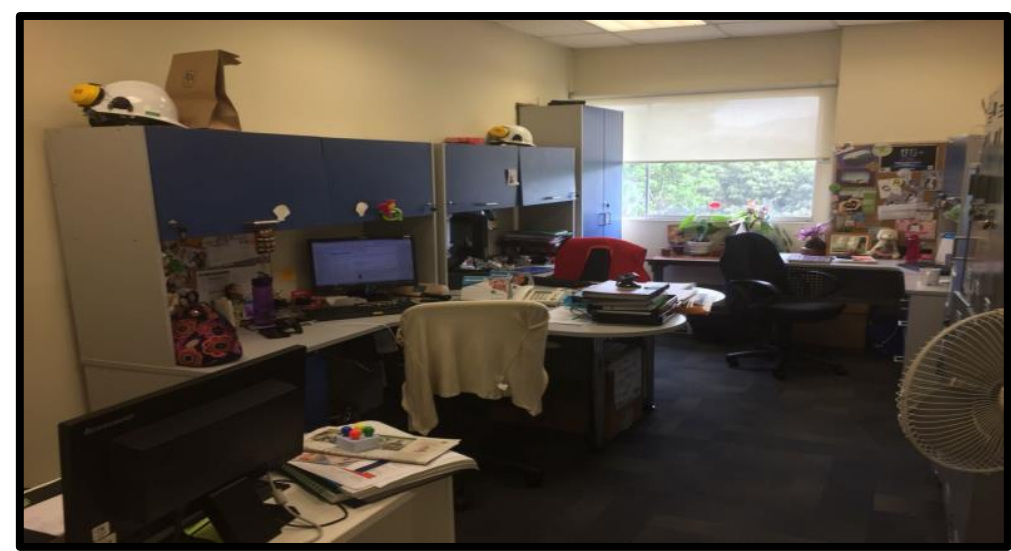

Figura 16: Fotografía de la Unidad de Ambiente, Seguridad, Salud y Responsabilidad Social - USIL.

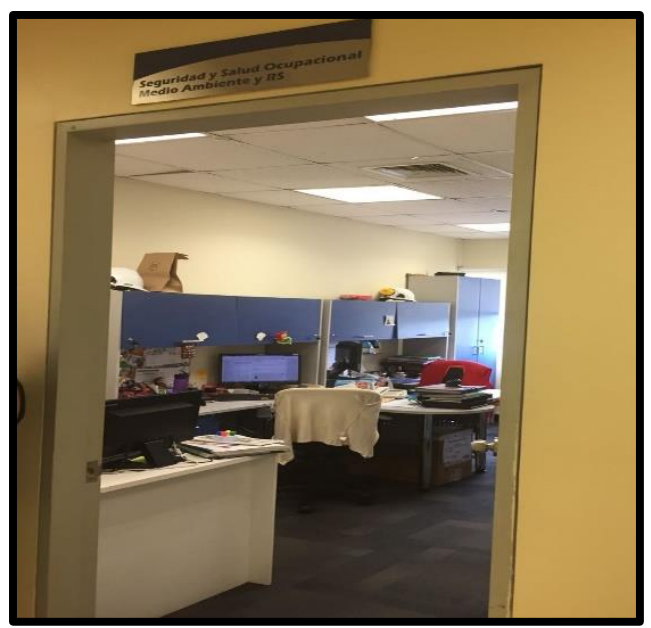

Figura 17: Fotografía de la Unidad de Ambiente, Seguridad, Salud y Responsabilidad Social - USIL. 
Funciones y Responsabilidades de los miembros de la Unidad de Medio Ambiente, Seguridad, Salud ocupación y Responsabilidad Social.

De acuerdo a lo presentado en el organigrama, a continuación, se detallan las funciones de cada uno de los puestos:

1. Jefe de Unidad Ambiental, Seguridad, Salud Ocupacional y Responsabilidad Social USIL.

- Establecer lineamientos del Sistema de Gestión en Medio Ambiente, Responsabilidad Social, Seguridad, y, Salud Ocupacional, los cuales debe estar alineados con el Plan Estratégico USIL.

- Realizar seguimiento a resultados y participar en la revisión periódica del Sistema de Gestión MRS y SSO USIL.

- Convocar y participar en los Comités de Seguridad y Salud Ocupacional de USIL.

- Coordinar permanentemente con el Comité de Sostenibilidad de USIL.

- Coordinar los presupuestos y requerimientos para la ESHS-U de USIL.

- Realizar los reportes de Medio Ambiente, Responsabilidad Social. y de Seguridad y Salud Ocupacional en los períodos requeridos por la autoridad o por otra institución relacionada a USIL.

- Coordinar e implementar Certificaciones en Medio Ambiente, Responsabilidad Social y de Seguridad y Salud Ocupacional de USIL.

- Implementar programas de motivación y premiación por desempeño en Medio Ambiente, Responsabilidad Social. y de Seguridad y Salud Ocupacional por los miembros de USIL.

- Participar en la reunión de seguimiento y resultados de USIL relacionados a Medio Ambiente, Responsabilidad Social y de Seguridad y Salud Ocupacional.

- Coordinar con las autoridades municipales o nacionales temas relacionados con Medio Ambiente, Responsabilidad Social, y de Seguridad y Salud Ocupacional.

- Coordinar con las áreas académicas alianzas internos que permitan mejorar los procesos en Medio Ambiente, Responsabilidad Social, Seguridad y Salud Ocupacional USIL. 
- Coordinar con proveedores y contratistas de construcción u otro servicio temas relacionados con Medio Ambiente, Responsabilidad Social y de Seguridad y Salud Ocupacional de USIL.

- Implementar Planes de capacitaciones en temas de Medio Ambiente, Responsabilidad Social y de Seguridad y Salud Ocupacional para todo USIL, incluyendo los miembros.

- Programar y participar en auditorías internas y externas al SG MRS y SSO USIL.

- Implementar la mejora continua al Sistema de Gestión MRS y SSO a través de las revisiones y análisis de resultados mensuales de la gestión.

- Identificar e implementar las demás medidas, planes e instrumentos que la normativa en Seguridad y Salud en el Trabajo señala.

\section{Analista de Medio Ambiente y Responsabilidad Social.}

- Dar soporte al Jefe de la unidad en temas documentarios

- Actualizar la documentación referente al Sistema de Gestión MRS y SSO.

- Solicitar equipos de protección personal para colaboradores.

- Llevar el registro de capacitaciones de todos los colaboradores USIL

- Llevar el registro de entrega de Equipos de Protección Personal de todos los colaboradores USIL.

- Comunicar y coordinar actividades de la Unidad con las diferentes áreas de USIL.

- Organizar charlas para los miembros USIL.

\section{Monitor de Seguridad.}

- Brindar soporte técnico a los administradores de todas las sedes USIL en temas de Medio Ambiente, Seguridad y Salud Ocupacional.

- Realizar inspecciones a los trabajos que se realizan en todas las sedes USIL.

- Dar soporte a monitoreos de agentes ocupacionales y ambientales de acuerdo al Plan de Monitoreo de USIL.

- Dar soporte técnico en procedimiento de Medio Ambiente, Seguridad y Salud Ocupacional a todo el personal contratista y proveedor que requiera realizar algún tipo de trabajo dentro de la institución. 
- Informar al Jefe de la unidad y a los responsables de áreas sobre las posibles desviaciones que se puedan presentar en la realización de un trabajo tercerizado dentro de la organización.

- Garantizar la realización de las inspecciones a los equipos que se consideraran críticos de todas las instalaciones de USIL.

- Realizar la entrega de Equipos de Protección Personal a todos los colaboradores.

- Realizar inspecciones a las áreas consideradas críticas dentro de la organización.

- Dictar charlas de capacitación en materia de Medio Ambiente, Seguridad y Salud Ocupacional a los miembros y colaboradores.

- Acompañar las inspecciones en Medio Ambiente, Seguridad y Salud Ocupacional.

- Firmar los permisos de trabajos críticos realizados dentro de USIL.

\section{Medico Ocupacional.}

- Realizar un diagnóstico situacional de la gestión en salud ocupacional.

- Brindar soporte en la elaboración de Identificación de Peligros, evaluación de riesgos e implementación de controles (IPERCJ y Mapa de Riesgos Laborales).

- Determinar la metodología y técnica necesaria para las evaluaciones medicaocupacionales en función a la exposición de los colaboradores.

- Supervisar el desarrollo de exámenes médicos ocupaciones (de ingreso, periódicos, de retiro y otras evaluaciones complementarias); así como evaluar y registrar adecuadamente los resultados.

- Determinar la necesidad (tipo y frecuencia) de exámenes médicos ocupacionales.

- Validar la aptitud medica de los colaboradores mediante las evaluaciones medicas ocupacionales en relación a las labores a realizar (apto, apto con restricciones o no apto).

- Implementar un sistema de historias clínicas a fin de registrar adecuadamente la información del desempeño de la salud de los colaborares y su historia ocupacional (labores realizadas, riesgos a los que están expuesto, entre otros).

- Crear, mantener y actualizar una base de datos confidenciales con la información de exámenes médicos ocupacionales. 
- Atender, registrar y notificar los accidentes de trabajo.

- Desarrollar un programa anual de salud ocupacional.

- Coordinar y colaborar con las áreas relacionadas a materia de seguridad y salud ocupacional.

- Preparar informes a fin de impulsar la mejora continua en la implementación de medidas de prevención y de reportes a las autoridades competentes según corresponda.

\subsection{Análisis de la Evaluación de Desempeño Ambiental USIL.}

La universidad realiza el seguimiento, medición, análisis y evaluación de su desempeño ambiental. Es en este sentido que, en el marco del Sistema de Gestión Ambiental que la universidad planea diseñar; debe formalizar y establecer, al más alto nivel, un mecanismo de evaluación y seguimiento.

Este mecanismo debe permitir, a la comunidad universitaria, conocer si las metas ambientales propuestas, así como los compromisos ambientales establecidos en la Política Integrada, se vienen cumpliendo.

En el marco del presente diagnóstico, se identificó la ausencia de un instrumento de gestión que permita monitorear, seguir y medir el desempeño ambiental de la organización en un periodo determinado de tiempo; así como, en base al resultado obtenido, contribuya a la construcción de diversas estrategias para mejorar el estado situacional de la gestión ambiental en la universidad. 
7.8 Matriz de Procesos - USIL.

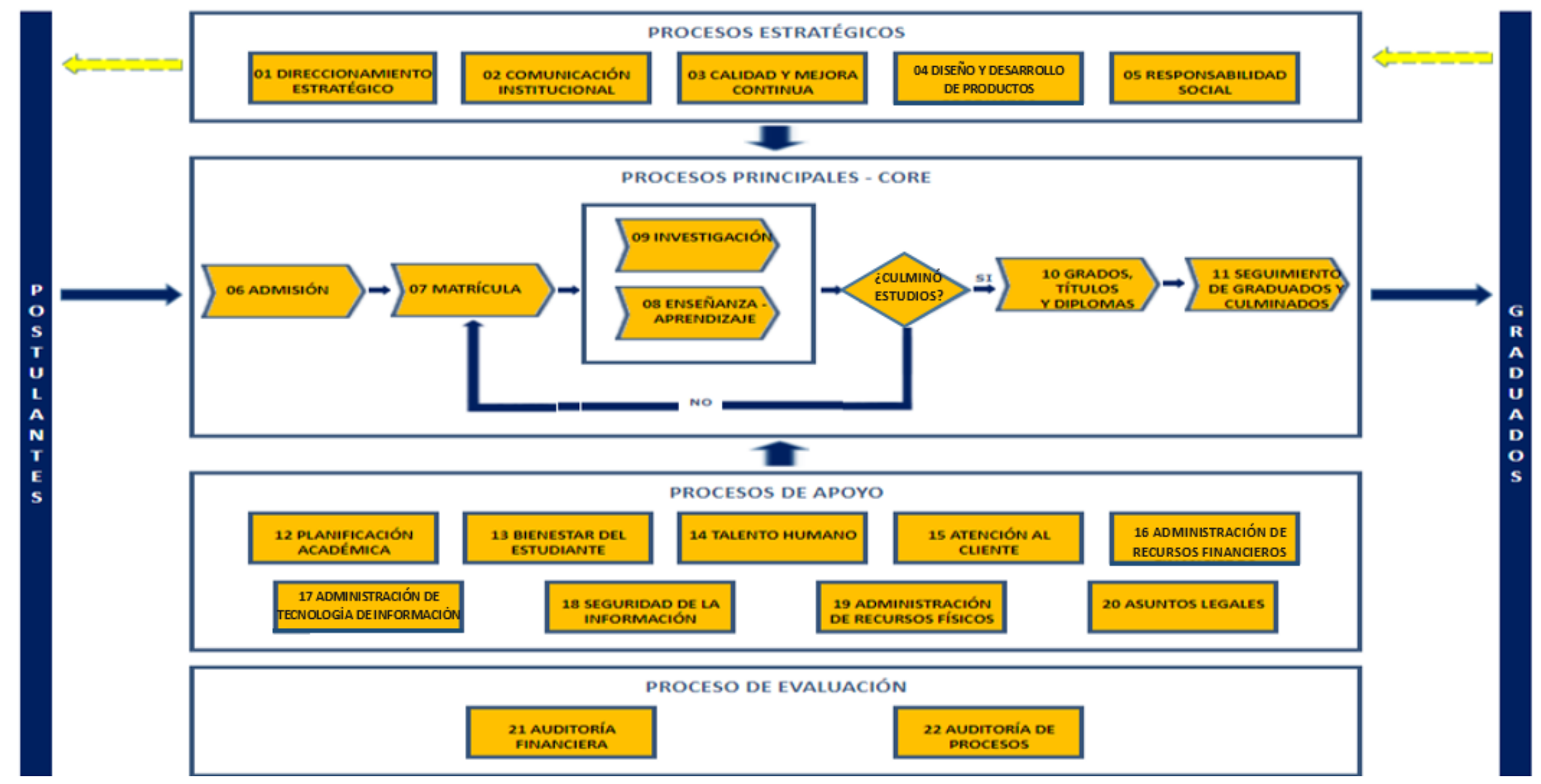

Figura 18: Mapa de procesos USIL. Fuente: USIL. 


\subsection{Diagnóstico de Aspectos e Impactos Ambientales USIL.}

\subsubsection{Metodología del Diagnóstico Ambiental.}

El diagnóstico ambiental representa el punto de partida de la gestión ambiental de la universidad; dado que es partir de este punto que se puede planificar actividades a futuro y establecer metas alcanzables. Es el inicio para alcanzar el concepto de universidad sostenible.

El presente diagnóstico USIL se circunscribe en el ámbito de la Universidad San Ignacio de Loyola, en el periodo 2018. Para la realización del diagnóstico se ha diseñado y formulado la "Matriz de Identificación de Aspectos e Impactos Ambientales". Esta matriz representa una herramienta de sistematización de información en base al diagnóstico ambiental a realizarse. Asimismo, ha sido validada por un especialista en Sistemas Integrados de Gestión.

\section{Tabla 06}

Matriz de Identificación de Aspectos e Impactos Ambientales.

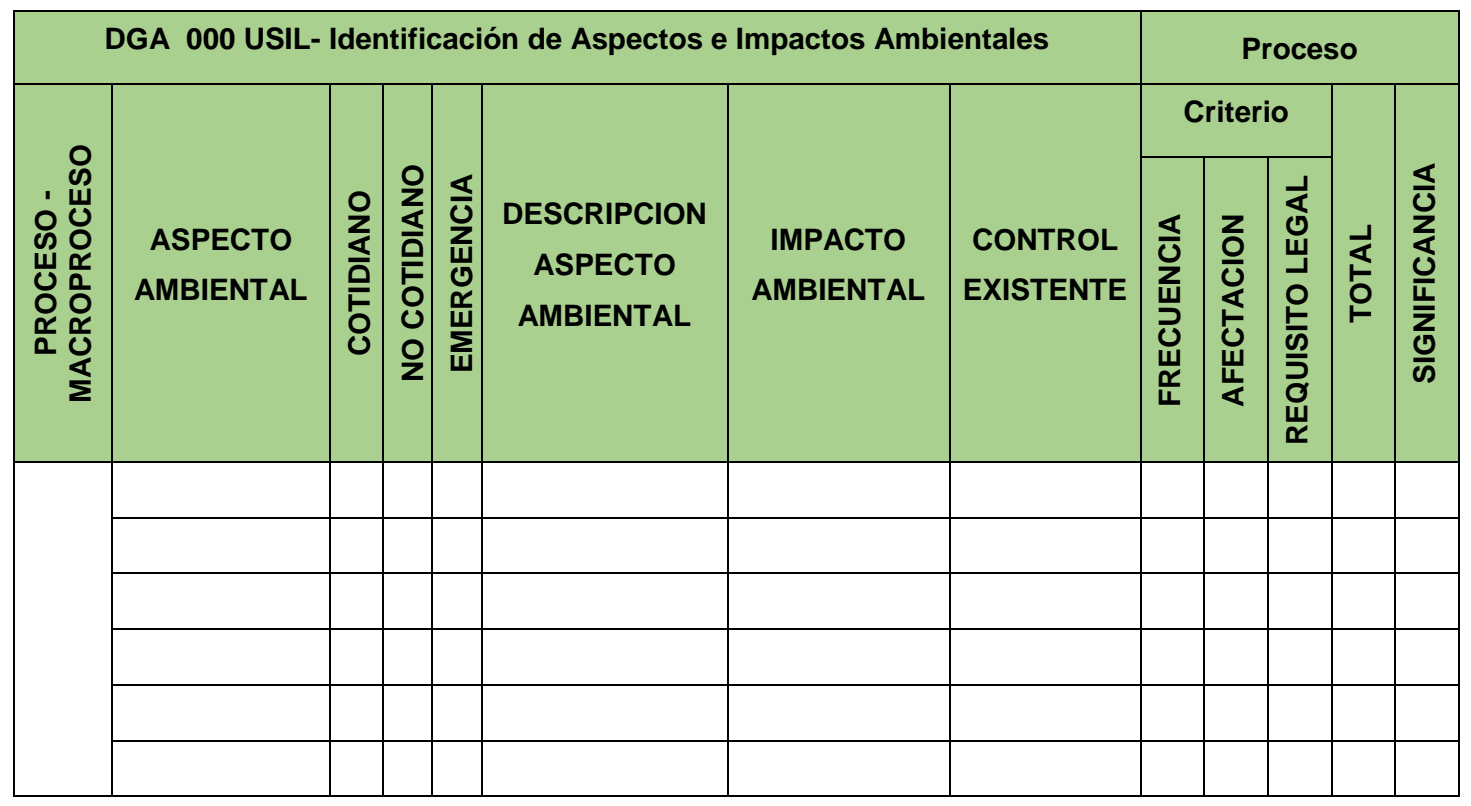

Fuente: Elaboración propia.

La matriz mencionada contiene los siguientes compartimientos basados en criterios:

Proceso o Macro proceso: En este espacio se registra el nombre completo del proceso o macro proceso de la universidad. Esta información se basa en el "Mapa de Procesos USIL". Asimismo, el mencionado proceso es el objeto de estudio.

Aspecto Ambiental: Elemento de actividades, proceso, productos o servicios de una organización que interactúa con el medio ambiente. A su vez, se puede caracterizar 
en aspecto ambiental cotidiano, no cotidiano y de emergencia. El primero de estos es el aspecto ambiental que tiene un impacto cotidiano en el medio ambiente; el segundo, es el aspecto ambiental que tiene un impacto ambiental no cotidiano; y, finalmente, el último es un impacto potencial o de emergencia.

Descripción del aspecto ambiental: En este espacio se detalla el aspecto ambiental a analizar. Asimismo, es un espacio para colocar características o notas relevantes en relación con el aspecto.

Impacto Ambiental: En este espacio se identifica el impacto sobre el medio ambiente generado por el aspecto ambiental.

Control existente: Se corrobora si existe algún mecanismo para controlar o mitigar el impacto sobre el medio ambiente producido por el aspecto ambiental.

Por otro lado, una vez rellenado los espacios mencionados en el párrafo precedente, se procede a evaluar y analizar el proceso desde la óptica ambiental bajo los siguientes criterios:

Frecuencia: Se atribuye el puntaje 1 en caso el impacto sea accidental; el puntaje 3 en caso el impacto sea episódico; y se atribuye el puntaje 5 en caso el impacto sea continuo.

Afectación: Va de acuerdo con la magnitud del impacto, se le atribuye puntaje $1 \mathrm{si}$ la afectación hacia el medio ambiente es débil; 3 puntos si es medio; y 5 puntos si el grado de afectación hacia el medio ambiente es fuerte.

Requisito Legal: Si el aspecto ambiental representa un requisito legal obtiene un puntaje de 3; caso contrario obtiene un puntaje de 0 puntos.

Posterior a la evaluación de los tres criterios, se procede a la suma de estos. Este puntaje es rellenado en el espacio "Total". Finalmente, el análisis de aspectos e impactos ambientales culmina con el reconocimiento de estos en el acápite "Significancia".

Si la suma de los criterios es mayor o igual a 9, el impacto ambiental es considerado significativo; es decir debe ser tratado, mitigado o tener una atención especial. Por otro lado, si el puntaje fuese menor a 9, el impacto ambiental no representa significancia. Sin embargo, la significancia no determina la importancia del impacto ambiental, por el contrario, determina prioridades. 
Se ha determinado al número 9 como el umbral entre significancia y no significancia dado que la postura ambiental en la universidad debe ser conservacionista. El puntaje máximo que podrá obtener un aspecto ambiental es de 13 puntos; es decir que su frecuencia sea continua (5), el grado de afectación es fuerte (5) y afecta a un requisito legal (3). En este sentido, bastaría que el aspecto ambiental tenga elevada frecuencia o afectación, y a su vez sea un requisito legal, para que sea considerado significante. Asimismo, si la afectación y frecuencia es media, y también afecta a un requisito legal, el aspecto se considera significativo.

Esta justificación, así como la consideración del número 9 como umbral de significancia, fue elaborada por el Tesista en estrecha coordinación con la Jefa de la Unidad de Seguridad, Salud, Medio Ambiente y Responsabilidad Social de la Universidad San Ignacio de Loyola (Anexo $\mathbf{N}^{\circ} 11$ : Carta de consentimiento informado - Unidad Seguridad, Salud, Medio Ambiente y Responsabilidad Social USIL). 
7.9.2 Matriz resumen de Aspectos ambientales significativos.

\begin{tabular}{|c|c|c|}
\hline $\begin{array}{l}\text { ASPECTO AMBIENTAL } \\
\text { SIGNIFICATIVO }\end{array}$ & UBICACIÓN DEL ASPECTO AMBIENTAL SIGNIFICATIVO & $\begin{array}{l}\text { IMPACTO AMBIENTAL } \\
\text { SIGNIFICATIVO }\end{array}$ \\
\hline Generación de residuos peligrosos & Presente en todos los macro procesos. & Ecotoxicidad de suelos \\
\hline Consumo de papel & $\begin{array}{l}\text { Presente en todos los macro procesos. Sin embargo, en algunos procesos representa significancia y en otro no, } \\
\text { según la priorización realizada. }\end{array}$ & Deforestación \\
\hline Generación de residuos no peligrosos & Presente en todos los procesos y ambientes de la universidad. & Ecotoxicidad de suelos \\
\hline Transporte - Voluntariado & $\begin{array}{l}\text { Presente cuando la Vicepresidencia de Responsabilidad Social realiza voluntariado con alumnos. Recordar que } \\
\qquad \text { realizar voluntariado es un requisito de Bachiller . }\end{array}$ & Contaminación del aire \\
\hline Generación de efluentes & $\begin{array}{l}\text { Presente en el proceso de enseñanza e investigación, dado que se hace uso del laboratorio. Asimismo, está } \\
\text { presente en el proceso de preparación de alimentos. }\end{array}$ & Ecotoxicidad del agua \\
\hline Consumo de agua & $\begin{array}{l}\text { Presente en el proceso de enseñanza e investigación; así como en el proceso de alimentación a la comunidad } \\
\text { universitaria; } y \text {, limpieza de ambientes y jardinería. }\end{array}$ & Agotamiento del recurso \\
\hline Consumo de energía eléctrica & $\begin{array}{l}\text { Presente en todos los macro procesos. Sin embargo, en algunos procesos representa significancia y en otro no, } \\
\text { según la priorización realizada. }\end{array}$ & Agotamiento del recurso \\
\hline Transporte - Dictado de clases & $\begin{array}{l}\text { Presente en el proceso de enseñanza e investigación dado que los alumnos reciben clases en la sede } \\
\text { Pachacamac. La universidad está a cargo del transporte. }\end{array}$ & Contaminación del aire \\
\hline Transporte - Movilización. & $\begin{array}{l}\text { Presente en el proceso de admisión, dado que la universidad facilita buses para el traslado de posibles nuevos } \\
\text { estudiantes. Además, personal de la universidad se traslada para realizar charlas informativas en diversos lugares. } \\
\text { Asimismo, el impacto está presente en el proceso de administración de recursos físicos (logística). }\end{array}$ & Contaminación del aire \\
\hline $\begin{array}{l}\text { Potencial uso de líquidos } \\
\text { desinfectantes no autorizados y } \\
\text { pesticidas }\end{array}$ & $\begin{array}{l}\text { Presente en el proceso de limpieza de ambientes; así como en el proceso de preparación de alimentos para la } \\
\text { comunidad universitaria. }\end{array}$ & Contaminación del aire y agua \\
\hline
\end{tabular}


El Diagnóstico Ambiental desarrollado en el marco de la presente investigación tuvo como instrumento inicial el Mapa de Procesos de la universidad. En este sentido, fueron 04 tipos de macro procesos (estratégicos; principales; apoyo y evaluación) los identificados.

El diagnóstico analizó a detalle cada uno de los procesos, identificando los aspectos e impactos ambientales que generaban. Asimismo, se identificaron los controles existentes en cada uno de ellos. Por otro lado, se contó con el apoyo y participación técnica de la Unidad de Seguridad, Salud, Medio Ambiente y Responsabilidad Social, a través de la priorización de aspectos e impactos ambientales por cada proceso (Anexo N 11: Carta de consentimiento informado - Unidad Seguridad, Salud, Medio Ambiente y Responsabilidad Social USIL).

Para la identificación de aspectos e impactos ambientales, se construyeron matrices por cada proceso, las mismas que se pueden observar en el Anexo $\mathbf{N}^{\circ} \mathbf{1 2}$ de la presente investigación. En adición, cada macro proceso contiene un matriz resumen, a manera de facilitar la sistematización.

En la tabla 06, tabla precedente, se observa a detalle los impactos ambientales priorizados; los cuales representan los impactos que deberían contar con mayor atención y acción inmediata. Además, cuenta con una descripción donde estipula la ubicación del proceso en donde se genera el impacto ambiental.

La priorización de aspectos e impactos ambientales es el principal insumo de la propuesta de Guía de Gestión Ambiental debido a que es la base de la Propuesta de Sistema de Gestión Ambiental; y del capítulo de Educación Ambiental de la misma.

El diagnóstico ambiental efectuado permite a la universidad conocer los impactos ambientales que genera sus actividades, decisiones $u$ omisiones; y representa el inicio de la implementación de acciones de mitigación de impactos en aras de contribuir a la mejora del desempeño ambiental de la universidad y lograr la sostenibilidad. 


\section{PROPUESTA DE GUÍA DE GESTIÓN AMBIENTAL USIL.}

La Universidad San Ignacio de Loyola (USIL) viene promoviendo los 17 Objetivos de Desarrollo Sostenible (ODS) propuestos por la Organización de las Naciones Unidas (ONU), está adherida al Pacto Global y viene alineando sus acciones a estándares ambientales y sociales internacionales.

Actualmente, la universidad realiza diversas acciones con la finalidad de mejorar su desempeño ambiental. En este sentido, posee una Política Integrada de Seguridad, Medio Ambiente, Salud Ocupacional y Responsabilidad Social; instrumento que busca establecer compromisos institucionales para el bien de la comunidad universitaria y del medio ambiente. La Política mencionada es una gran iniciativa para la mejora del desempeño ambiental en la organización; sin embargo, requiere de un instrumento de gestión ambiental que permita operativizar y establecer lineamientos para su correcto funcionamiento, en aras de contribuir al cumplimiento de los compromisos ambientales establecidos en la Política y lograr objetivos institucionales

La Guía de Gestión Ambiental USIL, es un instrumento de gestión ambiental, diseñado exclusivamente para la universidad, el cual permite tomar decisiones con el objetivo de mejorar el desempeño ambiental de la misma y contribuir al cumplimiento de los compromisos ambientales establecidos en la Política Integrada.

La Guía se basa en un Diagnóstico Ambiental realizado en el marco de la presente investigación, el cual ha permitido conocer la situación actual de la gestión ambiental de la universidad; así como conocer aspectos e impactos ambientales ocasionados por la propia actividad universitaria. Asimismo, para su desarrollo, se contó con el apoyo técnico de la Unidad de Medio Ambiente, Seguridad, Salud y Responsabilidad Social de la universidad, con la finalidad de priorizar los impactos ambientales identificados. Por este motivo, el diagnóstico representa insumo sustancial para la Guía, dado que permite planificar, establecer procedimientos, y proponer estrategias para la mejora del desempeño ambiental de la universidad.

En este sentido, la Guía, en su primer capítulo, presenta una propuesta de Sistema de Gestión Ambiental adecuada para la universidad. Este Sistema presenta un nuevo enfoque, dado que busca la participación y empoderamiento del alumno en la planificación ambiental de la institución. Finalmente, en su capítulo segundo; propone lineamientos para promover la Educación Ambiental en la universidad, como estrategia de formación académica - conceptual; así como, con el objetivo de formar ciudadanos social y ambientalmente responsables. 


\subsection{Propuesta de Sistema de Gestión Ambiental USIL.}

La Universidad San Ignacio de Loyola, a futuro, busca convertirse en una universidad sostenible; motivo por el cual viene adoptando cambios e implementando buenas prácticas que mejoren su desempeño ambiental, así como la relación con sus grupos de interés.

En este contexto, la presente Guía de Gestión Ambiental de la Universidad San Ignacio de Loyola, en base a lo identificado y determinado en el Diagnóstico Ambiental, presenta una Propuesta de Sistema de Gestión Ambiental, el cual es un instrumento de gestión que permite mostrar las acciones implementadas por la universidad; así como nuevas propuestas ajustadas al contexto de la universidad, de acuerdo a su alcance.

La implementación del Sistema de Gestión Ambiental es de carácter voluntario, dado que es un compromiso de la organización con la comunidad universitaria, sociedad y medio ambiente. Esta propuesta brinda a las autoridades y tomadores de decisión de la universidad una herramienta capaz de mejorar el desempeño ambiental, desde la óptica de la gestión. En este sentido, contribuye al cumplimiento de los compromisos ambientales establecidos en la Política Integrada de la universidad.

La presente propuesta busca proporcionar nuevos lineamientos y analizar nuevas ideas en cuanto al contexto de la organización, liderazgo, planificación, soporte institucional, control y seguimiento de aspectos ambientales significativos y evaluación del desempeño ambiental.

Esta propuesta de Sistema de Gestión Ambiental involucra a la totalidad de la comunidad universitaria, brindándole un espacio privilegiado de participación al alumno.

Además, la propuesta busca empoderar a los estudiantes, haciéndoles parte del sistema a través de una participación dinámica. Busca involucrarlos en la gestión y planificación ambiental de la universidad, como estrategia de adquisición de conocimientos y formación universitaria.

Finalmente, esta propuesta permite fortalecer la comunicación entre autoridades y estudiantes, creando un ambiente de coordinación y cooperación entre la comunidad universitaria; con el objetivo de contribuir a la sostenibilidad de la universidad, en el marco de la Responsabilidad Social Universitaria. 


\subsubsection{Contexto de la Organización.}

\subsubsection{Comprensión de la organización y su contexto.}

La Universidad San Ignacio de Loyola posee factores internos y externos que pueden afectar positiva o negativamente su accionar. Estos factores son detallados a continuación:

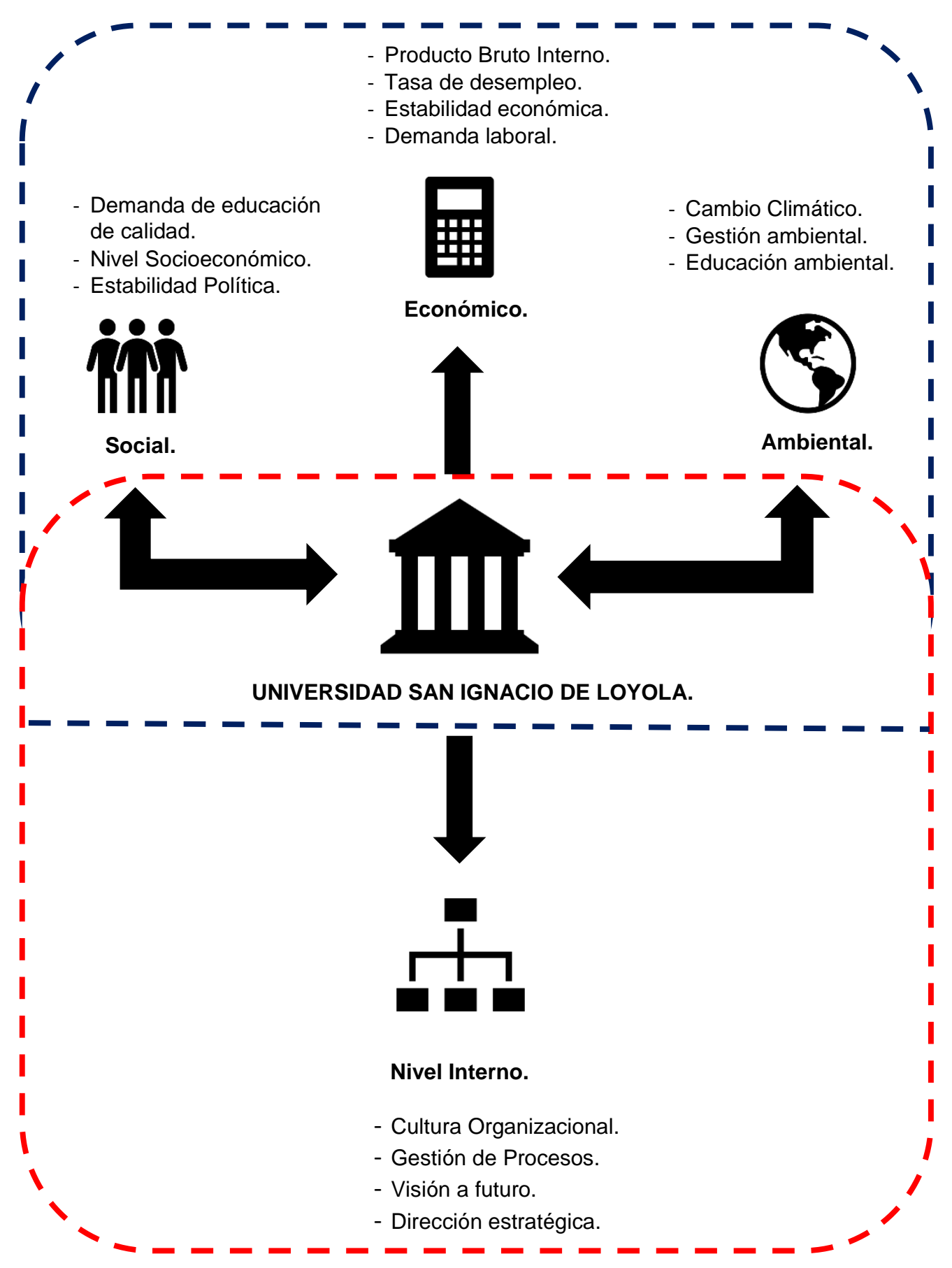

Figura 19: Contexto de la Organización - USIL. Fuente: Elaboración propia. 


\section{Factor Social:}

La Universidad San Ignacio de Loyola responde a factores externos que repercuten en su accionar. En este sentido, los factores sociales pueden impactar positiva 0 negativamente a la universidad.

Uno de los factores importantes para impartir educación es a quien impartirla. En este sentido, en los últimos 10 años se ha registrado una desaceleración en el crecimiento poblacional de $1.3 \%$. Sin embargo, el $50 \%$ de la población peruana es menor a 30 años (INEI, 2017). Esto muestra claramente que el Perú es un país en vías de desarrollo con población joven, lo cual representa una oportunidad para los centros de educación superior.

Asimismo, según la Asociación Peruana de Empresas de Investigación de Mercados (APEIM), en Lima, durante el año 2016, se registraron 2713165 hogares, de los cuales el $29.4 \%$ pertenecen a los Niveles Socioeconómicos (NSE) A y B, sectores a los que se dirige USIL. Un dato aún más específico es que al año 2017 en Lima Metropolitana el $41.3 \%$ de las personas es menor a 24 años, segmento de edad al que las universidades ven como nicho de mercado (Compañía Peruana de Estudios de Mercados y Opinión Pública - CPI, 2017).

Hoy el Perú es un país de renta media, con una clase social emergente y, por consiguiente, demanda y demandará educación; y qué mejor que educación de calidad. Este factor de demanda educativa por parte de los sectores viene siendo y deberá seguir siendo motivo para mantener los estándares de calidad educativa que hoy en día posee la USIL. Este factor es diferenciador respecto a la competencia.

\section{Factor Económico:}

En el caso específico de los factores económicos, la estabilidad económica de un país como el Perú, representa un factor relevante de inversión; dado que existe, como se mencionó en los factores sociales, un nuevo nicho de mercado que es la clase media emergente, la cual demanda educación de calidad para aspirar ser parte de la oferta laboral, profesional, de nuestro país.

Este último factor, oferta laboral, responde al contexto actual del Perú, el cual actualmente es un país de renta media, con demanda de profesionales para satisfacer las necesidades del mercado. La formación de estos profesionales representa una oportunidad para la universidad. 
Según el Instituto Nacional de Estadística e Informática - INEI, en el año 2017 la tasa de desempleo en Lima Metropolitana fue de 6.9\%, 0.7\% más que el año 2016. Este dato refleja que 325500 personas en Lima Metropolitana en el año 2017 buscaron trabajo activamente. El aumento en la Tasa de desempleo en Lima Metropolitana es un factor que afecta negativamente a la universidad, dado que los honorarios a nivel de Lima disminuyeron durante el año, lo cual dificulta que personas puedan acceder a educación de calidad en una institución privada (INEI, 2017).

Por otro lado, los niveles de inversión en el Perú vienen disminuyendo año tras año. El año 2015 la inversión disminuyo 6.4\% respecto al año anterior, mientras que en el 2016 disminuyo en 4.2\% respecto al 2015 (INEI, 2016). La disminución en inversión, tanto pública como privada, representa un factor que afecta a las universidades, dado que existirán menos puestos de trabajo para los profesionales y recién graduados.

Sin embargo, según Bruno Lanvín, especialista de UIT - Organismo Especializado de las Naciones Unidas para la Tecnologías de Información y Comunicación cuando los mercados financieros y los sectores económicos son afectados existe un dilema: parte de la población reduce sus costos de vida, limitan sus ambiciones y planes; y se enfocan en sobrevivir con una calidad de vida aceptable; sin embargo, otros consideran que ante los tiempos difíciles existe la necesidad de actuar y tomar decisiones a futuro, dado que aquí se sacará ventaja respecto al resto cuando se reanude la actividad y el crecimiento económico. En este sentido, ante una crisis económica existe la posibilidad de invertir en educación, dado que, al pasar la crisis, se demandarán de profesionales para acelerar el crecimiento o desarrollo.

\section{Factor Ambiental:}

Hoy en día la sociedad busca adaptarse al cambio climático y busca soluciones a problemas ambientales que vienen suscitándose. En este sentido, a nivel nacional e internacional existe la necesidad de contar con profesionales con enfoque de gestión ambiental y responsabilidad social. La demanda de este nuevo perfil de profesional es un factor positivo para la universidad, dado que sus alumnos, en la etapa de formación, son orientados al enfoque mencionado.

Actualmente, la percepción de la USIL como universidad sostenible y comprometida con el medio ambiente es medianamente baja, pese a que cuenta con tres carreras ligadas a la temática ambiental: Gestión Ambiental Empresarial; Ingeniería Ambiental; e Ingeniería del Agua. 
Esta percepción afecta a la atracción de nuevo alumnado para las carreras mencionadas, pese a que las mismas tienen alta demanda dado el contexto de incremento de sensibilización ambiental por parte de la sociedad.

Por otro lado, en la actualidad los grupos de interés muestran preocupación por el desempeño ambiental de las organizaciones, lo cual influencia en su imagen corporativa. En este sentido, la universidad viene realizando el uso eficiente de los recursos (principalmente agua y energía), a través de la implementación de nueva tecnología. Asimismo, promueve acciones de responsabilidad social ligadas a la temática ambiental, tales como el reciclaje y la reforestación (Reporte de Sostenibilidad USIL, 2015).

La gestión de impactos ambientales en la universidad viene fortaleciéndose, dado que se cuenta con iniciativas para la prevención de los mismos, así como campañas de capacitación y sensibilización para la comunidad universitaria. La gestión de impactos ambientales es un factor ambiental que puede repercutir positiva 0 negativamente el desempeño ambiental de la universidad.

Por lo mencionado, la universidad debe mostrar su compromiso ambiental a través de la visualización de buenas prácticas ambientales, como las que viene desarrollando, con miras a alcanzar la sostenibilidad.

Finalmente, la presente propuesta de Guía de Gestión Ambiental busca empoderar a la comunidad universitaria y hacerla parte del Sistema de Gestión Ambiental de la universidad. La importancia que le dé la universidad a su desempeño ambiental; formación de profesionales con enfoque de responsabilidad social; y, gestión y prevención de impactos ambientales, representará un valor agregado y un paso más para la consecución de los objetivos organizacionales trazados. 


\subsubsection{Comprensión de las necesidades y expectativas de las partes interesadas.}

Según el Reporte de Sostenibilidad USIL 2015, precisamente en el acápite "1.4.1 Dialogo con nuestros grupos de interés", la universidad identificó sus stakeholders, los cuales son representados en el cuadro siguiente:

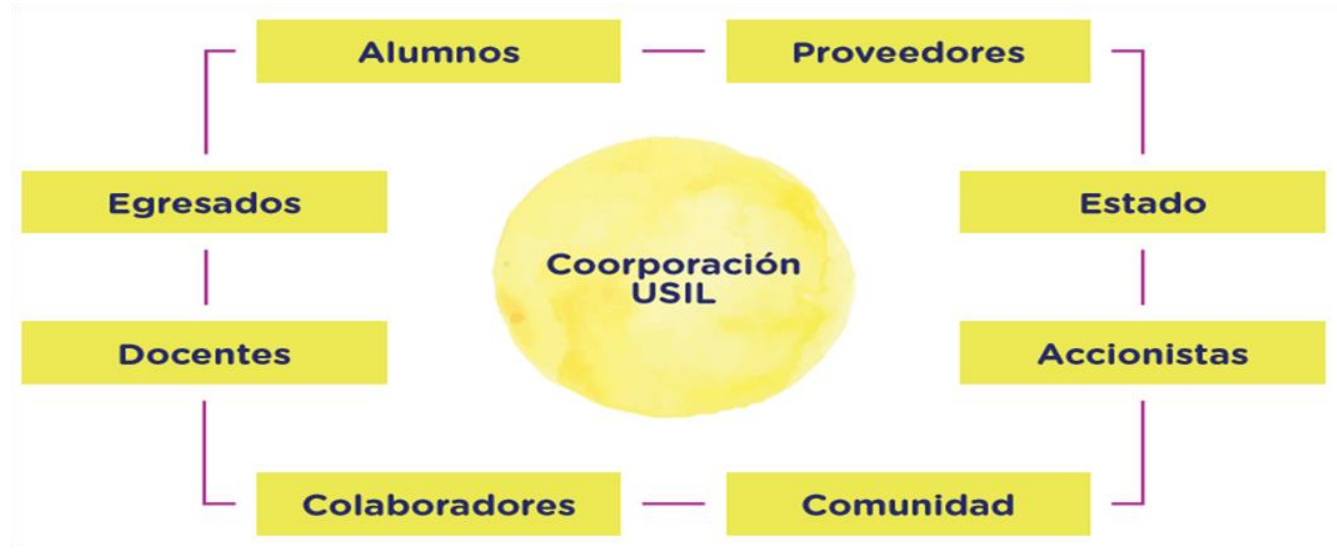

Figura 20: Grupos de Interés USIL. Fuente: Reporte de Sostenibilidad USIL 2015.

Los alumnos son el grupo principal, cuyo desarrollo profesional y humano es el objetivo central de todas las actividades de la organización. Destacan también los docentes y colaboradores, gracias a quienes la organización es capaz de aplicar su modelo de formación profesional y el conjunto de servicios que complementan el desarrollo de nuestros alumnos (Reporte de Sostenibilidad USIL, 2015).

Finalmente, la universidad analizó las expectativas de sus grupos de interés, utilizando la metodología "Análisis de madurez" recomendada por AccountAbility13, la cual es una organización líder a nivel mundial que ofrece soluciones innovadoras a los desafíos más críticos de la responsabilidad corporativa y el desarrollo sostenible. Asimismo, realizó el ejercicio de medir los impactos de sostenibilidad, logrando identificar los impactos significativos utilizando la metodología de evaluación de riesgos (Reporte de Sostenibilidad USIL, 2015). 


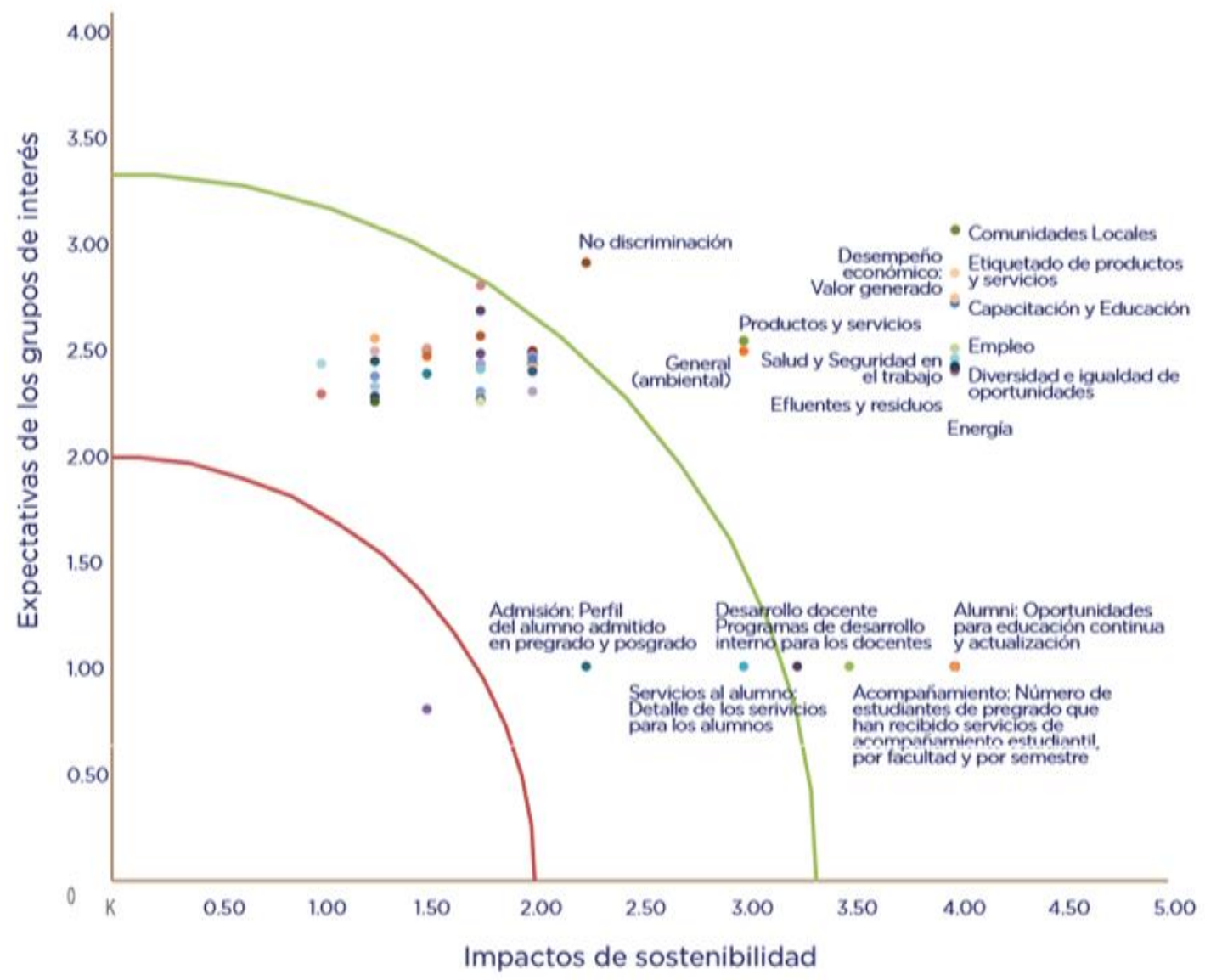

Figura 21: Expectativas de las partes interesadas. Fuente: Reporte de Sostenibilidad USIL 2015.

La figura presentada muestra el puntaje de cada aspecto o asunto identificado, calificándolo como impacto de sostenibilidad y expectativa de los grupos de interés.

\subsubsection{Delimitación del alcance de la Guía de Gestión Ambiental.}

El alcance de la presente Guía tendrá como límite físico las instalaciones de la universidad en las siguientes sedes: Campus Fernando Belaunde Terry - La Molina; y, Campus Almirante Miguel Grau - La Molina.

La Guía de Gestión Ambiental delimita su alcance a nivel de procesos, según Mapa de Procesos Institucional USIL, desde la admisión del postulante hasta la graduación del estudiante. Esta delimitación abarca los procesos siguientes: (i) Procesos Estratégicos; (ii) Procesos Principales; (iii) Procesos de Apoyo; y, (iv) Procesos de Evaluación. 


\subsubsection{Liderazgo: Comité de Gestión Ambiental USIL.}

El Comité de Gestión Ambiental USIL surge ante la necesidad de contar con un espacio institucional de diálogo multidisciplinario, donde la comunidad universitaria discuta la problemática ambiental de la universidad; con la finalidad de llegar a consensos que incluyan alternativas de solución, tomando acuerdos, planificando y comprometiéndose a la implementación de medidas correctivas.

A través del Comité de Gestión Ambiental USIL, la comunidad universitaria coordina, planifica y concierta el accionar ambiental de la universidad. Asimismo, este comité tiene por objetivo lograr la participación de las autoridades, directores de carrera, personal administrativo, personal de apoyo y alumnos.

Como tal, el Comité de Gestión Ambiental USIL, se inscribe dentro del Sistema de Gestión Ambiental; el cual tiene por instrumentos la Política y Guía de Gestión Ambienta USIL.

Por otro lado, el Comité de Gestión Ambiental USIL busca vincularse con otras instituciones (públicas o privadas) ligadas a la temática ambiental con la finalidad de compartir experiencias, recibir soporte técnico y articular acciones en beneficio de la comunidad universitaria en materia ambiental.

\subsubsection{Estructura del Comité de Gestión Ambiental}

La Universidad San Ignacio de Loyola, en el año 2013, contaba con un Comité de Sostenibilidad, el cual a la fecha no se encuentra operativo. En este sentido, no cuenta en la actualidad con un Comité que vele, organice, planifique y supervise la gestión ambiental de la universidad. En este sentido, se propone la creación del Comité de Gestión Ambiental USIL.

El Comité mencionado, debe estar conformado por los representantes siguientes:

- Rector de la Universidad (Presidente del Comité).

- Director de la Carrera de Gestión Ambiental Empresarial.

- Director de la Carrera de Ingeniería Ambiental.

- Director de la Carrea de Ingeniería del Agua.

- Representante de la Escuela de Postgrado.

- Gerente de Sostenibilidad y Responsabilidad Social USIL.

- Presidente del Consejo Estudiantil de Gestión Ambiental. 
Este Comité asume la responsabilidad y rendición de cuentas respecto a la implementación de la guía de gestión ambiental universitaria, la cual debe incluir actividades relacionadas a las temáticas de (i) diagnóstico ambiental, (ii) propuesta de sistema de gestión ambiental y (iii) educación ambiental universitaria. Asimismo, supervisa el cumplimiento del componente ambiental de la Política Integrada USIL. El Presidente es el máximo representante del Comité de Gestión Ambiental y toma decisiones consensuadas con los demás miembros.

El Comité de Gestión Ambiental cuenta con la presencia del Gerente de Sostenibilidad y Responsabilidad Social, quien es responsable de la coordinación de acciones a realizar con directores de carreras, profesores, alumnos y personal administrativo. Asimismo, es el nexo entre los actores mencionados y el Comité.

El Comité de Gestión Ambiental tendrá como áreas de soporte a las siguientes: (i) Área de Administración, Área de Capital Humano, Área Legal y Área de Finanzas. Por lo expuesto, se propone la siguiente estructura jerárquica para el Comité de Gestión Ambiental:

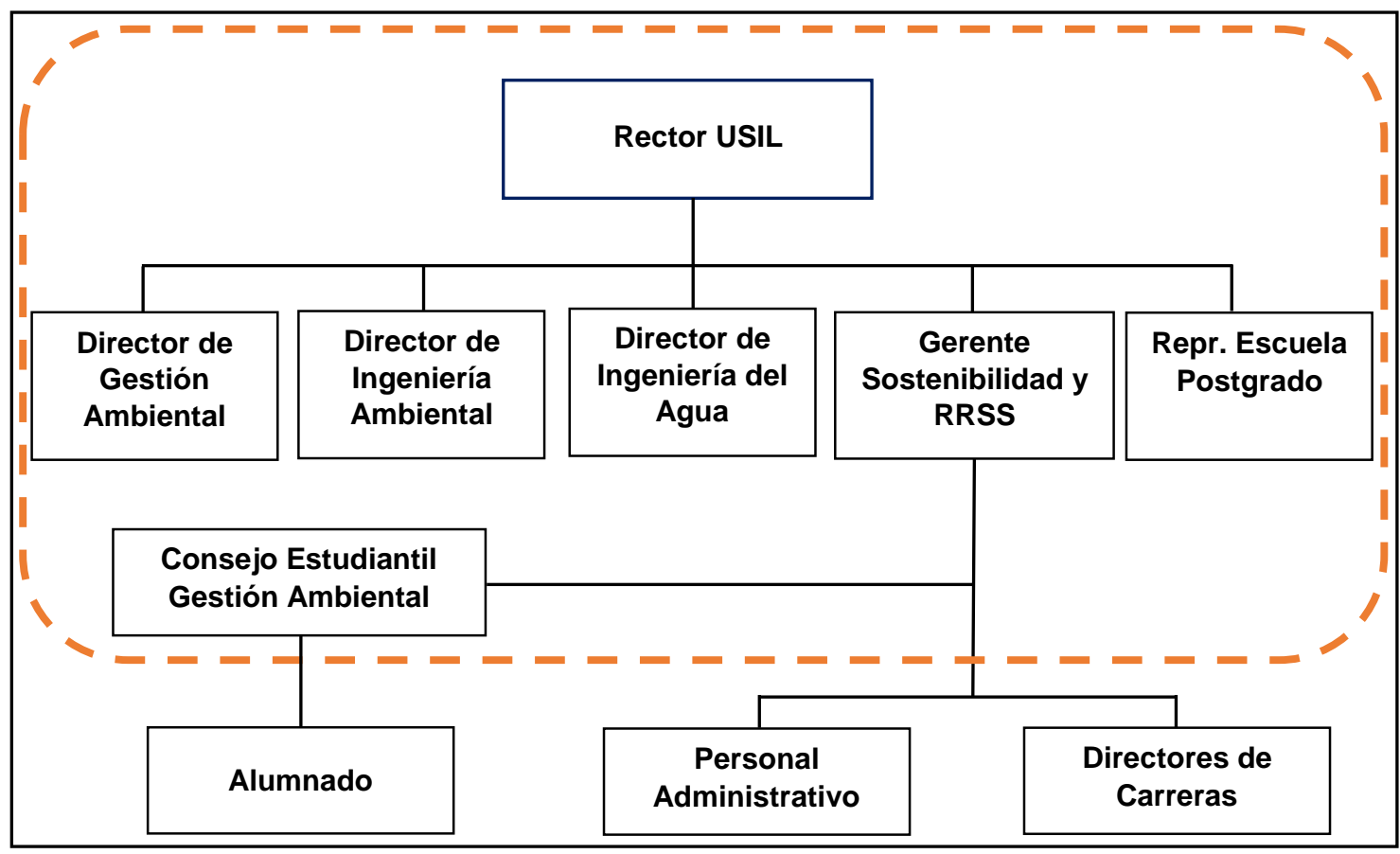

$r-\urcorner$

- Comité de Gestión Ambiental USIL.

Figura 22: Organigrama del Sistema de Gestión Ambiental USIL. Fuente: Elaboración propia. 


\subsubsection{Modelo de Política de Gestión Ambiental USIL}

La universidad, en el año 2016, presentó su Política donde integra 4 componentes:

(i) Seguridad; (ii) Salud; (iii) Medio Ambiente; y, (iv) Responsabilidad Social.

Esta Política, como se puede visualizar en el numeral 7.1 de la presente investigación, integra los 4 componentes; sin embargo, no hace mención de la temática de Responsabilidad Social, pilar institucional de la universidad.

Según el Centro de Normas Técnicas de Costa Rica, el establecimiento de una Política Integrada trae consigo una serie de beneficios tales como los siguientes:

- Permite el aumento de la eficiencia en la gestión de sistemas y en consecución de objetivos y metas.

- Incrementa la capacidad de respuesta (reacción) de la organización frente a las nuevas expectativas de los stakeholders.

- Mejora en la toma de decisiones, por parte de la Alta Dirección, dado que se dispone de una visión global de los sistemas.

- Simplificación en la documentación y registros.

- Reducción de recursos y tiempo empleado en realizar los procesos integrados.

- Mejora y facilita la comunicación interna y externa.

- Se habla de un único sistema de gestión integrada; y no de varios correlacionados.

Un primer paso para la integración de sistemas es la implementación de un Sistema de Gestión Ambiental, como lo viene realizando la universidad. Para esto se debe iniciar el diseño, establecimiento e implementación de un instrumento técnico de gestión ambiental, que contribuya al cumplimiento de los compromisos ambientales establecidos en la Política Integrada de la universidad; de forma tal que mejore la actividad ambiental de la universidad a futuro. En este sentido, se propone la presente Política Integrada (Seguridad y Salud Ocupacional, Ambiente y Responsabilidad Social). 
U

\section{POLITICA DE SEGURIDAD Y SALUD OCUPACIONAL, AMBIENTE Y RESPONSABILIDAD SOCIAL}

La Universidad San Ignacio de Loyola tiene como objetivo la formación de profesionales competentes, emprendedores, responsables socialmente y con capacidad plena para desenvolverse en el ámbito nacional e internacional. Asimismo, la Universidad San Ignacio de Loyola tiene como compromiso velar por la seguridad y salud ocupacional, además del ambiente. La Universidad San Ignacio de Loyola, mediante la presente Política Integrada, y sus respectivos instrumentos de gestión especializados, se compromete a:

1. Identificar y gestionar los aspectos e impactos ambientales, además de los peligros y riesgos en seguridad y salud ocupacional en las instalaciones universitarias.

2. Compatibilizar los Sistemas de Gestión Ambiental, Seguridad, y Salud Ocupacional; así como promover su mejora continua.

3. Diseñar y desarrollar planes de fortalecimiento de capacidades para la comunidad universitaria en materia ambiental, de seguridad y salud ocupacional.

4. Identificar y garantizar el cumplimiento de requisitos y obligaciones legales en materia de Seguridad, Salud Ocupacional y Ambiente; así como otros asumidos por la institución.

5. Promover y fortalecer la responsabilidad social - ambiental en toda la organización.

6. Proteger la integridad de todos los miembros de la organización mediante la formulación e implementación de estrategias orientadas a la prevención de lesiones, accidentes de trabajo o enfermedades ocupacionales. Así mismo, proteger el ambiente y prevenir la contaminación.

7. Diseñar e implementar instrumentos de gestión especializados en cada temática, los cuales contribuyan al logro de los objetivos establecidos en la presente Política.

\section{Rector de la Universidad San Ignacio de Loyola Presidente del Comité de Gestión Ambiental}

Figura 23: Propuesta de Política Integrada USIL. Fuente: Elaboración propia.

\subsubsection{Funciones y responsabilidades - Comité de Gestión Ambiental.}

Las funciones del Comité de Gestión Ambiental USIL son dictaminadas por el mismo Comité y pueden ser actualizadas siempre y cuando la mayoría de este lo considere. Estas funciones son las siguientes:

a) Promover y velar por el cumplimiento de la Política Ambiental USIL.

b) Implementar la Guía de Gestión Ambiental USIL como instrumento de política. 
c) En el marco de la Guía de Gestión Ambiental; implementar, planificar, coordinar, concertar, organizar y dirigir acciones en materia del sistema de gestión ambiental; diagnóstico ambiental y educación ambiental universitaria.

d) Organizar y dar seguimiento, con apoyo del área de sostenibilidad, al diagnóstico y auditoría ambiental realizados.

e) Promover, con apoyo del área de sostenibilidad, la educación ambiental en la comunidad universitaria a través de campañas y eventos institucionales.

f) Supervisar la organización, con apoyo del área de sostenibilidad, de los eventos en el Día Mundial del Agua y Día Mundial del Medio Ambiente.

g) Planificar y elaborar lineamientos para el voluntariado ambiental USIL.

h) Supervisar la elaboración y difusión del Reporte de Sostenibilidad anual.

i) Supervisar la difusión de material para la creación de conciencia ambiental en la comunidad universitaria.

j) Planificar, programar, desarrollar y apoyar las iniciativas en materia de protección y divulgación ambiental dentro y fuera de la Universidad.

k) Promover la responsabilidad ambiental dentro y fuera de las instalaciones de la universidad.

I) Evaluar, revisar y otorgar conformidad al Plan Operativo Ambiental universitario; Programa Anual de Auditorías y a los Informes Finales de Auditorías.

m) Promover la formulación y ejecución de proyectos de investigación en materia ambiental, así como, la expresión de las diversas visiones o ideas que desde las unidades académicas se puedan expresar.

n) Promover alianzas con organismos públicos y privados con interés en el tema.

o) Actualizar la Política de Gestión Ambiental y la Guía de Gestión Ambiental.

p) Organizar anualmente, con apoyo del área de sostenibilidad, las elecciones para la conformación del Consejo Estudiantil de Gestión Ambiental.

q) Otras funciones relacionadas al tema ambiental previamente consensuadas con el Comité. 


\subsection{Funciones y responsabilidades - Presidente del Comité.}

El Presidente del Comité de Gestión Ambiental es la máxima autoridad en materia ambiental de la universidad. Es el encargado de la suscripción y actualización de la Política de Gestión Ambiental; así como de la Guía de Gestión Ambiental.

Asimismo, el Presidente supervisa el cumplimiento de los dos instrumentos mencionados. Las funciones del Presidente en materia ambiental son:

a) Suscribir la Política y Guía de Gestión Ambiental USIL.

b) Actualizar, juntamente con los representantes del Comité de Gestión Ambiental, la Política y Guía de Gestión Ambiental USIL.

c) Presidir el Comité de Gestión Ambiental.

d) Supervisar la implementación de la Política y Guía de Gestión Ambiental.

e) Convocar a los representantes del Comité de Gestión Ambiental a reuniones extraordinarias.

f) Supervisar actividades desempeñadas por el Gerente de Sostenibilidad y RRSS.

g) Otorgar, juntamente con el área de presupuesto y logística, los recursos necesarios para la realización de actividades de gestión ambiental.

h) Otorgar conformidad y suscribir el Plan Operativo Ambiental universitario.

i) Suscribir alianzas con instituciones públicas y privadas que contribuyan a la mejora de la gestión ambiental en la universidad.

j) Otras funciones relacionadas al tema ambiental previamente consensuadas con el Comité.

\subsection{Funciones y responsabilidades - Gerente Sostenibilidad RRSS.}

El Gerente de Sostenibilidad y RRSS es el nexo entre el Comité de Gestión Ambiental y los directores de carrera; personal administrativo y alumnado. Asimismo, tiene a su cargo la coordinación del Consejo Estudiantil de Gestión Ambiental.

Es el actor más importante a nivel operativo en la implementación de la Guía de Gestión Ambiental, dado que es el responsable del cumplimiento de la Política de Gestión Ambiental. Su importancia radica en la formulación e implementación de estrategias que responden a los objetivos ambientales de la organización. El Gerente de Sostenibilidad y RRSS tiene las funciones siguientes: 
a) Ejecutar actividades para el cumplimiento de la Política de Gestión Ambiental.

b) Formular e implementar estrategias que respondan a los objetivos ambientales de la organización.

c) Liderar la implementación de la Guía de Gestión Ambiental.

d) Participar en la actualización de la Política y Guía de Gestión Ambiental USIL.

e) Coordinar y ejecutar actividades en apoyo del Consejo Estudiantil.

f) Organizar, con apoyo del Comité de Gestión Ambiental, y dirigir anualmente el diagnóstico ambiental de la universidad.

g) Promover, con apoyo Comité de Gestión Ambiental, la educación ambiental en la comunidad universitaria a través de campañas y eventos institucionales.

h) Realizar, con apoyo del Comité de Gestión Ambiental y Consejo Estudiantil, eventos en el Día Mundial del Agua; del Medio Ambiente; y de la Tierra.

i) Planificar y elaborar lineamientos para el voluntariado ambiental USIL.

j) Elaborar el Reporte de Sostenibilidad anual.

k) Coordinar con el área de comunicaciones, la difusión de material para la creación de conciencia ambiental en la comunidad universitaria y stakeholders.

I) Supervisar las auditorías al sistema de gestión ambiental y realizar los informes.

m) Organizar anualmente las elecciones para la conformación del Consejo Estudiantil de Gestión Ambiental.

n) Orientar técnicamente al Consejo Estudiantil de Gestión Ambiental.

o) Planificar, elaborar y coordinar con el Consejo Estudiantil de Gestión Ambiental el Plan Operativo Ambiental universitario.

p) Diseñar y ejecutar los programas de capacitación y sensibilización ambiental; así como evaluar los resultados de este.

q) Representar a la organización en eventos institucionales relacionados a la temática ambiental.

r) Gestionar las comunicaciones internas y externas de la organización relacionadas a la temática ambiental. 
s) Presupuestar las actividades relacionadas a la gestión ambiental de la organización.

t) Convocar a reuniones ordinarias al Comité de Gestión Ambiental.

u) Ejecutar el presupuesto anual de gestión ambiental.

v) Afianzar alianzas con entidades públicas y privadas para la mejora de la gestión ambiental en la universidad.

w) Supervisar la gestión de la información documentada.

x) Supervisar el cumplimiento del procedimiento de comunicación interna y externa.

y) Diseñar y organizar los "Talleres de Educación Ambiental" una vez por ciclo.

z) Otras funciones relacionadas al tema ambiental previamente consensuadas con el Comité.

\subsection{Funciones y responsabilidades - Directores de carrera.}

Los Directores de todas las carreras de la Universidad San Ignacio de Loyola, inclusive los Directores de la carrera de Ingeniería Ambiental; Ingeniería del Agua y Gestión Ambiental Empresarial; tienen las siguientes responsabilidades:

a) Coordinar con el Gerente de Sostenibilidad y RRSS el diseño de los programas de capacitación y sensibilización exclusivo para pregrado.

b) Integrar en el currículo de las carreras que dirigen, el componente ambiental.

c) Proponer ideas o nuevos mecanismos para mejorar el sistema de gestión ambiental de la universidad.

d) Velar por el cumplimiento de la Política de Gestión Ambiental.

e) Apoyar las actividades realizadas en el marco de la Guía de Gestión Ambiental.

f) Participar de los eventos institucionales ligados a la temática ambiental.

g) Difundir información que contribuya a la reducción de impactos ambientales.

h) Proveer información necesaria para la elaboración del Reporte de Sostenibilidad.

i) Apoyar la realización del Plan Operativo Ambiental Universitario.

j) Otras funciones relacionadas al tema ambiental previamente consensuadas con el Comité. 


\subsection{Funciones y Responsabilidades - Representante de Postgrado.}

La Escuela de Posgrado de la Universidad San Ignacio de Loyola cuenta con un representante en el Comité de Gestión Ambiental USIL. Se determina su participación dado que el alcance del Sistema de Gestión Ambiental abarca la educación a nivel de pre grado y posgrado. Finalmente, ambos niveles poseen los mismos procesos estratégicos, principales, de apoyo y de evaluación.

El representante de la Escuela de Posgrado USIL tiene las funciones y responsabilidades siguientes:

a) Coordinar con el Gerente de Sostenibilidad y RRSS el diseño de los programas de capacitación y sensibilización exclusivos para posgrado.

b) Integrar en el currículo de las maestrías que dirigen, el componente ambiental.

c) Proponer ideas o nuevos mecanismos para mejorar el sistema de gestión ambiental de la universidad.

d) Velar por el cumplimiento de la Política de Gestión Ambiental.

e) Apoyar las actividades realizadas en el marco de la Guía de Gestión Ambiental.

f) Participar de los eventos institucionales ligados a la temática ambiental.

g) Difundir información que contribuya a la reducción de impactos ambientales.

h) Proveer información necesaria para la elaboración del Reporte de Sostenibilidad.

i) Apoyar la realización del Plan Operativo Ambiental Universitario.

j) Otras funciones relacionadas al tema ambiental previamente consensuadas con el Comité.

\subsection{Funciones y responsabilidades - Presidente Estudiantil.}

El Presidente del Consejo Estudiantil de Gestión Ambiental electo tiene las siguientes funciones y responsabilidades:

a) Representar al Consejo Estudiantil ante el Comité de Gestión Ambiental.

b) Presidir el Consejo Estudiantil por el año de su elección.

c) Apoyar la ejecución de actividades en el marco de la Política y Guía de Gestión Ambiental. 
d) Planificar, elaborar y coordinar con el Gerente de Sostenibilidad y RRSS el Plan Operativo Ambiental universitario.

e) Coordinar con el Presidente Estudiantil saliente la postura del Consejo Estudiantil ante el Comité de Gestión Ambiental para la elaboración del Plan Operativo Ambiental universitario.

f) Convocar a elecciones del Consejo Estudiantil antes del mes de noviembre del año en curso.

g) Coordinar y ejecutar actividades en apoyo del Gerente de Sostenibilidad y RRSS.

h) Participar en el diagnóstico ambiental de la universidad.

i) Apoyar la realización de eventos en el Día Mundial del Agua y Día Mundial del Medio Ambiente.

j) Participar en la actualización de la Política y Guía de Gestión Ambiental USIL.

k) Participar en la elaboración del Reporte de Sostenibilidad anual.

I) Apoyar la ejecución de programas de capacitación y sensibilización ambiental.

m) Representar al Consejo Estudiantil en eventos institucionales.

n) Convocar a reuniones ordinarias y extraordinarias al Consejo Estudiantil.

o) Afianzar alianzas con entidades públicas y privadas para la mejora de la gestión ambiental en la universidad.

p) Velar por el buen entendimiento entre los Representantes del Consejo Estudiantil.

q) Otras dictaminadas por el Comité de Gestión Ambiental y Gerente de Sostenibilidad y RRSS.

\subsubsection{Consejo Estudiantil de Gestión Ambiental.}

El Consejo Estudiantil de Gestión Ambiental USIL es un espacio estudiantil de dialogo multidisciplinario donde participan alumnos de distintas facultades de la universidad. En este espacio se discute la problemática ambiental de la universidad, así como las acciones que contribuyan a la gestión ambiental universitaria. Este espacio busca apoyar al área de sostenibilidad de la universidad en la implementación y desarrollo de actividades de la Política de Gestión Ambiental y Guía de Gestión Ambiental (Instrumento de gestión). Asimismo, participa en la toma de decisiones del Comité de 
Gestión Ambiental USIL, a través de su Presidente (electo democráticamente por los representantes del Consejo Estudiantil).

Mediante el Consejo Estudiantil, los representantes de este - en coordinación con los estudiantes universitarios en general - pueden planificar y coordinar las acciones a ejecutarse durante el año a través del Plan Operativo Ambiental universitario.

Como tal, el Consejo Estudiantil, se inscribe dentro del Sistema de Gestión Ambiental; el cual tiene por instrumento la Política y Guía de Gestión Ambienta USIL. El Consejo tiene las funciones siguientes:

a) Promover y velar por el cumplimiento de la Política Ambiental USIL.

b) Apoyar en la implementación de la Guía de Gestión Ambiental USIL como instrumento de política.

c) Proponer ideas o nuevos mecanismos para mejorar el sistema de gestión ambiental de la universidad.

d) En el marco de la Guía de Gestión Ambiental; apoyar a la implementación, planificación, y organización de acciones en materia del sistema de gestión ambiental; diagnóstico ambiental y educación ambiental universitaria.

e) Colaborar en la realización del diagnóstico y auditoría ambiental.

f) Apoyar al área de sostenibilidad de la universidad en la realización de campañas y eventos institucionales.

g) Apoyar al área de sostenibilidad en la realización de eventos en el Día Mundial del Agua; Día Mundial del Medio Ambiente; y Día Mundial de la Tierra.

h) Apoyar en la elaboración del Reporte de Sostenibilidad anual.

i) Difundir el material, elaborado por el área de sostenibilidad y comunicaciones, para la creación de conciencia ambiental en la comunidad universitaria.

j) Promover la responsabilidad ambiental dentro y fuera de las instalaciones.

k) Planificar, elaborar y coordinar, con el Gerente de Sostenibilidad y RRSS, el Plan Operativo Ambiental universitario.

I) Proponer acciones, según sea conveniente, para la actualización de la Política y Guía de Gestión Ambiental USIL. 
m) Organizar anualmente, con apoyo del área de sostenibilidad, las elecciones para la conformación del Consejo Estudiantil de Gestión Ambiental.

n) Otras pertinentes donde prime la lógica y buenas costumbres a favor del ambiente.

\subsection{Estructura del Consejo Estudiantil de Gestión Ambiental.}

El Consejo Estudiantil será presidido por el Presidente del Consejo, quien tiene como colaboradores a los representantes del Consejo. Por lo mencionado, se propone la siguiente estructura:

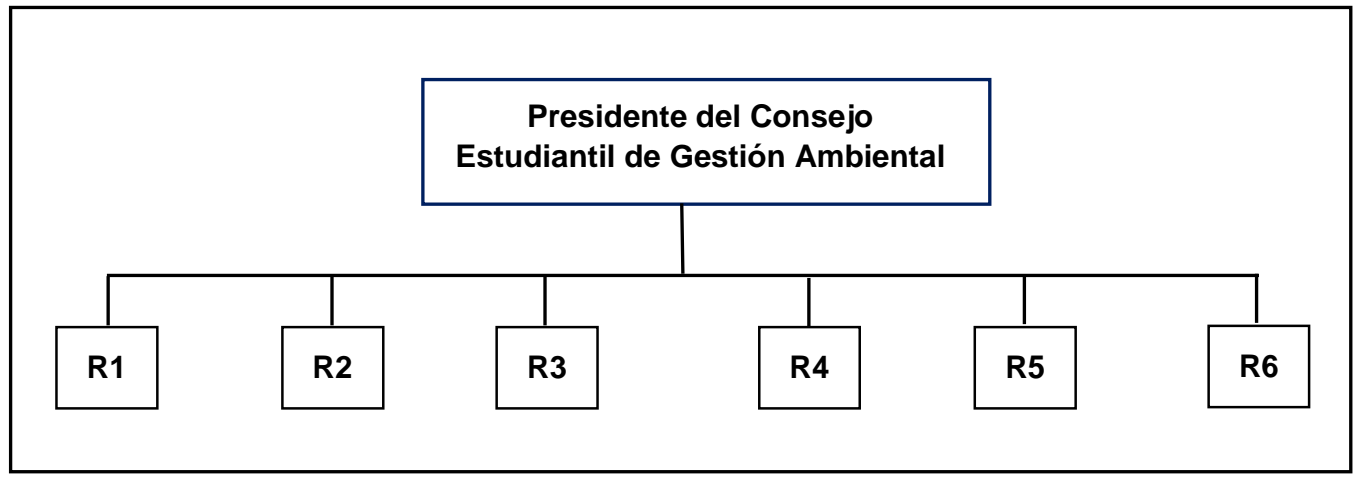

Figura 24: Organigrama del Consejo Estudiantil de Gestión Ambiental. Fuente: Elaboración propia.

\subsection{Integrantes Consejo Estudiantil de Gestión Ambiental.}

El Consejo Estudiantil de Gestión Ambiental USIL está conformado por 7 futuros profesionales multidisciplinarios, los cuales son elegidos democráticamente por los grupos estudiantiles a los que pertenecen. Los integrantes de este Comité son:

- R1: Representante de la Carrera de Ingeniería Ambiental.

- R2: Representante de la Facultad de Ingeniería.

- R3: Representante de la carrera de Gestión Ambiental Empresarial.

- R4: Representante de la Facultad de Ciencias Empresariales.

- R5: Representante de la Facultad de Educación.

- R6: Representante de la Facultad de Derecho.

- R7: Representante de Facultad distinta a las mencionadas.

El perfil de los 07 representantes del Consejo Estudiantil de Gestión Ambiental debe ser mínimamente el siguiente: 
a) Ser alumno activo de la Universidad San Ignacio de Loyola.

b) Contar con más de 120 créditos cursados y tener un promedio ponderado mínimo de nota 13.

c) No registrar antecedentes de conducta inadecuada.

d) Estar matriculado en el periodo actual en el que es elegido.

e) Tener interés por la gestión ambiental universitaria.

f) No podrán ser elegidos dos representantes de la misma carrera.

El perfil mencionado es revisado estrictamente por el área de sostenibilidad de la universidad. El mes de octubre es el indicado para la presentación de la documentación solicitada.

\subsection{Proceso electoral de integrantes y Presidente del Consejo Estudiantil de Gestión Ambiental.}

El proceso electoral para la elección de representantes del Consejo Estudiantil de Gestión Ambiental debe regirse bajo los lineamientos siguientes:

a) La elección de cada uno de los representantes se hará únicamente por los alumnados de su propia facultad.

b) Solo podrán votar los alumnos matriculados en el presente semestre académico.

c) Un alumno solo puede votar una vez. Salvo en caso de empate de los candidatos, podrá votar nuevamente.

d) Para el caso exclusivo del sétimo representante votarán los alumnos pertenecientes a las Facultades restantes.

e) La votación para la elección de representantes es voluntaria.

f) El representante ganador de la facultad será quien tenga la mayor cantidad de votos sobre el total. En caso de empate, se convocan a nuevas elecciones al día laborable siguiente entre los candidatos empatados.

g) Las campañas electorales se iniciarán desde el mes de octubre.

h) Tanto la votación como las campañas electorales se realizarán dentro de la universidad. El Gerente de Sostenibilidad y RRSS deberá definir fecha y hora.

i) La votación deberá realizarse antes de quincena de noviembre del año en curso. 
j) Tanto el proceso electoral como la votación será supervisada por el Gerente de Sostenibilidad y RRSS, quien otorgará conformidad a la misma. Caso contrario, convocará a nuevas elecciones dos días después de las que no fueron avaladas.

Una vez celebradas y culminadas las elecciones de los representantes; estos se reunirán una semana después de haberse realizado la votación; con la finalidad de elegir democráticamente al Presidente del Consejo Estudiantil de Gestión Ambiental USIL [Presidente del Consejo Estudiantil] bajo los lineamientos siguientes:

a) La elección del Presidente del Consejo Estudiantil se realiza únicamente por los representantes elegidos (07).

b) Un representante solo puede votar una vez. Salvo en caso de empate entre candidatos, se podrá votar nuevamente. Los candidatos empatados no votarán.

c) En el supuesto caso que todos votasen por sí mismos; el Gerente de Sostenibilidad y RRSS designará al Presidente después de la evaluación basada en los criterios para la postulación.

d) La votación para la elección del Presidente del Consejo Estudiantil es voluntaria.

e) El que ocupe el cargo de Presidente del Consejo Estudiantil será quien tenga la mayor cantidad de votos sobre el total de los votos efectuados.

f) La votación para la elección del Presidente del Consejo Estudiantil se realiza en el campus universitario. El Gerente de Sostenibilidad y RRSS define fecha y hora. Asimismo, supervisa y otorga conformidad a la elección. Caso contrario, convoca a nuevas elecciones 02 días útiles después de las no avaladas.

g) Asimismo, el Presidente del Consejo Estudiantil debe ser elegido antes de la segunda quincena del mes de noviembre del año en curso. Ambas elecciones se dan en el mes de noviembre debido a que, en el mes de diciembre del año en curso, se elabora el Plan Operativo Ambiental universitario del siguiente año.

h) En este sentido, el Presidente del Consejo saliente y el entrante, en diciembre, coordinarán y consensuarán la postura del Consejo ante el Comité de Gestión Ambiental para la elaboración del Plan Operativo Ambiental universitario. 
8.1.3 Planificación Ambiental USIL.

Tabla 08

Planificación Ambiental USIL 2017.

\begin{tabular}{|c|c|c|c|}
\hline Programa & Organización Aliada & \multicolumn{2}{|l|}{ Detalle } \\
\hline \multicolumn{2}{|c|}{ De Gestión de Calidad de Aire, ruido } & \multicolumn{2}{|c|}{$\begin{array}{c}\text { El objetivo es medir, controlar y garantizar el cumplimiento de medidas de mitigación identificadas y de esta manera } \\
\text { hacer un seguimiento a la evolución del desempeño ambiental de las mismas; en cumplimiento de las normas } \\
\text { ambientales aplicables a la calidad del aire y ruido. }\end{array}$} \\
\hline \multicolumn{2}{|c|}{ De Gestión de agua y aguas residuales } & \multicolumn{2}{|c|}{$\begin{array}{l}\text { Aseguramiento de la calidad del agua durante las operaciones de la USIL, y minimizando el riesgo de contaminación } \\
\text { del suelo, aguas superficiales o aguas subterráneas. }\end{array}$} \\
\hline \multicolumn{2}{|c|}{ De Gestión de residuos } & \multicolumn{2}{|c|}{$\begin{array}{l}\text { Asegurar la sostenibilidad de las operaciones a través de la gestión de los residuos que generen las actividades } \\
\text { que se desarrollan en USIL, en cumplimiento legal y evitar los impactos ambientales que pudiesen generarse. A } \\
\text { continuación, se detallan las actividades más resaltantes que soportan el programa: }\end{array}$} \\
\hline $\begin{array}{l}\text { Recíclame Cumple } \\
\text { Tu Papel }\end{array}$ & $\begin{array}{l}\text { Aldeas Infantiles } \\
\text { SOS }\end{array}$ & \multicolumn{2}{|c|}{$\begin{array}{l}\text { Es una campaña que busca crear conciencia social dirigida a todos los alumnos y colaboradores de la organización, } \\
\text { sobre la necesidad reúso y luego del reciclaje de papel y del cartón, como parte de la conservación ambiental; para lo } \\
\text { cual se les ha facilitado contenedores en cada oficina y en espacios comunes. } \\
\text { La actividad consiste en la promoción de reciclaje, como una práctica de cuidado medio ambiental y responsabilidad } \\
\text { social; que por cada } 2 \text { toneladas de papel donado, se financia } 10 \text { becas de alimentación para los niños de Aldeas } \\
\text { Infantiles para que reciban alimentación completa durante un mes. }\end{array}$} \\
\hline $\begin{array}{l}\text { Reciclar para } \\
\text { Ayudar }\end{array}$ & Aniquem & \multicolumn{2}{|c|}{$\begin{array}{c}\text { El objetivo es disminuir el impacto ambiental de los residuos sólidos de plástico y al mismo tiempo generar un valor } \\
\text { social a través de la donación de las botellas PET. La donación de las botellas recicladas sirven para financiar la } \\
\text { rehabilitación de niños, niñas y adolescentes con secuelas de quemaduras severas }\end{array}$} \\
\hline $\begin{array}{l}\text { Reciclemos para } \\
\text { Transformar }\end{array}$ & Entel & $\begin{array}{c}\text { Implementación de contenedores especiales para disponer y reciclar } \\
\text { residuos eléctricos y electrónicos }\end{array}$ & $\begin{array}{c}1 \text { contenedor en cada sede (Campus FBT, } \\
\text { MG y Pachacamac) }\end{array}$ \\
\hline Reciclaje de aceite & & \multicolumn{2}{|c|}{ El objetivo es el cuidado ambiental a través del reciclaje de aceite usado generado en cocinas - Facultad de Gastronomía. } \\
\hline \multicolumn{2}{|c|}{ Utilización de energías limpias } & \multicolumn{2}{|c|}{$\begin{array}{c}\text { Como parte de las políticas de eficiencia energética y el compromiso con el consumo responsable de recursos, USIL } \\
\text { optó por instalar cargadores de energía solar para celulares y otros dispositivos móviles; con ello, buscan empoderar a } \\
\text { la comunidad USIL a ser líderes en la promoción de una cultura ambiental a través de la adopción de una conducta de } \\
\text { consumo mucho más eficiente de energía. }\end{array}$} \\
\hline $\begin{array}{l}\text { Conectados con el } \\
\quad \text { Planeta }\end{array}$ & Entel & Implementación de cargadores solares & $\begin{array}{c}1 \text { cargador en campus FBT } \\
2 \text { cargadores en Campus MG } \\
2 \text { cargadores en sede Pachacamac }\end{array}$ \\
\hline
\end{tabular}

NOTA: Fuente: Universidad San Ignacio de Loyola Oficial - Unidad de Seguridad, Salud Ocupacional, Ambiente y Responsabilidad Social. 


\section{Tabla 09}

Planificación Ambiental USIL 2017- Capacitaciones efectuadas - Talleres de Sensibilización.

\begin{tabular}{|c|c|}
\hline Tema & Detalle \\
\hline $\begin{array}{l}\text { Capacitaciones sobre Medio ambiente y Responsabilidad - } \\
\text { Quincenal }\end{array}$ & \multirow{2}{*}{$\begin{array}{c}\text { Dirigido a colaboradores y docentes y } \\
\text { empresas contratistas }\end{array}$} \\
\hline Manejo de Residuos Sólidos & \\
\hline
\end{tabular}

NOTA: Fuente: Universidad San Ignacio de Loyola Oficial - Unidad de Seguridad, Salud Ocupacional, Ambiente y Responsabilidad Social.

\section{Tabla 10}

Planificación Ambiental USIL 2017- Eventos realizados.

\begin{tabular}{|c|c|c|c|}
\hline Evento & Detalle & Frecuencia & Publico dirigido \\
\hline Reciclaton & $\begin{array}{l}\text { Campaña de reciclaje de papel que se desarrolla un vez por } \\
\text { ciclo académico, para intercambiar papel reciclado por } \\
\text { obsequios del programa "Recíclame: Cumple Tu Papel" }\end{array}$ & 2 veces al año & $\begin{array}{l}\text { Alumnos, docentes y } \\
\text { colaboradores }\end{array}$ \\
\hline Embajador Verde & $\begin{array}{l}\text { Competencia de reciclaje de papel, a nivel administrativo de } \\
\text { la organización }\end{array}$ & 1 vez al año & Colaboradores \\
\hline $\begin{array}{l}\text { 2da Semana de sostenibilidad } \\
\text { y Responsabilidad Social }\end{array}$ & $\begin{array}{c}\text { En marco al día mundial del medio ambiente, tuvo como } \\
\text { finalidad brindar espacios de información, reflexión y } \\
\text { participación activa en relación a estos temas que nos } \\
\text { conciernen a nivel local e internacional. } \\
\end{array}$ & 1 vez al año & $\begin{array}{l}\text { Alumnos, docentes y } \\
\text { colaboradores y público general }\end{array}$ \\
\hline Hora del Planeta & Apagar luces de letreros grandes e insignia del campus & 1 vez al año & \\
\hline
\end{tabular}

NOTA: Fuente: Universidad San Ignacio de Loyola Oficial - Unidad de Seguridad, Salud Ocupacional, Ambiente y Responsabilidad Social. 


\subsubsection{Estructura del Plan Operativo Ambiental universitario.}

Tabla 11

Estructura del Plan Operativo Ambiental Universitario

\begin{tabular}{|c|c|c|c|c|c|c|c|c|c|}
\hline Componente & $\begin{array}{l}\text { Actividad - } \\
\text { Evento }\end{array}$ & $\begin{array}{l}\text { Objetivo } \\
\text { general }\end{array}$ & $\begin{array}{c}\text { Fecha de inicio } \\
\text { y término }\end{array}$ & Meta & $\begin{array}{l}\text { Público } \\
\text { objetivo }\end{array}$ & Responsable & $\begin{array}{l}\text { Recursos } \\
\text { requeridos }\end{array}$ & $\begin{array}{l}\text { Unidad de } \\
\text { Medida }\end{array}$ & $\begin{array}{c}\text { Medio de } \\
\text { verificación }\end{array}$ \\
\hline \multicolumn{10}{|l|}{ Agua } \\
\hline & & & & & & & & & \\
\hline \\
\hline \multicolumn{10}{|l|}{ Sólidos } \\
\hline & & & & & & & & & \\
\hline & & & & & & & & & \\
\hline \multicolumn{10}{|l|}{ Energía } \\
\hline & & & & & & & & & \\
\hline & & & & & & & & & \\
\hline \multicolumn{10}{|l|}{ Aire } \\
\hline & & & & & & & & & \\
\hline \\
\hline \multicolumn{10}{|l|}{ Ambiental } \\
\hline & & & & & & & & & \\
\hline & & & & & & & & & \\
\hline \multicolumn{10}{|l|}{ Capacitación } \\
\hline & & & & & & & & & \\
\hline
\end{tabular}

NOTA: Fuente: Elaboración propia. 


\section{Plan Ambiental Universitario.}

El Plan Ambiental Universitario (PAU) es un instrumento de diseño y planificación que tiene por objetivo programar y proyectar las actividades de la universidad con el objetivo de mejorar el desempeño ambiental organizacional.

La elaboración del PAU está a cargo de la Gerencia de Sostenibilidad y del Consejo Estudiantil de Gestión Ambiental; y es precisamente este espacio de elaboración donde interactúan representantes y estudiantes de la universidad, dándose un intercambio de información y expectativas. El Comité de Gestión Ambiental, a través de su Presidente, aprueba el PAU; el mismo que es implementado y supervisado por el Área de Sostenibilidad.

La gestión ambiental en una universidad, y dentro de ella la planificación, tal cual sucede en distintas organizaciones, tiene por objetivo mejorar el desempeño ambiental de la organización. Sin embargo, la mejora del desempeño o la eficiencia ambiental no depende exclusivamente de un área o unidad. Al contrario, depende de un sistema mayor, de un sistema integrado, que sea capaz de coordinar, articular e implementar acciones en favor del medio ambiente dentro de la organización.

La gestión ambiental en una institución educativa está en la obligación de integrar al estudiante como agente decisor desde la etapa de planificación; debido a que es el stakeholder a quien la universidad dirige su propuesta de valor.

EI PAU presenta una estructura no limitativa, dado que puede adecuarse a diferentes escenarios o condiciones a solicitud del Comité de Gestión Ambiental. Esta estructura considera necesaria la inclusión del objetivo de la actividad a realizar, fecha de inicio y término de la actividad, meta que se espera lograr, público objetivo al cual va dirigida la actividad, responsable de la actividad, recursos económicos o humanos requeridos, la unidad de medida (indicador) y modo de verificación (evidencias de implementación). 


\subsubsection{Control y seguimiento de aspectos ambientales significativos.}

\begin{tabular}{|c|c|c|c|c|}
\hline Aspecto Ambiental Significativo & Característica Clave & Indicador (Unidad) & Meta & Instrucciones \\
\hline Generación de residuos peligrosos & $\begin{array}{c}\text { Volumen de Residuos Peligrosos } \\
\text { dispuestos }\end{array}$ & \multirow{2}{*}{ Tonelada / mes } & \multirow{2}{*}{$100 \%$} & \multirow{2}{*}{$\begin{array}{l}\text { - Procedimiento de gestión de residuos } \\
\text { - Estadísticas de volumen de residuos } \\
\text { - Estadística de volumen de residuos reusables } \\
\text { - Controlar disposición final de residuos pese a ser tercerizada }\end{array}$} \\
\hline Generación de residuos no peligrosos & $\begin{array}{l}\text { Volumen de Residuos No Peligrosos } \\
\text { dispuestos }\end{array}$ & & & \\
\hline \multirow{3}{*}{ Consumo de papel } & Charlas de Sensibilización & Número de charlas / Sem & 1 semestral & - Realización de 2 charlas de sensibilización al año de consumo \\
\hline & Volumen de papel dispuesto & \multirow[t]{2}{*}{ Tonelada / mes } & $100 \%$ & $\begin{array}{l}\text { - Estadística de volumen de papel dispuesto } \\
\text { - Controlar la disposición final del papel }\end{array}$ \\
\hline & Volumen de papel reusado & & $25 \%$ & - Estadística de volumen de papel reusado \\
\hline $\begin{array}{l}\text { Transporte para voluntariado, para traslado } \\
\text { de alumnos a otra sede (dictado de clases) } \\
\text { y movilización de personal universitario. }\end{array}$ & Revisión técnica de movilidades & $\begin{array}{c}\text { Revisión Técnica } \\
\text { aprobada / Semestre }\end{array}$ & $\begin{array}{l}\text { Buses con revisión } \\
\text { técnica aprobada }\end{array}$ & $\begin{array}{l}\text { - Cronograma de revisión técnica y mantenimiento de movilidad } \\
\text { - Registro de bitácoras de movilidades }\end{array}$ \\
\hline \multirow{3}{*}{ Generación de efluentes } & Nivel de acidez de efluentes & $\mathrm{PH}$ & $6-9$ & - Monitoreo de efluentes y estadísticas de niveles de PH \\
\hline & Temperatura de efluentes & $\mathrm{C}^{\circ}$ & $35 \mathrm{C}^{\circ}$ & - Monitoreo de efluentes y medición de temperatura \\
\hline & Charlas de Sensibilización & Número de charlas / año & 2 al año & - Realización de 2 charlas de sensibilización al año \\
\hline \multirow{4}{*}{ Consumo de agua } & Cierre inadecuado de griferías & Unidad / mes & $\begin{array}{c}0 \text { cierre } \\
\text { inadecuado }\end{array}$ & - Verificación diaria de cierre de griferías \\
\hline & Charlas de Sensibilización & Número de charlas / Sem & 1 semestral & - Realización de 2 charlas de sensibilización al año de consumo \\
\hline & Existencia de medidor & Presencia o no / Sem. & $\begin{array}{l}\text { Instalar medidor } \\
\text { por facultad }\end{array}$ & - Instalación de medidor por facultad y estadísticas \\
\hline & Fugas de agua & Unidad / Mensual & 0 fugas & - Estadística de fugas y verificación mensual de cañerías \\
\hline \multirow{4}{*}{ Consumo de energía eléctrica } & Consumo de electricidad & Kwh/mes & 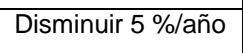 & - Instalación de medidores y llevar estadísticas de consumo. \\
\hline & $\begin{array}{l}\text { Espacios con interruptores encendidos } \\
\text { pese a fin de actividad. }\end{array}$ & Unidad / mes & Menor al $5 \%$ & - Verificación diaria del estado de apagado de luminarias. \\
\hline & Luminarias ahorradoras instaladas & Unidad / mes & $100 \%$ & - Instalación de luminarias ahorradoras y estadística de consumo \\
\hline & Charlas de Sensibilización & Número de charlas / Sem & 1 semestral & - Realización de 2 charlas de sensibilización al año de consumo \\
\hline $\begin{array}{l}\text { Potencial uso de líquidos desinfectantes no } \\
\text { autorizados y pesticidas }\end{array}$ & Desinfectante no autorizado & Unidad / Mensual & $\begin{array}{c}\text { No usar } \\
\text { desinfectante no } \\
\text { autorizado }\end{array}$ & $\begin{array}{l}\text { - Verificación de insumos utilizados por la empresa prestadora de } \\
\text { servicio (tercero). }\end{array}$ \\
\hline
\end{tabular}




\subsubsection{Soporte Institucional.}

\subsubsection{Recursos.}

La Universidad San Ignacio de Loyola, para la mejora de su gestión ambiental, a través de la implementación de la Guía de Gestión Ambiental, como instrumento de gestión de la Política de Gestión Ambiental, requiere recursos e insumos necesarios para el establecimiento, implementación, monitoreo y mejora progresiva de la misma.

A continuación, se detalla los requerimientos de la universidad para la formulación, implementación, monitoreo y mejora progresiva de la Guía de Gestión ambiental. Los requerimientos son los siguientes:

- Infraestructura: La Guía de Gestión Ambiental requiere de profesionales (Comité de Gestión Ambiental) quienes puedan implementarla. Estos profesionales necesitan ambientes adecuados amoblados para su instalación. Asimismo, el área de sostenibilidad de la universidad debe contar con una oficina debidamente amoblada, equipada y acondicionada; donde a su vez se puedan realizar las reuniones del Comité de Gestión Ambiental. En adición, el Consejo Estudiantil no cuenta con una sala de reuniones exclusiva para el desempeño de sus actividades. Los representantes del Consejo Estudiantil deben tramitar aulas para la realización de sus reuniones con el área de "Servicio al Alumno".

Actualmente, la unidad de Medio Ambiente, Seguridad, Salud y Responsabilidad Social cuenta con dos ambientes donde optimizan el espacio, sin ventilación. Se requiere un mayor metraje para el desempeño de los profesionales. Asimismo, a mayor espacio, mayor facilidad para trasladarse ante urgencia de sismo. Finalmente, es necesario contar con un ambiente para el almacenamiento y gestión de la documentación en materia ambiental.

- Recursos Humanos: Para la implementación de la Guía de Gestión Ambiental se requiere profesionales que integren el Comité de Gestión Ambiental, quienes a su vez son parte del Sistema de Gestión Ambiental de la universidad. Los profesionales precedentes (salvo el presidente del Consejo Estudiantil) son colaboradores de la Universidad. Finalmente, el Consejo Estudiantil, al ser una agrupación de estudiantes participan activamente como parte del Sistema de Gestión Ambiental. Los estudiantes de la universidad, pese a ser clientes, no solo se restringen a recibir un servicio educativo; sino que también participan de la gestión ambiental de la universidad. 
Por otro lado, el área de sostenibilidad deberá fortalecerse con las competencias (capacidad de organización, trabajo en equipo, conocimiento en temática ambiental, seguridad y salud ocupacional; liderazgo y planificación estratégica) de un profesional adicional, quien pueda colaborar con las actividades del área. El perfil del profesional estará a criterio del responsable del área.

Actualmente, la Unidad de Medio Ambiente, Seguridad, Salud y Responsabilidad Social, cuenta con 4 profesionales (Jefe de Unidad, Analista de Medio Ambiente, Monitorista de Seguridad y Médico Ocupacional); sin embargo, esta cantidad es insuficiente ante la gran demanda laboral que posee la unidad. Se sugiere la incorporación de un profesional que pueda coordinar las temáticas de Medio Ambiente, Seguridad y Salud Ocupacional. Este coordinador liderará a los tres profesionales de la Unidad y reportará al Jefe de la misma.

- Recursos económicos: Para la implementación de la Guía de Gestión Ambiental y las diversas acciones que contiene la misma, se requieren recursos económicos; los cuales deberán ser manejados por el área de sostenibilidad de la universidad. El área mencionada se encargará de la administración de los fondos y será responsable de su uso eficiente. La cantidad por entregar será la misma que la planificada en el Plan Operativo Ambiental universitario del año en curso. Asimismo, la entrega del presupuesto anual será progresiva, es decir, se entregará el dinero al área conforme se den los avances (la cuarta parte del total al inicio de cada trimestre). En caso de actualización del referido Plan, la unidad de presupuesto de la universidad debe evaluar la pertinencia de la ampliación del presupuesto programado para el año.

- Recursos tecnológicos: Para la implementación de la Guía de Gestión Ambiental y las diversas acciones que contiene la misma, se requieren recursos tecnológicos como computadoras. A futuro se espera que la universidad pueda adquirir equipos especializados para la medición (monitoreos) de sus impactos ambientales en aire, suelo y agua.

- Otros: El área de sostenibilidad deberá contar con mobiliario, equipos, útiles de oficina, entre otros. Asimismo, esta área deberá proveer de los mismos a los representantes del Consejo Estudiantil cuando tengan reuniones ordinarias. Para esto, el Consejo Estudiantil deberá coordinar y establecer una programación con el área en mención. 


\subsubsection{Comunicación.}

La implementación de la Guía de Gestión Ambiental debe ser debidamente comunicada (a nivel interno y externo) a la comunidad universitaria con la finalidad de informar avances, mantener su interés y sensibilizarlos en la temática ambiental.

El área de Sostenibilidad de la universidad es la encargada de administrar la comunicación interna y externa en materia ambiental, con el fin de lograr la óptima comprensión de información, que requiera ser transmitida; así como recibir, documentar y responder las comunicaciones pertinentes de las partes interesadas.

A nivel de comunicación interna, el área en mención debe informar sobre los avances en gestión ambiental de la universidad y decide la vía de comunicación (afiches, carteles, correos, intranet, comerciales, entre otros) más confortable y de mayor llegada a la comunidad universitaria. En este sentido, el área debe coordinar con el Consejo Estudiantil para el apoyo en difusión; y con el área de diseño para el arte en la comunicación.

Asimismo, el área legal de la universidad, a modo de comunicación interna, debe informar al área de sostenibilidad las modificaciones legales en relación con la temática ambiental. Esta información deberá ser aprovechada por el área de sostenibilidad, la cual debe estar siempre actualizada en la temática.

En torno a la comunicación externa, el área mencionada debe responder solicitudes siempre y cuando tenga autorización del área de comunicaciones institucionales. Asimismo, si llegase comunicación externa solicitando información confidencial como el diagnóstico ambiental, consumo de energía u otro; la universidad tendrá la potestad de decidir, si comunica o no externamente la información solicitada.

Independientemente si la comunicación es interna o externa; el área de sostenibilidad debe asegurarse si la información a brindar es actualizada y confiable. Para esta acción, se apoyará en la gestión adecuada de la información documentada; que, a su vez, también es responsabilidad de esta. (Anexo $\mathbf{N}^{\circ}$ 13: Propuesta de procedimiento Comunicacional)

En este contexto, el área mencionada deberá establecer, y actualizar cuando sea necesario, el procedimiento para la comunicación interna, entre los diversos niveles y funciones de la universidad. 


\subsubsection{Información documentada.}

El proceso de documentación tiene por finalidad ordenar y tener siempre a disposición los documentos relacionados a la implementación de la Guía de Gestión Ambiental que contribuye a la mejora de la gestión ambiental de la universidad. El área de sostenibilidad de la universidad es responsable de gestionar la información; específicamente de documentarla y archivarla en formato digital o físico según lo conveniente. Para el archivo y documentación de este último formato, debe contarse con un ambiente para su almacenamiento (recurso de infraestructura).

El área mencionada debe crear carpetas de información según la temática de gestión ambiental de la universidad. En este contexto, se propone la siguiente distribución anual de carpetas digitales o físicas, indicados en la Figura 25:

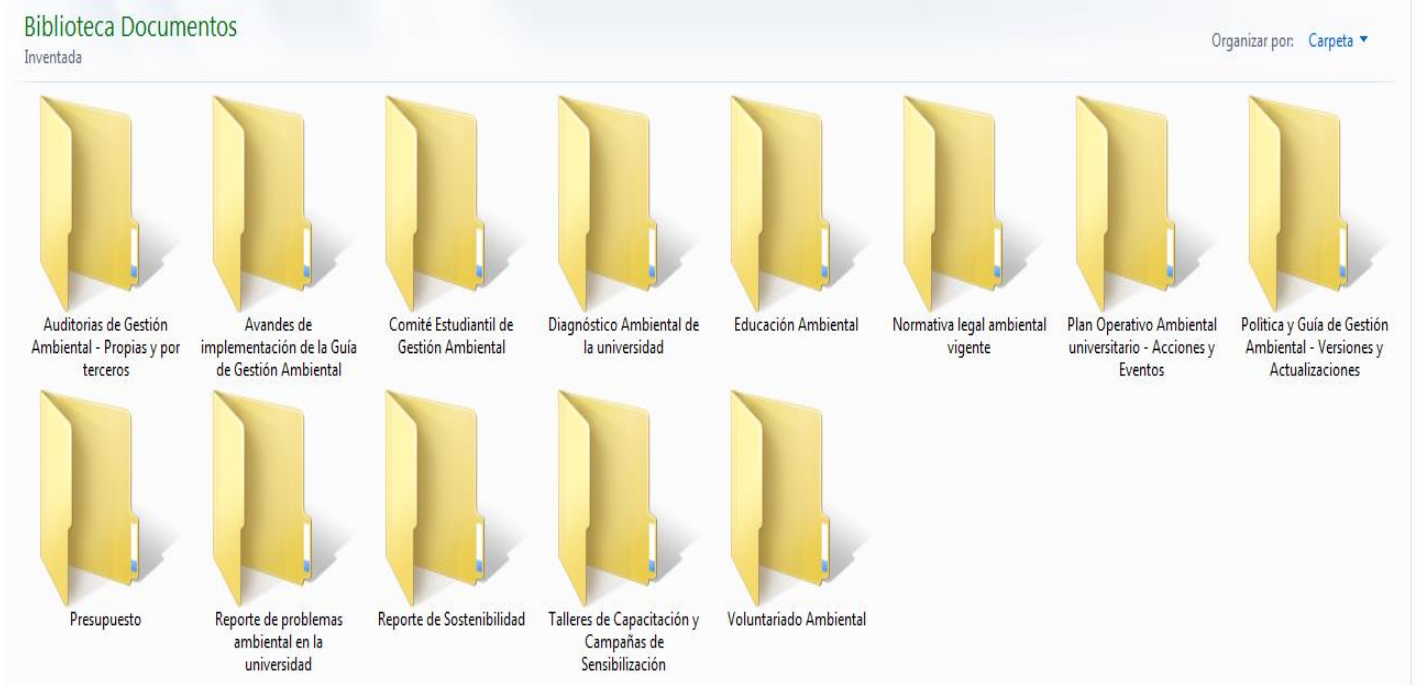

Figura 25: Distribución de Información Documentada - Formato digital. Fuente: Elaboración propia.

Por otro lado, el área de sostenibilidad de la universidad debe establecer las especificaciones para el formato de los documentos (tamaño, tipo de letra, interlineado, texto en imágenes, tipos de titulación según niveles, entre otros que determine el área). En adición, cada documento debe precisar fecha de revisión, autor, número de anexos y número de documento emitido por el autor.

Asimismo, el área mencionada debe establecer principios para la documentación de información. A continuación, se dejan a consideración los principios siguientes:

- La información documentada debe estar siempre disponible y ser adecuada para su utilización, en el momento y donde sea necesario.

- Debe estar siempre actualizada. 
- Debe estar protegida de forma adecuada; en formato virtual o en físico.

- Debe tener copia virtual obligatoria (escaneo).

- De estar escrita a mano, debe ser legible.

- La información documentada debe controlar todos los cambios (versiones).

- Debe ser accesible a la comunidad universitaria.

- Otros principios que dictamine el área de sostenibilidad.

\subsubsection{Evaluación de Desempeño}

La Universidad San Ignacio de Loyola, a través del área de sostenibilidad, debe realizar el seguimiento, medición, análisis y evaluación del desempeño ambiental de la organización. Por lo tanto, la organización debe determinar:

- Métodos de seguimiento, medición, análisis y evaluación de desempeño ambiental.

- Criterios para evaluar el desempeño ambiental e indicadores propuestos.

- Fecha para realizar el seguimiento y medición.

- Fecha para realizar el análisis y evaluación de resultados de seguimiento y medición.

- Establecer lineamientos para la calibración y verificación de equipos de medición.

Finalmente, se deberá comunicar de forma interna (comunidad universitaria) y externa (principales grupos de interés) información sobre el desempeño ambiental de la organización, según el procedimiento comunicacional de la organización y exigencias legales.

\subsubsection{Seguimiento, medición, análisis y evaluación.}

El área de sostenibilidad debe realizar el seguimiento, medición, análisis y evaluación de operaciones que puedan generar impacto significativo en el ambiente.

En este sentido, se ha desarrollado la Matriz de Monitoreo y Medición, la cual se presenta a continuación e incluye el aspecto ambiental significativo identificado en el diagnóstico ambiental de la universidad; el proceso y una breve descripción del mismo, indicador, meta, frecuencia, registros y calibración de instrumentos. 
Tabla 13: M.C.O USIL/2018 - MATRIZ DE MONITOREO Y MEDICIÓN DE ASPECTOS AMBIENTALES SIGNIFICATIVOS IDENTIFICADOS

\begin{tabular}{|c|c|c|c|c|c|c|c|c|c|}
\hline \multirow{2}{*}{$\begin{array}{l}\text { ASPECTO AMBIENTAL } \\
\text { SIGNIFICATIVO }\end{array}$} & \multirow{2}{*}{$\begin{array}{l}\text { CARACTERISTICA } \\
\text { CLAVE }\end{array}$} & \multirow{2}{*}{$\begin{array}{l}\text { INDICADOR } \\
\text { (UNIDAD) }\end{array}$} & \multirow{2}{*}{ META } & \multirow{2}{*}{ RESPONSABLE } & \multirow{2}{*}{ FRECUENCIA } & \multirow{2}{*}{ REGISTROS } & \multicolumn{3}{|c|}{ CALIBRACION DE EQUIPOS } \\
\hline & & & & & & & EQUIPOS & RESPONSABLE & FRECUENCIA \\
\hline $\begin{array}{c}\text { Generación de residuos } \\
\text { peligrosos }\end{array}$ & $\begin{array}{l}\text { Volumen de Residuos } \\
\text { Peligrosos dispuestos }\end{array}$ & \multirow{3}{*}{ Tonelada / mes } & \multirow{3}{*}{$100 \%$} & \multirow{3}{*}{$\begin{array}{l}\text { Responsable Área } \\
\text { Sostenibilidad }\end{array}$} & \multirow{3}{*}{ Mensual } & Manifiesto de Residuos & $\mathrm{N}$ & $\mathrm{N}$ & $\mathrm{N}$ \\
\hline \multirow{2}{*}{$\begin{array}{c}\text { Generación de residuos no } \\
\text { peligrosos }\end{array}$} & $\begin{array}{c}\text { Volumen de Residuos No } \\
\text { Peligrosos dispuestos }\end{array}$ & & & & & Peligrosos & $\mathrm{N}$ & $\mathrm{N}$ & $\mathrm{N}$ \\
\hline & $\begin{array}{l}\text { Volumen de Residuos } \\
\text { reciclables dispuestos }\end{array}$ & & & & & $\begin{array}{l}\text { Manifiesto de Residuos } \\
\text { reciclados }\end{array}$ & $\mathrm{N}$ & $\mathrm{N}$ & $\mathrm{N}$ \\
\hline \multirow{3}{*}{ Consumo de papel } & $\begin{array}{c}\text { Charlas de } \\
\text { Sensibilización }\end{array}$ & $\begin{array}{c}\text { Número de } \\
\text { charlas / Sem }\end{array}$ & 1 semestral & $\begin{array}{l}\text { Responsable Área } \\
\text { Sostenibilidad }\end{array}$ & Semestral & $\begin{array}{l}\text { Registro e informe de } \\
\text { charlas }\end{array}$ & $\mathrm{N}$ & $\mathrm{N}$ & $\mathrm{N}$ \\
\hline & $\begin{array}{c}\text { Volumen de papel } \\
\text { dispuesto }\end{array}$ & \multirow{2}{*}{ Tonelada / mes } & $100 \%$ & $\begin{array}{l}\text { Responsable Área } \\
\text { Sostenibilidad }\end{array}$ & Mensual & $\begin{array}{l}\text { Manifiesto de papel } \\
\text { dispuesto }\end{array}$ & $\mathrm{N}$ & $\mathrm{N}$ & $\mathrm{N}$ \\
\hline & $\begin{array}{l}\text { Volumen de papel } \\
\text { reusado }\end{array}$ & & $25 \%$ & $\begin{array}{l}\text { Responsable Área } \\
\text { Sostenibilidad }\end{array}$ & Mensual & $\begin{array}{l}\text { Manifiesto de papel } \\
\text { reciclado }\end{array}$ & $\mathrm{N}$ & $\mathrm{N}$ & $\mathrm{N}$ \\
\hline $\begin{array}{l}\text { ransporte para voluntariado, } \\
\text { para traslado de alumnos a } \\
\text { tra sede (dictado de clases) } \\
\text { y movilización de personal } \\
\text { universitario. }\end{array}$ & $\begin{array}{c}\text { Revisión técnica de } \\
\text { movilidad }\end{array}$ & $\begin{array}{c}\text { Revisión } \\
\text { Técnica } \\
\text { aprobada en el } \\
\text { semestre }\end{array}$ & $\begin{array}{l}\text { Buses con } \\
\text { revisión } \\
\text { técnica } \\
\text { aprobada }\end{array}$ & $\begin{array}{l}\text { Supervisor de } \\
\text { Servicios }\end{array}$ & Semestral & $\begin{array}{l}\text { Informe semestral de } \\
\text { bitácora y revisión } \\
\text { técnica }\end{array}$ & $\begin{array}{l}\text { Maquinas } \\
\text { mecánicas }\end{array}$ & Tercero & Semestral \\
\hline \multirow{3}{*}{ Generación de efluentes } & $\begin{array}{c}\text { Nivel de acidez de } \\
\text { efluentes }\end{array}$ & $\mathrm{PH}$ & $6-9$ & \multirow{2}{*}{ Jefe de Laboratorio } & Mensual & \multirow{2}{*}{$\begin{array}{l}\text { Informe de monitoreo de } \\
\text { efluentes }\end{array}$} & $\begin{array}{l}\text { Papel } \\
\text { Tornasol }\end{array}$ & Tercero & $\mathrm{N}$ \\
\hline & $\begin{array}{l}\text { Temperatura de } \\
\text { efluentes }\end{array}$ & $\mathrm{C}^{\circ}$ & $35 \mathrm{C}^{\circ}$ & & Mensual & & Termométro & Tercero & $\mathrm{N}$ \\
\hline & $\begin{array}{l}\text { Charlas de } \\
\text { Sensibilización }\end{array}$ & $\begin{array}{l}\text { Número de } \\
\text { charlas }\end{array}$ & 2 al año & $\begin{array}{l}\text { Gerente } \\
\text { Sostenibilidad y } \\
\text { RRSS }\end{array}$ & Semestral & $\begin{array}{l}\text { Registro e informe de } \\
\text { charlas }\end{array}$ & $\mathrm{N}$ & $\mathrm{N}$ & $\mathrm{N}$ \\
\hline Consumo de agua & Consumo de agua & $\mathrm{M}^{3} / \mathrm{mes}$ & $\begin{array}{l}\text { Disminuir en } \\
\text { un } 10 \%\end{array}$ & $\begin{array}{l}\text { Supervisor de } \\
\text { Servicios }\end{array}$ & Mensual & Factura del mes & $\mathrm{N}$ & $\mathrm{N}$ & $\mathrm{N}$ \\
\hline
\end{tabular}




\begin{tabular}{|c|c|c|c|c|c|c|c|c|c|}
\hline & $\begin{array}{l}\text { Cierre inadecuado de } \\
\text { griferías }\end{array}$ & Unidad / mes & $\begin{array}{c}0 \text { cierre } \\
\text { inadecuado }\end{array}$ & $\begin{array}{l}\text { Supervisor de } \\
\text { Servicios }\end{array}$ & Mensual & Informe de servicios & $\mathrm{N}$ & $\mathrm{N}$ & $\mathrm{N}$ \\
\hline & $\begin{array}{l}\text { Charlas de } \\
\text { Sensibilización }\end{array}$ & $\begin{array}{l}\text { Número de } \\
\text { charlas / mes }\end{array}$ & 2 al año & $\begin{array}{c}\text { Gerente } \\
\text { Sostenibilidad y } \\
\text { RRSS } \\
\end{array}$ & Mensual & $\begin{array}{l}\text { Registro e informe de } \\
\text { charlas }\end{array}$ & $\mathrm{N}$ & $\mathrm{N}$ & $\mathrm{N}$ \\
\hline & Existencia de medidor & Presencia o no & $\begin{array}{l}\text { Instalar } 1 \\
\text { medidor por } \\
\text { facultad }\end{array}$ & $\begin{array}{c}\text { Supervisor de } \\
\text { Servicios }\end{array}$ & Semestral & Informe de servicios & $\mathrm{N}$ & $\mathrm{N}$ & $\mathrm{N}$ \\
\hline & Fugas de agua & Unidad / mes & 0 fugas & $\begin{array}{l}\text { Supervisor de } \\
\text { Servicios }\end{array}$ & Mensual & Informe de servicios & $\mathrm{N}$ & $\mathrm{N}$ & $\mathrm{N}$ \\
\hline \multirow{4}{*}{$\begin{array}{c}\text { Consumo de energía } \\
\text { eléctrica }\end{array}$} & Consumo de electricidad & Kwh/mes & $\begin{array}{l}\text { Disminuir } 5 \\
\text { \%/año }\end{array}$ & $\begin{array}{l}\text { Supervisor de } \\
\text { Servicios }\end{array}$ & Mensual & Informe de servicios & $\mathrm{N}$ & $\mathrm{N}$ & $\mathrm{N}$ \\
\hline & $\begin{array}{c}\text { Espacios con } \\
\text { interruptores encendidos } \\
\text { pese a fin de actividad. }\end{array}$ & Unidad / mes & Menor al $5 \%$ & $\begin{array}{l}\text { Supervisor de } \\
\text { Servicios }\end{array}$ & Mensual & Informe de servicios & $\mathrm{N}$ & $\mathrm{N}$ & $\mathrm{N}$ \\
\hline & $\begin{array}{l}\text { Luminarias ahorradoras } \\
\text { instaladas }\end{array}$ & Unidad / mes & $100 \%$ & $\begin{array}{l}\text { Supervisor de } \\
\text { Servicios }\end{array}$ & Mensual & Informe de servicios & $\mathrm{N}$ & $\mathrm{N}$ & $\mathrm{N}$ \\
\hline & $\begin{array}{l}\text { Charlas de } \\
\text { Sensibilización }\end{array}$ & $\begin{array}{l}\text { Número de } \\
\text { charlas / Sem }\end{array}$ & 1 semestral & $\begin{array}{l}\text { Gerente } \\
\text { Sostenibilidad y } \\
\text { RRSS }\end{array}$ & Semestral & $\begin{array}{l}\text { Registro e informe de } \\
\text { charlas }\end{array}$ & $\mathrm{N}$ & $\mathrm{N}$ & $\mathrm{N}$ \\
\hline \multirow{2}{*}{$\begin{array}{l}\text { Potencial uso de líquidos } \\
\text { desinfectantes no } \\
\text { autorizados y pesticidas }\end{array}$} & $\begin{array}{c}\text { Cantidad de pesticidas } \\
\text { utilizados }\end{array}$ & Unidad / mes & $\begin{array}{c}\text { No usar } \\
\text { desinfectante } \\
\text { no autorizado }\end{array}$ & $\begin{array}{l}\text { Supervisor de } \\
\text { Servicios }\end{array}$ & Mensual & \multirow{2}{*}{ Informe de servicios } & $\mathrm{N}$ & $\mathrm{N}$ & $\mathrm{N}$ \\
\hline & $\begin{array}{c}\text { Cantidad de } \\
\text { desinfectantes utilizados }\end{array}$ & Unidad / mes & $\begin{array}{c}\text { No usar } \\
\text { desinfectante } \\
\text { no autorizado }\end{array}$ & $\begin{array}{l}\text { Supervisor de } \\
\text { Servicios }\end{array}$ & Mensual & & $\mathrm{N}$ & $\mathrm{N}$ & $\mathrm{N}$ \\
\hline
\end{tabular}

\section{N: Ninguno.}




\subsubsection{Auditoria interna.}

Las actividades realizadas en el marco del Sistema de Gestión Ambiental de la universidad, Guía de Gestión Ambiental o Política Integrada; debe ser ejecutadas correctamente de acuerdo a lo planificado en el Plan Operativo Ambiental Universitario aprobado por el Comité de Gestión Ambiental USIL.

El área de Sostenibilidad de la universidad, debe elaborar un Programa Anual de Auditorías Internas, basado en el Manual de Procedimientos para la realización de Auditorías Internas (Anexo № 14: Manual de procedimientos para auditoría interna), en donde se definen áreas y procesos que serán auditados. Asimismo, contendrá las fechas preliminares en las cuales se realizarán las auditorias.

El Programa Anual de Auditorías Internas permitirá establecer los lineamientos generales para realizar los procesos de auditoria interna del Sistema de Gestión Ambiental de la universidad, con la finalidad de determinar si este es conforme con las actividades planificadas en el Plan Operativo Ambiental Universitario, con los requisitos legales; y para comprobar si se ha implementado de manera eficaz.

Las auditorías a realizarse pueden ser internas o externas. Es recomendable realizar dos auditorías anuales. La primera auditoría deberá realizarse a nivel interno; mientras que la segunda deberá ser realizada por un auditor externo. En este sentido, el área de sostenibilidad debe proponer auditores certificados por el Sistema ISO; los mismos que deberán auditar mediante entrevistas, observación directa y revisión técnica de registros. 


\subsection{Educación Ambiental Universitaria USIL.}

La educación ambiental en la universidad deberá ser a futuro un pilar institucional como lo es hoy el día la responsabilidad social. La educación ambiental que debe impartir USIL es aquella que relaciona a la comunidad universitaria con su entorno (ambiente) y busca generar un cambio de actitud y conciencia sobre la importancia de proteger los recursos para nuestro presente y futuro.

La adopción de este cambio actitudinal y de conciencia depende de la educación y enseñanza recibida en la niñez, educación inicial y primaria. Por esta razón, corresponde a la pedagogía y a la escuela desempeñar un papel fundamental en este proceso.

La universidad recibe al alumno y debe seguir formándolo para generar un cambio de actitud, acción difícil; pero he ahí el reto. Este cambio de actitud que busca generar la universidad en el alumno, se integra al pensamiento en el cual la universidad busca crear profesionales social y ambientalmente responsables. Es precisamente aquí donde la universidad forma alumnos en beneficio de la sociedad.

En su definición sobre Educación Ambiental, las Naciones Unidas nos indica que ésta tiene como objetivos la formación de los individuos para conocer y reconocer las interacciones entre lo natural y lo social en su entorno; y el actuar en ese entorno.

La aplicación de la educación ambiental no consiste, en una mera aplicación de ajustes y complementos a los programas tradicionales de la educación; se trata más bien, de convocar a nuevos enfoques, nuevos contenidos y métodos, haciendo más flexibles las tradicionales estructuras de los sistemas educativos.

En este sentido, las instituciones educativas de sociedades modernas, no solo tienen el deber de incorporar estrategias para conseguir ciudadanos ambientalmente educados; además tienen la responsabilidad de predicar con el ejemplo, desarrollando actuaciones modélicas que incorporen en sus estructuras organizativas nuevos modelos de gestión y nuevas formas de aprovechamiento alternativo de los recursos. (Gutiérrez, 2004).

Existe un crecimiento en el acceso a educación superior por parte de los jóvenes. Esto convierte a las universidades en lugares privilegiados para la construcción de modelos sociales y económicos sostenibles (Gutiérrez y González, 2005).

El Libro Blanco de Educación Ambiental de España (1999), iniciativa que busca el desarrollo de principios, objetivos e instrumentos de gestión ambiental; así como el 
análisis y promoción de acciones a favor del medio ambiente en el contexto del ciudadano, entre ellos el contexto universitario; plantea que para lograr la "ambientalización" de la universidad se establecen tres grandes escenarios:

1) Adición de cursos ligados al medio ambiente en la malla curricular. Esto consiste en la incorporación del componente ambiental en la etapa de formación del alumno, independientemente si este es de pre o postgrado.

2) Gestión Ambiental. Consiste en planificar el accionar ambiental de la universidad, haciéndose responsable de los impactos que esta genera; considerando la participación activa de la comunidad universitaria.

3) Educación y participación ambiental. Consiste en formar y fomentar entre la comunidad universitaria la conciencia ambiental.

Por lo expuesto, se sugiere integrar como asignatura obligatoria el curso de Fundamentos de Desarrollo Sostenible; actual curso electivo de la Mención de Sostenibilidad y Responsabilidad Social, con la finalidad de educar ambientalmente a la comunidad universitaria y formar profesionales capaces de respetar y contribuir social y ambientalmente a la sociedad. Adicionalmente, deben organizarse "Talleres de Educación Ambiental" dirigidos a alumnos con el fin de darles a conocer las acciones en materia ambiental que realiza la universidad, el Sistema de Gestión Ambiental, la Política de Gestión Ambiental y la Guía de Gestión Ambiental USIL.

Por otro lado, es importante que profesores y personal administrativo también sean capacitados, con la finalidad que todos los stakeholders internos conozcan y estén informados sobre el Sistema de Gestión Ambiental y el accionar ambiental de la organización, de forma tal que fortalezcan la cultura organizacional. Otro camino para el fortalecimiento de la cultura ambiental es el voluntariado ambiental, el cual es una de iniciativa innovadora para promover la participación activa de la comunidad universitaria en el cuidado del medio ambiente (Cárdenas, 2014).

La implementación de la Guía de Gestión Ambiental USIL, instrumento de la Política de Gestión Ambiental de la universidad, contribuirá a mejorar el desempeño ambiental de la universidad. En este marco, buscará brindar educación ambiental de calidad al alumnado, con la finalidad de forjar una cultura ambiental entre la comunidad universitaria. Esta cultura ambiental reflejará el buen accionar de USIL, la educación que reciben sus alumnos y la calidad profesional de los mismos. 


\subsubsection{Educación Ambiental en la currícula universitaria USIL.}

Con la finalidad de fortalecer el Sistema de Gestión Ambiental, se propone adicionar una asignatura obligatoria que logre brindar conocimientos en materia ambiental y responsabilidad social a los alumnos en los primeros ciclos; así como, logre concientizar al alumnado. En esta asignatura se expondrá la temática de Desarrollo Sostenible, Gestión Ambiental y Responsabilidad Social.

La importancia de adicionar esta asignatura en la currícula de las carreras universitarias es fortalecer la actitud de los estudiantes hacia el cuidado y respeto al medio ambiente, proporcionarle conocimiento en materia ambiental y responsabilidad social; e influir positivamente en su formación profesional.

En este sentido, la universidad debe comprometerse a realizar los esfuerzos necesarios para la adición del curso "Fundamentos de Desarrollo Sostenible", el cual a la fecha es un curso electivo perteneciente a la Mención de Responsabilidad Social.

Se ha identificado que el mencionado curso será capaz de brindar a los estudiantes fundamentos sustanciales del desarrollo sostenible y responsabilidad social; en este sentido, el alumno podrá identificar factores sociales, económicos y ambientales, integrarlos y lograr la sostenibilidad a largo plazo en beneficio de la sociedad.

El curso en mención es teórico-aplicativo dado que permite a los alumnos conocer diferentes conceptualizaciones, relacionadas al Desarrollo Humano y a la Sostenibilidad. Esto, con la finalidad que puedan adquirir competencias que les permitan plantear soluciones innovadoras a los problemas que originan las actividades empresariales caracterizadas por la creación de riqueza de una manera no sostenible. Para ello, planificará la gestión eficaz y eficiente de actividades con un fuerte componente de criterio social y cuidado ambiental.

Este curso contará con 4 ejes temáticos o unidades de enseñanza. Como primera unidad se encuentra la "Gestión Ambiental Sostenible", donde el alumno será capaz de definir el concepto de desarrollo humano desde una perspectiva global; explicar el concepto de sostenibilidad referida a las acciones de las organizaciones con o sin fines de lucro; $y$, analizar situaciones de la vida diaria en las que la actividad humana atenta contra la sostenibilidad ambiental.

Como segunda unidad se impartirán conocimientos relacionados a "Instrumentos de Gestión Ambiental", donde el alumno aprenderá los instrumentos de gestión ambiental vigentes y aplicables a la norma peruana. Asimismo, será informado sobre 
los instrumentos de gestión ambiental que se vienen implementando en la universidad, tales como la Guía de Gestión Ambiental. Finalmente, el alumno estará informado del acontecer ambiental y de las acciones que implementa la universidad en materia ambiental.

La tercera unidad considera el tema "Empresa y ambiente", donde el alumno será capaz de conocer conceptos básicos de gestión empresarial o fundamentos de la administración; externalidades originadas por las empresas; y la relación bidireccional entre la empresa y el medio ambiente (entorno). Finalmente, identificará oportunidades de negocio en el contexto global siendo ambientalmente responsable. En esta unidad, se abordará la temática de responsabilidad social empresarial y valor compartido, concepto fundamental para el profesional USIL.

Como última unidad, se encuentra la temática denominada "Ambiente y comunidad", donde los alumnos aprenderán a reconocer el origen de los conflictos sociales, identificar actores involucrados y proponer alternativas de solución. 
Tabla 14

Estructura del curso "Fundamentos del Desarrollo Sostenible".

\begin{tabular}{|c|c|c|c|c|c|}
\hline \multicolumn{6}{|c|}{ FUNDAMENTOS DE DESARROLLO SOSTENIBLE } \\
\hline Ses & Sem & (hrs) & Tipo & Contenido & $\begin{array}{c}\text { Logro Esperado y Actividades de } \\
\text { Aprendizaje Recursos }\end{array}$ \\
\hline \multicolumn{6}{|c|}{ UNIDAD N 1: LA GESTIÓN AMBIENTAL SOSTENIBLE } \\
\hline 1 & 1 & 2.0 & AP & Introducción al Curso & $\begin{array}{l}\text { 1. Reconoce conceptos básicos relacionados } \\
\text { al manejo ambiental. } \\
\text { 2. Identifica la importancia de la gestión social } \\
\text { y ambiental. }\end{array}$ \\
\hline 2 & 1 & 2.0 & AP & $\begin{array}{l}\text { Problemas Sociales y } \\
\text { Ambientales del } \\
\text { siglo XXI. }\end{array}$ & $\begin{array}{l}\text { 1. Identifica problemas sociales y } \\
\text { ambientales actuales. } \\
\text { 2. Comprende los procesos de cambio y } \\
\text { transformación a nivel social y ambiental. } \\
\text { 3. Reconoce la necesidad de desarrollar } \\
\text { estrategias de manejo socio-ambiental de } \\
\text { cada emprendimiento. }\end{array}$ \\
\hline 3 & 2 & 2.0 & AP & $\begin{array}{l}\text { Problemas Sociales y } \\
\text { Ambientales del } \\
\text { siglo XXI. }\end{array}$ & $\begin{array}{l}\text { 1. Explica origen de problemas sociales y } \\
\text { ambientales actuales. } \\
\text { 2. Reconoce el efecto de problemas sociales } \\
\text { y ambientales en la sociedad actual y retos } \\
\text { futuros. } \\
\text { 3. Conoce el concepto de cambio climático y } \\
\text { lo reconoce como problema a solucionar. }\end{array}$ \\
\hline 4 & 2 & 2.0 & AP & Conservación y Desarrollo & $\begin{array}{l}\text { 1. Relaciona conservación y desarrollo. } \\
\text { 2. Identifica la necesidad de implementar } \\
\text { estrategias de manejo ambiental en el uso } \\
\text { de recursos naturales para garantizar la } \\
\text { sostenibilidad. }\end{array}$ \\
\hline 5 & 3 & 2.0 & AP & Desarrollo Sostenible & $\begin{array}{l}\text { 1. Entiende el concepto de Desarrollo } \\
\text { Sostenible y reconoce su aplicación } \\
\text { 2. Reconoce la importancia de la } \\
\text { multidisciplinariedad en la resolución de } \\
\text { problemas }\end{array}$ \\
\hline 6 & 4 & 2.0 & AP & $\begin{array}{l}\text { Políticas ambientales en el } \\
\text { contexto internacional }\end{array}$ & $\begin{array}{l}\text { 1. Conoce las tendencias en política } \\
\text { ambiental a nivel internacional. } \\
\text { 2. Identifica y analiza los diferentes acuerdos } \\
\text { mundiales }\end{array}$ \\
\hline 7 & 5 & 2.0 & AP & $\begin{array}{l}\text { Políticas ambientales en el } \\
\text { contexto nacional }\end{array}$ & $\begin{array}{l}\text { 1. Identifica y reconoce la política ambiental } \\
\text { peruana. } \\
\text { 2. Entiende su aplicación en distintos niveles } \\
\text { de acción: nacional, regional y local }\end{array}$ \\
\hline 8 & 5 & 2.0 & AP & Gestión Ambiental en el Perú & $\begin{array}{l}\text { 1. Identifica la importancia de la } \\
\text { implementación de instrumentos de } \\
\text { gestión ambiental. } \\
\text { 2. Reconoce la necesidad de establecer } \\
\text { Políticas Ambientales }\end{array}$ \\
\hline \multicolumn{6}{|c|}{ UNIDAD Nº 2: INSTRUMENTOS DE GESTIÓN AMBIENTAL } \\
\hline 9 & 6 & 2.0 & AP & $\begin{array}{l}\text { Instrumentos de Gestión } \\
\text { Ambiental }\end{array}$ & $\begin{array}{l}\text { 1. Identifica los diferentes instrumentos de } \\
\text { gestión ambiental en la normativa nacional. } \\
\text { 2. Reconoce su aplicabilidad y utilidad } \\
\text { durante el ciclo de vida de los proyectos. } \\
\text { 3. Conoce los instrumentos de gestión } \\
\text { ambiental y su correcta implementación en } \\
\text { la universidad. }\end{array}$ \\
\hline
\end{tabular}




\begin{tabular}{|c|c|c|c|c|c|}
\hline 10 & 7 & 2.0 & AP & $\begin{array}{l}\text { Instrumentos de Gestión } \\
\text { Ambiental }\end{array}$ & $\begin{array}{l}\text { 1. Evalúa y reconoce el accionar ambiental } \\
\text { de la universidad } \\
\text { 2. Identifica y evalúa la importancia de la } \\
\text { implementación de un sistema de gestión } \\
\text { ambiental en la empresa y universidad. } \\
\text { 3. Reconoce los pasos metodológicos para } \\
\text { su implementación, seguimiento y mejora. }\end{array}$ \\
\hline \multicolumn{6}{|c|}{ UNIDAD N 3: EMPRESA Y AMBIENTE } \\
\hline 11 & 8 & 2.0 & AP & Bonos Verdes - Proyectos MDL & $\begin{array}{l}\text { 1. Entiende las características que deben } \\
\text { cumplir los proyectos para ser elegidos } \\
\text { dentro del marco MDL. } \\
\text { 2. Identifica los beneficios del MDL para } \\
\text { desarrollar el proyecto. } \\
\text { 3. Analiza el avance de los MDL en Perú. }\end{array}$ \\
\hline 12 & 8 & 2.0 & AP & $\begin{array}{l}\text { La Huella ecológica, la huella de } \\
\text { carbono y la huella hídrica. }\end{array}$ & $\begin{array}{l}\text { 1. Identifica los conceptos de los } 3 \text { tipos de } \\
\text { huella y reconoce su importancia en el } \\
\text { contexto mundial. } \\
\text { 2. Calculo práctico de la huella ecológica } \\
\text { personal }\end{array}$ \\
\hline 13 & 9 & 2.0 & AP & Producción Más Limpia & $\begin{array}{l}\text { 1. Conoce técnicas de producción más } \\
\text { limpia. } \\
\text { 2. Entiende los beneficios que genera la } \\
\text { Producción más limpia. }\end{array}$ \\
\hline 14 & 9 & 2.0 & AP & Manejo de residuos & $\begin{array}{l}\text { 1. Analiza las etapas de la gestión integral de } \\
\text { residuos. } \\
\text { 2. Reconoce los procesos para el manejo de } \\
\text { residuos peligrosos y hospitalarios. } \\
\text { 3. Evalúa el valor económico del manejo de } \\
\text { residuos como proceso. }\end{array}$ \\
\hline 15 & 10 & 2.0 & AP & $\begin{array}{l}\text { Responsabilidad Social y } \\
\text { Ambiental Corporativa }\end{array}$ & $\begin{array}{l}\text { 1. Conoce el concepto de Responsabilidad } \\
\text { Social y Ambiental Corporativa; y valor } \\
\text { compartido. } \\
\text { 2. Conoce estrategias de responsabilidad } \\
\text { social. } \\
\text { 3. Desarrolla su capacidad de análisis } \\
\end{array}$ \\
\hline 16 & 10 & 2.0 & AP & ISO 14000 e ISO 26000 & $\begin{array}{l}\text { 1. Reconoce la importancia de la } \\
\text { implementación de sistemas de gestión. } \\
\text { 2. Conoce la normativa internacional en } \\
\text { materia ambiental y responsabilidad social }\end{array}$ \\
\hline 17 & 11 & 2.0 & AP & $\begin{array}{l}\text { Cadenas Productivas- } \\
\text { Biocomercio- Comercio Justo }\end{array}$ & $\begin{array}{l}\text { 1. Identifica los principios esenciales del } \\
\text { Biocomercio y aquellos que defiende el } \\
\text { comercio justo. } \\
\text { 2. Desarrolla un análisis de procesos } \\
\text { productivos e identifica los aspectos } \\
\text { ambientales significativos. }\end{array}$ \\
\hline \multicolumn{6}{|c|}{ UNIDAD N 4: AMBIENTE Y COMUNIDAD. } \\
\hline 18 & 12 & 2.0 & AP & Educación Ambiental & $\begin{array}{l}\text { 1. Conoce el concepto de Educación } \\
\text { Ambiental y reconoce su importancia. } \\
\text { 2. Identifica mecanismos y estrategias para la } \\
\text { implementación de cultura y educación } \\
\text { ambiental en organizaciones. }\end{array}$ \\
\hline 19 & 12 & 2.0 & AP & Planeamiento estratégico & $\begin{array}{l}\text { 1. Identifica el concepto y los beneficios del } \\
\text { planeamiento estratégico: visión, misión, } \\
\text { política corporativa y valores. } \\
\text { 2. Analiza las etapas del proceso. }\end{array}$ \\
\hline 20 & 13 & 2.0 & AP & Conflictos Sociales y Ambientales & $\begin{array}{l}\text { 1. Reconoce las etapas de conflictos } \\
\text { 2. Diferencia tipos de actores en un conflicto. } \\
\text { 3. Identifica estrategias para la resolución de } \\
\text { conflictos }\end{array}$ \\
\hline
\end{tabular}




\subsubsection{Capacitación de integrantes del SGA USIL.}

Los integrantes del Sistema de Gestión Ambiental de la universidad deben ser capacitados en gestión ambiental. Esta capacitación, presencial o virtual, permitirá a la comunidad universitaria recibir educación en materia ambiental ligada a la organización en la que se desempeña.

La capacitación en materia ambiental que brindará la universidad busca cumplir los objetivos/compromisos ambientales establecidos en la Política Integrada de la universidad, mediante la implementación de la Guía de Gestión Ambiental bajo el contexto del Sistema de Gestión Ambiental.

La capacitación que brindará la universidad deberá constar de tres niveles de formación para la comunidad universitaria, en los cuales se reflejará el grado de formación ambiental de la organización. A continuación, se presenta una propuesta de diferenciación de capacitación por niveles:

El primer nivel será una formación introductoria a la gestión ambiental de la universidad. Esta capacitación se hará en formato presencial vía "Talleres de Educación Ambiental" dirigido a los alumnos; mientras que los profesores y personal administrativo contarán con cursos virtuales evaluados. La finalidad de este primer nivel es concientizar a la comunidad universitaria sobre la importancia de reducir impactos ambientales y cuidar nuestro entorno.

El segundo nivel, corresponde a la capacitación dirigida a trabajadores que realicen actividades donde puedan generar aspectos e impactos significativos. Los trabajadores que serán capacitados en este segundo nivel serán identificados con la elaboración del diagnóstico ambiental de la universidad. La capacitación especializada a estos trabajadores estará a cargo del área de sostenibilidad de la universidad.

El tercer nivel es la capacitación que recibirán los integrantes del Comité de Gestión Ambiental y colaboradores del Área de Sostenibilidad de la universidad. Se considera importante la capacitación de ambos grupos debido a que poseen la responsabilidad de mantener operativo el Sistema de Gestión Ambiental a través de sus instrumentos de gestión. 


\subsubsection{Lineamientos para capacitación de alumnos.}

El "Taller de Educación Ambiental" reforzará lo aprendido por los alumnos en el curso de Fundamentos de Desarrollo Sostenible, curso obligatorio en la nueva currícula universitaria de todas las carreras que imparte la universidad. La mencionada capacitación obedece a los lineamientos siguientes:

a) Todos los alumnos de la universidad están obligados a recibir y aprobar el "Taller de Educación ambiental" al menos una vez en su vida académica.

b) En caso no reciba o no apruebe el Taller mencionado, no podrá graduarse (requisito de bachiller).

c) Los Talleres de Educación Ambiental se brindarán dos semanas antes de la realización de los exámenes finales de cada ciclo.

d) Se llevarán a cabo 10 Talleres en las 02 semanas previas a los exámenes finales; un Taller por día (lunes a viernes) en el horario y lugar designado por el área de sostenibilidad.

e) Podrán ser capacitados un máximo de 50 alumnos por Taller.

f) El Área de Sostenibilidad es la responsable del diseño y organización del Taller de Educación Ambiental.

g) El capacitador de los Talleres será el Gerente de Sostenibilidad y RRSS (o quien designe el mismo) de la universidad, y contará con el apoyo y soporte del Consejo Estudiantil de Gestión Ambiental.

h) La duración del Taller será un máximo de dos horas académicas, sin intermedios.

i) La metodología que se utilizará serán exposiciones, las cuales serán enviadas a los correos de los alumnos, de acuerdo con el registro de asistencia, al finalizar el Taller.

j) El contenido académico del Taller debe dividirse en dos bloques. El primero de ellos sobre el entorno ambiental actual en el Perú y el mundo; mientras que el segundo, sobre la Gestión Ambiental USIL.

k) Los bloques mencionados deben tener un esquema temático. En el caso del primer bloque deberá exponerse sobre cambio climático, empresas social y 
ambientalmente responsables, Política Nacional del Medio Ambiente y experiencias exitosas.

I) Los bloques mencionados deben tener un esquema temático. En el caso del segundo bloque deberá exponerse sobre la educación ambiental en la universidad, Comité de Gestión Ambiental, Sistema de Gestión Ambiental, Guía de Gestión Ambiental, logros ambientales organizacionales y Política Integrada USIL.

m) Al finalizar el Taller, los alumnos asistentes serán evaluados vía examen virtual en un plazo menor de 5 días laborables. El examen virtual mencionado será elaborado por el área de sostenibilidad; y aprobado por el Comité de Gestión Ambiental.

n) En caso el alumno desapruebe la evaluación, podrá registrarse nuevamente en el Taller del siguiente ciclo.

Podrá adicionarse cualquier lineamiento dictaminado por el Comité de Gestión Ambiental.

\subsubsection{Lineamientos para capacitación de profesores y personal administrativo.}

Es importante que el personal administrativo conozca las acciones realizadas por la universidad en materia de gestión ambiental, dado que son el primer contacto informativo/comunicacional con los estudiantes nuevos. Asimismo, los profesores son los formadores y deben conocer las acciones ambientales que se dan en la universidad con la finalidad de facilitar la información.

Profesores y personal administrativo, al iniciar sus contratos y actividades, reciben charlas de inducción para conocer los diferentes procesos y gestión de la organización. En este sentido, deberá incluirse una breve exposición del Sistema de Gestión Ambiental, Política de Gestión Ambiental y la Guía de Gestión Ambiental USIL; dado que serán los instrumentos que normarán su comportamiento ambiental en la organización.

Tanto el personal administrativo como los profesores deberán ser capacitados en materia de gestión ambiental; motivo por el cual se establecen los lineamientos siguientes: 
a) Profesores y personal administrativo, serán capacitados obligatoriamente de forma virtual dos veces al año. La primera capacitación se dará en el mes de junio; mientras que la segunda en el mes de diciembre.

b) La elaboración de la capacitación virtual, incluyendo la evaluación, estará a cargo del Área de Sostenibilidad de la universidad. Cada capacitación tendrá una duración de media hora; sin contar el tiempo de la evaluación.

c) La capacitación virtual incluirá videos explicativos del Gerente de Sostenibilidad y RRSS sobre la educación ambiental en la universidad, Comité de Gestión Ambiental, Sistema de Gestión Ambiental, Guía de Gestión Ambiental, Política de Gestión Ambiental USIL, entre otros.

d) La capacitación virtual podrá darse en la plataforma más conveniente para el área de sostenibilidad.

e) La capacitación virtual se desarrollará en horario de trabajo y en el lugar asignado al trabajador. De no tener una maquina asignada, podrá realizarlo desde el lugar que le convenga.

f) La capacitación virtual tendrá una evaluación obligatoria. De no aprobarse la evaluación, el usuario tendrá la posibilidad de realizar más intentos.

\subsubsection{Voluntariado y Servicio Social Ambiental.}

«El voluntariado crea fortaleza, resistencia y solidaridad comunitaria, así como de cohesión social, y puede propiciar cambios sociales positivos promoviendo el respeto por la diversidad, la igualdad y la participación. El voluntariado se cuenta entre los activos más importantes de una sociedad». (Ban Ki-moon, 2015).

En efecto, el voluntariado es la acción desarrollada por libre albedrio, no remunerada, y que busca generar un impacto o cambio positivo en las personas y sociedad. Por otro lado, el servicio social se diferencia del voluntariado dado que es una acción obligatoria que complementa la etapa formativa - académica del alumnado.

El voluntariado ambiental viene configurándose como una iniciativa potente e innovadora para la generación de sensibilidad ambiental y promoción de la participación de la comunidad universitaria en la solución de problemas ambientales (Cárdenas, 2014). 
En este sentido, la universidad deberá seguir promoviendo el voluntariado ambiental desde la Vicepresidencia de Responsabilidad Social, como lo viene haciendo actualmente.

En este sentido, a través del voluntariado, la universidad logra que su alumnado obtenga los siguientes beneficios:

a) Conversión en un agente del cambio, dado que buscarás crear impactos positivos en grupos vulnerables y sociedad en general.

b) Compartir experiencias con profesionales de diversas áreas.

c) Poner en práctica la capacidad de comunicar ideas.

d) Resolver problemas en favor de la sociedad.

e) Cambio de actitud y concientización.

La universidad - a través de la Vicepresidencia de Responsabilidad Social - debe continuar afianzando alianzas con diversas instituciones con la finalidad que su alumnado puede ejercer el voluntariado. Asimismo, la Vicepresidencia es la encargada de gestionar el voluntariado de la universidad; por lo que el alumnado deberá alinearse a las políticas ya establecidas; así como a sus modificaciones.

Finalmente, ser voluntario USIL es una experiencia única que te forma como ser humano, mejora tu perfil profesional y te permite aportar al desarrollo del país. Desde el año 2012, es requisito obligatorio para los alumnos USIL participar en actividades de responsabilidad social (Reglamento de Estudios de la USIL). 


\section{ENCUESTA - ESCALA LIKERT.}

La escala de Likert es una escala de medición utilizada por investigadores con la finalidad de evaluar y conocer opiniones y actitudes de un individuo. Asimismo, sirve para efectuar mediciones y conocer el grado de conformidad o de acuerdo del individuo hacia algo determinado.

Este método afirma que la fuerza e intensidad de la opinión o experiencia es lineal; motivo por el cual tiene como límites el "Totalmente desacuerdo" y el "Totalmente de acuerdo". Estos niveles pueden variar en sus escalas.

Para efectos de la presente investigación, se utilizarán 5 escalas (Totalmente de acuerdo; De acuerdo; $\mathrm{Ni}$ acuerdo ni desacuerdo; Desacuerdo; Totalmente Desacuerdo). A continuación, se presentan las fases para el desarrollo y aplicación de encuestas usando la escala Likert:

\section{Fase I: Formulación de la problemática:}

Para la aplicación de encuestas usando la escala Likert, definir el problema es la fase más importante. Esta fase consiste en la formulación del problema; es decir, establecer el objeto de estudio en un marco de espacio y tiempo determinado.

\section{Fase II: Selección de autoridades o expertos:}

Esta fase presenta dos dimensiones complementarias:

- Dimensión cualitativa: Selección en función a criterios alineados al objeto de estudio. Estos criterios pueden ser: Experiencia, conocimiento en el tema, responsabilidades en la organización, acceso a la información y disponibilidad.

- Dimensión cuantitativa: Elección del número de autoridades o expertos en función a los recursos económicos y de tiempo disponible.

Asimismo, una vez conformado el panel de expertos, el ejecutor de la encuesta debe proporcionar al panel la información siguiente:

- Objetivo del estudio a realizarse.

- Criterios por los cuales han sido seleccionados.

- Cronograma y tiempo estimado de duración.

- Resultados esperados y usos potenciales.

- Recompensa prevista. 


\section{Fase III: Elaboración y lanzamiento de encuestas:}

Las encuestas deben ser elaboradas lo más entendibles posible y deberán facilitar la respuesta de los encuestados. Las respuestas serán cuantificadas y ponderadas.

\section{Fase IV: Explotación de resultados:}

Una vez efectuada la encuesta, el ejecutor deberá analizarlas y sacar conclusiones.

\subsection{Definición de la problemática.}

¿Qué tan de acuerdo están las autoridades y expertos en materia ambiental de la Universidad San Ignacio de Loyola en relación al diseño e implementación de la propuesta de Guía de Gestión Ambiental, instrumento que contribuirá al cumplimiento de los compromisos ambientales establecidos en la Política Integrada de la universidad?

\subsection{Selección de Expertos.}

La USIL, en su Reporte de Sostenibilidad del año 2015, muestra su organigrama académico, según como consta en la figura siguiente:

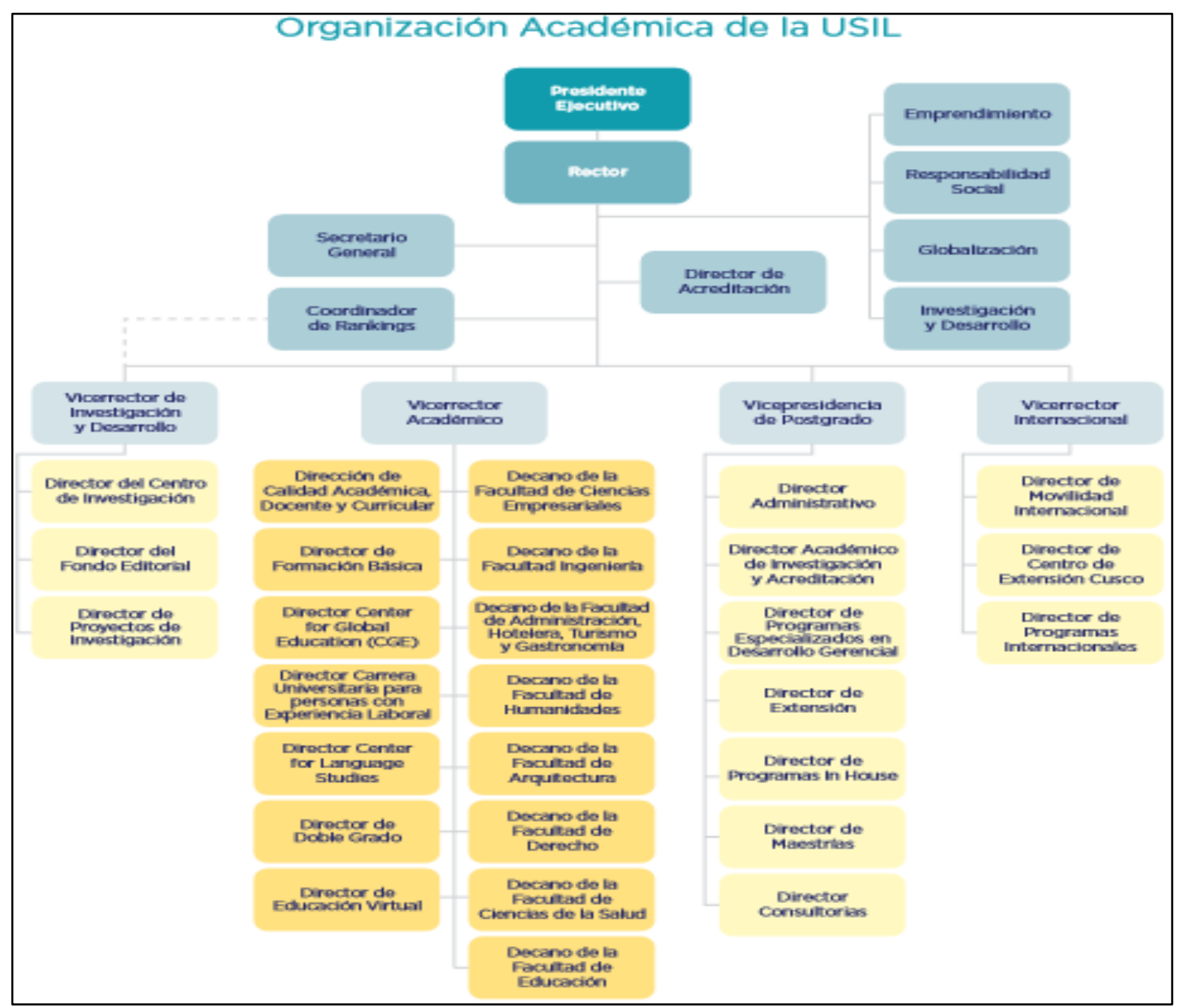

Figura 26: Organigrama académico USIL. Fuente: Reporte de Sostenibilidad USIL, 2015. 
En base a este organigrama, se establecieron criterios para la selección del panel de expertos y tomadores de decisión. A continuación, se procede a detallar la pertinencia de cada uno de los criterios:

- Relación con la temática ambiental USIL: Se considera este criterio dado que el experto o autoridad debe conocer directamente las acciones ambientales ejecutadas por la universidad. Esto permite la mejor toma de decisión posible, dado que tiene pleno conocimiento del estado situacional actual de la gestión ambiental universitaria; y reconocerá si la guía representa un mecanismo de mejora a la gestión ambiental y contribuye al cumplimiento de los compromisos ambientales establecidos en la Política Integrada de la universidad.

- Toma de decisiones en materia ambiental: Se ha considerado este criterio dado que el experto o autoridad debe tener poder decisión. Sin embargo, este nivel de decisión tiene que estar directamente relacionado con el conocimiento de la situación actual de la gestión ambiental en la universidad. Este criterio permite que el experto sea un profesional que pueda avalar un instrumento de gestión ambiental capaz de mejorar el accionar ambiental de la organización.

- Acceso a la información ambiental USIL: El experto seleccionado debe, adicionalmente a los demás criterios, tener acceso a la información ambiental de la universidad. Se valora más si el experto ha contribuido en la construcción de la información precitada. Este criterio permite que el experto pueda evaluar las estrategias propuestas en la guía en relación con la realidad de la organización.

- Disponibilidad y predisposición: Este criterio es más operativo y va relacionado directamente con la aplicación de las encuestas. Dado los altos cargos en la organización y la recarga laboral, se busca acceder a expertos y autoridades con disponibilidad y predisposición de colaborar con la presente investigación.

Para esta selección de expertos, se ha procedido al diseño de una tabla donde se analiza el accionar y perfil de los profesionales de la universidad, en relación con los criterios establecidos. Por otro lado, se otorga un puntaje por cada criterio de la forma siguiente:

- Cero o 1 punto: Nivel bajo con relación al criterio.

- 3 puntos: Nivel medio con relación al criterio.

- 5 puntos: Nivel alto con relación al criterio. 
El umbral para la selección de autoridades o expertos en materia ambiental de la universidad deberá ser mayor o igual a 16 puntos. Se estableció este puntaje como umbral de selección, dado que se buscó que los encuestados tengan un nivel alto de relación con la temática ambiental de la universidad; tomen decisiones en materia ambiental; tengan acceso completo a la información ambiental de la universidad; y cuenten con disponibilidad y predisposición para revisar y analizar una propuesta de Guía de Gestión Ambiental (instrumento) para la universidad.

En este sentido, se seleccionó a los profesionales que cuenten con un nivel alto en dos criterios (sin incluir disponibilidad) y mínimamente un criterio a nivel medio (sin incluir disponibilidad). Asimismo, se valoró que contasen con un mínimo de disponibilidad para revisar la propuesta de Guía de Gestión Ambiental USIL.

Cabe precisar que la tabla completa de análisis se encuentra en el Anexo $\mathbf{N}^{\circ} \mathbf{1 5}$ : Criterios para la selección del panel de expertos. En este sentido, se presentan los resultados de la selección de expertos, aplicando los criterios mencionados, en la siguiente tabla resumen.

\section{Tabla 15}

Criterios para selección de Panel de Expertos.

\begin{tabular}{|c|c|c|c|c|c|c|}
\hline \multirow[b]{2}{*}{ CARGO USIL } & \multicolumn{6}{|c|}{ Criterios para selección de Panel de Expertos } \\
\hline & $\begin{array}{c}\text { Relación con } \\
\text { la temática } \\
\text { ambiental } \\
\text { USIL }\end{array}$ & $\begin{array}{c}\text { Toma de } \\
\text { decisiones } \\
\text { en materia } \\
\text { ambiental }\end{array}$ & $\begin{array}{c}\text { Acceso a la } \\
\text { información } \\
\text { ambiental } \\
\text { USIL }\end{array}$ & $\begin{array}{l}\text { Disponibilidad } \\
\text { y } \\
\text { predisposición }\end{array}$ & Total & $\begin{array}{l}\text { Integra } \\
\text { Panel }\end{array}$ \\
\hline Rector & 5 & 5 & 5 & 1 & 16 & Si \\
\hline $\begin{array}{l}\text { Vicepresidencia } \\
\text { Responsabilidad } \\
\text { Social }\end{array}$ & 5 & 5 & 5 & 3 & 18 & Si \\
\hline $\begin{array}{l}\text { Vicerrectorado de } \\
\text { Investigación y } \\
\text { Desarrollo }\end{array}$ & 5 & 3 & 5 & 3 & 16 & $\mathrm{Si}$ \\
\hline $\begin{array}{l}\text { Director Carrera de } \\
\text { Gestión Ambiental }\end{array}$ & 5 & 3 & 5 & 3 & 16 & Si \\
\hline $\begin{array}{l}\text { Coordinador } \\
\text { Académico de la } \\
\text { Carrera de Gestión } \\
\text { Ambiental }\end{array}$ & 5 & 3 & 5 & 3 & 16 & Si \\
\hline $\begin{array}{l}\text { Director Carrera de } \\
\text { Ingeniería Ambiental }\end{array}$ & 5 & 3 & 5 & 3 & 16 & Si \\
\hline $\begin{array}{l}\text { Coordinador } \\
\text { Académico Carrera de } \\
\text { Ingeniería Ambiental }\end{array}$ & 5 & 3 & 5 & 3 & 16 & Si \\
\hline $\begin{array}{l}\text { Director Carrera de } \\
\text { Ingeniería del Agua }\end{array}$ & 5 & 3 & 5 & 3 & 16 & Si \\
\hline $\begin{array}{l}\text { Coordinador } \\
\text { Académico Carrera de } \\
\text { Ingeniería del Agua }\end{array}$ & 5 & 3 & 5 & 3 & 16 & Si \\
\hline
\end{tabular}

Fuente: Elaboración propia. 
Es preciso mencionar que, por razones estrictamente de la universidad; algunos cargos son ocupados por el mismo profesional. En este sentido, se describe a continuación la duplicidad de cargo a nivel de cargo oficial y encargos.

- Rector de la Universidad San Ignacio de Loyola: Ramiro Salas Bravo.

- Vicepresidencia Responsabilidad Social: Miu Huang Li.

- Vicerrectorado de Investigación y Desarrollo: Ana María Muñoz Jauregui.

- Director Carrera de Gestión Ambiental: Carlos Mejía Bejarano (e).

- Coordinador Académico Carrera de Gestión Ambiental: Lenny García Naranjo

- Director Carrera de Ingeniería Ambiental: Johanna Poggi Dávila.

- Coordinador Académico Carrera de Ingeniería Ambiental: July Zegarra.

- Director Carrera de Ingeniería del Agua: Johanna Poggi Dávila (e).

- Coordinador Académico Carrera de Ingeniería del Agua: Luis Santillán.

Son nueve cargos los que integran el panel de expertos y autoridades del presente estudio. Sin embargo, existen dos posiciones encargadas por un mismo profesional, motivo por el panel de expertos y autoridades en materia ambiental abarca 08 autoridades o expertos.

En este sentido, en el marco de la aplicación de encuestas usando la escala de medición Likert, se comunicó, vía correo electrónico o presencial, a cada uno de los integrantes del Panel propuesto, sobre su disponibilidad de acceder a una breve entrevista donde se le explique el contexto de la presente investigación, así como el análisis a la Guía de Gestión Ambiental que deberían realizar y el llenado de la encuesta. A continuación, se presenta el resumen de la comunicación con cada uno de los integrantes del panel:

- Rector de la Universidad San Ignacio de Loyola: Ramiro Salas Bravo.

Se realizaron intentos telefónicos con la finalidad de acceder a una entrevista; sin embargo, dado el cargo y a su recargada agenda, no pudo ser parte del panel de profesionales que realizaron en llenado de la encuesta. Asimismo, sugirió que la Vicepresidenta de Responsabilidad Social, podría colaborar con la presente investigación. Anexo N 16: Correo electrónico - Secretaria del Rector. 
- Vicepresidencia Responsabilidad Social: Miu Huang Li.

La Vicepresidenta accedió muy amablemente con el llenado de la encuesta (Anexo N 17: Encuesta Vicepresidenta Responsabilidad Social); así como con el llenado de la Carta de Consentimiento (Anexo $\mathbf{N}^{\circ}$ 18: Carta de Consentimiento Vicepresidenta Responsabilidad Social).

- Vicerrectorado de Investigación y Desarrollo: Ana María Muñoz Jauregui. La Vicerrectora accedió muy amablemente a contribuir con el llenado de la encuesta (Anexo N 19: Encuesta Vicerrectora de Investigación y Desarrollo).

- Director de la Carrera de Gestión Ambiental: Carlos Mejía Bejarano (e) Con fecha 17 de mayo 2018, el cargo de Decano de la Facultad de Ciencias Empresariales; así como la Dirección de la carrera de Gestión Ambiental, recaía sobre el señor Javier Alva García. En este sentido, en la fecha precitada y en el marco de la presente investigación, se sostuvo una entrevista con el señor Javier Alva. En la precitada reunión se explicó el desarrollo de la investigación, el diseño de la propuesta de Guía de Gestión Ambiental; el llenado de la carta de consentimiento informado; así como la aplicación de la encuesta.

El señor Javier Alva se mostró interesado en la presente investigación y muy amablemente se comprometió con el análisis de la Guía de Gestión Ambiental; es por este motivo que con fecha 17 de mayo 2018, suscribe la Carta de Consentimiento (Anexo $\mathbf{N}^{\circ}$ 20: Carta de Consentimiento del Decano Facultad de Ciencias Empresariales y Director de la Carrera de Gestión Ambiental hasta el 17 de mayo 2018).

Sin embargo, en el mes de junio 2018, por razones laborales, el señor Carlos Mejía Bejarano, Vicerrector Académico, asume el cargo de Decano interino de la Facultad de Ciencias Empresariales; y, por ende, la Dirección de la carrera de Gestión Ambiental. Finalmente, mediante la secretaria del Vicerrector Académico, se buscó sostener una reunión con la finalidad de exponer los alcances de la Guía de Gestión Ambiental, así como la aplicación de la encuesta. Por razones de agenda y cargo, el Vicerrector sugirió que el Coordinador de la carrera de Gestión Ambiental, podría colaborar con la presente investigación. (Anexo $\mathbf{N}^{\circ}$ 21: Correo electrónico - Secretaria del Vicerrector Académico / Decano de la Facultad de Ciencias Empresariales / Director de la carrera de Gestión Ambiental). 
- Coordinador Académico Carrera de Gestión Ambiental: Lenny García Naranjo El coordinador en mención accedió muy amablemente a contribuir con el llenado de la encuesta (Anexo $\mathbf{N}^{\circ}$ 22: Encuesta Coordinador Académico Carrera de Gestión Ambiental); así como con el llenado de la Carta de Consentimiento (Anexo $\mathbf{N}^{\circ}$ 23: Carta de Consentimiento Coordinador Académico Carrera de Gestión Ambiental).

- Director Carrera de Ingeniería Ambiental e Ingeniería del Agua: Johanna Poggi Dávila.

El 17 de mayo 2018, el Tesista y la Directora de la carrera de Ingeniería Ambiental y encargada de la Dirección de la carrea de Ingeniería del Agua, sostuvieron una breve reunión donde se le explicó el marco de la presente investigación. La Directora, muy amablemente, brindó sugerencias y comentarios al contenido de la investigación; sin embargo, por la carga laboral asignada a su persona, no pudo analizar la Guía de Gestión Ambiental y por ende no efectuó la encuesta.

El 05 de julio 2018, el Tesista, como segundo intento, escribe un correo electrónico solicitando la participación de la Directora. Este correo no obtuvo respuesta. (Anexo $\mathrm{N}^{\circ}$ 24: Correo electrónico del Tesista a Directora de la carrera de Ingeniería Ambiental y encargada de la Dirección de la carrea de Ingeniería del Agua).

- Coordinador Académico Carrera de Ingeniería Ambiental: July Zegarra. La coordinadora en mención accedió muy amablemente a contribuir con el llenado de la encuesta (Anexo N²5: Encuesta Coordinadora Académico Carrera de Ingeniería Ambiental); así como con el llenado de la Carta de Consentimiento (Anexo N 26: Carta de Consentimiento Coordinadora Académico Carrera de Ingeniería Ambiental).

- Coordinador Académico Carrera de Ingeniería del Agua: Luis Santillán.

El coordinador en mención accedió muy amablemente a contribuir con el llenado de la encuesta (Anexo $\mathbf{N}^{\circ}$ 27: Encuesta Coordinador Académico Carrera de Ingeniería del Agua); así como con el llenado de la Carta de Consentimiento (Anexo No 28: Carta de Consentimiento Coordinador Académico Carrera de Ingeniería del Agua). 


\subsection{Encuesta Likert.}

\section{Encuesta \\ “Guía de Gestión Ambiental USIL”}

La presente encuesta se realiza en el marco del Proyecto de Tesis "Guía de Gestión Ambiental para la Universidad San Ignacio de Loyola". Como requisito indispensable para iniciar la encuesta, el Encuestador debe entregar, en formato físico, la "Guía de Gestión Ambiental USIL" al Encuestado, para su análisis y revisión. El plazo máximo para el llenado de la Encuesta es de 7 días calendarios.

Nombre del Encuestado:

Cargo del Encuestado:

Fecha de la encuesta:

Siendo 1: Totalmente desacuerdo; Siendo 2: Desacuerdo; Siendo 3: Ni acuerdo ni en desacuerdo; Siendo 4: De acuerdo; y, Siendo 5: Totalmente de acuerdo

\begin{tabular}{|c|c|c|c|c|c|}
\hline & \multicolumn{5}{|c|}{$\begin{array}{l}\text { Grado de } \\
\text { acuerdo }\end{array}$} \\
\hline \multicolumn{6}{|c|}{$\begin{array}{l}\text { 1. Por favor, indique su grado de acuerdo con las siguientes premisas sobre los beneficios de la } \\
\text { implementación de la Guía de Gestión Ambiental USIL presentada. }\end{array}$} \\
\hline $\begin{array}{l}\text { a. Es una herramienta para la toma de decisiones en la planificación ambiental de } \\
\text { la universidad. }\end{array}$ & 1 & 2 & 3 & 4 & 5 \\
\hline $\begin{array}{l}\text { b. Fomenta la integración de la comunidad universitaria para mejorar el } \\
\text { desempeño ambiental de la universidad. }\end{array}$ & 1 & 2 & 3 & 4 & 5 \\
\hline $\begin{array}{l}\text { c. Marca el inicio para la implementación de un Sistema de Gestión Ambiental en } \\
\text { la universidad. }\end{array}$ & 1 & 2 & 3 & 4 & 5 \\
\hline $\begin{array}{l}\text { d. Permite conocer los aspectos e impactos ambientales que posee la universidad } \\
\text { a causa de sus acciones, decisiones u omisiones. }\end{array}$ & 1 & 2 & 3 & 4 & 5 \\
\hline $\begin{array}{l}\text { e. La correcta implementación de la Guía contribuirá a la mejora del desempeño } \\
\text { ambiental de la universidad. }\end{array}$ & 1 & 2 & 3 & 4 & 5 \\
\hline \multicolumn{6}{|c|}{$\begin{array}{l}\text { 2. Por favor, indique su grado de acuerdo con las siguientes premisas sobre la gestión ambiental actual } \\
\text { en la universidad. }\end{array}$} \\
\hline $\begin{array}{l}\text { f. La comunidad universitaria conoce los aspectos e impactos ambientales en los } \\
\text { que incurre la universidad }\end{array}$ & 1 & 2 & 3 & 4 & 5 \\
\hline g. La universidad se percibe ante la sociedad como una universidad sostenible. & 1 & 2 & 3 & 4 & 5 \\
\hline \multicolumn{6}{|c|}{$\begin{array}{l}\text { 3. Por favor, indique su grado de acuerdo con las siguientes premisas sobre la participación actual del } \\
\text { alumnado y tomadores de decisión en el accionar ambiental de la universidad. }\end{array}$} \\
\hline $\begin{array}{l}\text { h. Los tomadores de decisión conocen las iniciativas ambientales que viene } \\
\text { desarrollando la universidad. }\end{array}$ & 1 & 2 & 3 & 4 & 5 \\
\hline $\begin{array}{l}\text { i. El alumnado conoce las iniciativas ambientales que viene desarrollando la } \\
\text { universidad. }\end{array}$ & 1 & 2 & 3 & 4 & 5 \\
\hline $\begin{array}{l}\text { j. El alumnado participa en la toma de decisiones en materia ambiental de la } \\
\text { universidad. }\end{array}$ & 1 & 2 & 3 & 4 & 5 \\
\hline \multicolumn{6}{|c|}{$\begin{array}{l}\text { 4. Por favor, indique su grado de acuerdo con las siguientes premisas sobre el capítulo "Propuesta de } \\
\text { Sistema de Gestión Ambiental" de la Guía. }\end{array}$} \\
\hline k. Es viable la implementación de la Propuesta de Sistema de Gestión Ambiental & 1 & 2 & 3 & 4 & 5 \\
\hline $\begin{array}{l}\text { I. El capítulo precitado propone estrategias y acciones que deberían } \\
\text { implementarse con fines de mejorar el desempeño ambiental de la universidad. }\end{array}$ & 1 & 2 & 3 & 4 & 5 \\
\hline \multicolumn{6}{|c|}{$\begin{array}{l}\text { 5. Por favor, indique su grado de acuerdo con las siguientes premisas sobre el capítulo "Educación } \\
\text { Ambiental" de la Guía. }\end{array}$} \\
\hline $\begin{array}{l}\text { m. Debe impartirse un curso ambiental obligatorio dentro de la malla curricular de } \\
\text { todas las carreras universitarias. }\end{array}$ & 1 & 2 & 3 & 4 & 5 \\
\hline n. Debe capacitarse a alumnos y personal administrativo en materia ambiental. & 1 & 2 & 3 & 4 & 5 \\
\hline \multicolumn{6}{|c|}{$\begin{array}{l}\text { 6. Por favor, indique su grado de acuerdo con las siguientes premisas sobre la implementación de la } \\
\text { "Guía de Gestión Ambiental USIL" }\end{array}$} \\
\hline $\begin{array}{l}\text { o. Contribuye al cumplimiento de los compromisos establecidos en la Política } \\
\text { Integral de la universidad. }\end{array}$ & 1 & 2 & 3 & 4 & 5 \\
\hline $\begin{array}{l}\text { p. La creación del Comité Estudiantil Ambiental, conforme lo estipula la Guía, } \\
\text { contribuirá a mejorar la planificación ambiental universitaria. }\end{array}$ & 1 & 2 & 3 & 4 & 5 \\
\hline q. Debe implementarse a futuro la Guía de Gestión Ambiental USIL & 1 & 2 & 3 & 4 & 5 \\
\hline
\end{tabular}

Figura 27: Encuesta “Guía de Gestión Ambiental USI”. Fuente: Elaboración propia.

En el Anexo $\mathbf{N}^{\circ} \mathbf{0 7}$ se relacionan las categorías de análisis con las premisas establecidas. 


\section{RESULTADOS.}

\subsection{Presentación de Resultados.}

En el marco de la tabulación de encuestas, se utilizaron las siglas siguientes:

- TD: Totalmente Desacuerdo.

- D: Desacuerdo.

- NA / ND: Ni acuerdo ni desacuerdo.

- DA: De acuerdo.

- TDA: Totalmente de acuerdo.

Habiéndose desarrollado las encuestas, usando la escala de medición Likert, se obtuvieron los resultados siguientes, los mismos que constan en Anexo $\mathbf{N}^{\circ}$ 29: Resultados de la aplicación de Encuesta.

- Categoría de análisis: Beneficios de la implementación de la Guía de Gestión Ambiental USIL.

\section{Tabla 16}

Tabla resumen de resultados - Categoría de análisis.

\begin{tabular}{|c|c|c|c|c|c|c|}
\hline 1 & $\begin{array}{l}\text { Categoría de análisis: Beneficios de la } \\
\text { implementación de la Guía de Gestión Ambiental } \\
\text { USIL. }\end{array}$ & TD & D & NA/ND & DA & TDA \\
\hline a & $\begin{array}{l}\text { Es una herramienta para la toma de decisiones en la } \\
\text { planificación ambiental de la universidad. }\end{array}$ & $0 \%$ & $0 \%$ & $20 \%$ & $0 \%$ & $80 \%$ \\
\hline b & $\begin{array}{l}\text { Fomenta la integración de la comunidad universitaria } \\
\text { para mejorar el desempeño ambiental de la } \\
\text { universidad. }\end{array}$ & $0 \%$ & $0 \%$ & $0 \%$ & $100 \%$ & $0 \%$ \\
\hline C & $\begin{array}{l}\text { Marca el inicio para la implementación de un Sistema } \\
\text { de Gestión Ambiental en la universidad. }\end{array}$ & $0 \%$ & $20 \%$ & $20 \%$ & $20 \%$ & $40 \%$ \\
\hline$d$ & $\begin{array}{l}\text { Permite conocer los aspectos e impactos ambientales } \\
\text { que posee la universidad a causa de sus acciones, } \\
\text { decisiones u omisiones. }\end{array}$ & $0 \%$ & $0 \%$ & $20 \%$ & $20 \%$ & $60 \%$ \\
\hline e & $\begin{array}{l}\text { La correcta implementación de la Guía contribuirá a la } \\
\text { mejora del desempeño ambiental de la universidad. }\end{array}$ & $0 \%$ & $0 \%$ & $20 \%$ & $0 \%$ & $80 \%$ \\
\hline
\end{tabular}

\section{Resultados:}

1. El $80 \%$ de los encuestados se mostró totalmente de acuerdo con que la "Guía de Gestión Ambiental para la Universidad San Ignacio de Loyola" (Guía) es una herramienta para la toma de decisiones en la planificación ambiental de la universidad. El 20\% restante, ni acuerdo ni desacuerdo. 
2. El $100 \%$ de los encuestados se mostró totalmente de acuerdo con que la Guía fomenta la integración de la comunidad universitaria para mejorar el desempeño ambiental de la universidad.

3. El $60 \%$ de los encuestados se mostró de acuerdo y totalmente de acuerdo con que la implementación de la Guía marca el inicio de la implementación de un Sistema de Gestión Ambiental en la universidad. Un 20\% ni acuerdo ni desacuerdo; y el $20 \%$ restante se muestra en desacuerdo.

4. El $80 \%$ de los encuestados se mostró de acuerdo y totalmente de acuerdo con que la Guía permite conocer los aspectos e impactos ambientales que posee la universidad a causa de sus acciones, decisiones u omisiones. El $20 \%$ restante, ni acuerdo ni desacuerdo.

5. El $80 \%$ de los encuestados se mostró totalmente de acuerdo con que la correcta implementación de la Guía contribuirá a la mejora del desempeño ambiental de la universidad. El 20\% restante, ni acuerdo ni desacuerdo.

- Categoría de análisis: Gestión ambiental actual USIL.

Tabla 17

Tabla resumen de resultados - Categoría de análisis.

\begin{tabular}{|c|l|c|c|c|c|c|}
\hline 2 & Categoría de análisis: Gestión ambiental actual USIL & TD & D & NA/ND & DA & TDA \\
\hline f & $\begin{array}{l}\text { La comunidad universitaria conoce los aspectos e } \\
\text { impactos ambientales en los que incurre la universidad }\end{array}$ & $0 \%$ & $80 \%$ & $20 \%$ & $0 \%$ & $0 \%$ \\
\hline g & $\begin{array}{l}\text { La universidad se percibe ante la sociedad como una } \\
\text { universidad sostenible }\end{array}$ & $0 \%$ & $0 \%$ & $40 \%$ & $60 \%$ & $0 \%$ \\
\hline
\end{tabular}

\section{Resultados:}

6. El $80 \%$ de los encuestados se mostró desacuerdo con el siguiente enunciado "La comunidad universitaria conoce los aspectos e impactos ambientales en los que incurre la universidad". El $20 \%$ restante, ni acuerdo ni desacuerdo.

7. El $60 \%$ de los encuestados se mostró de acuerdo con que la universidad se percibe ante la sociedad como una universidad sostenible. El $40 \%$ restante, ni acuerdo ni desacuerdo. 
- Categoría de análisis: Participación de partes interesadas.

Tabla 18

Tabla resumen de resultados - Categoría de análisis.

\begin{tabular}{|c|l|c|c|c|c|c|}
\hline 3 & $\begin{array}{l}\text { Categoría de análisis: Participación de partes } \\
\text { interesadas. }\end{array}$ & TD & D & NA/ND & DA & TDA \\
\hline $\mathrm{h}$ & $\begin{array}{l}\text { Los tomadores de decisión conocen las iniciativas } \\
\text { ambientales que viene desarrollando la universidad }\end{array}$ & $0 \%$ & $0 \%$ & $20 \%$ & $60 \%$ & $20 \%$ \\
\hline $\mathrm{i}$ & $\begin{array}{l}\text { El alumnado conoce las iniciativas ambientales que } \\
\text { viene desarrollando la universidad. }\end{array}$ & $0 \%$ & $20 \%$ & $40 \%$ & $40 \%$ & $0 \%$ \\
\hline $\mathrm{j}$ & $\begin{array}{l}\text { El alumnado participa en la toma de decisiones en } \\
\text { materia ambiental de la universidad. }\end{array}$ & $0 \%$ & $40 \%$ & $40 \%$ & $20 \%$ & $0 \%$ \\
\hline
\end{tabular}

\section{Resultados:}

8. El $80 \%$ de los encuestados consideran que los tomadores de decisión conocen las iniciativas ambientales que viene desarrollando la universidad. El $20 \%$ restante, ni acuerdo ni desacuerdo.

9. El $40 \%$ de los encuestados se mostró de acuerdo con el siguiente enunciado: "El alumnado conoce las iniciativas ambientales que viene desarrollando la universidad"; mientras que el $20 \%$ se mostró en desacuerdo con el enunciado. El 40\% restante, ni acuerdo ni desacuerdo.

10. El $40 \%$ de los encuestados se mostró desacuerdo con el siguiente enunciado: "El alumnado participa en la toma de decisiones en materia ambiental de la universidad". El 40\% ni acuerdo ni desacuerdo; mientras que el 20\% restante está de acuerdo con el enunciado.

- Categoría de análisis: Propuesta de Sistema de Gestión Ambiental.

Tabla 19

Tabla resumen de resultados - Categoría de análisis.

\begin{tabular}{|c|l|c|c|c|c|c|}
\hline 4 & $\begin{array}{l}\text { Categoría de análisis: Propuesta de Sistema de } \\
\text { Gestión Ambiental }\end{array}$ & TD & D & NA/ND & DA & TDA \\
\hline k & $\begin{array}{l}\text { Es viable la implementación de la Propuesta de } \\
\text { Sistema de Gestión Ambiental }\end{array}$ & $0 \%$ & $0 \%$ & $40 \%$ & $40 \%$ & $20 \%$ \\
\hline & $\begin{array}{l}\text { El capítulo precitado propone estrategias y acciones } \\
\text { que deberían implementarse con fines de mejorar el } \\
\text { desempeño ambiental de la universidad }\end{array}$ & $0 \%$ & $0 \%$ & $20 \%$ & $40 \%$ & $40 \%$ \\
\hline
\end{tabular}




\section{Resultados:}

11. El $60 \%$ de los encuestados considera viable la implementación de la Propuesta de Sistema de Gestión Ambiental. El 40\% restante, ni acuerdo ni desacuerdo.

12. El $80 \%$ de los encuestados se mostró de acuerdo y totalmente de acuerdo con que el capítulo Propuesta de Sistema de Gestión Ambiental propone estrategias y acciones que deberían implementarse con fines de mejorar el desempeño ambiental de la universidad. El 20\% restante, ni acuerdo ni desacuerdo.

- Categoría de análisis: Educación Ambiental.

Tabla 20

Tabla resumen de resultados - Categoría de análisis.

\begin{tabular}{|c|l|c|c|c|c|c|}
\hline $\mathbf{5}$ & Categoría de análisis: Educación Ambiental & TD & D & NA/ND & DA & TDA \\
\hline $\mathrm{m}$ & $\begin{array}{l}\text { Debe impartirse un curso ambiental obligatorio dentro } \\
\text { de la malla curricular de todas las carreras } \\
\text { universitarias }\end{array}$ & $0 \%$ & $0 \%$ & $20 \%$ & $60 \%$ & $20 \%$ \\
\hline $\mathrm{n}$ & $\begin{array}{l}\text { Debe capacitarse a alumnos y personal administrativo } \\
\text { en materia ambiental }\end{array}$ & $0 \%$ & $0 \%$ & $0 \%$ & $60 \%$ & $40 \%$ \\
\hline
\end{tabular}

\section{Resultados:}

13. El $80 \%$ de los encuestados considera que debe impartirse un curso ambiental obligatorio dentro de la malla curricular de todas las carreras universitarias. El $20 \%$ restante, ni acuerdo ni desacuerdo.

14. El $100 \%$ de los encuestados se mostraron de acuerdo y totalmente de acuerdo con el enunciado siguiente: "Debe capacitarse a alumnos y personal administrativo en materia ambiental". 


\section{- Categoría de análisis: Educación Ambiental.}

Tabla 21

Tabla resumen de resultados - Categoría de análisis.

\begin{tabular}{|c|l|c|c|c|c|c|}
\hline 6 & $\begin{array}{l}\text { Categoría de análisis: Implementación de la } \\
\text { propuesta de Guía de Gestión Ambiental USIL. }\end{array}$ & TD & D NA/ND & DA & TDA \\
\hline o & $\begin{array}{l}\text { Contribuye al cumplimiento de los compromisos } \\
\text { establecidos en la Política Integral de la universidad. }\end{array}$ & $0 \%$ & $0 \%$ & $20 \%$ & $20 \%$ & $60 \%$ \\
\hline p & $\begin{array}{l}\text { La creación del Comité Estudiantil Ambiental, } \\
\text { conforme lo estipula la Guía, contribuirá a mejorar la } \\
\text { planificación ambiental universitaria }\end{array}$ & $0 \%$ & $0 \%$ & $0 \%$ & $60 \%$ & $40 \%$ \\
\hline q & $\begin{array}{l}\text { Debe implementarse a futuro la Guía de Gestión } \\
\text { Ambiental USIL }\end{array}$ & $0 \%$ & $0 \%$ & $20 \%$ & $40 \%$ & $40 \%$ \\
\hline
\end{tabular}

\section{Resultados:}

15. El $80 \%$ de los encuestados se mostraron de acuerdo y totalmente de acuerdo con el enunciado siguiente: "La implementación de la Guía contribuirá al cumplimiento de los compromisos ambientales establecidos en la Política Integrada de la universidad". El 20\% restante, ni acuerdo ni desacuerdo.

16. El $100 \%$ de los encuestados se mostraron de acuerdo y totalmente de acuerdo con el enunciado siguiente: "La creación del Comité Estudiantil Ambiental, conforme lo estipula la Guía, contribuirá a mejorar la planificación ambiental universitaria".

17. El $75 \%$ de los encuestados se mostraron de acuerdo y totalmente de acuerdo con el enunciado siguiente: "Debe implementarse a futuro la Guía de Gestión Ambiental USIL". El 25\% restante, ni acuerdo ni desacuerdo. 


\subsection{Discusión.}

En la presente investigación se buscó conocer el grado de acuerdo de autoridades y expertos en materia ambiental de la universidad en relación al diseño e implementación de la propuesta de Guía de Gestión Ambiental, instrumento que contribuirá al cumplimiento de los objetivos ambientales establecidos en la Política Integrada de la universidad.

De acuerdo a los resultados obtenidos, uno de los principales hallazgos de esta investigación es que autoridades y expertos en materia ambiental de la universidad consideran importante la creación de espacios para el dialogo en materia ambiental entre la comunidad universitaria. Esto se basa en que el $100 \%$ de autoridades y expertos señalan que la creación del Consejo Estudiantil Ambiental contribuirá a mejorar la planificación ambiental.

En este contexto, es posible que la inclusión del alumnado en la toma de decisiones ambientales de la universidad, fortalezca el compromiso de la comunidad universitaria, empodere al alumno y contribuya a la consecución de objetivos ambientales de la universidad; cumpliendo con uno de tres escenarios (participación ambiental) estipulados en el Libro Blanco de Educación Ambiental de España para la ambientalización de universidades, el cual es una iniciativa del Gobierno Español que busca el desarrollo de principios, objetivos e instrumentos de gestión ambiental; así como el análisis y promoción de acciones a favor del medio ambiente en el contexto del ciudadano, entre ellos el contexto universitario.

Considerando que la responsabilidad social representa un pilar institucional en la universidad, el desempeño ambiental de la misma debe enmarcarse hacia la sostenibilidad. Sin embargo, en base a los resultados obtenidos, un hallazgo fue que la comunidad universitaria no conoce en su gran mayoría los impactos ambientales que genera la universidad ( $80 \%$ de autoridades y expertos opinan lo afirmado).

En este sentido, como oportunidad de mejora, la universidad debería gestionar los impactos ambientales que generan sus actividades y fortalecer la difusión de buenas prácticas ambientales. Estos resultados guardan relación con lo mencionado por Gutiérrez (2004), en la Ambientalización de centros educativos como factor de calidad de la gestión de organizaciones; donde señala que la universidad tiene la responsabilidad de predicar con el ejemplo; desarrollando actuaciones modélicas que incorporen a sus estructuras organizativas nuevos modelos de gestión y nuevas formas de aprovechamiento alternativo de los recursos. 
Asimismo, el $80 \%$ de los encuestados señala que la correcta implementación de la Guía de Gestión Ambiental, instrumento de gestión, contribuirá a mejorar el desempeño ambiental de la universidad y representa una herramienta para la toma de decisiones. Lo mencionado concuerda con Pinillo y Fernández (2011), en Desde la RSC a la sostenibilidad corporativa: una evolución necesaria para la creación de valor; documento en el cual señala que los instrumentos de gestión ambiental buscan identificar, analizar, controlar y gestionar los impactos ambientales dentro de las organizaciones, con la finalidad de transformar su gestión en una ventaja competitiva.

Basándonos en el análisis del entorno de la universidad, se sostiene que el componente ambiental viene impulsándose, dado que vienen desarrollándose acciones a nivel operativo y educativo en favor del medio ambiente, tales como sensibilización a la comunidad universitaria y uso eficiente de recursos. En este sentido, la Guía de Gestión Ambiental contribuye al cumplimiento de compromisos establecidos en la Política Integrada en la universidad $(80 \%$ de autoridades y expertos opinan lo afirmado). Lo mencionado se alinea con lo manifestado por Alba (2006), en el Análisis de los procesos de gestión y educación para la sostenibilidad en las universidades públicas españolas; donde señala que los instrumentos de gestión ambiental son la plataforma sobre la cual se realizan actividades alineadas a los principios de la política, con el objetivo de cumplir las metas institucionales previamente establecidas.

El desarrollo de la siguiente investigación contó con limitaciones relacionadas al reducido número de autoridades y expertos en materia ambiental en la universidad. Sin embargo, esta limitación fue superada dado que las autoridades y expertos encuestados, tienen relación con la temática ambiental de la universidad, toman decisiones en materia ambiental y tienen acceso a información ambiental de la misma.

Finalmente, en el marco del desarrollo de la presente investigación, surgieron lecciones aprendidas tales como: (i) La implementación de la Política Integrada en la universidad representa una buena iniciativa institucional; sin embargo, la ausencia de instrumentos de gestión que permitan su operatividad, limita su accionar hacia la sostenibilidad; (ii) La participación y compromiso de la comunidad universitaria es el principal factor de la universidad para la mejora de su desempeño ambiental; (iii) La inclusión del medio ambiente como stakeholder de la universidad reforzaría el compromiso ambiental de una institución educativa como es la Universidad San Ignacio de Loyola. 


\subsection{Conclusiones.}

La conclusión principal de la presente investigación, en relación a su objetivo general, es la siguiente:

"El $80 \%$ de las autoridades y expertos en materia ambiental de la Universidad San Ignacio de Loyola consideran que la implementación de la Guía de Gestión Ambiental contribuirá al cumplimiento de los compromisos ambientales establecidos en la Política Integrada de la universidad".

Asimismo, se obtuvieron conclusiones complementarias relevantes:

- El medio ambiente representa un stakeholder con identidad propia para la Universidad, dado que afecta y es afectado por el accionar de la misma. La afectación de la universidad hacia el medio ambiente radica en la generación de impactos ambientales propios de su actividad; mientras que, el medio ambiente afecta a la universidad mediante la reducción de su capacidad disipadora de contaminación.

- El establecimiento de espacios participativos para la planificación ambiental, tales como el Comité de Gestión Ambiental y Consejo Estudiantil de Gestión Ambiental; permitirá alinear y comprometer a la comunidad universitaria en la consecución de objetivos institucionales.

- El diagnóstico, elaborado en el marco de la presente investigación, permite establecer la línea base ambiental de la universidad; lo cual representa el punto de partida para el diseño de estrategias que mejoren el desempeño ambiental actual de la universidad.

- La implementación de la Guía de Gestión Ambiental USIL contribuirá al fortalecimiento del Sistema de Gestión Ambiental de la universidad.

- La Guía de Gestión Ambiental USIL es un documento diseñado exclusivamente para la universidad; motivo por el cual, no es aplicable su generalización. Según los resultados de la presente investigación, autoridades y expertos en materia ambiental de la universidad, consideran necesaria su implementación. Finalmente, es un documento perfectible que deberá ser fortalecido con aportes de la comunidad universitaria. 


\subsection{Recomendaciones.}

- Incluir al medio ambiente como stakeholder en el contexto de la organización; dado que afecta y se ve afectado por el accionar de la universidad. La decisión de integrar al medio ambiente como grupo de interés deberá tomarse al más alto nivel organizacional y reflejará el compromiso ambiental de la universidad.

- Crear espacios para la toma de decisiones en materia ambiental; y propiciar la participación de la comunidad universitaria en el accionar ambiental de la universidad.

- Implementar las estrategias ambientales corporativas de renovación a partir de la información y datos obtenidos de los diagnósticos realizados, con la finalidad de incrementar la eficiencia en el desempeño ambiental de la universidad.

- Actualizar periódicamente el diagnóstico ambiental y compartir los resultados (transparencia) con los principales stakeholders internos y externos.

- Promover la creación de instrumentos de gestión ambiental de forma participativa con la comunidad universitaria con la finalidad de lograr la consecución de objetivos organizacionales.

- Establecer el componente de Sostenibilidad como pilar organizacional de la universidad, dado que engloba factores sociales, económicos y ambientales.

- Fortalecer el Sistema de Gestión Ambiental de la universidad y evaluar su certificación bajo estándares ambientales internacionales, dado que representaría una ventaja competitiva para la organización.

- Actualizar y fortalecer periódicamente la Guía de Gestión Ambiental propuesta, con la finalidad de poseer a futuro un instrumento de gestión que cuente con lineamientos para la mejora del desempeño ambiental de la universidad. 


\section{REFERENCIAS BIBLIOGRÁFICAS.}

Alba, D. (2006). Análisis de los procesos de gestión y educación para la sostenibilidad en las universidades públicas españolas. Trabajo de investigación para la obtención de Diploma de Estudios Avanzados (Doctorado), Universidad Autónoma de Madrid.

AUNUEIS. 1999. La educación superior ante los desafíos de la sustentabilidad. Vol. 1. En torno al desarrollo sustentable. Vol. 2. En torno a la educación ambiental. aunuies-u de g-semarnap. México.

Benayas, J. (2004). La ambientalización de los campus universitarios. El caso de la Universidad Autónoma de Madrid. Tercer Congreso Andaluz de Educación Ambiental. Sevilla: Consejería de Educación de la Junta de Andalucía.

Brugger, E., 1993. Del Desarrollo Sostenible a la Eco- eficiencia. En "La implementación de un Desarrollo Sostenible en América Latina". Buenos Aires. Fundación MAPFRE.

Cárdenas, J. (2014). Guía para Universidades Ambientalmente Responsables. Responsabilidad Ambiental Universitaria: Compromiso y oportunidad. Lima. Red Ambiental Interuniversitaria - Interuniversia Perú.

Caride G., J., 2006. La educación ambiental en las Universidades y la Enseñanza Superior: viejas y nuevas perspectivas para la acción en clave de futuro. En V Congreso Ibero- americano de Educación Ambiental. Joinville, Brasil. pp. 429- 442.

Caride, J., 2005. In the name of environmental education: words and things in the complex territory of education- environmental- development relations. Policy Futures in Education. Vol. 3. № 3. Pp. 260- 270. Citado en: http://qqq.words.co.uk/pfie/contents/pdfs/3/issue33.asp

Castellasno Narciso, José; Cruz Pulido, Mauricio, 2014. Una Mirada a la Evolución Histórica de la Estrategia Organizacional.

Centers and Programs. (2018). Stanford Woods Institute for the Environment. Retrieved 14 April 2018, from https://woods.stanford.edu/research/centers-programs

Centro de Desarrollo Industrial - SNI. (2018). Cdi.org.pe. Retrieved 14 April 2018, from http://www.cdi.org.pe/asistencia_iso14000.htm

Clements, R., 1997. Guía completa de las Normas ISO 14000. España. Ediciones Gestión 2000 S.A. p. 285.

Cohen, M., 1986. Leadership and Ambiguity. The American College President. Second Edition. Harvard, Business School Press. Boston. p. 298

Cole, L., 2003. Assessing sustainability on Canadian University campuses: development of a campus sustainability assesment framework. Canada: Royal Roads University. p 30.

Comisión Brundtland. (1987). Comisión mundial sobre medio ambiente y desarrollo. Nuestro futuro común.

Conexión ESAN, 2016. La Estrategia corporativa ambiental. hwww.esan.edu.pe/apuntes-empresariales/2016/04/la-estrategia-corporativaambiental/

Cortese, A., 2005. Integrating sustainability in the learning community. Facilities Manager. 21 (1): $29-34$ 
de la Educación Ambiental, L. B. (1999). en España. Ministerio de Medio Ambiente.

Delpiano, C. y Sanhuesa, Andrea. Módulos de participación ciudadana, Publicaciones Corporación Participa, México, 2003, p. 4.

Educación Ambiental | Secretaría de Medio Ambiente. (2018). Sma.edomex.gob.mx. Retrieved 14 April 2018, from http://sma.edomex.gob.mx/educacion_ambiental

Elizabete, M. et al., 2005. Systemic thinking in environmental management: support for sustainable development. Journal of cleaner production. 13:1197- 202

Enkerlin Hoeflich, E. C., Cano, G., Garza Cuevas, R. A., \& Vogel Martínez, E. (1997). Ciencia ambiental y desarrollo sostenible. In Ciencia ambiental y desarrollo sostenible. International Thomson.

Espluga Trenc, Josep; Prades, Ana; Vallejos - Romero, Arturo. (2015). Riesgos ambientales, sostenibilidad y políticas de implicación ciudadana. Universidad Autónoma de Barcelona.

Fernández-Vitora, C., RIPOLL, V., Ripoll, L. C., \& Fernández-Vítora, V. C. (1997). Los instrumentos de la gestión ambiental en la empresa. Mundi-Prensa.

Formoso, J. F., Couce, L. C., Rodriguez, G. I., Ponte, A. C., \& GUERREIRO, M. R. (2011). La integración de los sistemas de gestión. Necesidad de una nueva cultura empresarial. Dyna, 78(167), 44-49.

Gutiérrez Pérez, J. y González Dulzaides, A. (2005): Ambientalizar la Universidad: Un reto para el aseguramiento de la calidad ambiental en los ámbitos curriculares y de la gestión

Gutiérrez Pérez, J (2004): "La Ambientalización de centros educativos como factor de calidad de la gestión de organizaciones". Simposium 5: La Ambientalización de los centros educativos. Ecoescuelas y ecouniversidades. Presentación Iller Congreso Andaluz de Educación Ambiental, Consejería de Educación de la Junta de Andalucía.

Herremans, I. et al., 2000. Environmental management systems at North American Universities: What drives good performance? International Journal of Sustainability in Higher Education.

Latorre, E., 1996. Empresa y Medio Ambiente en Colombia. Bogotá. FESCOL. p. 282.

Leff, Enrique, 2004. Racionalidad ambiental: la reapropiación social de la naturaleza, Siglo XXI. México. P. 210- 211

Ley N²29338, Ley de Recursos Hídricos; 2009.

Ley N²7345, Ley de Promoción del Uso Eficiente de la Energía; 2000.

Decreto Legislativo N 1278, Ley de Gestión Integral de Residuos Sólidos; 2016.

Lourdel, N., et al., 2005. Introduction of sustainable development in engineer's curricula problematic and evaluation methods. International Journal of sustainability in Higher Education. 6(3): 254- 264

Loyola Cajahuaringa, G. and Cabrera Melgar, P. (2017). Guía para la implementación de la norma ISO 14001 en el Centro de Información, Control Toxicológico y Apoyo a la Gestión Ambiental (CICOTOX) de la Facultad de Farmacia y Bioquímica de la UNMSM. [online] Cybertesis.unmsm.edu.pe. 
Lozano, M., et al., 2007. An analysis of the implementation of an environmental management system in a local public administration. Journal of Environmental Management. 82(4): 495- 510

Machado, R. E., Fracasso, E. M., Tometich, P., \& Nascimento, L. F. (2013). Práticas de Gestão Ambiental em universidades brasileiras. Revista de Gestão Social e Ambiental, 7(3), 37-51.

María Joaquín (2007) Un sistema de gestión ambiental para la facultad de Ciencias e Ingeniería de la Pontificia Universidad Católica del Perú, PUCP.

Martínez, A. G. (2008). La conciencia ambiental como herramienta para la educación ambiental: conclusiones y reflexiones de un estudio en el ámbito universitario. Universidad de Córdoba.

Mrazek, R., et al., 1997. Research in Environmental Education, 1981- 1990: Environmental Education for the Next Generation- Professional Development and Teacher Trainning. NAAEE. Troy, Ohio. p. 152.

Nardia Haigh y Andrew Griffiths, septiembre de 2009 El entorno natural como actor principal: el caso del cambio climático, en Estrategia empresarial y medio ambiente, Volumen 18, Número 6, páginas 347-359, [en línea] Disponible en: https: // onlinelibrary.wiley.com/doi/10.1002/bse.602/abstract.

Newman, L., 2006. Change, uncertainty and futures of sustainable development. Futures. 38(5): 633- 637.

Oliveira, E., 2006. Educao Ambiental e Universidade: ensino, pesquisa e extensao. En: Perspectivas de la Educación Ambiental en Iberoamerica. Brasil.

Organización de las Naciones Unidas, 1992. Agenda 21. United Nations conference on environmental and development. Río de Janeiro.

Organización Sostenible USIL. (2018). Usil.edu.pe. Retrieved 14 April 2018, from http://www.usil.edu.pe/nosotros/organizacion-sostenible

Ortega, R., et al. 1994. Manual de gestión del medio ambiente. Madrid. Editorial MAPFRE. p. 342.

Pilares Institucionales. (2018). Usil.edu.pe. Retrieved 14 April 2018, from http://www.usil.edu.pe/nosotros/pilares-institucionales

Pinillos, A. A., \& Fernández, J. L. F. (2011). De la RSC a la sostenibilidad corporativa: una evolución necesaria para la creación de valor. Harvard-Deusto Business Review, 207, 5-21.

Piper, J., 2002. CEA and sustainable development: evidence from UK case studies. Environmental Impact Asessment Review. 22: 17- 35

Política Nacional del Ambiente - Ministerio del Ambiente del Perú, 2009

Reconocimiento Internacional | CENTRUM Católica Business School | Maestrías | MBA | Doctorados. (2018). CENTRUM católica. Retrieved 14 April 2018, from http://centrum.pucp.edu.pe/centrum/nuestras-fortalezas/reconocimientointernacional/

Repositorio de la Universidad San Ignacio de Loyola: Pregrado. (2018). Repositorio.usil.edu.pe. Retrieved 14 April 2018, from http://repositorio.usil.edu.pe/handle/123456789/1616 
Ridgway, B., 2005. Environmental management system provides tolos for delivering on environmental impact asessment commitments. Impact Assessment and Project Appraisal. 23(4): 325- 331

Riojas, J., 2000. La complejidad ambiental en la Universidad. En Leff, E. (coord.), La complejidad ambiental, Siglo XXI- PNUMA, México. pp. 139- 215.

Rodríguez Córdova, D. (2014). Gestión Ambiental de Empresas.

Rodríguez, M., et al. 2002. Gestión ambiental en América Latina y el Caribe. Washington, D.C. David Wilk Editor. p. 265.

SANCHEZ, F. (2010). Responsabilidad Social Ambiental Empresarial. Colombia: Universidad la Gran Colombia, 76.

Sarukhan, J., 1998. Misión de la Universidad en el desarrollo cultural y en la educación: el caso de América Latina. En: Porta, J. y Lladanosa, M. (coords). La Universidad en el cambio de siglo. Alianza Editorial. Madrid. pp. 217- 230.

Sharp, L., 1999. The Road from little Victories to Systemic Transformation. Harvard University. P. 18.

Shriberg, M., 2002. Institutional assessment tools for sustainability in higher education: strengths, weaknesses and implications for practice and theory. Higher Education. 15: 153- 166

Simkins, G., et al., 2004. Environmental management system in universities. Occasional paper for environmental association for universities and colleges. pp. 17

SPDA, 2015. Fiscalización Ambiental: recomendaciones para un fortalecimiento integral.

Starik, M. 1995. ¿Deberían los árboles tener una posición gerencial? Hacia el estado de los interesados para la naturaleza no humana Journal of Business Ethics, 1995, Volumen 14, Número 3, Página 207 - 217. [en línea] Disponible en: https://link.springer.com/article/10.1007\%2FBF00881435.

Steger, U., 2000. Environmental management systems: empirical evidence and further perspectives. European Mangement Journal. 18(1): 23- 37

Freeman Edward, 1984. Strategic Management: A stakeholder Aprroach.

Tigrera, R. (2011). Impacto de la regulación ambiental en las actividades de la alta gerencia corporativa. Telos, 5(3).

UNESCO, 1972. Stockholm Declaration.

UNESCO, 1990. Kyoto Declaration. Ninth International association of universities round table.

UNESCO, 1997. Thessaloniki Declaration.

Um.es. (2017). Gestión ambiental - Universidad de Murcia. [online] www.um.es/web/campussostenible/ambiental/gestion.

Universidad Politécnica de Valencia. Oficina Verde. (2018). Magrama.gob.es. Retrieved $14 \quad$ April 2018, from http://www.magrama.gob.es/es/ceneam/recursos/quien-es-quien/upv.aspx

Upv.es. (2017). Política Ambiental: Unidad de Medio Ambiente: UPV. [online] 
Vallaeys, F. (2008). Responsabilidad Social Universitaria: una nueva filosofía de gestión ética e inteligentes para las universidades. Revista Educación Superior y Sociedad (ESS) ISSN: 0798-1228, 13(2), 191-220.

Viebahn, P., 2002. An environmental management model for universities: from environmental guidelines to staff involvement. Journal of Cleaner Production. 10: 311

Wall, G., 2008. Ciudad Universitaria, Ciudad Sostenible. UIS. Bucaramanga, Colombia. Citado en: www.uis.edu.co/portal/catedra.../articulo3.html (02/08/2009)

Wright, T., 2002. Definitions and frameworks for environmental sustainability in higher education. Higher Education Policy. 15: 153- 67

(2018). Apeim.com.pe. Retrieved 14 April 2018, from http://www.apeim.com.pe/wpcontent/themes/apeim/docs/nse/APEIM-NSE-2017.pdf

(2018). Oecd.org. $\quad$ Retrieved 14 April 2018, from https://www.oecd.org/pisa/pisaproducts/42467312.pdf

(2018). Responsabilidadsocial.usil.edu.pe. Retrieved 14 April 2018, from http://responsabilidadsocial.usil.edu.pe/quienes-somos.html

(2018). Usil.edu.pe. Retrieved 14 April 2018, from http://www.usil.edu.pe/sites/default/files/usil-reporte-de-sostenibilidad-2015.pdf

14001:2015, I. (2018). ISO 14001:2015 - Environmental management systems -Requirements with guidance for use. Iso.org. Retrieved 14 April 2018, from http://www.iso.org/iso/catalogue_detail?csnumber=60857. 


\section{ANEXOS}

- ANEXO N 01: Registro de Plan de Tesis - INFOSIL.

- ANEXO N02: Aprobación de Plan de Tesis.

- ANEXO N 03: Aprobación a las modificaciones realizadas en el marco de la investigación - Lic. Susana Tejada.

- ANEXO N 04: Solicitud de aprobación a modificaciones en el marco de la investigación "Propuesta de Guía de Gestión Ambiental para la Universidad San Ignacio de Loyola" - Bach. Luiggi Ballardo.

- ANEXO N 05: Evolución de cantidad de empresas con certificación ISO 14001 - Nivel Mundial.

- ANEXO N06: Acciones estratégicas y metas priorizadas 2017 - 2022. Plan Nacional de Educación Ambiental (PLANEA).

- ANEXO N 07: Relación entre categoría de análisis y premisas.

- ANEXO N 08: Carta de Validación de Matriz de Identificación de Aspectos e Impactos Ambientales.

- ANEXO N 09: Acta de creación, conformación y funcionamiento del Comité de Sostenibilidad USIL.

- ANEXO N 10: Estructura de la Unidad Ambiental, Social, Seguridad y Salud ocupacional USIL.

- ANEXO № 11: Carta de consentimiento informado - Jefa Unidad de Medio Ambiente, Seguridad y Salud ocupacional USIL.

- ANEXO N 12: Matriz de Identificación de aspectos e impactos ambientales.

- ANEXO N 13: Manual de procedimiento comunicacional.

- ANEXO N 14: Manual de procedimiento para realización de auditorías internas.

- ANEXO N 15: Criterios para la selección del panel de expertos.

- ANEXO N 16: Correo electrónico - Secretaria del Rector.

- ANEXO N 17: Encuesta Vicepresidenta de Responsabilidad Social. 
- ANEXO N 18: Consentimiento informado Vicepresidenta Responsabilidad Social

- ANEXO N 19: Encuesta Vicerrectora de Investigación y Desarrollo USIL.

- ANEXO No 20: Carta de Consentimiento Informado Decano de la Faculta de Ciencias Empresariales - Director de la carrera de Gestión Ambiental USIL.

- ANEXO N²1: Correo del Decano de la Facultad de Ciencias Empresariales Director de la carrera de Gestión Ambiental - Vicerrector Académico USIL.

- ANEXO N 22: Encuesta Coordinador Académico de la carrera de Gestión Ambiental USIL.

- ANEXO No 23: Carta de Consentimiento Informado Coordinador Académico de la carrera de Gestión Ambiental USIL.

- ANEXO No 24: Correo electrónico a la Directora de Ingeniería Ambiental Solicitud de llenado de encuesta.

- ANEXO N²5: Encuesta Coordinador Académico de la carrera de Ingeniería Ambiental USIL.

- ANEXO N²6: Carta de Consentimiento Informado Coordinador Académico de la carrera de Ingeniería Ambiental USIL.

- ANEXO N²7: Encuesta Coordinador Académico de la carrera de Ingeniería del Agua USIL.

- ANEXO N²8: Carta de Consentimiento Informado Coordinador Académico de la carrera de Ingeniería del Agua USIL.

- ANEXO N²9: Resultados de la aplicación de Encuesta.

- ANEXO N³0: Matriz de Consistencia. 
Anexo $N^{\circ} 01$.

SOLICITUD DE ASESORIA DE TESIS N ${ }^{\circ} 72$

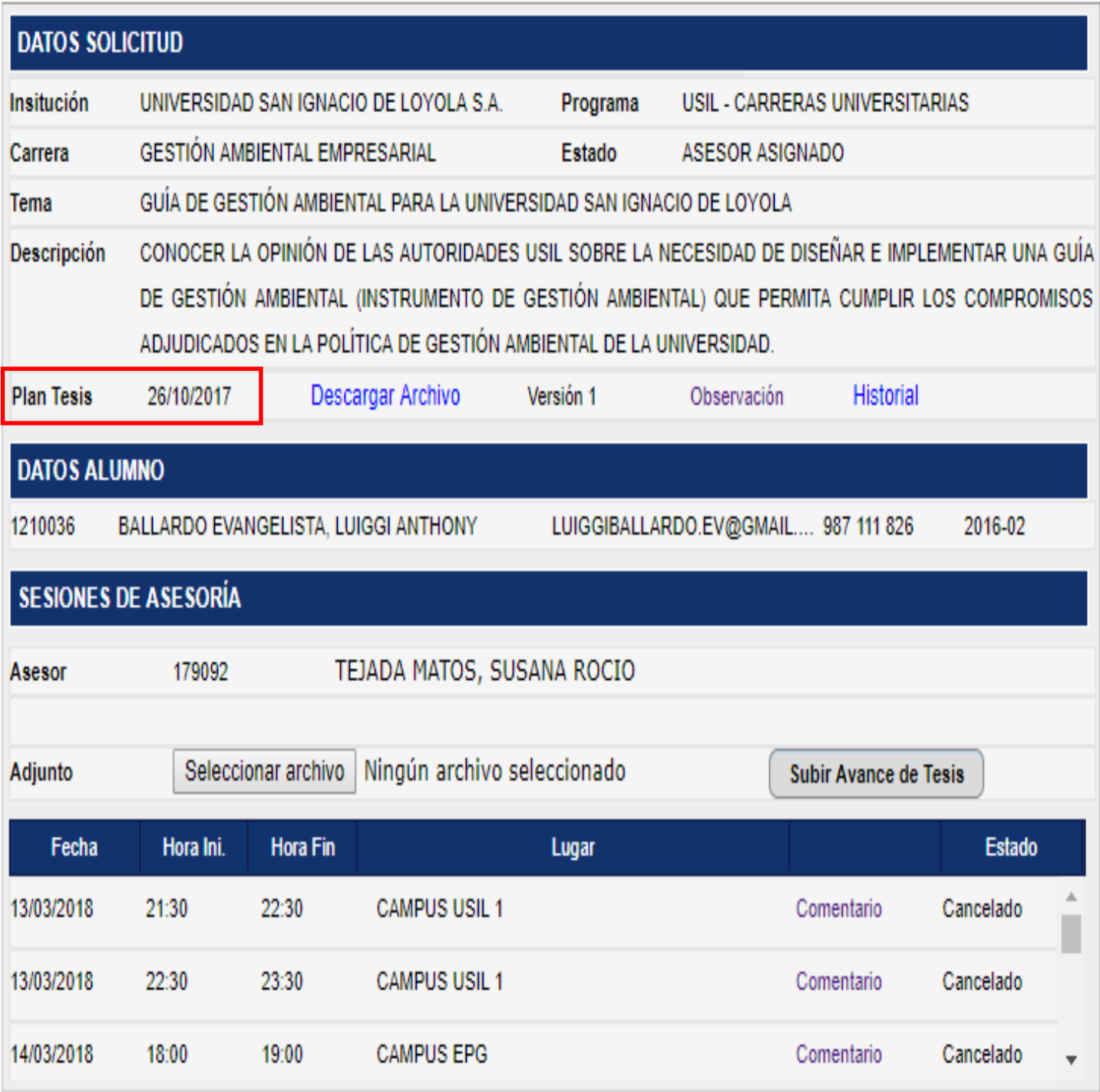

Figura 28: Registro de Plan de Tesis 26/10/2017 - INFOSIL 


\section{Anexo $\mathbf{N}^{\circ} 02$.}

Fany Rojas Noa <frojas@usil.edu.pe>

para Fany 0

Estimados señores:

En primer lugar los felicito por su resultado oprobatorio de su plan de tesis. Lo que sigue o continuación es comenzar a desorrollar su informe de tesis con la supervisión de su asesor.

En cuanto a la parte operotiva:

Cacín de derechos por concepto de Asescrí de tesis. Nos informan que pueden realizar dicho pogo en Caja de USII o en las siguientes entidades boncarias: (a)

El plazo para la cancelación de derechos es de 60 días, una vez aprobados su plan de tesis.

作

Una vez asignado su asesor(a) podrán iniciar las reuniones de asesoría, las cuales serán programadas también por el INFOSIL en los días y horas acordados entre ustedes y su asesor(a)

El bachiller tiene un plazo para desarrollo y culminación de su informe de tesis: Mínimo de cuatro (4) meses y máximo de nueve (9) meses, contados a partir de la fecha del registro del Plan de Tesis. Su fecha de registro de plan es el día $24 / 11 / 17$. Soludos

\section{FANY ROJAS NOA, MBA}

Coordinador Acasámioo

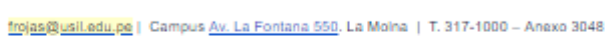

\section{5. \\ COMPROMETIDOS CON
LA EXCELENCIA ACADÉMICA}

Figura 29: Aprobación de Plan de Tesis "Guía de Gestión Ambiental para la Universidad San Ignacio de Loyola". 


\section{Anexo $\mathrm{N}^{\circ} 03$.}

Lima, 14 de mayo 2018

Estimado Bach. Luiggi Ballardo

Tesista

Asunto: Modificaciones en Proyecto de Tesis

En razón al documento presentado, donde solicita modificaciones al Proyecto de Tesis "Guía de Gestión Ambiental para la Universidad San Ignacio de Loyola", y en base al sustento descrito, informarle lo siguiente:

1. Se aprueba la modificación del título de la investigación. En este sentido el título es el siguiente:

"Propuesta de Guía de Gestión Ambiental para la Universidad San Ignacio de Loyola".

2. Se aprueba la modificación del objetivo general del Proyecto de Tesis. En este sentido, el objetivo general es el siguiente:

Conocer el grado de acuerdo de las autoridades y expertos en materia ambiental de la Universidad San Ignacio de Loyola en relación al diseño e implementación de la propuesta de Guía de Gestión Ambiental, instrumento que contribuirá al cumplimiento de los compromisos ambientales establecidos en la Política Integrada de la universidad.

3. Se aprueba la aplicación de encuestas usando la escala de medición Likert en lugar del Método Delphi.

En este sentido, agradeceré comunicar a la Coordinación de la Carrera de Gestión Ambiental Empresarial sobre las modificaciones efectuadas.

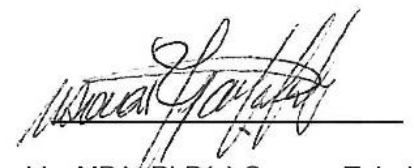

Lic. MBA PhD(c) Susana Tejada

Asesora de Tesis

Figura 30: Aprobación a modificaciones realizadas en el marco de la investigación - Lic. Susana Tejada. 
Anexo $\mathbf{N}^{\circ} 04$.

Estimada Lic. Susana Tejada

Lima, 09 de mayo 2018

Asesora de Tesis

Asunto: Modificaciones en Proyecto de Tesis

En el marco del Proyecto de Tesis "Guía de Gestión Ambiental para la Universidad San Ignacio de Loyola", del cual usted es "Asesora de Tesis", informarle las modificaciones que he de ejecutar en relación al Plan de Tesis presentado por el suscrito el 24 de noviembre 2017.

1. Se modifica el título de la Tesis al siguiente enunciado: "Propuesta de Guía de Gestión Ambiental para la Universidad San Ignacio de Loyola".

Sustento de la modificación: Se adiciona el término "Propuesta" dado que la Guía de Gestión Ambiental no es un documento oficial de inmediata implementación.

2. El Plan de Tesis presentado contenía el presente objetivo general:

Conocer la opinión de las autoridades USIL sobre la necesidad de diseñar e implementar una Guía de Gestión Ambiental (Instrumento de Gestión Ambiental) que permita cumplir los compromisos adjudicados en la Política de Gestión Ambiental de la universidad.

Por consiguiente, se propone la siguiente redacción:

Conocer el grado de acuerdo de las autoridades y expertos en materia ambiental de la Universidad San Ignacio de Loyola en relación al diseño e implementación de la propuesta de Guía de Gestión Ambiental, instrumento que contribuirá al cumplimiento de los compromisos ambientales establecidos en la Politica integrada de la universidad.

Sustento de la modificación: Se modifica el término "conocer opinión" por "conocer el grado de acuerdo" debido a que a través de la escala de medición Likert (instrumento utilizado en la presente investigación) se determina el grado de acuerdo en relación a una premisa y no la opinión en relación a esta. Esta modificación es netamente de precisión.

Asimismo, se adiciona el término "expertos en materia ambiental" con la finalidad de ampliar el número de encuestados. Por otro lado, se modifica el término "Política de Gestión Ambiental" por "Política Integrada" dado que la universidad no posee un Política exclusiva de medio ambiente; sin embargo, presenta una Política Integrada que abarca los componentes de Seguridad, Salud Ocupacional, Medio Ambiente y Responsabilidad Social.

3. Se modifica la aplicación del Método Delphi por la aplicación de encuestas usando la escala de medición Likert.

Sustento de la modificación: La modificación en cuanto al método radica en que el método Delphi requiere que un individuo efectúe una encuesta dos o más veces con la finalidad de reducir la dispersión de opiniones. Esto representa una limitación dado que las autoridades y expertos en materia ambiental de la universidad disponen de reducido tiempo para el análisis de la "Guia de Gestión Ambiental" y posterior desarrollo de encuestas. Esta justificación consta en el capítulo "Limitaciones" de la Tesis precitada.

En este sentido, tengo a bien solicitar vuestra conformidad a las modificaciones sustentadas en el marco del Proyecto de Tesis precitado.

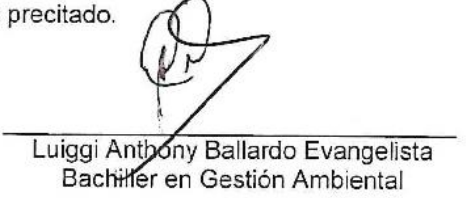

Figura 31: Solicitud de aprobación a modificaciones en el marco de la investigación "Propuesta de Guía de Gestión Ambiental para la Universidad San Ignacio de Loyola - Bach. Luiggi Ballardo. 
Anexo $\mathbf{N}^{\circ} 05$.

Tabla 22

Evolución de Cantidad de Empresas con certificación ISO 14001 - Nivel Mundial.

\begin{tabular}{|c|c|c|c|c|c|c|}
\hline Código & $\begin{array}{l}\text { Sector Industrial certificado con ISO } \\
14001\end{array}$ & 2013 & 2014 & 2015 & 2016 & 2017 \\
\hline 1 & Agriculture, fishing & 2467 & 2215 & 2408 & 2149 & 2396 \\
\hline 2 & Mining and quarrying & 2532 & 2520 & 2548 & 2674 & 2429 \\
\hline 3 & Food products, beverages and tobacco & 6890 & 7219 & 6842 & 6693 & 6402 \\
\hline 4 & Textiles and textile products & 4163 & 4020 & 4274 & 4606 & 4299 \\
\hline 5 & Leather and leather products & 727 & 620 & 655 & 651 & 595 \\
\hline 6 & Wood and wood products & 1891 & 1816 & 1976 & 3013 & 1662 \\
\hline 7 & Pulp, paper, paper products & 2888 & 2957 & 3077 & 2971 & 2894 \\
\hline 8 & Publishing companies & 270 & 187 & 96 & 113 & 112 \\
\hline 9 & Printing companies & 3064 & 3024 & 3045 & 2966 & 2871 \\
\hline 10 & $\begin{array}{l}\text { Manufacture of coke \& refined petroleum } \\
\text { products }\end{array}$ & 768 & 783 & 700 & 711 & 709 \\
\hline 11 & Nuclear fuel & 127 & 151 & 148 & 115 & 108 \\
\hline 12 & Chemicals products \& fibres & 11554 & 11890 & 11978 & 12277 & 11734 \\
\hline 13 & Pharmaceuticals & 1237 & 1341 & 1146 & 1195 & 1078 \\
\hline 14 & Rubber and plastic products & 12957 & 13410 & 14007 & 14741 & 14091 \\
\hline 15 & Non-metallic mineral products & 3447 & 3621 & 3524 & 3538 & 3410 \\
\hline 16 & Concrete, cement, plaster & 3480 & 3718 & 3810 & 15814 & 4433 \\
\hline 17 & Basic metal \& fabricated metal products & 24791 & 26050 & 26494 & 27374 & 26136 \\
\hline 18 & Machinery and equipment & 12892 & 13980 & 15209 & 16561 & 16202 \\
\hline 19 & Electrical and optical equipment & 22663 & 23768 & 25690 & 26728 & 25642 \\
\hline 24 & Recycling & 3276 & 3523 & 453 & 618 & 430 \\
\hline 25 & Electricity supply & 3695 & 3263 & 313 & 365 & 253 \\
\hline 26 & Gas supply & 577 & 642 & 4287 & 17357 & 3696 \\
\hline 27 & Water supply & 1695 & 1232 & 4096 & 8913 & 4173 \\
\hline 28 & Construction & 40430 & 43999 & 4133 & 4143 & 2788 \\
\hline 29 & $\begin{array}{l}\text { Wholesale \& retail trade; repairs of motor, } \\
\text { vehicles, etc. }\end{array}$ & 15516 & 16878 & 3402 & 2846 & 2017 \\
\hline 30 & Hotels and restaurants & 1511 & 1873 & 513 & 487 & 317 \\
\hline 31 & Transport, storage, communication & 8666 & 8729 & 1149 & 1270 & 903 \\
\hline 32 & Financial intermediation & 3351 & 3357 & 46910 & 49837 & 51384 \\
\hline 33 & Information technology & 3064 & 3858 & 19396 & 22554 & 23848 \\
\hline 34 & Engineering Services & 11850 & 12551 & 1772 & 1786 & 1555 \\
\hline 36 & Public administration & 1875 & 1799 & 8607 & 8961 & 7585 \\
\hline 37 & Education & 905 & 781 & 4411 & 5244 & 6063 \\
\hline 38 & Health and social work & 1008 & 1018 & 5395 & 7237 & 8620 \\
\hline 39 & Other social services & 6344 & 7679 & 14438 & 15389 & 16213 \\
\hline \multicolumn{2}{|r|}{ TOTAL } & 240891 & 254108 & 267971 & 314405 & 275776 \\
\hline
\end{tabular}

Nota: Fuente: ISO, 2017. 
ANEXO No 06.

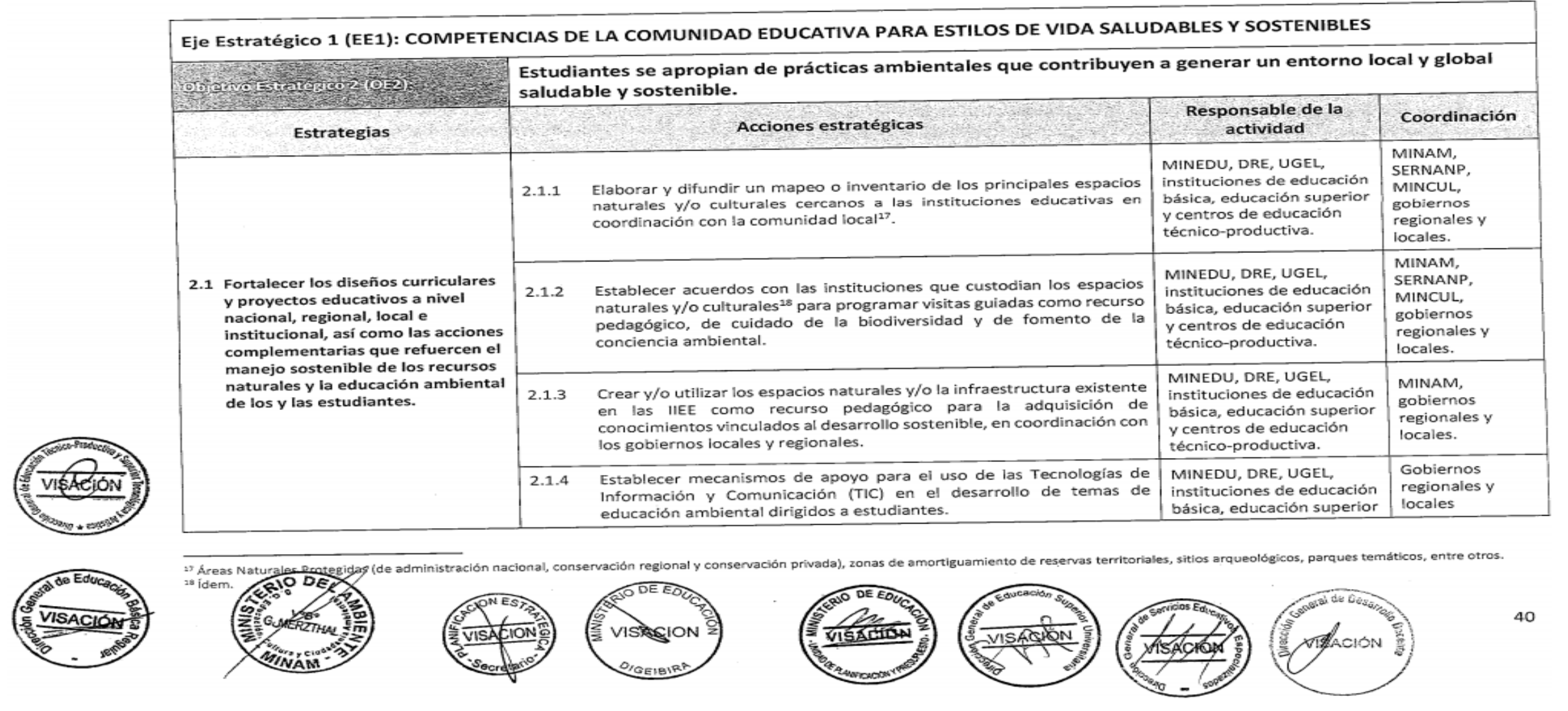

Figura 32: Acciones estrategias y metas priorizadas 2017 - 2022. Plan Nacional de Educación Ambiental (PLANEA). Fuente: Decreto Supremo No 16 - 2016 - Minedu 


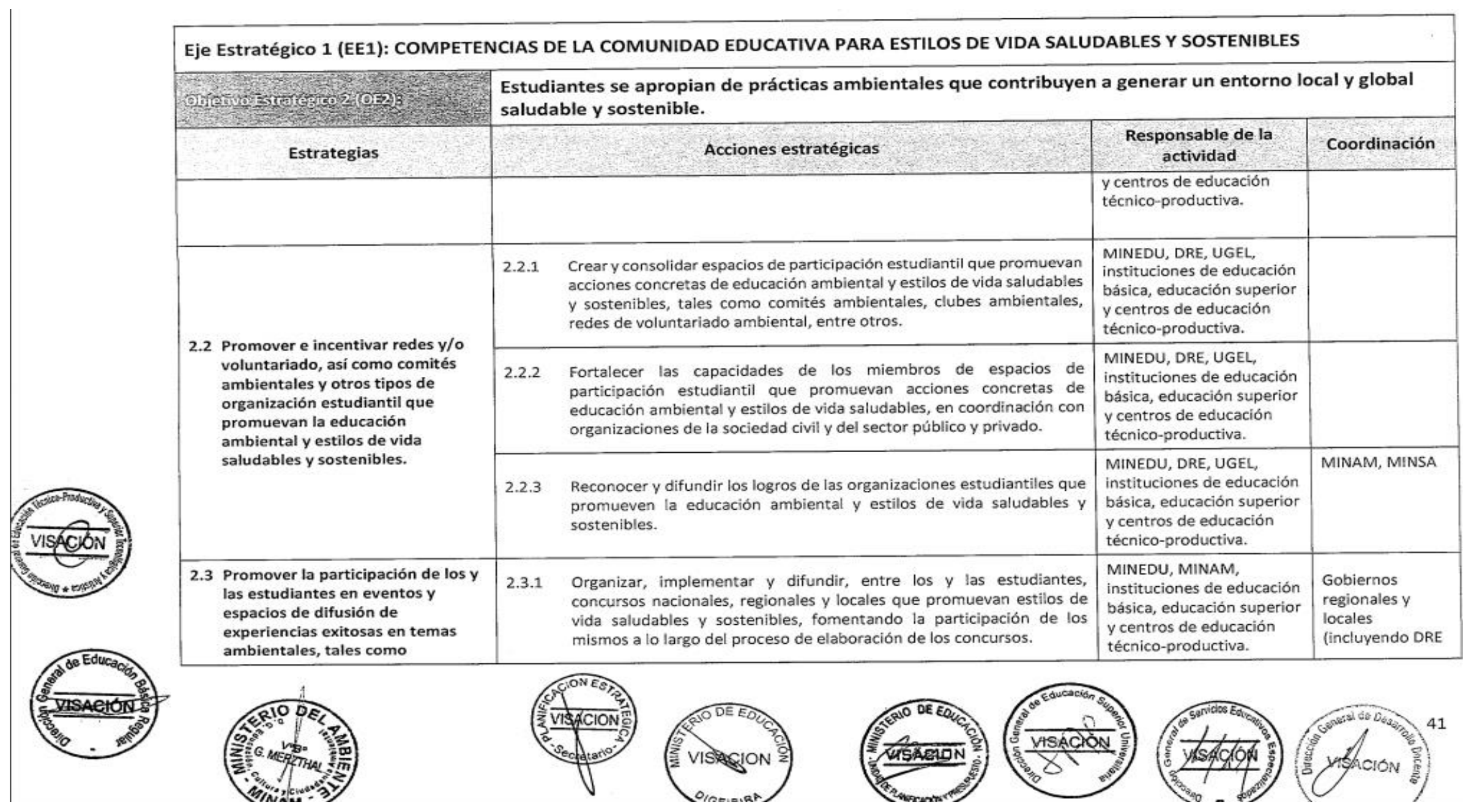

Figura 32: Acciones estrategias y metas priorizadas 2017 - 2022. Plan Nacional de Educación Ambiental (PLANEA). Fuente: Decreto Supremo Nº 16 - 2016 - Minedu 


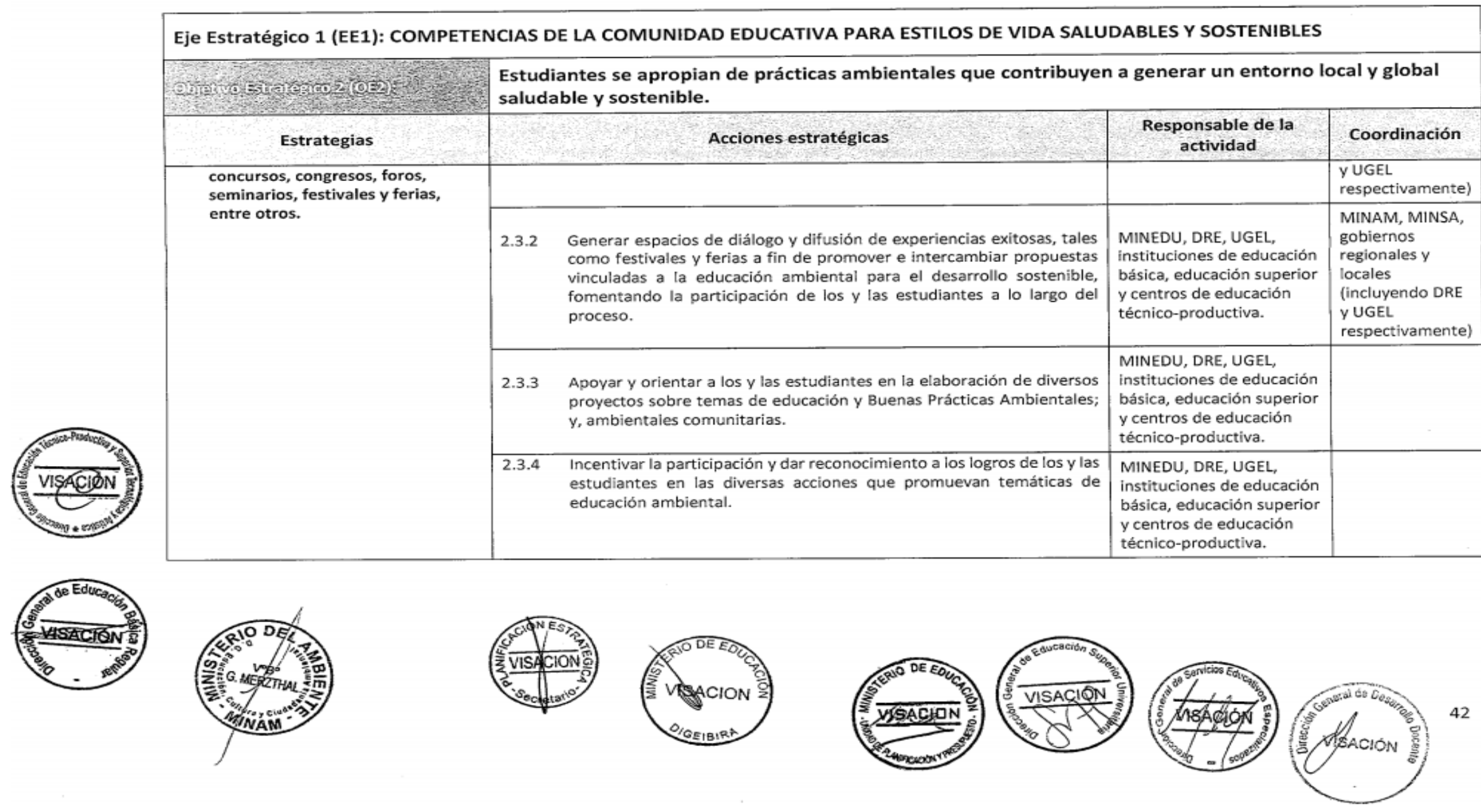

Figura 32: Acciones estrategias y metas priorizadas 2017 - 2022. Plan Nacional de Educación Ambiental (PLANEA). Fuente: Decreto Supremo No 16 - 2016 - Minedu 


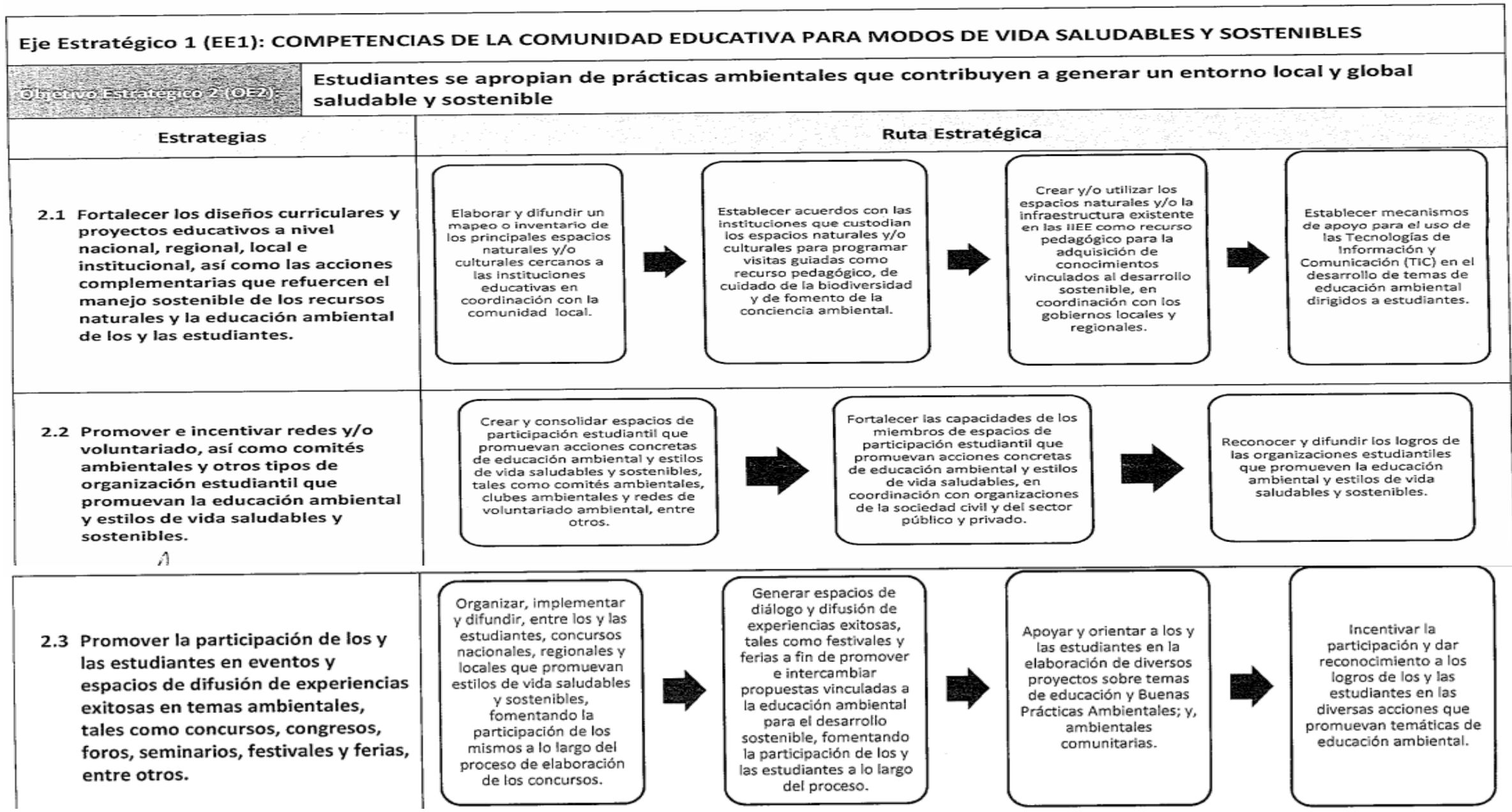

Figura 32: Acciones estrategias y metas priorizadas 2017 - 2022. Plan Nacional de Educación Ambiental (PLANEA). Fuente: Decreto Supremo No 16 - 2016 - Minedu 
ANEXO Nº7.

Tabla 23: Relación entre categoría de análisis y premisas.

\begin{tabular}{|c|c|c|c|}
\hline $\mathbf{N}^{\circ}$ & $\begin{array}{l}\text { Categoría de } \\
\text { Análisis }\end{array}$ & Literal & Premisa \\
\hline \multirow{5}{*}{1} & \multirow{5}{*}{$\begin{array}{l}\text { Beneficios de la } \\
\text { implementación de } \\
\text { Guía de Gestión } \\
\text { Ambiental }\end{array}$} & a. & $\begin{array}{l}\text { Es una herramienta para la toma de decisiones en la } \\
\text { planificación ambiental de la universidad }\end{array}$ \\
\hline & & b. & $\begin{array}{l}\text { Fomenta la integración de la comunidad universitaria para } \\
\text { mejorar el desempeño ambiental de la universidad. }\end{array}$ \\
\hline & & c. & $\begin{array}{l}\text { Marca el inicio para la implementación de un Sistema de } \\
\text { Gestión Ambiental en la universidad }\end{array}$ \\
\hline & & d. & $\begin{array}{l}\text { Permite conocer los aspectos e impactos ambientales que } \\
\text { posee la universidad a causa de sus acciones, decisiones u } \\
\text { omisiones. }\end{array}$ \\
\hline & & e. & $\begin{array}{l}\text { La correcta implementación de la Guía contribuirá a la mejora } \\
\text { del desempeño ambiental de la universidad. }\end{array}$ \\
\hline \multirow{2}{*}{2.} & \multirow{2}{*}{$\begin{array}{l}\text { Gestión Ambiental } \\
\text { actual USIL }\end{array}$} & f. & $\begin{array}{l}\text { La universidad se percibe ante la sociedad como una } \\
\text { universidad sostenible }\end{array}$ \\
\hline & & g. & $\begin{array}{l}\text { La universidad se percibe ante la sociedad como una } \\
\text { universidad sostenible }\end{array}$ \\
\hline \multirow{3}{*}{3.} & \multirow{3}{*}{$\begin{array}{l}\text { Participación de } \\
\text { partes interesadas }\end{array}$} & h. & $\begin{array}{l}\text { Los tomadores de decisión conocen las iniciativas } \\
\text { ambientales que viene desarrollando la universidad. }\end{array}$ \\
\hline & & i. & $\begin{array}{l}\text { El alumnado conoce las iniciativas ambientales que viene } \\
\text { desarrollando la universidad }\end{array}$ \\
\hline & & j. & $\begin{array}{l}\text { El alumnado participa en la toma de decisiones en materia } \\
\text { ambiental de la universidad }\end{array}$ \\
\hline \multirow[b]{2}{*}{4.} & \multirow{2}{*}{$\begin{array}{l}\text { Propuesta de } \\
\text { Sistema de Gestión } \\
\text { Ambiental }\end{array}$} & $\mathrm{k}$. & $\begin{array}{l}\text { Es viable la implementación de la Propuesta de Sistema de } \\
\text { Gestión Ambiental }\end{array}$ \\
\hline & & I. & $\begin{array}{l}\text { El capítulo precitado propone estrategias y acciones que } \\
\text { deberían implementarse con fines de mejorar el desempeño } \\
\text { ambiental de la universidad. }\end{array}$ \\
\hline \multirow[b]{2}{*}{5.} & \multirow{2}{*}{ Educación Ambiental } & $\mathrm{m}$. & $\begin{array}{l}\text { Debe impartirse un curso ambiental obligatorio dentro de la } \\
\text { malla curricular de todas las carreras universitarias. }\end{array}$ \\
\hline & & $\mathrm{n}$. & $\begin{array}{l}\text { Debe capacitarse a alumnos y personal administrativo en } \\
\text { materia ambiental. }\end{array}$ \\
\hline \multirow{3}{*}{6.} & \multirow{3}{*}{$\begin{array}{l}\text { Implementación de la } \\
\text { Guía de Gestión } \\
\text { Ambiental }\end{array}$} & 0. & $\begin{array}{l}\text { Contribuye al cumplimiento de los compromisos establecidos } \\
\text { en la Política Integral de la universidad. }\end{array}$ \\
\hline & & p. & $\begin{array}{l}\text { La creación del Comité Estudiantil Ambiental, conforme lo } \\
\text { estipula la Guía, contribuirá a mejorar la planificación } \\
\text { ambiental universitaria. }\end{array}$ \\
\hline & & q. & $\begin{array}{l}\text { Debe implementarse a futuro la Guía de Gestión Ambiental } \\
\text { USIL }\end{array}$ \\
\hline
\end{tabular}




\section{ANEXO $\mathbf{N}^{\circ} 08$.}

\section{Carta de validación de Matriz de identificación}

de Aspectos e Impactos Ambientales

yo Susann Tejoba, en calidad de especialista en Sistemas Integrados de Gestión (SIG), reconocido (a) con DNI N 10287302 por medio del presente hago constar que he tomado conocimiento, leido, evaluado; $y$, por ende, valido el instrumento para recolección de datos denominado "Matriz de Identificación de Aspectos e Impactos Ambientales", el cual ha sido propuesto por el Sr. Luiggi Anthony Ballardo Evangelista, con DNI N* 76066089 Bachiller de la carrera de Gestión Ambiental Empresarial de la Universidad San Ignacio de Loyola.

La validación del presente instrumento para recolección de datos se celebra en el marco de la Tesis: "Guía de Gestión Ambiental para la Universidad San Ignacio de Loyola*,

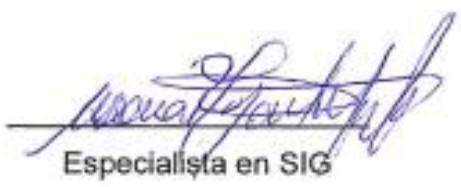

Sr.(a) Susana Tejarda

DNI: 10287302

Fecha: $14,12,2017$

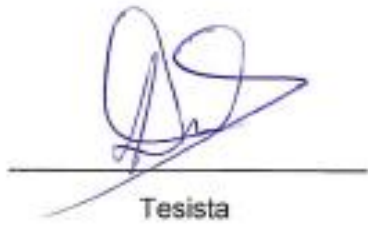

Sr.(a)

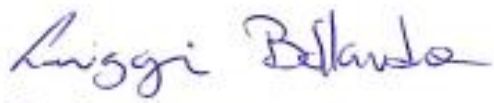

DNI: 76066089

Fecha: $14 / 2 / 20 / 7$

Figura 33: Carta de Validación de Matriz de Identificación de Aspectos e Impactos Ambientales. 


\section{ANEXO $N^{\circ} 09$.}

\section{UNIVERSIDAD SAN IGNACIO DE LOYOLA S.A.}

\section{ACTA DE GERENCIA DEL 13 DE FEBRERO DE 2013}

Siendo las quince horas, en el local de la sociedad sito en la Averida La Fontana 550, La Molina. Lima, redacta y suscribe la presente Acta el señor Juan Manuel Ostoja Carmeino en su calidad de Gerente General de la Sociedad. con la finalidod de aprobar la creación, contormación y funcionamiento del Comité de Sostenlbilidad de la Universidad San Ignacio de Loyola S.A.

Manifiesta que dado nuestro compromiso con el cuidado del medio ambiente y con los ternas virculados a la resporsabilidad social, seguridad $y$ salud ocupacional, resultobo converiente crear un Comilé de Sostenibilidad, que tendrá como funciones las siguientes:

- Brindar soporte técnico-legal a la Uridad Ambiental. Social, y de Seguridad y Salud Ocupacional, en lo que respecta a la implementación de los planes conforme a los términos y condiciones que se vienen negociando con el Banco Interameficano de Descrrollo para el otorgamiento de un financiamiento, enfre los que se encuentran el Plan de Gestión Ambiental y Social, asi como el Plan de Contingencia y Respuesta a Emergencia y el Manual del Medio Amblente. Social, y de Soguridad y Salud Ocupacional.

- Velar por que se lleve a cabo la implementoción de los planes y/o manual exígidos por el Banco interamericano de Desarrollo para el otorgamiento de una operación de financiamionto.

A continuación, indica que los demás aspectos vinculados a la elaboración, cumplimiento y vigilancia de las exigencias señalodas por el Banco interamericano do Desarrollo en razón de los planes y manual referidos, asi como de los aspectos socicles. se encuentran a cargo de la denominoda Unidad Ambiental. Social. y de Seguridad y Salud Ocupacional lantes Jefatura do Seguridad. Salud y Medio Amblente, que ho sido recientemente reestrucluradia por la Vicepresidencia de Capital Humano para cumplí los estándares de calidad en materia ambiental, social, y de segunidad y salud ocupacional exigidos por la legislación peruana y por las entidades bancarias y financieras, nacionales o intemacionales, para el otorgamiento de tinanciamientos).

Dicha Unidad, ha asumido las funciones que desempenaba la Jefatura de Seguridad. Salud y Medio Ambiente, detalladas en el Anexo 1 adjunto a la presente acta y, por tonto es la responsable del cumplimiento de las exigencias legales en materio ambiental. social y de seguridad y salud ocupacional.

En cuanto a la conformación y funcionamiento dal Comité de Sosteniblidad, el Gerente General establece lo siguiente:

- E Comité estaró conformado por un minimo de cinco [5] y un máximo de siete (7) miembros elegidos por el periodo de un año renovable.

- La Presidencia y Vice-Presidencia ejercerán el cargo también por un anto renovable.

- E Comité se reunird por lo menos una vez al mes para supervisar la implementación de los planes y manual a los que se ha hecho relerencia precedentemente.

- El quorum será de cuatro [4] miembros como mínimo.

- Los acuerdos deberán ser adoptados por mayoría simple de los miembros del Comité y deberón constar en Actos.

Figura 34: Acta de creación, conformación y funcionamiento del Comité de Sostenibilidad USIL. 
- El Presidente dirigirá el Comité y tendrá voto drimente en caso de empate en las votaciones.

- El Vice-Presidente reemplazará al Presidente en ausencia de este último.

- El Comité podrá contar con asesores externos o intemos, así como con asistentes que coadyuven al óptimo cumplimiento de las funciones señalados.

Añadió que la creación del referido Comité fortalecerá el compromiso de la Universidad de ser una empresa ambiental y sociaimente responsable.

A continuación, manifestó que el Comité de Sosienlblildad estará conformado por las siguientes personas:

- Juan Manuel Ostoja Carmelino, Gerente General, con D.N.I. N 07879742

- Jonathan Hugo Uribe Madrid, Sub-Gerente de Administración, con D.N.I. NN 43319460

- Maria Marcela Palacios Toledo, Jefe de Salud y Seguridad, con D.N.I. N0 40138087

- Diego Alberto Castrilí́n Dioses, Funcionario, con D.N.I. NN 42067195.

- Pamela del Rocio Núñez Therese, Asesora Laboral, con D.N.I. № 43451027 .

- Alexeis Alberto Ravello Joo, Vicepresidente de Capital Humano, con DN1 0787986.

- Maria Julia Garay Sotomayor, Vicepresidente de Finanzos, con DNI 07543684.

Los miembros del Comité se reunirán en el transcurso del presente mes para elegir a su Presidente y Vice-Presidente.

Seguidamente, la Gerencia General aprobó la creación del Comité de Sostenibilidad en los términos antes descritos.

No habiendo otro asunto que tratar, siendo las dieciséis horas, se levantó la sesión, previa lectura, redacción y aproboción del Acta, la cual fue suscrita en señal de plena conformidad.

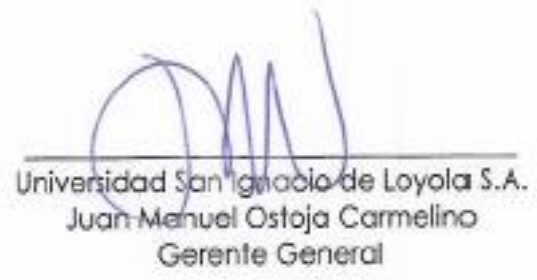

Figura 34: Acta de creación, conformación y funcionamiento del Comité de Sostenibilidad USIL. 
ANEXO No 10.

\section{UNIDAD DE AMBIENTAL, SOCIAL Y DE SEGURIDAD Y SALUD OCUPACIONAL}

\section{ALCANCE}

Alineados con el plan estratégico de la Universidad San Ignacio De Loyola S.A. (USIL) se creó la Unidad Ambiental, Social. y de Segunidad y Salud Ocupocional USIL. (ESHS-U), ente ejecutor responsable, de entre otros de implementar el Sistema de Gestión en Medio Ambiente, Responsabilidad Social y de Seguridad y Salud Ocupacional ([SG MRS y SSO] de USIL, permitiendo el cumplimiento de la normatividad vigente $y$ de aquellos requerimientos exigidios por el Banco Interamericano de Desarrolio (BID) $u$ atra institución relacionada con usı referente a los aspectos Medioambientales, de Responsabilidad Social, y de Seguridad y Salud Ocupacional.

\section{OBJETIVO GENERAL}

Implementar en toda la USiL el Sistema de Gestión en Medio Ambiente, Responsabilidad Social y de Seguridad y Salud Ocupacional de USIL con el fin de identificar rlesgos, prevenir accidentes y enfermedades laborales, garantizar la conservación del medio ambiente y mantener un adecuado relacionamiento con nuestros grupos de interés. Asimismo implementar las demás medidas exigidas por la normatividad en las materias referidas.

\section{OBJETIVOS ESPECIFICOS}

- Proteger la seguridad y salud de todos los miembros de la USll mediante la identificación, revisión e implementación de objetivos, metas, programas y planes orientados a la prevención de lesiones, dolencias, accidentes e incidentes de trabajo. y enfermedades ocupacionales

- Identificar los aspectos ambientales significativos de nuestras operaciones y gestionarlos eficientemente para proteger el medio ambiente e evitar impactos en sus grupos de interés.

- Identificar y garantizar el cumplimiento de las requisitos y obligaciones legales en materia de Medio Ambiental. Responsabilidad Social y de Seguridad y Salud Ocupacional, asi como los asumidos voluntariamente por USIL.

- Disenar y desarrollar planes de capacitación, entrenamiento y sensibilización para todos los miembros en materia de Medio Ambiente y de Seguridad y Salud ocupacional.

Figura 35: Estructura de la Unidad Ambiental, Social, Seguridad y Salud Ocupacional USIL. 
- Exigir que los miembros cumplan con las normas aplicables en materia de Medio Ambiente, Responsablilidad Social y de Seguridad y Salud ocupacional.

- Revisar y analizar periódicamente los resultados del Sistema de Gestión en Medio Ambiente, Responsabilidad Social y de Seguridad y Salud Ocupacional, propiciando așíl la mejora continúa del sistema para lograr la excelencia mundial.

- Garantizar la participación de los trabajadores, sus representantes y sus grupos de interés en todos los elementos del Sistema de Gestión en Medio Ambiente, Responsabilidad Social y de Seguridad y Salud Ocupacional.

- Garantizar la compatibilidad o la integración del Sistema de Gestión en Medio Ambiente, Responsabilidad Social y de Seguridad y Salud Ocupacional con los otros sistemas de gestión de la Organización.

- Implementar y desarrollar planes de Salud Ocupacional dentro de USIL.

- Medidas de prevención, control y/o mítigación de impactos ambientales y sociales que pudieran generarse durante el desarrollo de las actividades y en la ejecución de proyectos.

- Implementar sistemas de monitoreo de proyectos que permiton mitigar y compensar los riesgos.

- Identificar e implementar las demás medidas, planes e instrumentos que la normativa en Seguridad y Salud en el Trabajo señala.

"Cabe referir que se entiende por miembro a los proveedores, contratistas, trabajadores directos, autónomos y personas bajo modalidod formativa laboral.

\section{ESTRUCTURA}

Para cumplir con los objetivos propuestos será necesario contar con la siguiente estructura en la Unidad Ambiental, Social, y de Seguridad y Salud Ocupacional

Figura 35: Estructura de la Unidad Ambiental, Social, Seguridad y Salud Ocupacional USIL. 


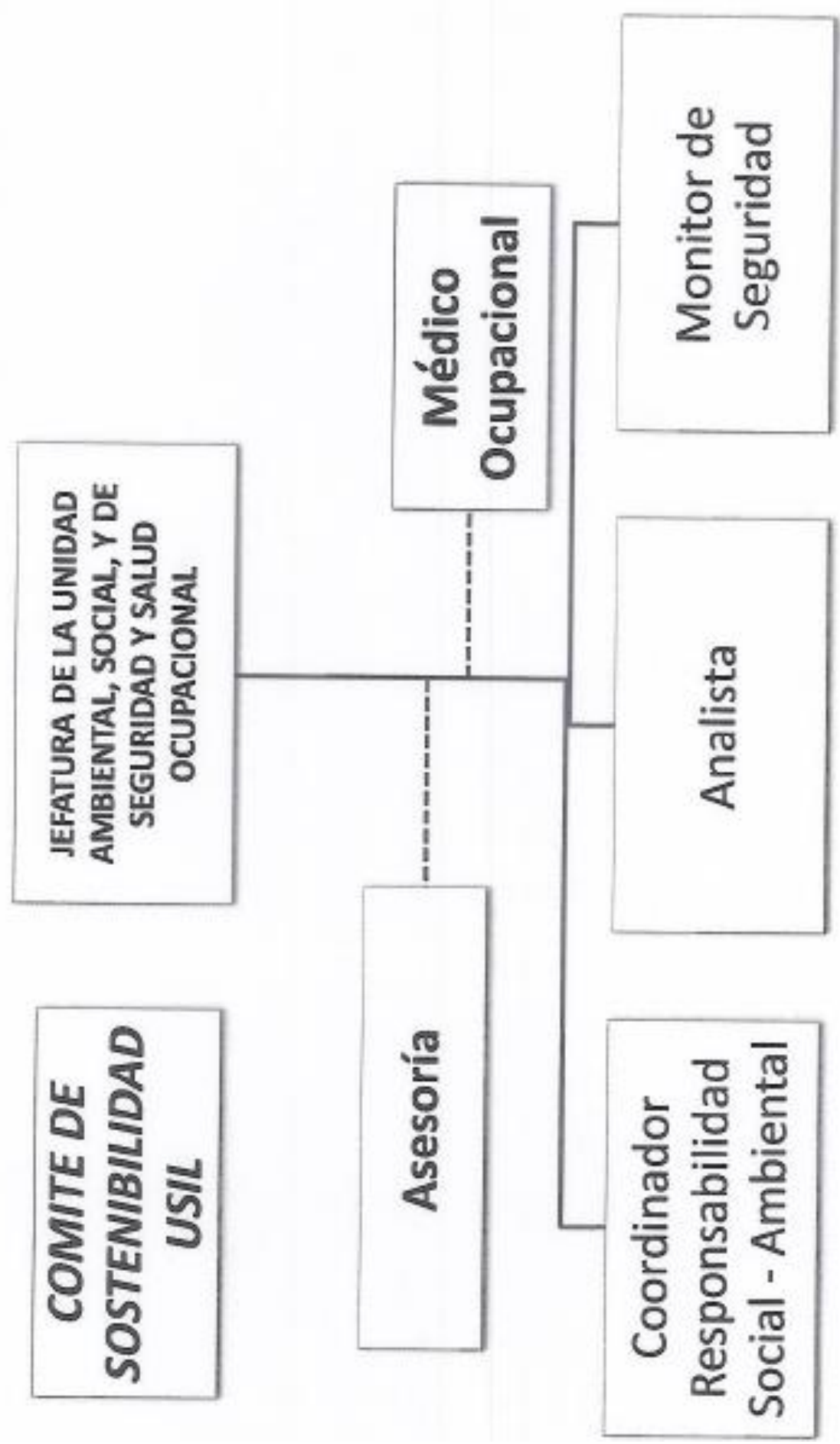

Figura 35: Estructura de la Unidad Ambiental, Social, Seguridad y Salud Ocupacional USIL. 


\section{RESPONSABILIDADES DE LOS MIEMBROS DE LA UNIDAD}

De acuerdo con lo presentado en el organigrama a continuación se detalla las funciones de cada uno de los puestas.

\section{Jefe de Unidad Ambiental, Social, y de Segurldad y Salud Ocupacional USIL (ESHS-U]}

- Establecer lineamientos del Sistema de Gestión en Medio Ambiente, Responsabilidad Social, y Seguridad y Salud Ocupacional de USIL, alineados con el Plan Estratégico de la USIL.

- Realizar seguimiento a resultados y participar en la revisión periódicamente del SG MRS Y SSO de USIL.

- Convocar y participar en los Comités de Seguridad y Salud Ocupacional de USIL

- Coordinar permanentemente con el Comité de Sostenibilidad de USIL.

- Coordinar los presupuestos y roquerimientos para la ESHS-U de USIL.

- Realizar los reportes de Medio Ambiente. Responsabilidad Social, y de Seguridad y Salud Ocupacional en los períodos requeridos por la autoridad o por otra institución relacionada a USIL

- Coordinar e implementar Certificaciones en Medio Ambiente, Respornsabilidad Social y de Seguridod y sclud Ocupacional de USIL.

- implementar programas de motivación y premiación por desempeño en Medio Ambiente, Responsablidad social, y de Seguridad y Salud Ocupacional para los miembros de USIL.

- Porticipar en la reurión de seguimiento y resultados de USIL relacionados a Medio Ambiente. Responsabilidad Social y de Seguridad y Salud Ocupacional.

- Coordinar con las autoridades muricipales o nacionales temas relacionados con Medio Amblente. Responsabilidad Social, y de Seguridad y Salud Ocupocional.

- Coordinar con las áreas académicas alianzas internos que permitan mejorar los procesos en Medio Ambiente, Responsabilidad Social y de Seguridad y Salud Ocupacional de USIL.

- Coordinar con proveedores y contratistas de construcción u otro servicio temas relacionados con Mecio Ambiente, Responsabilidad Social y de Seguridad y Salud Ocupacional de USIL.

- Implementar Planes de copacilaciones en temas de Medio Ambiente. Responsabilidad Social y de Seguridad y Salud Ocupacional para todo USIL. incluyendo los miembros.

- Programar y participar en ouditorías internas y externas al SG MRS y SSO de USIL.

- Implementar mejora continua al Sistema de Gestion MRS y SSO a través de las revisiones y análisis de resultados mensuales de la gestión.

- Idenfificar $e$ implementar las demás medidas, planes e instrumentos que la normativo en Seguridad y Salud en el Trabajo señala.

\section{Analista}

- Dar el soporte al Jefe de ESHS -U de USL en femos documentarios.

- Mantener aciualizados la documentación referente al Sistema de Gestión MRS y SSO.

Figura 35: Estructura de la Unidad Ambiental, Social, Seguridad y Salud Ocupacional USIL. 
- Solicitar los equipos de protección personal para todos los trabajadores (colaboradores) de USIL.

- Llevar un registro de las capacitaciones de todos los trabajadores (colaboradores) de USIL.

- Llevar el registro de la entrega de los Equipos de Protección Personal de todos los trabajadores (colaboradicres) de USIL.

- Comuricar y cocrdinar actividades de la ESHS-U con las diferentes áreas de USIL.

- Organizar las charlos para los miembros de USIL.

\section{Monitor de Segurldad}

- Soportar técnicamente a los administradores de todas las sedes de USIL en femas de Medio Ambiente y de Seguridad y Solud Ocupacional.

- Realizar inspecciones a todos los trabojas que se realizan en todas las sedes de USIL.

- Soportar los monitoreos de agentes ocupacionales y amblentales de acuerdo al Plan de Monitoreo de USIL.

- Soportar técnicamente en procedimientos de Medio Ambiente y de Seguridad y Salud Ocupacional a tado el personal contratista y proveedor que requicra realizar algún tipo de trabajo dentro de USIL.

- Informar al Jele de ESHS-U, al Cocrdinadar de Medio Ambiente y a los responsables de las áreas sobre las posibles desviaciones que se puedan presentar en la realización de un trabajo externo dentro de USIL.

- Garantizar la realización de las inspecciones a los equipos que se consideraran criticos de todas las instalaciones de USIL.

- Realizar entrego de Equipos de protección personal a los trabajadores (colabcradores) de USIL:

- Realizar inspecciones a las áreas consideradas como criticas dentro de USIL.

- Dictar la charlas de capacitación en materia de Medio Ambiente y de Seguridad y Salud Ocupacional a los miembros

- Acompañar en las inspecciones en Medio Ambiente y de Seguridad y Salud Ocupacional en las áreas criticas de USIL.

- Firmar los permisos de frabajos críticos realizados dentro de USIL.

\section{Coordinodor de Responsabilldad Amblental y Social}

- Elobarar y garantizar el cumplimiento de los planes en Responsablidad social que la empresa ha considerodo como importontes para el desarrollo de USIL.

- Monitcrear los estados de los grupos de infereses en fodas las sedes de USIL.

- Implementar un programa de voluntariado pora trabajadores (colaboradores) dentro de la USIL.

- Coordinar con el Decanato de Responsablidod Social sobre participación de trabajodores (colaboradores) u otro grupo de interés en programas que el Decanato implementa con el alumnado.

- Promover la participación en concursos nacionales relacionados con Resporsobilidad Social.

Figura 35: Estructura de la Unidad Ambiental, Social, Seguridad y Salud Ocupacional USIL. 
- Recepcionar y cocrdinar las comunicaciones con los grupos de interés.

- Actualizar el mapeo de grupos de interés de USIL y elaborar mejoras continuas que sean requerldas por esta.

- Realizar seguimiento a las cerlificaciones Sociales obtenidas por USIL.

- Monitorear los programos sociales implementados.

- Elaborar y garantizar el cumplimiento de los planes Ambientales para USIL.

- Implementar el Plan de Monitoreos Amblentales y realizar su seguimiento en USIL.

- Realizar aucitorias en Medio Ambiente y en Seguridad y Salud Ocupacional a los trabajos que se realizan en USIL.

- Realizar seguimiento a las certificociones en temas Ambientales obtenidas por la orgarización (LEED, ISO 14001, etc).

- implementar Proyectos Ambientales que permitan a USIL obtener reconocimientos nacionoles e internacionales.

\section{Medico Ocupacional}

- Realizar un diognósfico situacional de la gestión en salud ocupacional.

- Brindar soporte en la eloboración del Identificación de Peligros, evaluación de riesgos e implementoción de controles (IPERC) y el Mapa de Riesgos Laborales.

- Determinar la metodologia y técnica necesarios para las evaluaciones médico ocupacionales en función a la exposición de los frabajadores (colaboradores).

- Supervisar el desarrolo de los exámenes médicos ocupacionales (de ingreso, periódicos, de retiro y otras evaluaciones ocupacionales complementarias de ser el casol, asi como evaluar y registrar adecuadamente los resultados.

- Determinar la necesidad, tipo y frecuencia de exámenes médico ocupacionales complementarios.

- Vaidar la aptitud medica de los trabojadores (colaboradores) mediante las evaluaciones mádico ocupacionales en relación a las labores a realizar fapto. apto con resiricciones, no apto)

- Implementar un sisterna de histarias clínicas a fin de registrar adecuadamente la información del desempeño de la salud de los trabajadares y su historia ocupacional (labcres realizadas, riesgos a los que estuvieron expuestos, etc.)

- Crear, mantener y actualizar una bose de datos confidencial con la información de los exámenes médicos ocupaciondes.

- Atender, registrar y notificar los accidentes de trabajo.

- Desarroliar un programa anual de salud ocupocional.

- Coordinar y colaborar con los áreas relacionadas en materia de seguridod y salud en el trabajo.

- Preparación de inlormes a fin de impulsar la mejora continua en la implementación de medidas de prevención y de reportes a las autoridades competentes según corresponda.

Figura 35: Estructura de la Unidad Ambiental, Social, Seguridad y Salud Ocupacional USIL. 
ANEXO $\mathbf{N}^{\circ} 11$.

\section{CARTA DE CONSENTIMIENTO INFORMADO}

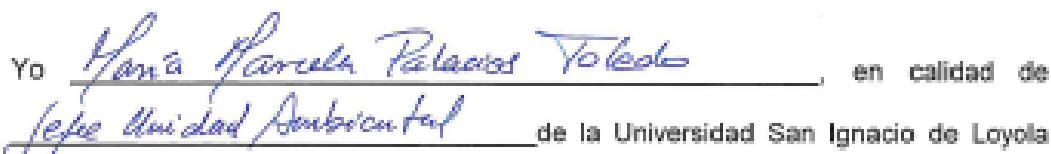
[USIL] y reconocida con DNI $\mathrm{N}^{*} 40 / 3808^{2}$; por medio de la presente dejo constancia que he contribuido con la Tesis "Guia de Gestión Ambiental para la Universidad San Ignacio de Loyola" [Investigación], cuyo autor es el Bachiller Luiggi Anthony Ballardo Evangelista [Tesista); a través de la priorización de aspectos e impactos ambientales identificados mediante el Diagnóstico Ambiental, desarrollado por el Tesista, en el marco de la presente investigación.

Adicionalmente se me informó que:

> Mi participación en esta investigación es completamente libre y voluntaria, estoy en libertad de refirarme de ella en cualquier momento.

No recibiré beneficio personal de ninguna clase por la participación en este proyecto de investigación. Sin embargo, se espera que los resultados oblenidos permitirán mejorar el desempeño ambiental de la universidad.

Hago constar que el presente documento ha sido leido y entendido por mi en su integridad de manera lbre y espontánea.

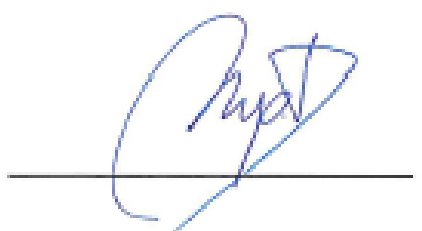

Sr.(a) Marcele Ralucios tdedo

DNI: 40138087

Fecha: $27 / 04 / 2018$

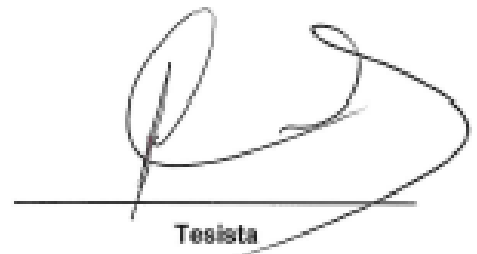

Sr.(a)

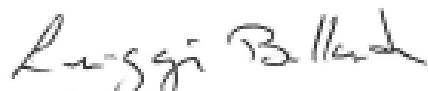
DNI: 76066089

Fecha: $27 / 01 / 1018$

Figura 36: Carta de consentimiento informado - Jefa Unidad Seguridad, Salud, Medio Ambiente y Responsabilidad Social USIL. 
ANEXO N ${ }^{\circ} 12$.

\begin{tabular}{|c|c|c|c|c|c|c|c|c|c|c|c|c|c|c|}
\hline \multicolumn{10}{|c|}{ Tabla 24: D.A. 001 USIL - MATRIZ DE IDENTIFICACIÓN DE ASPECTOS E IMPACTOS AMBIENTALES } & \multirow{2}{*}{\multicolumn{5}{|c|}{$\begin{array}{c}\text { PROCESO ESTRATÉGICO } \\
\text { Criterio } \\
\end{array}$}} \\
\hline \multirow{2}{*}{\multicolumn{3}{|c|}{ 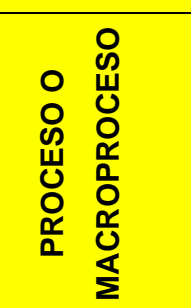 }} & \multirow[b]{2}{*}{$\begin{array}{l}\text { ASPECTO } \\
\text { AMBIENTAL }\end{array}$} & \multirow[b]{2}{*}{ 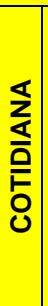 } & \multirow[b]{2}{*}{ 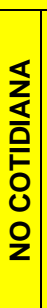 } & \multirow[b]{2}{*}{ 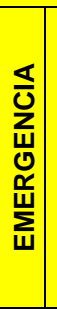 } & \multirow[b]{2}{*}{ DESCRIPCION ASPECTO AMBIENTAL } & \multirow[b]{2}{*}{$\begin{array}{l}\text { IMPACTO } \\
\text { AMBIENTAL }\end{array}$} & \multirow[b]{2}{*}{$\begin{array}{l}\text { CONTROL } \\
\text { EXISTENTE }\end{array}$} & & & & & \\
\hline & & & & & & & & & & 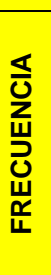 & 吕 & 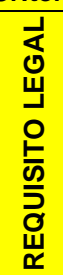 & $\frac{1}{\overleftarrow{5}}$ & $\begin{array}{l}\frac{5}{0} \\
\frac{\delta}{0} \\
\frac{0}{4} \\
\frac{0}{\omega}\end{array}$ \\
\hline \multirow{6}{*}{ 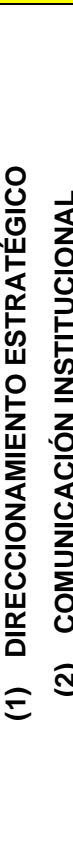 } & \multirow{6}{*}{\multicolumn{2}{|c|}{$\begin{array}{l} \\
\end{array}$}} & Consumo de papel & $\mathrm{x}$ & & & $\begin{array}{l}\text { Impresiones en general, documentación, cartulina, } \\
\text { folcote, papel para difusión de información y } \\
\text { comunicacionales }\end{array}$ & Deforestación & $\begin{array}{l}\text { Segregados en los espacios } \\
\text { comunes. Se reciclan gracias a } \\
\text { convenios institucionales. }\end{array}$ & 5 & 5 & 0 & 10 & SI \\
\hline & & & $\begin{array}{l}\text { Generación de residuos } \\
\text { peligrosos }\end{array}$ & & $x$ & & Residuos como toner, pilas; cartuchos de tinta & $\begin{array}{l}\text { Ecotoxicidad de } \\
\text { suelos }\end{array}$ & $\begin{array}{l}\text { En los espacios comunes, los } \\
\text { residuos no se segregan. }\end{array}$ & 1 & 3 & 3 & 7 & NO \\
\hline & & & $\begin{array}{l}\text { Generación de residuos } \\
\text { no peligrosos }\end{array}$ & $x$ & & & $\begin{array}{c}\text { Restos de alimento, papel, útiles de oficina, botellas } \\
\text { plásticas, envolturas, tecnopor, plásticos y } \\
\text { empaques. }\end{array}$ & $\begin{array}{l}\text { Ecotoxicidad de } \\
\text { suelos }\end{array}$ & $\begin{array}{l}\text { Segregados en espacios } \\
\text { comunes. }\end{array}$ & 3 & 3 & 3 & 9 & SI \\
\hline & & & $\begin{array}{l}\text { Consumo de energía } \\
\text { eléctrica }\end{array}$ & $\mathrm{x}$ & & & $\begin{array}{c}\text { Uso de computadoras, celulares, impresoras, } \\
\text { equipos de diseño, scanner, pantallas y proyector. } \\
\text { Asimismo, iluminación de ambientes. }\end{array}$ & $\begin{array}{l}\text { Agotamiento } \\
\text { del recurso }\end{array}$ & $\begin{array}{l}\text { No se controla. El servicio } \\
\text { eléctrico es continuo }\end{array}$ & 5 & 3 & 0 & 8 & NO \\
\hline & & & Potencial incendio & & & $\mathrm{x}$ & $\begin{array}{l}\text { Nunca se ha dado, pero existe posibilidad de corto } \\
\text { circuito dada la demanda de corriente eléctrica. }\end{array}$ & $\begin{array}{l}\text { Contaminación } \\
\text { del aire }\end{array}$ & $\begin{array}{l}\text { Existe plan de contingencia de } \\
\text { incendios y se realizan } \\
\text { simulacros. }\end{array}$ & 1 & 3 & 0 & 4 & NO \\
\hline & & & $\begin{array}{l}\text { Fuga de R12 - aire } \\
\text { acondicionado }\end{array}$ & & & $\mathrm{x}$ & $\begin{array}{l}\text { Todos los ambientes cuentan con aire } \\
\text { acondicionado y existe la posibilidad de fuga de } \\
\text { ozono, siempre y cuando no se realice el } \\
\text { mantenimiento adecuado. }\end{array}$ & $\begin{array}{l}\text { Contaminación } \\
\text { del aire }\end{array}$ & $\begin{array}{l}\text { Se revisan y efectúan } \\
\text { mantenimiento a los equipos. }\end{array}$ & 1 & 3 & 3 & 7 & NO \\
\hline
\end{tabular}




\begin{tabular}{|c|c|c|c|c|c|c|c|c|c|c|c|c|}
\hline \multicolumn{8}{|c|}{ Tabla 25: D.A. 002 USIL- MATRIZ DE IDENTIFICACIÓN DE ASPECTOS E IMPACTOS AMBIENTALES } & \multirow{2}{*}{\multicolumn{5}{|c|}{$\begin{array}{c}\text { PROCESO ESTRATÉGICO } \\
\text { Criterio } \\
\end{array}$}} \\
\hline \multirow[b]{2}{*}{ 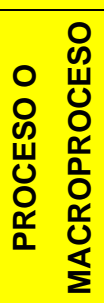 } & \multirow[b]{2}{*}{$\begin{array}{l}\text { ASPECTO } \\
\text { AMBIENTAL }\end{array}$} & \multirow[b]{2}{*}{ 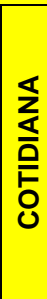 } & \multirow[b]{2}{*}{ 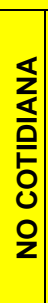 } & \multirow[b]{2}{*}{ 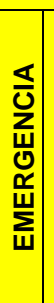 } & \multirow[b]{2}{*}{ DESCRIPCION ASPECTO AMBIENTAL } & \multirow[b]{2}{*}{ IMPACTO AMBIENTAL } & \multirow[b]{2}{*}{$\begin{array}{l}\text { CONTROL } \\
\text { EXISTENTE }\end{array}$} & & & & & \\
\hline & & & & & & & & 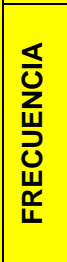 & 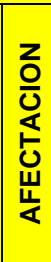 & 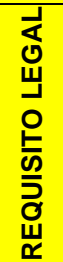 & $\frac{1}{<}$ & $\begin{array}{l}\frac{\varangle}{0} \\
z \\
\frac{0}{4} \\
\frac{0}{\omega}\end{array}$ \\
\hline \multirow{7}{*}{ 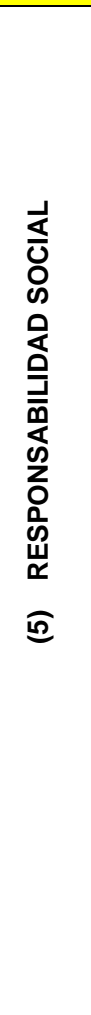 } & Consumo de papel & $\mathrm{x}$ & & & $\begin{array}{l}\text { Las actividades propias del proceso requieren } \\
\text { del uso de papel para impresiones. Asimismo, } \\
\text { la vicepresidencia hace uso de material de } \\
\text { difusión y comunicacional. }\end{array}$ & Deforestación & $\begin{array}{l}\text { Segregados en los espacios } \\
\text { comunes. Se reciclan gracias a } \\
\text { convenios institucionales. }\end{array}$ & 5 & 3 & 0 & 8 & NO \\
\hline & $\begin{array}{l}\text { Generación de } \\
\text { residuos peligrosos }\end{array}$ & & $\mathrm{x}$ & & $\begin{array}{l}\text { Residuos como toner, pilas, pinturas y } \\
\text { cartuchos de tinta }\end{array}$ & Ecotoxicidad de suelos & $\begin{array}{l}\text { En los espacios comunes, los } \\
\text { residuos no se segregan. }\end{array}$ & 1 & 3 & 3 & 7 & NO \\
\hline & $\begin{array}{l}\text { Generación de } \\
\text { residuos no } \\
\text { peligrosos }\end{array}$ & $\mathrm{x}$ & & & $\begin{array}{l}\text { Restos de papel, alimentos, envolturas, } \\
\text { botellas, papelería, plástico y útiles de oficina, }\end{array}$ & Ecotoxicidad de suelos & Segregados en espacios comunes. & 5 & 3 & 3 & 11 & SI \\
\hline & $\begin{array}{c}\text { Consumo de } \\
\text { energía eléctrica }\end{array}$ & $x$ & & & Iluminación, computadoras, e impresoras. & Agotamiento del recurso & $\begin{array}{l}\text { No se controla. Los ambientes no } \\
\text { cuentan con control de iluminación o } \\
\text { de corriente. El servicio es continuo. }\end{array}$ & 5 & 1 & 0 & 6 & NO \\
\hline & Potencial incendio & & & $x$ & $\begin{array}{l}\text { Nunca se ha dado, pero existe posibilidad de } \\
\text { corto circuito. }\end{array}$ & Contaminación del aire & $\begin{array}{c}\text { Existe plan de contingencia de } \\
\text { incendios y se realizan simulacros. }\end{array}$ & 1 & 5 & 0 & 6 & NO \\
\hline & $\begin{array}{l}\text { Transporte - } \\
\text { Voluntariado }\end{array}$ & & $\mathrm{x}$ & & $\begin{array}{l}\text { La vicepresidencia organiza voluntariados; } \\
\text { motivo por el cual el alumnado de desplaza } \\
\text { hacia los lugares programados. }\end{array}$ & Contaminación del aire & $\begin{array}{l}\text { Los buses cuentan con la inspección } \\
\text { técnica vigente. }\end{array}$ & 5 & 3 & 3 & 11 & SI \\
\hline & $\begin{array}{l}\text { Fuga de R12 - aire } \\
\text { acondicionado }\end{array}$ & & & $\mathrm{x}$ & $\begin{array}{l}\text { El ambiente de la vicepresidencia cuenta con } \\
\text { aire acondicionado y existe la posibilidad de } \\
\text { fuga de ozono, siempre y cuando no se realice } \\
\text { el mantenimiento adecuado. }\end{array}$ & Contaminación del aire & $\begin{array}{l}\text { Se revisan y efectúan mantenimiento } \\
\text { a los equipos. }\end{array}$ & 1 & 3 & 3 & 7 & NO \\
\hline
\end{tabular}




\begin{tabular}{|c|c|c|c|c|}
\hline \multicolumn{4}{|c|}{ Tabla 26: Resumen de Aspectos e Impactos Ambientales - R.D.A. 001} & \multirow{2}{*}{$\begin{array}{c}\text { Proceso Estratégico } \\
\text { Puntaje } \\
\text { Significancia }\end{array}$} \\
\hline Proceso & Aspecto Ambiental & $\begin{array}{l}\text { Impacto } \\
\text { Ambiental }\end{array}$ & Requisito Legal Asociado & \\
\hline \multirow{3}{*}{ 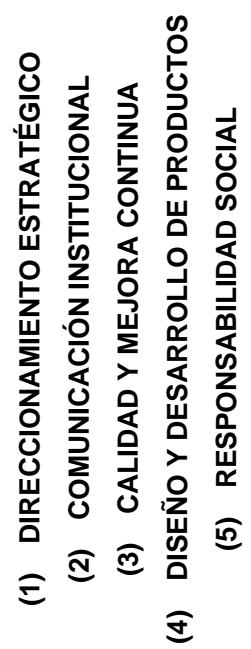 } & $\begin{array}{l}\text { Generación de residuos no } \\
\text { peligrosos }\end{array}$ & Ecotoxicidad de suelos & Ley de Residuos Sólidos & 11 \\
\hline & Transporte - Voluntariado & Contaminación del aire & $\begin{array}{c}\text { DECRETO SUPREMO № 047-2001- } \\
\text { MTC }\end{array}$ & 11 \\
\hline & Consumo de papel & Deforestación & & 10 \\
\hline
\end{tabular}




\begin{tabular}{|c|c|c|c|c|c|c|c|c|c|c|c|c|}
\hline \multicolumn{8}{|c|}{ Tabla 27: D.A. 003 USIL - MATRIZ DE IDENTIFICACIÓN DE ASPECTOS E IMPACTOS AMBIENTALES } & \multirow{2}{*}{\multicolumn{5}{|c|}{$\begin{array}{c}\text { PROCESOS PRINCIPALES } \\
\text { Criterio } \\
\end{array}$}} \\
\hline \multirow[b]{2}{*}{ 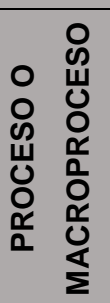 } & \multirow[b]{2}{*}{ ASPECTO AMBIENTAL } & \multirow[b]{2}{*}{ 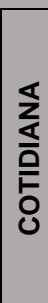 } & \multirow[b]{2}{*}{ 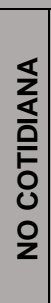 } & \multirow[b]{2}{*}{ 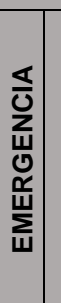 } & \multirow[b]{2}{*}{ DESCRIPCION ASPECTO AMBIENTAL } & \multirow[b]{2}{*}{$\begin{array}{l}\text { IMPACTO } \\
\text { AMBIENTAL }\end{array}$} & \multirow[b]{2}{*}{$\begin{array}{l}\text { CONTROL } \\
\text { EXISTENTE }\end{array}$} & & & & & \\
\hline & & & & & & & & 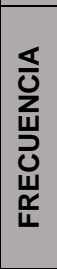 & 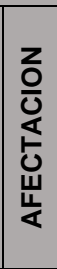 & 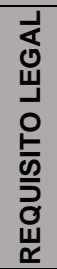 & $\underset{\leftarrow}{\stackrel{1}{\leftarrow}}$ & 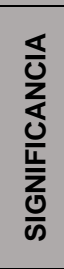 \\
\hline \multirow{7}{*}{ 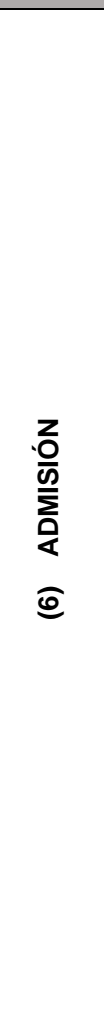 } & Consumo de papel & $\mathrm{x}$ & & & $\begin{array}{l}\text { Impresiones en general, documentación, papel para } \\
\text { difusión de carreras universitarias y material } \\
\text { promocional de la universidad. }\end{array}$ & Deforestación & $\begin{array}{l}\text { Segregados en los espacios } \\
\text { comunes. Se reciclan gracias } \\
\text { a convenios institucionales. }\end{array}$ & 5 & 5 & 0 & 10 & SI \\
\hline & $\begin{array}{l}\text { Generación de residuos } \\
\text { peligrosos }\end{array}$ & & $\mathrm{x}$ & & Residuos como toner, pilas; cartuchos de tintas & $\begin{array}{l}\text { Ecotoxicidad de } \\
\text { suelos }\end{array}$ & $\begin{array}{l}\text { En los espacios comunes, los } \\
\text { residuos no se segregan. }\end{array}$ & 1 & 1 & 3 & 5 & NO \\
\hline & $\begin{array}{l}\text { Generación de residuos no } \\
\text { peligrosos }\end{array}$ & $x$ & & & $\begin{array}{l}\text { Restos de alimento, papel, útiles de oficina, botellas } \\
\text { plásticas, envolturas, plásticos y empaques. }\end{array}$ & $\begin{array}{l}\text { Ecotoxicidad de } \\
\text { suelos }\end{array}$ & $\begin{array}{l}\text { Segregados en espacios } \\
\text { comunes. }\end{array}$ & 5 & 3 & 3 & 11 & SI \\
\hline & Consumo de energía eléctrica & $x$ & & & $\begin{array}{l}\text { Uso de computadoras, celulares, impresoras, } \\
\text { scanner, pantallas e iluminación de ambientes. }\end{array}$ & $\begin{array}{l}\text { Agotamiento } \\
\text { del recurso }\end{array}$ & $\begin{array}{l}\text { No se controla. El servicio } \\
\text { eléctrico es continuo }\end{array}$ & 5 & 3 & 0 & 8 & NO \\
\hline & Potencial incendio & & & $\mathrm{x}$ & $\begin{array}{l}\text { Nunca se ha dado, pero existe posibilidad de corto } \\
\text { circuito dada la alta demanda de corriente eléctrica. }\end{array}$ & $\begin{array}{l}\text { Contaminación } \\
\text { del aire }\end{array}$ & $\begin{array}{l}\text { Existe plan de contingencia } \\
\text { de incendios y se realizan } \\
\text { simulacros. }\end{array}$ & 1 & 5 & 0 & 6 & NO \\
\hline & $\begin{array}{l}\text { Fuga de R12 - aire } \\
\text { acondicionado }\end{array}$ & & & $x$ & $\begin{array}{l}\text { El ambiente de "admisión" cuenta con aire } \\
\text { acondicionado y existe la posibilidad de fuga de } \\
\text { ozono, siempre y cuando no se realice el } \\
\text { mantenimiento adecuado. }\end{array}$ & $\begin{array}{l}\text { Contaminación } \\
\text { del aire }\end{array}$ & $\begin{array}{l}\text { Se revisan y efectúan } \\
\text { mantenimiento a los equipos. }\end{array}$ & 1 & 3 & 3 & 7 & NO \\
\hline & Transporte - Movilización & & $x$ & & $\begin{array}{l}\text { Se trasladan posibles nuevos alumnos para que } \\
\text { conozcan la universidad; así como para charlas de } \\
\text { carreras universitarias. Asimismo, personal de la } \\
\text { universidad se traslada a diversos lugares para bridar } \\
\text { charlas a información al público seleccionado. }\end{array}$ & $\begin{array}{l}\text { Contaminación } \\
\text { del aire }\end{array}$ & $\begin{array}{l}\text { Las movilidades cuentan con } \\
\text { inspección técnica vigente. }\end{array}$ & 3 & 3 & 3 & 9 & SI \\
\hline
\end{tabular}




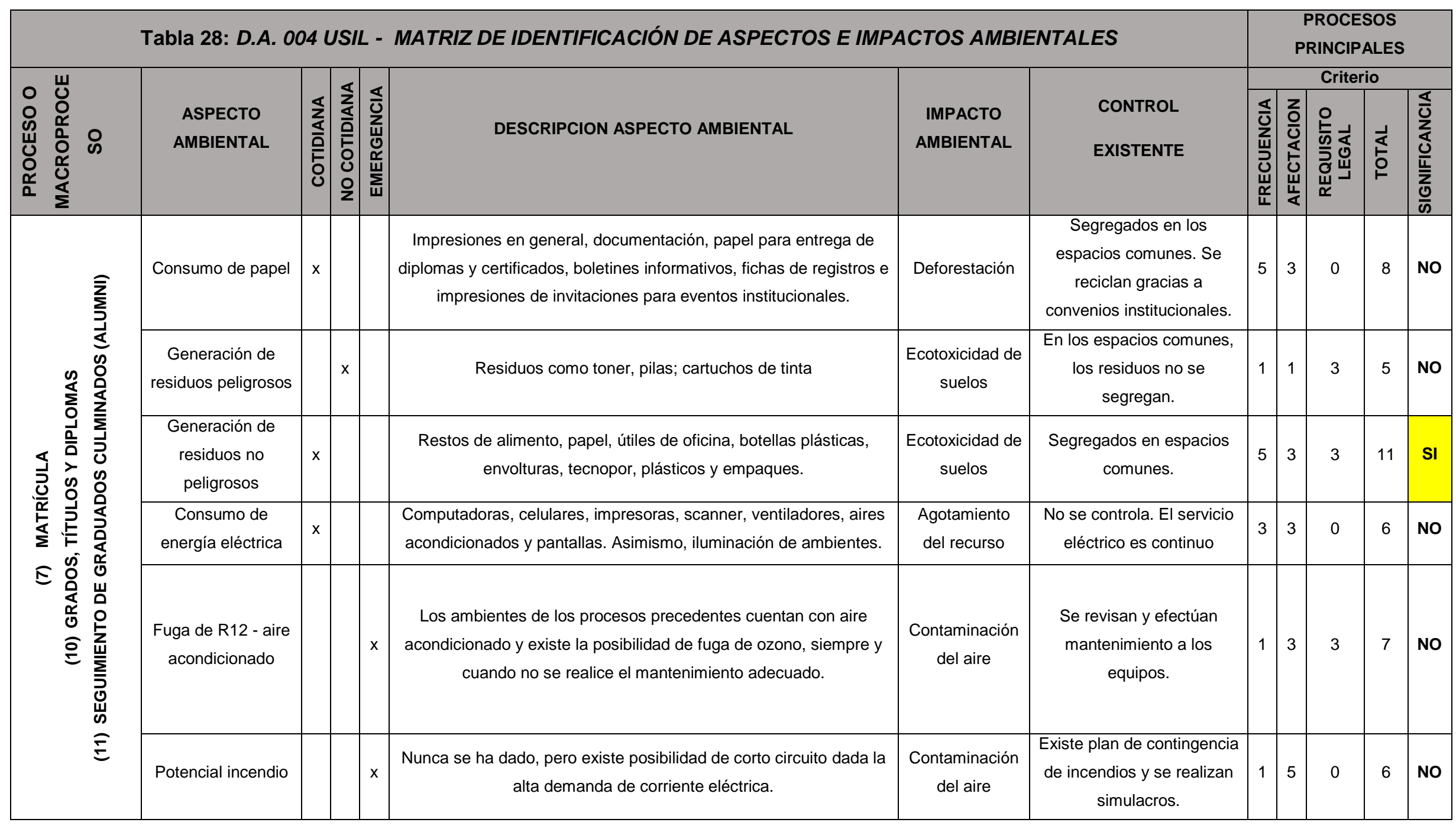




\begin{tabular}{|c|c|c|c|c|c|c|c|c|c|c|c|c|}
\hline \multicolumn{8}{|c|}{ Tabla 29: D.A. 005 USIL - MATRIZ DE IDENTIFICACIÓN DE ASPECTOS E IMPACTOS AMBIENTALES } & \multirow{2}{*}{\multicolumn{5}{|c|}{$\begin{array}{l}\text { PROCESOS } \\
\text { PRINCIPALES } \\
\text { Criterio } \\
\end{array}$}} \\
\hline \multirow[b]{2}{*}{ 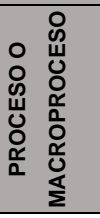 } & \multirow[b]{2}{*}{ ASPECTO AMBIENTAL } & \multirow[b]{2}{*}{ 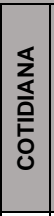 } & \multirow[b]{2}{*}{ 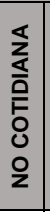 } & \multirow[b]{2}{*}{ 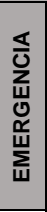 } & \multirow[b]{2}{*}{ DESCRIPCION ASPECTO AMBIENTAL } & \multirow[b]{2}{*}{$\begin{array}{l}\text { IMPACTO } \\
\text { AMBIENTAL }\end{array}$} & \multirow[b]{2}{*}{$\begin{array}{l}\text { CONTROL } \\
\text { EXISTENTE }\end{array}$} & & & & & \\
\hline & & & & & & & & 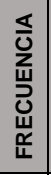 & 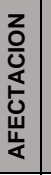 & 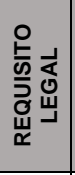 & $\begin{array}{l}\vec{\leftarrow} \\
\stackrel{5}{\circ} \\
\vdash\end{array}$ & $\begin{array}{l}\frac{5}{0} \\
\frac{2}{4} \\
\frac{d}{4} \\
\frac{u}{2} \\
\frac{0}{\omega}\end{array}$ \\
\hline \multirow{10}{*}{ 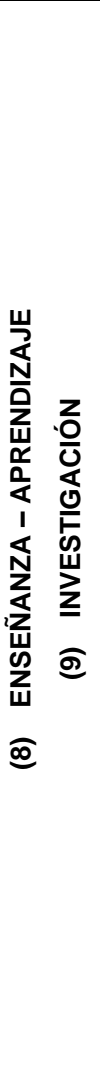 } & Consumo de papel & $\mathrm{x}$ & & & $\begin{array}{l}\text { Impresiones para comunicados universitarios, exámenes, papel } \\
\text { para presentación de trabajos, papelógrafos, cartulinas, papel } \\
\text { fotografía y documentario, material educativo - informativo. }\end{array}$ & Deforestación & $\begin{array}{l}\text { Segregados en los espacios } \\
\text { comunes. Se reciclan gracias a } \\
\text { convenios institucionales. }\end{array}$ & 5 & 5 & 0 & 10 & SI \\
\hline & $\begin{array}{l}\text { Generación de residuos } \\
\text { peligrosos }\end{array}$ & & $x$ & & $\begin{array}{l}\text { Residuos tales como toner, pilas y cartuchos de tinta. En el } \\
\text { laboratorio se utilizan insumos químicos que pueden ser } \\
\text { contaminantes; así como material biológico. }\end{array}$ & $\begin{array}{l}\text { Ecotoxicidad de } \\
\text { suelos y agua }\end{array}$ & $\begin{array}{l}\text { En los espacios comunes, los } \\
\text { residuos no se segregan. }\end{array}$ & 5 & 5 & 3 & 13 & SI \\
\hline & $\begin{array}{l}\text { Generación de residuos no } \\
\text { peligrosos }\end{array}$ & $\mathrm{x}$ & & & $\begin{array}{l}\text { Restos de alimento (HTG), residuos orgánicos, cartón, papel, } \\
\text { útiles de oficina, botellas plásticas y empaques. En laboratorios } \\
\text { desechan guantes de plásticos y papel higiénico. }\end{array}$ & $\begin{array}{l}\text { Ecotoxicidad de } \\
\text { suelos y agua }\end{array}$ & $\begin{array}{l}\text { En áreas comunes se segregan } \\
\text { usando tachos. En laboratorios sí se } \\
\text { segregan los residuos. }\end{array}$ & 5 & 5 & 3 & 13 & SI \\
\hline & $\begin{array}{l}\text { Consumo de energía } \\
\text { eléctrica }\end{array}$ & $x$ & & & $\begin{array}{c}\text { Computadoras, aire acondicionado, impresoras, ventiladores y } \\
\text { otros. En laboratorio usan instrumentos especializados que } \\
\text { utilizan corriente eléctrica. }\end{array}$ & $\begin{array}{l}\text { Agotamiento del } \\
\text { recurso }\end{array}$ & $\begin{array}{l}\text { No se controla. El servicio eléctrico es } \\
\text { continuo }\end{array}$ & 5 & 5 & 0 & 10 & SI \\
\hline & Consumo de agua & $x$ & & & Aspecto identificado en las clases de laboratorio y cocina. & $\begin{array}{c}\text { Agotamiento del } \\
\text { recurso }\end{array}$ & $\begin{array}{l}\text { No se controla. El consumo depende } \\
\text { si cierran o no la grifería. }\end{array}$ & 5 & 5 & 0 & 10 & SI \\
\hline & Potencial incendio & & $\mathrm{x}$ & & $\begin{array}{l}\text { Nunca se ha dado, pero existe posibilidad de corto circuito. En } \\
\text { el laboratorio trabajan con insumos químicos inflamables. }\end{array}$ & $\begin{array}{l}\text { Contaminación } \\
\text { del aire }\end{array}$ & $\begin{array}{l}\text { Existe plan de contingencia de } \\
\text { incendios y realizan simulacros. }\end{array}$ & 1 & 5 & 0 & 6 & NO \\
\hline & Generación de efluentes & $x$ & & & $\begin{array}{c}\text { Agua con jabón, agua con detergente, y aguas contaminadas } \\
\text { por los experimentos. }\end{array}$ & $\begin{array}{l}\text { Ecotoxicidad del } \\
\text { agua }\end{array}$ & $\begin{array}{l}\text { Si se controla. Se mide la descarga al } \\
\text { alcantarillado }\end{array}$ & 5 & 5 & 3 & 13 & SI \\
\hline & $\begin{array}{l}\text { Potencial derrame de } \\
\text { solventes orgánicos o } \\
\text { inorgánicos. }\end{array}$ & & & $x$ & $\begin{array}{l}\text { Se respeta el protocolo de seguridad: sin embargo, existirá el } \\
\text { riesgo derrame de sustancias. }\end{array}$ & $\begin{array}{l}\text { Ecotoxicidad en } \\
\text { suelos }\end{array}$ & $\begin{array}{l}\text { Se controla bajo protocolo de } \\
\text { seguridad }\end{array}$ & 1 & 3 & 3 & 7 & NO \\
\hline & $\begin{array}{l}\text { Transporte - Dictado de } \\
\text { clase }\end{array}$ & $\mathrm{x}$ & & & $\begin{array}{c}\text { Traslado del alumnado a sede Pachacamac para el dictado de } \\
\text { clases, entre otras actividades. }\end{array}$ & $\begin{array}{l}\text { Contaminación } \\
\text { del aire }\end{array}$ & $\begin{array}{l}\text { Los buses cuentan con la inspección } \\
\text { técnica vigente. }\end{array}$ & 5 & 5 & 3 & 13 & SI \\
\hline & $\begin{array}{l}\text { Fuga de R12 - aire } \\
\text { acondicionado }\end{array}$ & & & $x$ & $\begin{array}{c}\text { Algunas aulas cuentan con aire acondicionado y existe la } \\
\text { posibilidad de fuga de ozono, siempre y cuando no se realice el } \\
\text { mantenimiento adecuado. }\end{array}$ & $\begin{array}{l}\text { Contaminación } \\
\text { del aire }\end{array}$ & $\begin{array}{l}\text { Se revisan y efectúan mantenimiento } \\
\text { a los equipos. }\end{array}$ & 1 & 3 & 3 & 7 & NO \\
\hline
\end{tabular}




\begin{tabular}{|c|c|c|c|c|}
\hline \multicolumn{4}{|c|}{ Tabla 30: Resumen de Aspectos e Impactos Ambientales - R.D.A. 002} & \multirow{2}{*}{$\begin{array}{c}\text { Procesos } \\
\text { Principales } \\
\text { Puntaje } \\
\text { Significancia }\end{array}$} \\
\hline Proceso & Aspecto Ambiental & Impacto Ambiental & Requisito Legal Asociado & \\
\hline \multirow{8}{*}{ 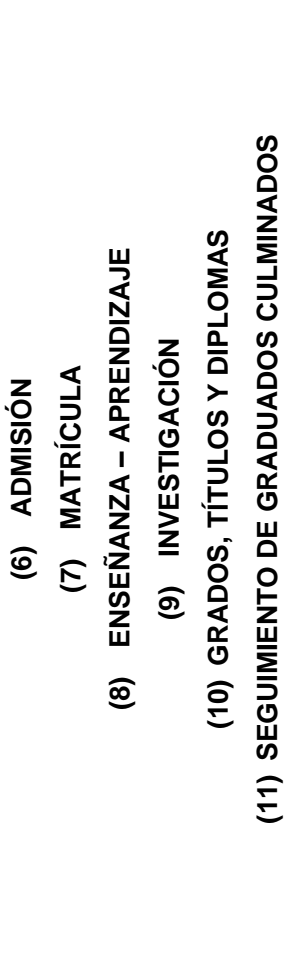 } & Generación de residuos peligrosos & Ecotoxicidad de suelos & Ley de Residuos Sólidos & 13 \\
\hline & Generación de efluentes & Ecotoxicidad del agua & Reglamento de Desagües & 13 \\
\hline & Transporte - Dictado de clase & Contaminación del aire & $\begin{array}{c}\text { DECRETO SUPREMO № 047-2001- } \\
\text { MTC }\end{array}$ & 13 \\
\hline & Generación de residuos no peligrosos & Ecotoxicidad de suelos & Ley de Residuos Sólidos & 13 \\
\hline & Consumo de agua & Agotamiento del recurso & & 10 \\
\hline & Consumo de papel & Deforestación & & 10 \\
\hline & Consumo de energía eléctrica & Agotamiento del recurso & & 10 \\
\hline & Transporte - Movilización & Contaminación del aire & $\begin{array}{c}\text { DECRETO SUPREMO № 047-2001- } \\
\text { MTC }\end{array}$ & 9 \\
\hline
\end{tabular}




\begin{tabular}{|c|c|c|c|c|c|c|c|c|c|c|c|c|c|c|}
\hline \multicolumn{10}{|c|}{ Tabla 31: D.A. 006 USIL - MATRIZ DE IDENTIFICACIÓN DE ASPECTOS E IMPACTOS AMBIENTALES } & \multicolumn{5}{|c|}{ PROCESOS DE APOYO } \\
\hline & & & \multirow[b]{2}{*}{$\begin{array}{l}\text { ASPECTO } \\
\text { AMBIENTAL }\end{array}$} & \multirow[b]{2}{*}{ 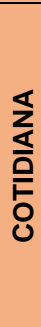 } & \multirow[b]{2}{*}{ 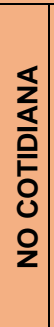 } & \multirow[b]{2}{*}{ 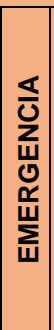 } & \multirow[b]{2}{*}{ DESCRIPCION ASPECTO AMBIENTAL } & \multirow[b]{2}{*}{$\begin{array}{l}\text { IMPACTO } \\
\text { AMBIENTAL }\end{array}$} & \multirow[b]{2}{*}{$\begin{array}{l}\text { CONTROL } \\
\text { EXISTENTE }\end{array}$} & \multicolumn{5}{|c|}{ Criterio } \\
\hline 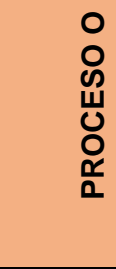 & 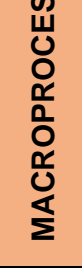 & & & & & & & & & 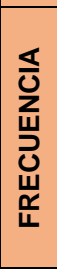 & 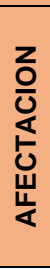 & 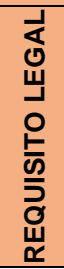 & $\underset{\leftarrow}{\stackrel{5}{\circ}}$ & 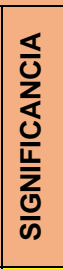 \\
\hline \multirow{6}{*}{ 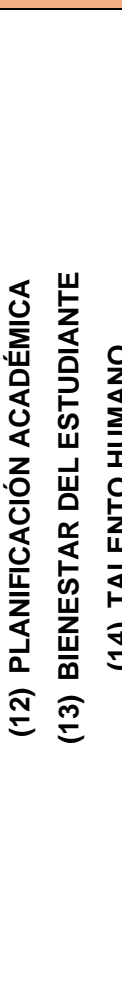 } & \multirow{6}{*}{ 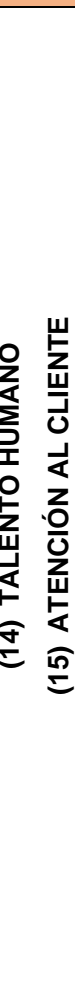 } & \multirow{6}{*}{ 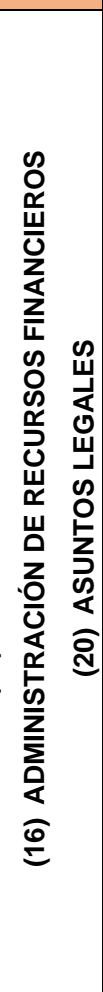 } & Consumo de papel & $\mathrm{x}$ & & & $\begin{array}{l}\text { Impresiones en general, documentación, papel } \\
\text { para difusión de información, fichas de registro, } \\
\text { boletas de pago e informes }\end{array}$ & Deforestación & $\begin{array}{l}\text { Segregados en los } \\
\text { espacios comunes. Se } \\
\text { reciclan gracias a } \\
\text { convenios institucionales. }\end{array}$ & 5 & 5 & 0 & 10 & SI \\
\hline & & & $\begin{array}{l}\text { Generación de } \\
\text { residuos peligrosos }\end{array}$ & & $\mathrm{x}$ & & Residuos como toner, pilas; cartuchos de tintas & $\begin{array}{l}\text { Ecotoxicidad de } \\
\text { suelos }\end{array}$ & $\begin{array}{l}\text { En los espacios comunes, } \\
\text { los residuos no se } \\
\text { segregan. }\end{array}$ & 1 & 1 & 3 & 5 & NO \\
\hline & & & $\begin{array}{l}\text { Generación de } \\
\text { residuos no } \\
\text { peligrosos }\end{array}$ & $x$ & & & $\begin{array}{l}\text { Restos de alimento, papel, útiles de oficina, botellas } \\
\text { plásticas, envolturas, plásticos y empaques. }\end{array}$ & $\begin{array}{l}\text { Ecotoxicidad de } \\
\text { suelos }\end{array}$ & $\begin{array}{l}\text { Segregados en espacios } \\
\text { comunes. }\end{array}$ & 3 & 3 & 3 & 9 & SI \\
\hline & & & $\begin{array}{l}\text { Consumo de } \\
\text { energía eléctrica }\end{array}$ & $x$ & & & $\begin{array}{l}\text { Uso de computadoras, celulares, impresoras, } \\
\text { scanner, ventiladores, aire acondicionado y } \\
\text { pantallas. Asimismo, iluminación de ambientes. }\end{array}$ & $\begin{array}{l}\text { Agotamiento del } \\
\text { recurso }\end{array}$ & $\begin{array}{l}\text { No se controla. El servicio } \\
\text { eléctrico es continuo }\end{array}$ & 5 & 3 & 0 & 8 & NO \\
\hline & & & $\begin{array}{l}\text { Fuga de R12 - aire } \\
\text { acondicionado }\end{array}$ & & & $\mathrm{x}$ & $\begin{array}{l}\text { Todos los ambientes cuentan con aire } \\
\text { acondicionado y existe la posibilidad de fuga de } \\
\text { ozono, siempre y cuando no se realice el } \\
\text { mantenimiento adecuado. }\end{array}$ & $\begin{array}{l}\text { Contaminación } \\
\text { del aire }\end{array}$ & $\begin{array}{l}\text { Se revisan y efectúan } \\
\text { mantenimiento a los } \\
\text { equipos. }\end{array}$ & 1 & 3 & 3 & 7 & NO \\
\hline & & & Potencial incendio & & & $x$ & $\begin{array}{l}\text { Nunca se ha dado, pero existe posibilidad de corto } \\
\text { circuito dada la alta demanda de corriente eléctrica. }\end{array}$ & $\begin{array}{l}\text { Contaminación } \\
\text { del aire }\end{array}$ & $\begin{array}{l}\text { Existe plan de contingencia } \\
\text { de incendios y se realizan } \\
\text { simulacros. }\end{array}$ & 1 & 5 & 0 & 6 & NO \\
\hline
\end{tabular}




\begin{tabular}{|c|c|c|c|c|c|c|c|c|c|c|c|c|}
\hline \multicolumn{8}{|c|}{ Tabla 32: D.A. 007 USIL - MATRIZ DE IDENTIFICACIÓN DE ASPECTOS E IMPACTOS AMBIENTALES } & \multirow{2}{*}{\multicolumn{5}{|c|}{$\begin{array}{c}\text { PROCESOS DE APOYO } \\
\text { Criterio } \\
\end{array}$}} \\
\hline \multirow[b]{2}{*}{ 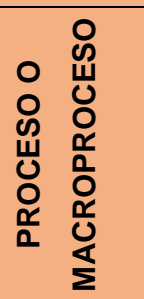 } & \multirow[b]{2}{*}{ ASPECTO AMBIENTAL } & \multirow[b]{2}{*}{ 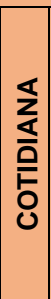 } & \multirow[b]{2}{*}{ 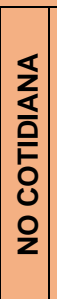 } & \multirow[b]{2}{*}{ 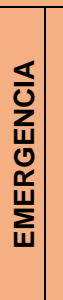 } & \multirow[b]{2}{*}{ DESCRIPCION ASPECTO AMBIENTAL } & \multirow[b]{2}{*}{$\begin{array}{c}\text { IMPACTO } \\
\text { AMBIENTAL }\end{array}$} & \multirow[b]{2}{*}{$\begin{array}{l}\text { CONTROL } \\
\text { EXISTENTE }\end{array}$} & & & & & \\
\hline & & & & & & & & 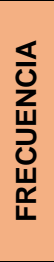 & $\begin{array}{l}z \\
\frac{0}{0} \\
\frac{1}{5} \\
\text { 岁 } \\
\frac{1}{4}\end{array}$ & 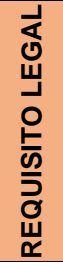 & $\frac{1}{\ll}$ & $\begin{array}{l}\frac{\Xi}{0} \\
z \\
\frac{\delta}{u} \\
\sum \\
\frac{0}{\omega}\end{array}$ \\
\hline \multirow{7}{*}{ 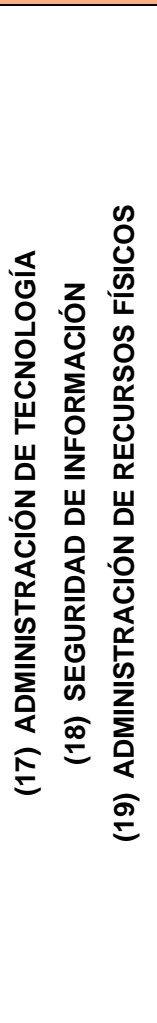 } & Consumo de papel & $x$ & & & $\begin{array}{l}\text { Impresiones en general, documentación, fichas de } \\
\text { registro, boletas de pago e informes }\end{array}$ & Deforestación & $\begin{array}{l}\text { Segregados en los espacios } \\
\text { comunes. Se reciclan gracias a } \\
\text { convenios institucionales. }\end{array}$ & 3 & 3 & 0 & 6 & NO \\
\hline & $\begin{array}{l}\text { Generación de residuos } \\
\text { peligrosos }\end{array}$ & & $x$ & & $\begin{array}{l}\text { Residuos como toner, pilas; cartuchos de tintas, } \\
\text { tornillos, materiales metálicos, restos de pintura y } \\
\text { repuestos electrónicos. }\end{array}$ & $\begin{array}{l}\text { Ecotoxicidad de } \\
\text { suelos }\end{array}$ & $\begin{array}{l}\text { En los espacios comunes, los } \\
\text { residuos no se segregan. }\end{array}$ & 5 & 5 & 3 & 13 & SI \\
\hline & $\begin{array}{l}\text { Generación de residuos } \\
\text { no peligrosos }\end{array}$ & $x$ & & & $\begin{array}{l}\text { Restos de alimento, papel, útiles de oficina, botellas } \\
\text { plásticas, envolturas, plásticos, empaques, cintas de } \\
\text { embalaje, cajas de tecnopor - cartón y trapeadores. }\end{array}$ & $\begin{array}{l}\text { Ecotoxicidad de } \\
\text { suelos }\end{array}$ & $\begin{array}{l}\text { Segregados en espacios } \\
\text { comunes. }\end{array}$ & 5 & 5 & 3 & 13 & SI \\
\hline & $\begin{array}{l}\text { Consumo de energía } \\
\text { eléctrica }\end{array}$ & $x$ & & & $\begin{array}{l}\text { Uso de computadoras, celulares, impresoras, } \\
\text { scanner, ventiladores, aire acondicionado, } \\
\text { procesadores, repuestos electrónicos y pantallas. } \\
\text { Asimismo, iluminación de ambientes. }\end{array}$ & $\begin{array}{l}\text { Agotamiento } \\
\text { del recurso }\end{array}$ & $\begin{array}{l}\text { No se controla. El servicio } \\
\text { eléctrico es continuo }\end{array}$ & 5 & 5 & 0 & 10 & SI \\
\hline & $\begin{array}{l}\text { Fuga de R12 - aire } \\
\text { acondicionado }\end{array}$ & & & $x$ & $\begin{array}{l}\text { Todos los ambientes cuentan con aire acondicionado } \\
\text { y existe la posibilidad de fuga de ozono, siempre y } \\
\text { cuando no se realice el mantenimiento adecuado. }\end{array}$ & $\begin{array}{l}\text { Contaminación } \\
\text { del aire }\end{array}$ & $\begin{array}{l}\text { Se revisan y efectúan } \\
\text { mantenimiento a los equipos. }\end{array}$ & 1 & 3 & 3 & 7 & NO \\
\hline & Potencial incendio & & & $x$ & $\begin{array}{l}\text { Nunca se ha dado, pero existe posibilidad de corto } \\
\text { circuito dada la alta demanda de corriente eléctrica. } \\
\text { El área de logística maneja materiales inflamables. }\end{array}$ & $\begin{array}{l}\text { Contaminación } \\
\text { del aire }\end{array}$ & $\begin{array}{l}\text { Existe plan de contingencia de } \\
\text { incendios y se realizan } \\
\text { simulacros. }\end{array}$ & 1 & 5 & 0 & 6 & NO \\
\hline & Transporte - Movilización & & & & $\begin{array}{l}\text { El personal se traslada para la adquisición, recepción } \\
\qquad y \text { traslado de recursos físicos }\end{array}$ & $\begin{array}{l}\text { Contaminación } \\
\text { del aire }\end{array}$ & $\begin{array}{l}\text { Los buses cuentan con la } \\
\text { inspección técnica vigente. }\end{array}$ & 5 & 3 & 3 & 11 & SI \\
\hline
\end{tabular}




\begin{tabular}{|c|c|c|c|c|}
\hline \multicolumn{4}{|c|}{ Tabla 33: Resumen de Aspectos e Impactos Ambientales - R.D.A. 003} & \multirow{2}{*}{$\begin{array}{c}\text { Procesos de Apoyo } \\
\text { Puntaje } \\
\text { Significancia }\end{array}$} \\
\hline Proceso & Aspecto Ambiental & Impacto Ambiental & Requisito Legal Asociado & \\
\hline \multirow{5}{*}{ 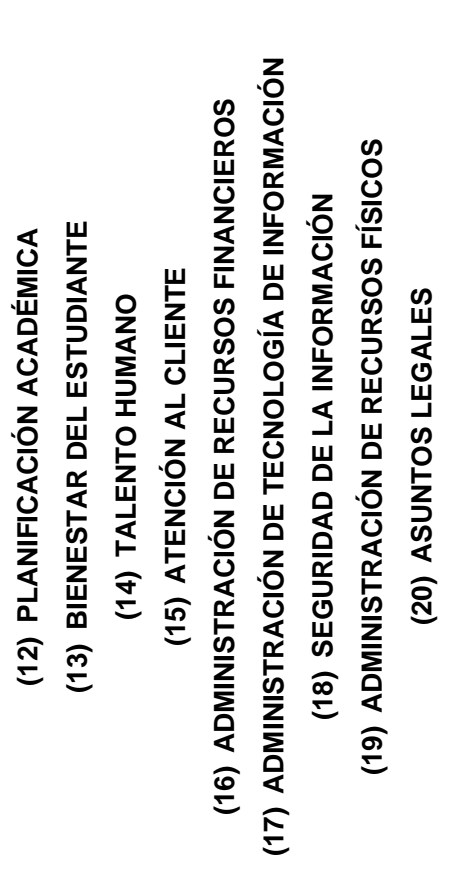 } & $\begin{array}{c}\text { Generación de residuos } \\
\text { peligrosos }\end{array}$ & Ecotoxicidad de suelos & Ley de Residuos Sólidos & 13 \\
\hline & $\begin{array}{c}\text { Generación de residuos no } \\
\text { peligrosos }\end{array}$ & Ecotoxicidad de suelos & Ley de Residuos Sólidos & 13 \\
\hline & Transporte - Movilización & Contaminación del aire & DECRETO SUPREMO № 047-2001-MTC & 11 \\
\hline & Consumo de papel & Deforestación & & 10 \\
\hline & $\begin{array}{c}\text { Consumo de energía } \\
\text { eléctrica }\end{array}$ & Agotamiento del recurso & & 10 \\
\hline
\end{tabular}




\begin{tabular}{|c|c|c|c|c|c|c|c|c|c|c|c|c|}
\hline \multicolumn{8}{|c|}{ Tabla 34: D.A. 008 USIL - MATRIZ DE IDENTIFICACIÓN DE ASPECTOS E IMPACTOS AMBIENTALES } & \multicolumn{5}{|c|}{$\begin{array}{l}\text { PROCESOS DE } \\
\text { EVALUACIÓN }\end{array}$} \\
\hline \multirow[b]{2}{*}{ 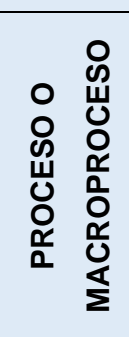 } & \multirow[b]{2}{*}{ ASPECTO AMBIENTAL } & \multirow[b]{2}{*}{ 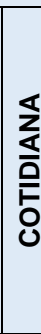 } & \multirow[b]{2}{*}{ 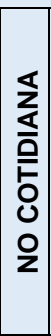 } & \multirow[b]{2}{*}{ 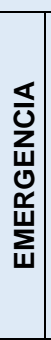 } & \multirow[b]{2}{*}{$\begin{array}{l}\text { DESCRIPCION ASPECTO } \\
\text { AMBIENTAL }\end{array}$} & \multirow[b]{2}{*}{ IMPACTO AMBIENTAL } & \multirow[b]{2}{*}{$\begin{array}{l}\text { CONTROL } \\
\text { EXISTENTE }\end{array}$} & \multicolumn{5}{|c|}{ Criterio } \\
\hline & & & & & & & & 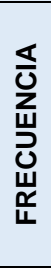 & 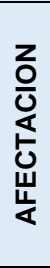 & 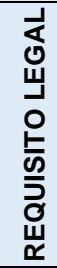 & 崖 & 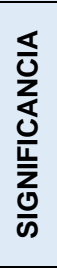 \\
\hline \multirow{6}{*}{ 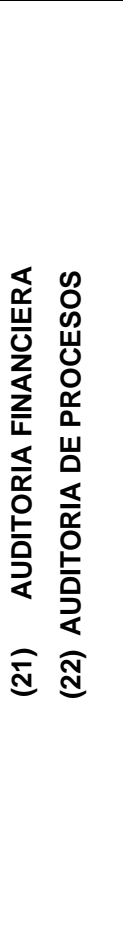 } & Consumo de papel & $\mathrm{x}$ & & & $\begin{array}{l}\text { Impresiones en general, } \\
\text { documentación, fichas de registro, } \\
\text { boletas de pago e informes }\end{array}$ & Deforestación & $\begin{array}{l}\text { Segregados en los espacios } \\
\text { comunes. Se reciclan gracias a } \\
\text { convenios institucionales. }\end{array}$ & 5 & 5 & 0 & 10 & SI \\
\hline & $\begin{array}{l}\text { Generación de residuos } \\
\text { peligrosos }\end{array}$ & & $\mathrm{x}$ & & $\begin{array}{l}\text { Residuos como toner, pilas; cartuchos } \\
\text { de tintas }\end{array}$ & Ecotoxicidad de suelos & $\begin{array}{l}\text { En los espacios comunes, los } \\
\text { residuos no se segregan. }\end{array}$ & 1 & 1 & 3 & 5 & NO \\
\hline & $\begin{array}{l}\text { Generación de residuos } \\
\text { no peligrosos }\end{array}$ & $x$ & & & $\begin{array}{l}\text { Restos de alimento, papel, útiles de } \\
\text { oficina, botellas plásticas, envolturas, } \\
\text { plásticos y empaques. }\end{array}$ & Ecotoxicidad de suelos & $\begin{array}{l}\text { Segregados en espacios } \\
\text { comunes. }\end{array}$ & 3 & 3 & 3 & 9 & SI \\
\hline & $\begin{array}{l}\text { Consumo de energía } \\
\text { eléctrica }\end{array}$ & $x$ & & & $\begin{array}{l}\text { Uso de computadoras, celulares, } \\
\text { impresoras, scanner, ventiladores, aire } \\
\text { acondicionado y pantallas. Asimismo, } \\
\text { iluminación de ambientes. }\end{array}$ & Agotamiento del recurso & $\begin{array}{l}\text { No se controla. El servicio } \\
\text { eléctrico es continuo }\end{array}$ & 3 & 1 & 0 & 4 & NO \\
\hline & $\begin{array}{l}\text { Fuga de R12 - aire } \\
\text { acondicionado }\end{array}$ & & & $x$ & $\begin{array}{l}\text { Los ambientes cuentan con aire } \\
\text { acondicionado y existe la posibilidad de } \\
\text { fuga de ozono, siempre y cuando no se } \\
\text { realice el mantenimiento adecuado. }\end{array}$ & Contaminación del aire & $\begin{array}{c}\text { Se revisan y efectúan } \\
\text { mantenimiento a los equipos. }\end{array}$ & 1 & 3 & 3 & 7 & NO \\
\hline & Potencial incendio & & & $x$ & $\begin{array}{l}\text { Nunca se ha dado, pero existe } \\
\text { posibilidad de corto circuito dada la alta } \\
\text { demanda de corriente eléctrica. }\end{array}$ & Contaminación del aire & $\begin{array}{l}\text { Existe plan de contingencia de } \\
\text { incendios y se realizan } \\
\text { simulacros. }\end{array}$ & 1 & 5 & 0 & 6 & NO \\
\hline
\end{tabular}




\begin{tabular}{|c|c|c|c|c|}
\hline \multicolumn{4}{|c|}{ Tabla 35: Resumen de Aspectos e Impactos Ambientales - R.D.A. 004} & \multirow{2}{*}{$\begin{array}{c}\begin{array}{c}\text { Procesos de } \\
\text { Evaluación }\end{array} \\
\text { Puntaje } \\
\text { Significancia }\end{array}$} \\
\hline Proceso & Aspecto Ambiental & Impacto Ambiental & Requisito Legal Asociado & \\
\hline \multirow{2}{*}{ 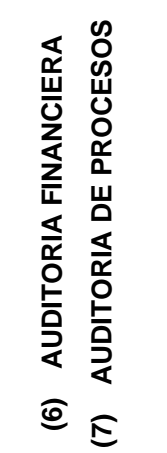 } & Consumo de papel & Deforestación & & 10 \\
\hline & Generación de residuos no peligrosos & Ecotoxicidad de suelos & Ley de Residuos Sólidos & 9 \\
\hline
\end{tabular}




\begin{tabular}{|c|c|c|c|c|c|c|c|c|c|c|c|c|}
\hline \multicolumn{8}{|c|}{ Tabla 36: D.A. 009 USIL - MATRIZ DE IDENTIFICACIÓN DE ASPECTOS E IMPACTOS AMBIENTALES } & \multirow{2}{*}{\multicolumn{5}{|c|}{$\begin{array}{c}\text { PROCESOS } \\
\text { TERCERIZADOS } \\
\text { Criterio } \\
\end{array}$}} \\
\hline \multirow[b]{2}{*}{ 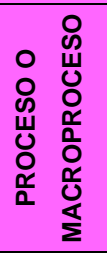 } & \multirow[b]{2}{*}{ ASPECTO AMBIENTAL } & \multirow[b]{2}{*}{ 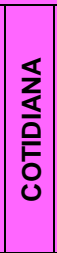 } & \multirow[b]{2}{*}{ 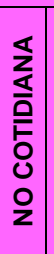 } & \multirow[b]{2}{*}{ 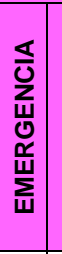 } & \multirow[b]{2}{*}{ DESCRIPCION ASPECTO AMBIENTAL } & \multirow[b]{2}{*}{$\begin{array}{l}\text { IMPACTO } \\
\text { AMBIENTAL }\end{array}$} & \multirow[b]{2}{*}{$\begin{array}{l}\text { CONTROL } \\
\text { EXISTENTE }\end{array}$} & & & & & \\
\hline & & & & & & & & 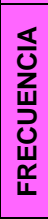 & 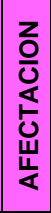 & 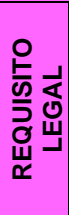 & 造 & 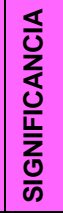 \\
\hline \multirow{7}{*}{ 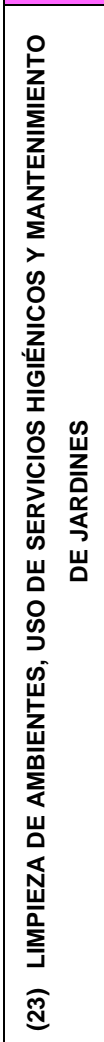 } & Consumo de papel & $x$ & & & $\begin{array}{l}\text { Uso de papel higiénico y papel toalla en servicios } \\
\text { higiénicos }\end{array}$ & Deforestación & $\begin{array}{c}\text { Existen avisos para realizar un uso } \\
\text { eficiente. }\end{array}$ & 5 & 3 & 0 & 8 & NO \\
\hline & $\begin{array}{l}\text { Generación de residuos } \\
\text { peligrosos }\end{array}$ & & $x$ & & $\begin{array}{l}\text { Para la limpieza de ambientes y servicios } \\
\text { higiénicos se utilizan insumos químicos (envases } \\
\text { de legía, ambientadores, cera, desinfectante). } \\
\text { Estos envases son desechados en los cestos de } \\
\text { basura comunes. }\end{array}$ & $\begin{array}{l}\text { Ecotoxicidad de } \\
\text { suelos }\end{array}$ & $\begin{array}{l}\text { No se controla la generación de residuos } \\
\text { peligrosos, no existe segregación y la } \\
\text { disposición final no es la adecuada. }\end{array}$ & 5 & 5 & 3 & 13 & SI \\
\hline & $\begin{array}{l}\text { Generación de residuos no } \\
\text { peligrosos }\end{array}$ & $x$ & & & $\begin{array}{l}\text { Restos de papel higiénico, papel toalla, toallas } \\
\text { higiénicas, trapos sucios, entre otros. En jardinería, } \\
\text { no se usan los restos para elaboración de compost. }\end{array}$ & $\begin{array}{l}\text { Ecotoxicidad de } \\
\text { suelos }\end{array}$ & $\begin{array}{l}\text { No se controla, no se segregan y la } \\
\text { disposición final no es la adecuada dada } \\
\text { la mezcla con residuos peligrosos como } \\
\text { trapos sucios con residuos de insumos } \\
\text { de limpieza. En jardinería no se reúsa. }\end{array}$ & 5 & 5 & 3 & 13 & SI \\
\hline & $\begin{array}{l}\text { Consumo de energía } \\
\text { eléctrica }\end{array}$ & $x$ & & & Iluminación de ambientes. & $\begin{array}{l}\text { Agotamiento } \\
\text { del recurso }\end{array}$ & No se controla. & 5 & 5 & 0 & 10 & SI \\
\hline & Consumo de agua & $x$ & & & $\begin{array}{l}\text { Uso del recurso para la limpieza, uso de servicios } \\
\text { higiénicos y riego de jardines. }\end{array}$ & $\begin{array}{l}\text { Agotamiento } \\
\text { del recurso }\end{array}$ & $\begin{array}{l}\text { Existen griferías de cierre automático e } \\
\text { inodoros de bajo consumo en agua. En } \\
\text { cuanto al riego de jardines, no se } \\
\text { controla. }\end{array}$ & 5 & 3 & 0 & 8 & NO \\
\hline & $\begin{array}{c}\text { Potencial uso de líquidos } \\
\text { desinfectantes no autorizados } \\
\text { y pesticidas }\end{array}$ & & $x$ & & $\begin{array}{l}\text { La limpieza de servicios higiénicos necesita el uso } \\
\text { de insumos químicos. Asimismo, para la } \\
\text { conservación de las plantas se requiere pesticidas. }\end{array}$ & $\begin{array}{l}\text { Contaminación } \\
\text { del aire y agua }\end{array}$ & $\begin{array}{l}\text { No se controla. No existe registro de } \\
\text { insumos no permitidos. }\end{array}$ & 1 & 3 & 3 & 7 & NO \\
\hline & Generación de efluentes & & $\mathrm{x}$ & & $\begin{array}{l}\text { Agua con jabón, agua con detergente, y aguas } \\
\text { contaminadas por los insumos de limpieza }\end{array}$ & $\begin{array}{l}\text { Ecotoxicidad } \\
\text { del agua }\end{array}$ & $\begin{array}{l}\text { Si se controla. Se mide la descarga al } \\
\text { alcantarillado }\end{array}$ & 5 & 5 & 3 & 13 & SI \\
\hline
\end{tabular}




\begin{tabular}{|c|c|c|c|c|c|c|c|c|c|c|c|c|}
\hline \multicolumn{8}{|c|}{ Tabla 37: D.A. 010 USIL - MATRIZ DE IDENTIFICACIÓN DE ASPECTOS E IMPACTOS AMBIENTALES } & \multicolumn{5}{|c|}{$\begin{array}{c}\text { PROCESOS } \\
\text { TERCERIZADOS } \\
\text { Criterio } \\
\end{array}$} \\
\hline 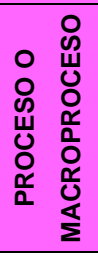 & ASPECTO AMBIENTAL & 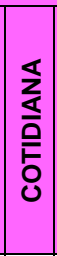 & 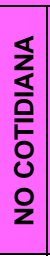 & 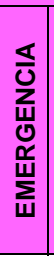 & DESCRIPCION ASPECTO AMBIENTAL & $\begin{array}{l}\text { IMPACTO } \\
\text { AMBIENTAL }\end{array}$ & $\begin{array}{l}\text { CONTROL } \\
\text { EXISTENTE }\end{array}$ & 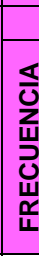 & 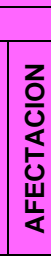 & 을 & $\frac{1}{\leftarrow}$ & 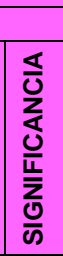 \\
\hline \multirow{8}{*}{ 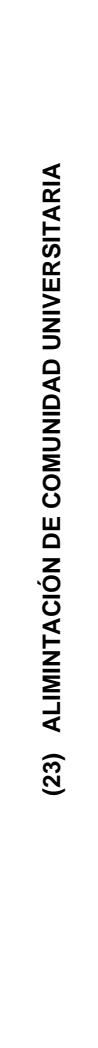 } & Consumo de papel & $x$ & & & Uso de papel higiénico y papel toalla & Deforestación & No se controla. & 3 & 3 & 0 & 6 & NO \\
\hline & $\begin{array}{l}\text { Generación de residuos } \\
\text { peligrosos }\end{array}$ & $\mathrm{x}$ & & & $\begin{array}{l}\text { La limpieza de la cocina, instrumentos de cocción, mesas y } \\
\text { sillas de cafetería, requieren insumos químicos (envases de } \\
\text { legía, ambientadores, cera, desinfectante). Estos envases } \\
\text { son desechados en los cestos de basura comunes. }\end{array}$ & $\begin{array}{l}\text { Ecotoxicidad de } \\
\text { suelos }\end{array}$ & $\begin{array}{l}\text { No se controla la generación de } \\
\text { residuos peligrosos, no existe } \\
\text { segregación y la disposición } \\
\text { final no es la adecuada. }\end{array}$ & 5 & 5 & 3 & 13 & SI \\
\hline & $\begin{array}{l}\text { Generación de residuos no } \\
\text { peligrosos }\end{array}$ & $x$ & & & $\begin{array}{l}\text { Restos de residuos orgánicos, papel higiénico, servilletas, } \\
\text { papel toalla, trapos, estropajos, envoltura de alimentos, } \\
\text { plásticos, entro otros. }\end{array}$ & $\begin{array}{l}\text { Ecotoxicidad de } \\
\text { suelos }\end{array}$ & $\begin{array}{l}\text { Se segregan en lugares } \\
\text { comunes. En este caso, } \\
\text { específicamente en la cafetería. }\end{array}$ & 5 & 5 & 3 & 13 & SI \\
\hline & $\begin{array}{l}\text { Consumo de energía } \\
\text { eléctrica }\end{array}$ & $x$ & & & $\begin{array}{l}\text { lluminación de ambientes, refrigerador, mostradores, } \\
\text { microondas, jarras eléctricas, licuadoras, batidoras, entre } \\
\text { otros artefactos. }\end{array}$ & $\begin{array}{l}\text { Agotamiento del } \\
\text { recurso }\end{array}$ & No se controla. & 5 & 1 & 0 & 6 & NO \\
\hline & Consumo de agua & $x$ & & & $\begin{array}{l}\text { Uso del recurso para cocinar, lavado de instrumentos de } \\
\text { cocina, lavado de insumos, lavado de cubiertos y limpieza. }\end{array}$ & $\begin{array}{l}\text { Agotamiento del } \\
\text { recurso }\end{array}$ & Si se controla & 5 & 5 & 0 & 10 & SI \\
\hline & $\begin{array}{c}\text { Potencial uso de líquidos } \\
\text { desinfectantes no autorizados } \\
\text { y pesticidas }\end{array}$ & & $x$ & & $\begin{array}{l}\text { La limpieza de la cocina en general, requiere uso de } \\
\text { desinfectantes y pesticidas para prevenir plagas. }\end{array}$ & $\begin{array}{l}\text { Contaminación } \\
\text { del aire y agua }\end{array}$ & $\begin{array}{l}\text { No se controla. No existe } \\
\text { registro de insumos no } \\
\text { permitidos. }\end{array}$ & 5 & 5 & 3 & 13 & SI \\
\hline & Generación de efluentes & & $x$ & & $\begin{array}{l}\text { Agua con jabón y detergente, aguas contaminadas por los } \\
\text { insumos de limpieza y agua de lavado de utensilios. }\end{array}$ & $\begin{array}{l}\text { Ecotoxicidad del } \\
\text { agua }\end{array}$ & $\begin{array}{l}\text { Si se controla. Se mide la } \\
\text { descarga al alcantarillado. }\end{array}$ & 5 & 3 & 3 & 11 & SI \\
\hline & Potencial incendio & & & $x$ & $\begin{array}{c}\text { Dado que se hace uso del fuego y gas, el riesgo siempre } \\
\text { está presente. }\end{array}$ & $\begin{array}{l}\text { Contaminación } \\
\text { del aire }\end{array}$ & $\begin{array}{l}\text { No se controla. Se tiene un } \\
\text { plan de contingencia. }\end{array}$ & 1 & 3 & 3 & 7 & NO \\
\hline
\end{tabular}




\begin{tabular}{|c|c|c|c|c|}
\hline \multicolumn{7}{|c|}{ Tabla 38: Resumen de Aspectos e Impactos Ambientales - R.D.A. 005 } & Procesos Tercerizados \\
\hline Proceso & Aspecto Ambiental & Impacto Ambiental & Requisito Legal Asociado & Puntaje \\
Significancia
\end{tabular}


ANEXO N 13.

\begin{tabular}{|c|c|c|}
\hline $\begin{array}{c}\text { Guía de Gestión } \\
\text { Ambiental }\end{array}$ & Manual de Procedimientos & Año \\
\hline USIL & Procedimiento Comunicacional & $\begin{array}{c}\text { Área de } \\
\text { Sostenibilidad }\end{array}$ \\
\hline
\end{tabular}

1. Alcance.

Proceso de comunicación interna y externa del Sistema de Gestión Ambiental integrado en la Guía de Gestión Ambiental USIL.

2. Objetivo.

Establecer el procedimiento de comunicación interna y externa con la finalidad de lograr la óptima comprensión de información, que requiera ser transmitida; así como recibir, documentar y responder las comunicaciones pertinentes de las partes interesadas.

\section{Referencias o Documentos de sustento.}

Guía de Gestión Ambiental USIL.

\section{Responsable (área o persona).}

Profesional del área de sostenibilidad; supervisado por el Gerente del área.

5. Contenido.

Comunicación interna: Utiliza los siguientes instrumentos. (Tabla 39)

\begin{tabular}{|c|c|c|}
\hline Medio de Comunicación & ¿A quién va dirigido? & Contenido o propósito \\
\hline Correos vía Intranet & Comunidad universitaria & $\begin{array}{c}\text { Informar a la comunidad universitaria sobre los } \\
\text { avances de la gestión ambiental USIL }\end{array}$ \\
\hline Murales, afiches y revistas & Comunidad universitaria & $\begin{array}{c}\text { Brindar información sobre las acciones y avances en la } \\
\text { implementación de la Guía de Gestión Ambiental }\end{array}$ \\
\hline Talleres de sensibilización & Comunidad universitaria & $\begin{array}{c}\text { Sensibilizar a la comunidad universitaria en la temática } \\
\text { ambiental. Propiciar la educación ambiental. }\end{array}$ \\
\hline Publicidad Infosil & Comunidad universitaria & $\begin{array}{c}\text { Informar a la comunidad universitaria sobre los } \\
\text { avances de la gestión ambiental USIL }\end{array}$ \\
\hline Correos vía Intranet & Personal administrativo & $\begin{array}{c}\text { Informar sobre las modificaciones legales en materia } \\
\text { ambiental; así como contenido relacionado al tópico. }\end{array}$ \\
\hline
\end{tabular}

Comunicación externa: La respuesta a toda comunicación externa (oficios, cartas, comunicados, otros) que signifique la difusión o entrega de información confidencial en materia ambiental de la universidad, deberá ser consultada previamente con el área de comunicación institucional. Toda comunicación externa deberá ser archivada correctamente. 
ANEXO №14.

\begin{tabular}{|c|c|c|}
\hline $\begin{array}{c}\text { Guía de Gestión } \\
\text { Ambiental }\end{array}$ & Manual de Procedimientos & Año \\
\hline USIL & AUDITORIAS INTERNA & $\begin{array}{c}\text { Área de } \\
\text { Sostenibilidad }\end{array}$ \\
\hline
\end{tabular}

1. Alcance.

Se aplica a la Universidad San Ignacio de Loyola en sus tres campus universitarios

\section{Objetivo.}

Establecer los lineamientos generales para realizar los procesos de auditoria interna del Sistema de Gestión Ambiental de la universalidad, con la finalidad de determinar si este es conforme con las actividades planificadas en el Plan Operativo Ambiental Universitario, con los requisitos legales; y para comprobar si se ha implementado de manera eficaz.

\section{Referencias o Documentos de sustento.}

Guía de Gestión Ambiental USIL.

\section{Responsable (área o persona).}

Profesional (Área de sostenibilidad y RRSS); supervisado por el Gerente del área.

5. Contenido.

Planificación de la Auditorías - Proceso de selección de auditoría.

5.1 El profesional encargado por el Gerente de Sostenibilidad y RRSS, elabora la propuesta del Programa Anual de Auditorías Internas. En este documento definirá áreas, fechas y procesos a auditar. En este sentido, deberá priorizar las áreas a auditar basándose en las auditorías previas.

5.2 El Comité de Gestión Ambiental revisa y aprueba el Programa Anual de Auditorías Internas. En caso que posea observaciones, el responsable deberá corregirlas.

5.3 Aprobado el Programa Anual de Auditorías, el responsable propone un grupo auditor (1 o 2 personas). Este grupo auditor deberá estar certificado o contar con calificación apropiada para desempeñar la actividad.

5.4 El responsable designará un líder por cada grupo auditor. Asimismo, deberá definir fechas, horarios, grupos auditores, auditados y documentos de sustento para la auditoría. Estas coordinaciones deberán ser comunicadas con anticipación al grupo auditor. 
5.5 El responsable brindará copias no contraladas de la documentación requerida a los grupos auditores para permitir el desarrollo de la auditoría.

\section{Preparación de la Auditoría.}

5.6 Los grupos auditores coordinarán con el responsable el área, fecha y hora de la auditoría, con la finalidad de que pueda asistir todo el personal del área al momento de la auditoría.

5.7 En caso de reprogramación de fecha u hora de la auditoría programada, el grupo auditor deberá comunicar el responsable los motivos de la no factibilidad de la misma. El responsable evaluará si procede o no la solitud del grupo auditor.

5.8 De presentarse un incumplimiento en cuanto a la ejecución de la auditoría sin comunicación de reprogramación, el grupo auditor o el auditado procederán a generar la respectiva Oportunidades de Mejora (OM).

5.9 El equipo auditor, previa realización de la auditoría, deberá realizar un estudio preliminar de escritorio sobre la documentación del área o proceso a estudiar. Asimismo, deberá elaborar el formato siguiente:

\section{Tabla 40}

Ficha de Observaciones.

\begin{tabular}{|l|}
\hline \multicolumn{2}{|l|}{ Nombre del documento: } \\
\hline Área a auditar: \\
\hline Fecha de la auditoría: \\
\hline Nombre del auditado: \\
\hline Nombre del auditor: \\
\hline Evaluación del requisito: Conforme / No conforme / No aplica \\
\hline Observaciones técnicas: \\
\hline Firma del auditado: \\
\end{tabular}

Nota: Fuente: Elaboración propia.

5.10 Los auditores proceden al recojo de evidencia mediante el uso de entrevistas, observaciones de actividades y procesos; y, revisiones de registros. Se efectúa dicha acción con fines de compararlos con los criterios establecidos por la auditoría e identificar posibles hallazgos.

5.11 En caso de no conformidad, debe considerar los criterios siguientes:

- Conforme: La prueba existe.

- No conforme: La prueba no existe. 
- No aplicable.

$5.12 \mathrm{El}$ equipo auditor elabora las OM para todas las no conformidades identificadas durante la auditoría. Asimismo, deberá mencionara en donde fue identificado el hallazgo y a qué requisito de la normativa certificada por la universidad afecta; o con que norma interna no cumple.

5.13 El equipo auditor informe de los hallazgos al responsable de la auditoría.

5.14 El auditado, mediante el responsable y el Gerente de Sostenibilidad y RRSS, coordinarán el levantamiento de las no conformidades.

\section{Seguimiento.}

5.15 El responsable de la auditoría presentará ante el Comité de Gestión Ambiental, el Informe Final de Auditoría, el cual comprende los resultados de la misma. La estructura de Informe es la siguiente:

\section{Tabla 41}

Estructura de Informe Final de Auditoría.

\begin{tabular}{|l|l|}
\hline \multicolumn{2}{|l|}{$N^{\circ}$ de auditoría: } \\
\hline Área o proceso auditado: & Fecha de auditoría: \\
\hline Responsable del área auditada: & Auditor: \\
\hline Resumen de resultados de auditoría efectuada: \\
\hline \\
\hline Documentos de referencia \\
\hline \\
\hline$N^{\circ}$ de OM: \\
\hline Conclusiones de la auditoría: \\
\hline $\begin{array}{l}\text { Firma del responsable de la auditoría: } \\
\text { Fecha: }\end{array}$ \\
\hline $\begin{array}{l}\text { Firma del Gerente de Sostenibilidad y RRS: } \\
\text { Fecha: }\end{array}$ \\
\hline
\end{tabular}

Nota: Fuente: Elaboración propia.

5.16 El Comité de Gestión Ambiental evalúa los resultados y planifica las acciones a implementar para la mejora de procesos y actividades en la universidad. 
ANEXO N $\mathbf{N}^{\circ} 15$.

Tabla 42

Criterios para la selección del panel de expertos.

\begin{tabular}{|c|c|c|c|c|c|c|}
\hline \multirow[b]{2}{*}{ CARGO USIL } & \multicolumn{6}{|c|}{ Criterios para selección de Panel de Expertos } \\
\hline & $\begin{array}{c}\text { Relación con } \\
\text { la temática } \\
\text { ambiental } \\
\text { USIL }\end{array}$ & $\begin{array}{c}\text { Toma de } \\
\text { decisiones } \\
\text { en materia } \\
\text { ambiental }\end{array}$ & $\begin{array}{c}\text { Acceso a la } \\
\text { información } \\
\text { ambiental } \\
\text { USIL }\end{array}$ & Disponibilidad & Total & $\begin{array}{l}\text { Integra } \\
\text { Panel }\end{array}$ \\
\hline Presidente Ejecutivo & 5 & 5 & 5 & 0 & 15 & No \\
\hline Rector & 5 & 5 & 5 & 1 & 16 & $\mathrm{Si}$ \\
\hline Secretario General & 3 & 1 & 5 & 1 & 10 & No \\
\hline $\begin{array}{l}\text { Director de } \\
\text { Acreditación }\end{array}$ & 1 & 1 & 5 & 1 & 8 & No \\
\hline $\begin{array}{l}\text { Coordinador de } \\
\text { Rankings }\end{array}$ & 1 & 1 & 5 & 3 & 10 & No \\
\hline $\begin{array}{l}\text { Responsable de } \\
\text { Emprendimiento }\end{array}$ & 1 & 1 & 5 & 3 & 10 & No \\
\hline $\begin{array}{l}\text { Vicepresidencia } \\
\text { Responsabilidad } \\
\text { Social }\end{array}$ & 5 & 5 & 5 & 3 & 18 & $\mathrm{Si}$ \\
\hline $\begin{array}{l}\text { Responsable de } \\
\text { Globalización }\end{array}$ & 1 & 1 & 5 & 3 & 10 & No \\
\hline $\begin{array}{l}\text { Responsables de } \\
\text { Investigación y } \\
\text { Desarrollo }\end{array}$ & 3 & 1 & 5 & 3 & 12 & No \\
\hline $\begin{array}{l}\text { Vicerrector de } \\
\text { Investigación y } \\
\text { Desarrollo }\end{array}$ & 5 & 3 & 5 & 3 & 16 & $\mathrm{Si}$ \\
\hline $\begin{array}{l}\text { Director del Centro } \\
\text { de Investigación }\end{array}$ & 3 & 1 & 5 & 3 & 12 & No \\
\hline $\begin{array}{l}\text { Director del Fondo } \\
\text { Editorial }\end{array}$ & 1 & 1 & 5 & 3 & 10 & No \\
\hline $\begin{array}{l}\text { Director de } \\
\text { Proyectos de } \\
\text { Investigación }\end{array}$ & 3 & 1 & 5 & 3 & 12 & No \\
\hline $\begin{array}{l}\text { Vicerrector } \\
\text { Académico }\end{array}$ & 3 & 3 & 5 & 3 & 14 & No \\
\hline $\begin{array}{l}\text { Director de Calidad } \\
\text { Académica, Docente } \\
\text { y Curricular }\end{array}$ & 1 & 1 & 5 & 3 & 10 & No \\
\hline $\begin{array}{l}\text { Director de } \\
\text { Formación Básica }\end{array}$ & 1 & 1 & 5 & 3 & 10 & No \\
\hline $\begin{array}{l}\text { Director Center for } \\
\text { Global Education }\end{array}$ & 1 & 1 & 5 & 3 & 10 & No \\
\hline $\begin{array}{l}\text { Director Carrera } \\
\text { Universitaria para } \\
\text { personas con } \\
\text { Experiencia Laboral }\end{array}$ & 1 & 1 & 5 & 3 & 10 & No \\
\hline $\begin{array}{l}\text { Director Center for } \\
\text { Language Studies }\end{array}$ & 1 & 1 & 5 & 3 & 10 & No \\
\hline $\begin{array}{l}\text { Director de Doble } \\
\text { Grado }\end{array}$ & 1 & 1 & 5 & 3 & 10 & No \\
\hline $\begin{array}{l}\text { Director de } \\
\text { Educación virtual }\end{array}$ & 1 & 1 & 5 & 3 & 10 & No \\
\hline $\begin{array}{l}\text { Decano Facultad } \\
\text { Ciencias } \\
\text { Empresariales }\end{array}$ & 3 & 3 & 5 & 3 & 14 & No \\
\hline $\begin{array}{l}\text { Decano Facultad de } \\
\text { Ingeniería }\end{array}$ & 3 & 3 & 5 & 3 & 14 & No \\
\hline $\begin{array}{l}\text { Decano Facultad de } \\
\text { HTG }\end{array}$ & 5 & 1 & 5 & 3 & 14 & No \\
\hline $\begin{array}{l}\text { Decano Facultad de } \\
\text { Humanidades }\end{array}$ & 5 & 1 & 5 & 3 & 14 & No \\
\hline $\begin{array}{l}\text { Decano Facultad de } \\
\text { Arquitectura }\end{array}$ & 5 & 1 & 5 & 3 & 14 & No \\
\hline
\end{tabular}




\begin{tabular}{|c|c|c|c|c|c|c|}
\hline $\begin{array}{l}\text { Decano Facultad de } \\
\text { Derecho }\end{array}$ & 5 & 1 & 5 & 3 & 14 & No \\
\hline $\begin{array}{l}\text { Decano Facultad de } \\
\text { Ciencias de la Salud }\end{array}$ & 5 & 1 & 5 & 3 & 14 & No \\
\hline $\begin{array}{l}\text { Decano Facultad de } \\
\text { Educación }\end{array}$ & 5 & 1 & 5 & 3 & 14 & No \\
\hline $\begin{array}{l}\text { Director Carrera de } \\
\text { Gestión Ambiental }\end{array}$ & 5 & 3 & 5 & 3 & 16 & $\mathrm{Si}$ \\
\hline $\begin{array}{l}\text { Coordinador } \\
\text { Académico de la } \\
\text { Carrera de Gestión } \\
\text { Ambiental }\end{array}$ & 5 & 3 & 5 & 3 & 16 & Si \\
\hline $\begin{array}{l}\text { Director Carrera de } \\
\text { Ingeniería Ambiental }\end{array}$ & 5 & 3 & 5 & 3 & 16 & Si \\
\hline $\begin{array}{l}\text { Coordinador } \\
\text { Académico Carrera } \\
\text { de Ingeniería } \\
\text { Ambiental }\end{array}$ & 5 & 3 & 5 & 3 & 16 & Si \\
\hline $\begin{array}{l}\text { Director Carrera de } \\
\text { Ingeniería del Agua }\end{array}$ & 5 & 3 & 5 & 3 & 16 & Si \\
\hline $\begin{array}{l}\text { Coordinador } \\
\text { Académico Carrera } \\
\text { de Ingeniería del } \\
\text { Agua }\end{array}$ & 5 & 3 & 5 & 3 & 16 & Si \\
\hline $\begin{array}{l}\text { Vicepresidencia de } \\
\text { Postgrado }\end{array}$ & 3 & 3 & 5 & 3 & 14 & No \\
\hline $\begin{array}{l}\text { Director } \\
\text { Administrativo }\end{array}$ & 1 & 1 & 5 & 3 & 10 & No \\
\hline $\begin{array}{l}\text { Director Académico } \\
\text { de Investigación y } \\
\text { Acreditación }\end{array}$ & 1 & 1 & 5 & 3 & 10 & No \\
\hline $\begin{array}{l}\text { Director de } \\
\text { Programas } \\
\text { Especializados en } \\
\text { Desarrollo Gerencial }\end{array}$ & 1 & 1 & 5 & 3 & 10 & No \\
\hline $\begin{array}{l}\text { Director de } \\
\text { Extensión }\end{array}$ & 1 & 1 & 5 & 3 & 10 & No \\
\hline $\begin{array}{l}\text { Director de } \\
\text { Programas In House }\end{array}$ & 1 & 1 & 5 & 3 & 10 & No \\
\hline $\begin{array}{l}\text { Director de } \\
\text { Maestrías }\end{array}$ & 1 & 1 & 5 & 3 & 10 & No \\
\hline $\begin{array}{l}\text { Director } \\
\text { Consultorías }\end{array}$ & 1 & 1 & 5 & 3 & 10 & No \\
\hline $\begin{array}{l}\text { Vicerrector } \\
\text { Internacional }\end{array}$ & 3 & 3 & 5 & 3 & 14 & No \\
\hline $\begin{array}{l}\text { Director de } \\
\text { Movilidad } \\
\text { Internacional } \\
\end{array}$ & 1 & 1 & 5 & 3 & 10 & No \\
\hline $\begin{array}{l}\text { Director de Centro } \\
\text { de Extensión Cusco }\end{array}$ & 1 & 1 & 5 & 3 & 10 & No \\
\hline $\begin{array}{l}\text { Director de } \\
\text { Programas } \\
\text { Internacionales }\end{array}$ & 1 & 1 & 5 & 3 & 10 & No \\
\hline
\end{tabular}


ANEXO N $\mathbf{N}^{\circ} 16$.

Estimada Sita. Mallqui Asistenta del Rector USIL

Mi nombre es Luiggi Ballardo, egresado de la carrera de Gestión Ambiental. Actualmente vengo desarrollando mi tesis, la cual recibe el nombre de Guía de Gestión Ambiental USIL.

Esta guía es un instrumento para la toma de decisiones en materia ambiental de la universidad. Comprende una etapa de diagnóstico ambiental donde se reconocen los impactos ambientales que incurre la universidad. Como segunda etapa, se propone un Sistema de Gestión Ambiental; y la tercera etapa comprende sugerencias en materia de educación ambiental.

En este sentido, y en el marco de la presente investigación, vengo encuestando a tomadores de decisión de la universidad, sobre la posibilidad de implementar o no la Guía de Gestión Ambiental en la universidad.

Es por este motivo que, solicito por favor agendar una breve reunión de diez minutos con el Señor Ramiro Salas, el día martes 29 de mayo 2018 a las $18: 00$ horas, con la finalidad de otorgarle la encuesta y la Guía en mención.

Espero el Señor Salas pueda colaborar con la elaboración de la presente investigación; pese a que conozco de su apretada agenda

Muchas gracias.

Saludos cordiales

Luiggi Ballardo Evangelista

Teléfono: 887111826

Ana Mallqui Villarreal a través de usiloffice 365 . onmicrosoft.com

para mi $\nabla$

Estimado Luiggi,

Tal coma lo también conversado vía telefónica, lamentablemente, el Rector se encuentra fuera del pais en estas fechas, y como comprenderás, su Agenda es un tanto complicada. Esperamos que puedas gestionar alguna reunión con la Vicepresidencia de Responsabilidad Social, Miaohong Huang Li, quien trabaja activamente en el tema ambiental en nuestra Universidad.

Saludos cordiales.

Ana María Mallqui Villarreal

Executive Assistant

Universidad San Ignacio de Loyola

Rectorado

amallquigusiledu.pe

$\frac{\text { Av. La Fontana } 750 \text {. La Molina, Lima - PERU }}{\text { T.(511) } 317-1000-3662}$

\section{UST UNIVERSIDAD \\ S- SAN IGNACIO DE LOYOLA}

Figura 37: Correo electrónico Secretaria del Rector USIL. 


\section{ANEXO $\mathbf{N}^{\circ} 17$. \\ Encuesta \\ "Guía de Gestión Ambiental USIL"}

La presente encuesta se realiza en el marco del Proyecto de Tesis "Guía de Gestión Ambiental para la Universidad San Ignacio de Loyola". Como requisito indispensable para iniciar la encuesta, el Encuestador debe entregar, en formato físico, la "Guía de Gestión Ambiental USIL" al Encuestado, para su análisis y revisión. El plazo máximo para el llenado de la Encuesta es de 7 días calendarios.

Nombre del Encuestado: Mi a ohong Hang li Fecha de la encuesta: $21 \operatorname{los} / 2018$

Siendo 1: Totalmente desacuerdo; Siendo 2: Desacuerdo; Siendo 3: Ni acuerdo ni en desacuerdo; Siendo 4: De acuerdo; $y$, Siendo 5: Totalmente de acuerdo

\begin{tabular}{|l|r}
\hline & $\begin{array}{r}\text { Grado de } \\
\text { acuerdo }\end{array}$ \\
\hline 1. Por favor, indique su grado de acuerdo con las siguientes premisas sobre los beneficios de
\end{tabular} implementación de la Guía de Gestión Ambiental USIL presentada.

a. Es una herramienta para la toma de decisiones en la planificación ambiental de la universidad. \begin{tabular}{l|l|l|l|l|l|} 
la universidad. & 1 & 2 & $(3)$ & 4 & 5 \\
$\begin{array}{l}\text { b. Fomenta la integración de la comunidad universitaria para mejorar el } \\
\text { desempeño ambiental de la universidad. }\end{array}$ & 1 & 2 & 3 & (4) & 5
\end{tabular}

c. Marca el inicio para la implementación de un Sistema de Gestión Ambiental en la universidad.

d. Permite conocer los aspectos e impactos ambientales que posee la universidad a causa de sus acciones, decisiones u omisiones.

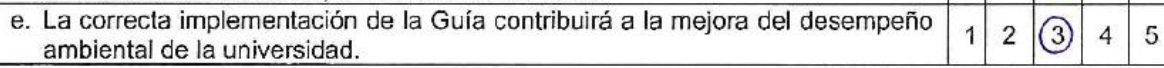

2. Por favor, indique su grado de acuerdo con las siguientes premisas sobre la gestión ambiental actual en la universidad.

f. La comunidad universitaria conoce los aspectos e impactos ambientales en los que incurre la universidad

\begin{tabular}{|l|l|l|l|l|l|}
\hline g. La universidad se percibe ante la sociedad como una universidad sostenible. & 1 & 2 & 3 & (4) & 5
\end{tabular}

3. Por favor, indique su grado de acuerdo con las siguientes premisas sobre la participación actual del alumnado y tomadores de decisión en el accionar ambiental de la universidad.

h. Los tomadores de decisión conocen las iniciativas ambientales que viene desarrollando la universidad.

i. El alumnado conoce las iniciativas ambientales que viene desarrollando la universidad.

j. El alumnado participa en la toma de decisiones en materia ambiental de la universidad.

4. Por favor, indique su grado de acuerdo con las siguientes premisas sobre el capítulo "Propuesta de Sistema de Gestión Ambiental" de la Guia.

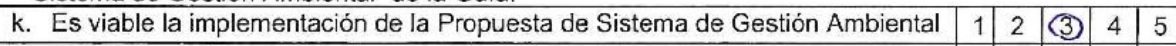
\begin{tabular}{lll|l|l|l|l|} 
I. El capítulo precitado propone estrategias y acciones que deberían & 1 & 2 & $(3)$ & 4 & 5 \\
implementarse con fines de mejorar el desempeño ambiental de la universidad.
\end{tabular}

5. Por favor, indique su grado de acuerdo con las siguientes premisas sobre el capítulo "Educación Ambiental" de la Guia.

$\mathrm{m}$. Debe impartirse un curso ambiental obligatorio dentro de la malla curricular de todas las carreras universitarias.

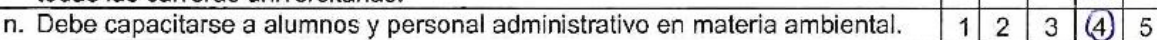

6. Por favor, indique su grado de acuerdo con las siguientes premisas sobre la implementación de la "Guia de Gestión Ambiental USIL"

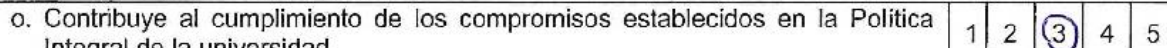
Integral de la universidad.

p. La creación del Comité Estudiantil Ambiental, conforme lo estipula la Guia, contribuirá a mejorar la planificación ambiental universitaria.

q. Debe implementarse a futuro la Guía de Gestión Ambiental USIL

Figura 38: Encuesta Vicepresidenta de Responsabilidad Social USIL. 
ANEXO $N^{\circ} 18$.

\section{CARTA DE CONSENTIMIENTO INFORMADO}

Yo Miciohong Huang Li en calidad de vicepresidenta de Resp. Solval de la Universidad San Ignacio de Loyola [USIL] y reconocido (a) con DNI N 43085840 ; por medio de la presente dejo constancia que he contribuido con la Tesis "Guía de Gestión Ambiental para la Universidad San Ignacio de Loyola” [Investigación], cuyo autor es el Bachiller Luiggi Anthony Ballardo Evangelista [Tesista]; a través del llenado de la Encuesta "Guia de Gestión Ambiental USIL", desarrollado por el Tesista, en el marco de la presente investigación.

Adicionalmente se me informó que:

$>$ Mi participación en esta investigación es completamente libre y voluntaria, estoy en libertad de retirarme de ella en cualquier momento.

No recibiré beneficio personal de ninguna clase por la participación en este proyecto de investigación. Sin embargo, se espera que los resultados obtenidos permitan mejorar el desempeño ambiental de la universidad.

Hago constar que el presente documento ha sido leído y entendido por mi en su integridad de manera libre y espontánea.

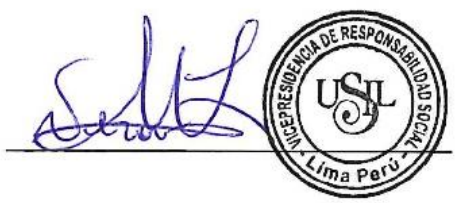

Sr.(a) Hichohong thang Li

DNI: 43055840

Fecha: $24 \operatorname{los} 12018$

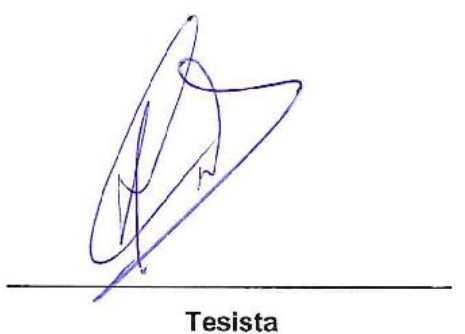

Tesista

Sr.(a)

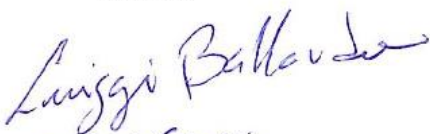

DNI:

Fecha:

Figura 39: Carta de Consentimiento Informado Vicepresidenta de Responsabilidad Social USIL. 


\section{ANEXO № 19. \\ Encuesta \\ "Guía de Gestión Ambiental USIL"}

La presente encuesta se realiza en el marco del Proyecto de Tesis "Guía de Gestión Ambiental para la Universidad San Ignacio de Loyola". Como requisito indispensable para iniciar la encuesta, el Encuestador debe entregar, en formato fisico, la "Guía de Gestión Ambiental USIL" al Encuestado, para su análisis y revisión. El plazo máximo para el llenado de la Encuesta es de 7 días calendarios.

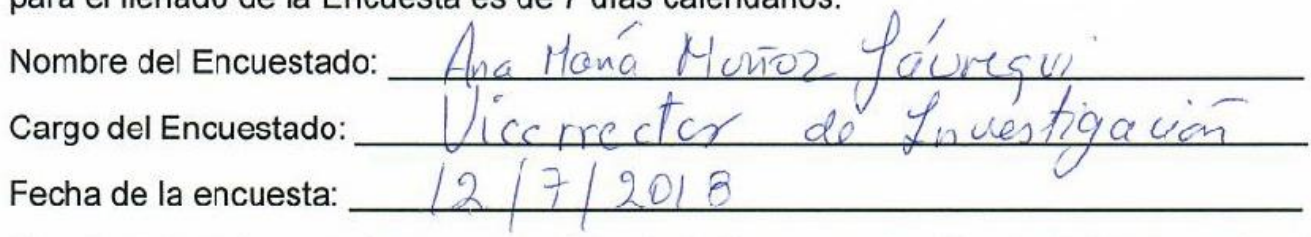

Siendo 1: Totalmente desacuerdo; Siendo 2: Desacuerdo; Siendo 3: $\mathrm{Ni}$ acuerdo ni en desacuerdo; Siendo 4: De acuerdo; $y$, Siendo 5: Totalmente de acuerdo

\begin{tabular}{|c|c|c|c|c|c|}
\hline & \multicolumn{5}{|c|}{$\begin{array}{l}\text { Grado de } \\
\text { acuerdo }\end{array}$} \\
\hline \multicolumn{6}{|c|}{$\begin{array}{l}\text { 1. Por favor, indique su grado de acuerdo con las siguientes premisas sobre los beneficios de la } \\
\text { implementación de la Guía de Gestićn Ambiental USIL presentada. }\end{array}$} \\
\hline $\begin{array}{l}\text { a. Es una herramienta para la toma de decisiones en la planificación ambiental de } \\
\text { la universidad. }\end{array}$ & 1 & 2 & 3 & 4 & \\
\hline $\begin{array}{l}\text { b. Fomenta la integración de la comunidad universitaria para mejorar el } \\
\text { desempeño ambiental de la universidad. }\end{array}$ & 1 & 2 & 3 & 4 & 5 \\
\hline $\begin{array}{l}\text { c. Marca el inicio para la implementación de un Sistema de Gestión Ambiental en } \\
\text { la universidad. }\end{array}$ & 1 & 2 & 3 & 4 & 5 \\
\hline $\begin{array}{l}\text { conocer los aspectos e impactos ambientales que posee la universidad } \\
\text { de sus acciones, decisiones u omisiones. }\end{array}$ & 1 & 2 & 3 & 4 & 5 \\
\hline $\begin{array}{l}\text { c. La correcta implementación de la Guía contribuirá a la mejora del desempeño } \\
\text { ambiental de la universidad. }\end{array}$ & 1 & 2 & 3 & 4 & 5 \\
\hline \multicolumn{6}{|c|}{$\begin{array}{l}\text { 2. Por favor, indique su grado de acuerdo con las siguientes premisas sobre la gestión ambiental actual } \\
\text { en la universidad. }\end{array}$} \\
\hline $\begin{array}{l}\text { f. La comunidad universitaria conoce los aspectos e impactos ambientales en los } \\
\text { que incurre la universidad }\end{array}$ & 1 & 2 & 3 & 4 & 5 \\
\hline g. La universidad se percibe ante la sociedad como una universidad sostenible. & 1 & 2 & 3 & 4 & 5 \\
\hline \multicolumn{6}{|c|}{$\begin{array}{l}\text { 3. Por favor, irdique su grado de acuerdo con las siguientes premisas sobre la participación actual del } \\
\text { alumnado y tomadores de decisión en el accionar ambiental de la universidad. }\end{array}$} \\
\hline $\begin{array}{l}\text { h. Los tomadores de decisión conocen las iniciativas ambientales que viene } \\
\text { desarrollando la universidad. }\end{array}$ & 1 & 2 & 3 & 4 & 5 \\
\hline $\begin{array}{l}\text { i. El alumnado conoce las iniciativas ambientales que viene desarrollando la } \\
\text { universidad. }\end{array}$ & 1 & R & 3 & 4 & 5 \\
\hline $\begin{array}{l}\text { j. El alumnado participa en la toma de decisiones en materia ambiental de la } \\
\text { universidad. }\end{array}$ & 1 & $2 x$ & 3 & 4 & 5 \\
\hline \multicolumn{6}{|c|}{$\begin{array}{l}\text { 4. Por favor, indique su grado de acuerdo con las siguientes premisas sobre el capítulo "Propuesta de } \\
\text { Sistema de Gestión Ambiental" de la Guia. }\end{array}$} \\
\hline k Es viable la implementación de la Propuesta de Sistema de Gestión Ambiental & 1 & 2 & 3 & 4 & 5 \\
\hline $\begin{array}{l}\text { I. El capítulo precitado propone estrategias y acciones que deberian } \\
\text { implementarse con fines de mejorar el desempeño ambiental de la universidad. }\end{array}$ & 1 & 2 & 3 & 4 & 5 \\
\hline \multicolumn{6}{|c|}{$\begin{array}{l}\text { 5. Por favor, indique su grado de acuerdo con las siguientes premisas sobre el capítulo "Educación } \\
\text { Ambiental" de la Guía. }\end{array}$} \\
\hline $\begin{array}{l}\text { m. Debe impartirse un curso ambiental obligatorio dentro de la malla curricular de } \\
\text { todas las carreras universitarias. }\end{array}$ & 1 & 2 & 3 & 4 & 5 \\
\hline n. Debe capacitarse a alumnos y personal administrativo en materia ambiental. & 1 & 2 & 3 & 4 & 5 \\
\hline \multicolumn{6}{|c|}{$\begin{array}{l}\text { 6. Por favor, indique su grado de acuerdo con las siguientes premisas sobre la implementación de la } \\
\text { "Guía de Gestión Ambiental USIL" }\end{array}$} \\
\hline $\begin{array}{l}\text { o. Contribuye al cumplimiento de los compromisos establecidos en la Política } \\
\text { Integral de la universidad. }\end{array}$ & 1 & 2 & 3 & 4 & 5 \\
\hline $\begin{array}{l}\text { p. La creación del Comité Estudiantil Ambiental, conforme lo estipula la Guia, } \\
\text { contribuiré a mejorar la planificación ambiental universitaria. }\end{array}$ & 1 & 2 & 3 & 4. & 5 \\
\hline q. Debe implementarse a futuro la Guía de Gestión Ambiental USIL & 1 & 2 & 3 & 4 & 5 \\
\hline
\end{tabular}

Figura 40: Encuesta Vicerrectora de Investigación y Desarrollo USIL. 
ANEXO $\mathbf{N}^{\circ} 20$.

\section{CARTA DE CONSENTIMIENTO INFORMADO}

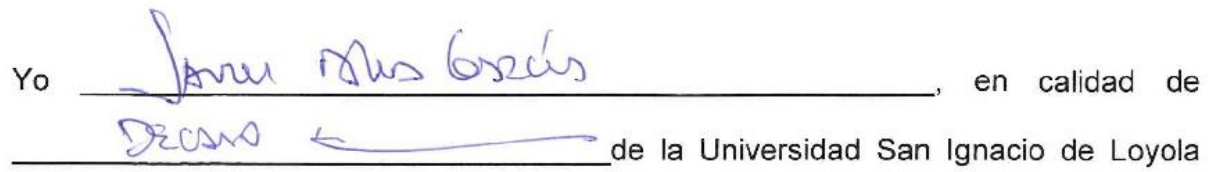

[USIL] y reconocido (a) con DNI $\mathrm{N}^{\circ}$ ; por medio de la presente dejo constancia que he contribuido con la Tesis "Guía de Gestión Ambiental para la Universidad San Ignacio de Loyola" [Investigación], cuyo autor es el Bachiller Luiggi Anthony Ballardo Evangelista [Tesista]; a través del llenado de la Encuesta "Guía de Gestión Ambiental USIL", desarrollado por el Tesista, en el marco de la presente investigación.

Adicionalmente se me informó que:

Mi participación en esta investigación es completamente libre y voluntaria, estoy en libertad de retirarme de ella en cualquier momento.

No recibiré beneficio personal de ninguna clase por la participación en este proyecto de investigación. Sin embargo, se espera que los resultados obtenidos permitan mejorar el desempeño ambiental de la universidad.

Hago constar que el presente documento ha sido leído y entendido por mí en su integridad de manera libre y espontánea.
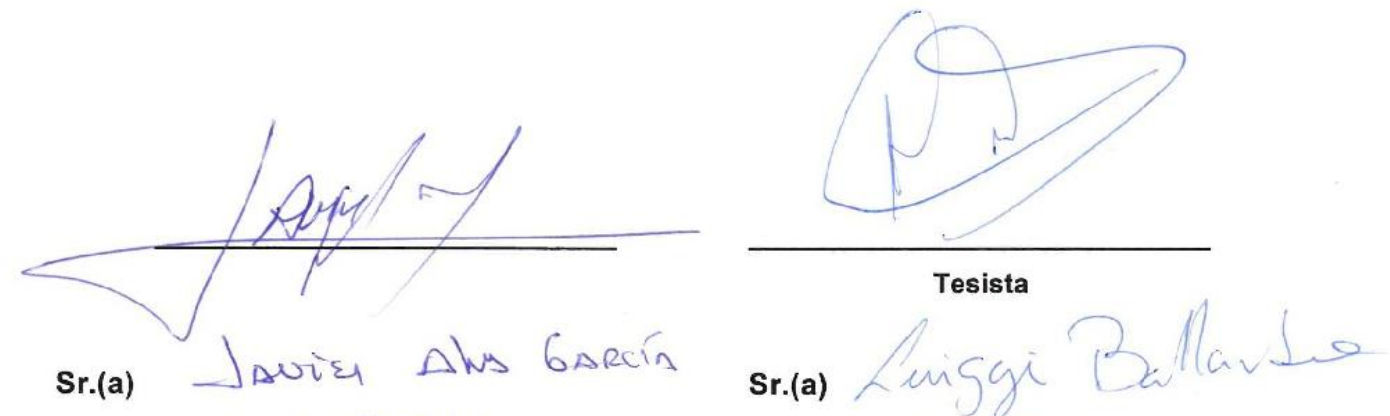

DNI: $\quad 0985.1262$

DNI:

Fecha: $\quad 17.05 \cdot 2018$ Fecha:

Figura 41: Carta de Consentimiento Informado Decano de la Faculta de Ciencias Empresariales Director de la carrera de Gestión Ambiental USIL. 


\section{ANEXO N 21}

Carolina Chumpitasi Diaz a través de usiloffice365.onmicrosoft.com

Estimado alumno:

El coordinador de la Carrera de Gestión Ambiental lo atenderá para lo solicitado.

Saludos cordiales,

Carolina Chumpitasi Diaz

Asistente

Vicerrectorado Académico

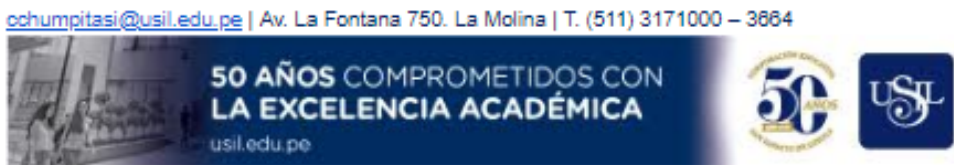

Figura 42: Correo del Decano de la Facultad de Ciencias Empresariales - Director de la carrera de Gestión Ambiental - Vicerrector Académico USIL. 


\section{ANEXO No 22. \\ Encuesta \\ "Guía de Gestión Ambiental USIL"}

La presente encuesta se realiza en el marco del Proyecto de Tesis "Guía de Gestión Ambiental para la Universidad San Ignacio de Loyola". Como requisito indispensable para iniciar la encuesta, el Encuestador debe entregar, en formato físico, la "Guía de Gestión Ambiental USIL" al Encuestado, para su análisis y revisión. El plazo máximo para el llenado de la Encuesta es de 7 días calendarios.

Nombre del Encuestado: LenNy Garcle NandNio Lasyzas Cargo del Encuestado: Coondivacon Académ Mico GaE

Fecha de la encuesta:

Siendo 1: Totalmente desacuerdo; Siendo 2: Desacuerdo; Siendo 3: Ni acuerdo ni en desacuerdo; Siendo 4: De acuerdo; y, Siendo 5: Totalmente de acuerdo

\begin{tabular}{|c|c|c|c|c|c|}
\hline \multirow{2}{*}{\multicolumn{6}{|c|}{\begin{tabular}{l|l} 
& $\begin{array}{c}\text { Grado de } \\
\text { acuerdo }\end{array}$ \\
1. Por favor, indique su grado de acuerdo con las siguientes premisas sobre los beneficios de la \\
implementación de la Guia de Gestión Ambiental USIL presentada.
\end{tabular}}} \\
\hline & & & & & \\
\hline $\begin{array}{l}\text { a. Es una herramienta para la toma de decisiones en la planificación ambiental de } \\
\text { la universidad. }\end{array}$ & 1 & 2 & 3 & 4 & \\
\hline $\begin{array}{l}\text { b. Fomenta la integración de la comunidad universitaria para mejorar el } \\
\text { desempeño ambiental de la universidad. }\end{array}$ & 1 & 2 & 3 & (4) & 5 \\
\hline $\begin{array}{l}\text { c. Marca el inicio para la implementación de un Sistema de Gestión Ambiental en } \\
\text { la universidad. }\end{array}$ & 1 & 2 & 3 & (4) & 5 \\
\hline $\begin{array}{l}\text { d. Permite conocer los aspectos e impactos ambientales que posee la universidad } \\
\text { a causa de sus acciones, decisiones u omisiones. }\end{array}$ & 1 & 2 & 3 & 4 & \\
\hline $\begin{array}{l}\text { e. La correcta implementación de la Guía contribuirá a la mejora del desempeño } \\
\text { ambiental de la universidad. }\end{array}$ & 1 & 2 & 3 & 4 & \\
\hline
\end{tabular}

2. Por favor, indique su grado de acuerdo con las siguientes premisas sobre la gestión ambiental actual en la universidad.

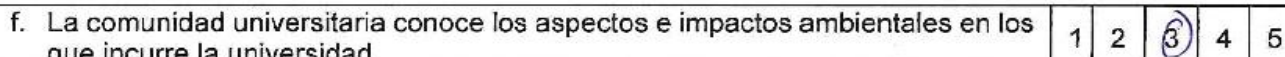
que incurre la universidad

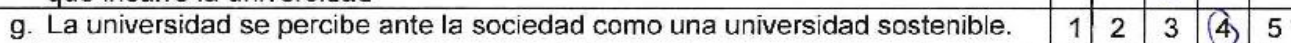

3. Por favor, indique su grado de acuerdo con las siguientes premisas sobre la participación actual del alumnado y tomadores de decisión en el accionar ambiental de la universidad.

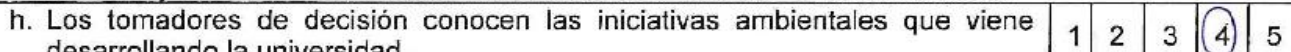
desarrollando la universidad.

i. El alumnado conoce las iniciativas ambientales que viene desarrollando la universidad. j. El alumnado participa en la toma de decisiones en materia ambiental de la
universidad.

4. Por favor, indique su grado de acuerdo con las siguientes premisas sobre el capítulo "Propuesta de Sistema de Gestión Ambiental" de la Guia.

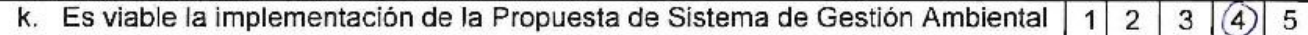

I. El capitulo precitado propone estrategias y acciones que deberian 132 3 (4) 5 implementarse con fines de mejorar el desempeño ambiental de la universidad.

5. Por favor, indique su grado de acuerdo con las siguientes premisas sobre el capítulo "Educación Ambiental" de la Guia.

$\mathrm{m}$. Debe impartirse un curso ambiental obligatorio dentro de la malla curricular de todas las carreras universitarias.

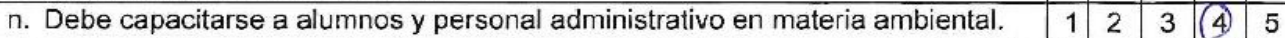

6. Por favor, indique su grado de acuerdo con las siguientes premisas sobre la implementación de la "Guia de Gestión Ambiental USIL"

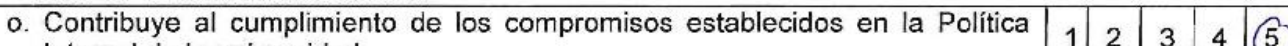
Integral de la universidad.

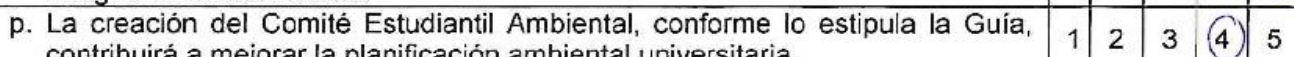
contribuirá a mejorar la planificación ambiental universitaria.

q. Debe implementarse a futuro la Guía de Gestión Ambiental USIL

Figura 43: Encuesta Coordinador Académico de la carrera de Gestión Ambiental USIL. 
ANEXO N 23.

\section{CARTA DE CONSENTIMIENTO INFORMADO}

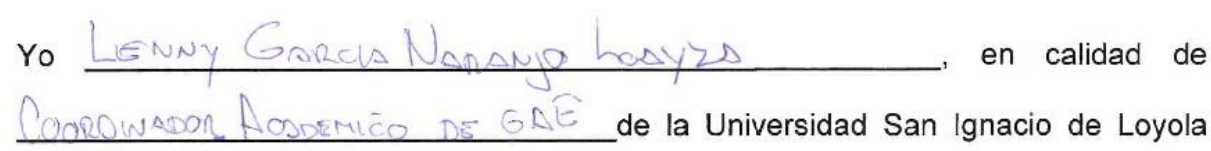

[USIL] y reconocido (a) con DNI No 10788667 ; por medio de la presente dejo constancia que he contribuido con la Tesis "Guía de Gestión Ambiental para la Universidad San Ignacio de Loyola" [Investigación], cuyo autor es el Bachiller Luiggi Anthony Ballardo Evangelista [Tesista]; a través del Ilenado de la Encuesta "Guía de Gestión Ambiental USIL", desarrollado por el Tesista, en el marco de la presente investigación.

Adicionalmente se me informó que:

Mi participación en esta investigación es completamente libre y voluntaria, estoy en libertad de retirarme de ella en cualquier momento.

No recibiré beneficio personal de ninguna clase por la participación en este proyecto de investigación. Sin embargo, se espera que los resultados obtenidos permitan mejorar el desempeño ambiental de la universidad.

Hago constar que el presente documento ha sido leído y entendido por mí en su integridad de manera libre y espontánea.
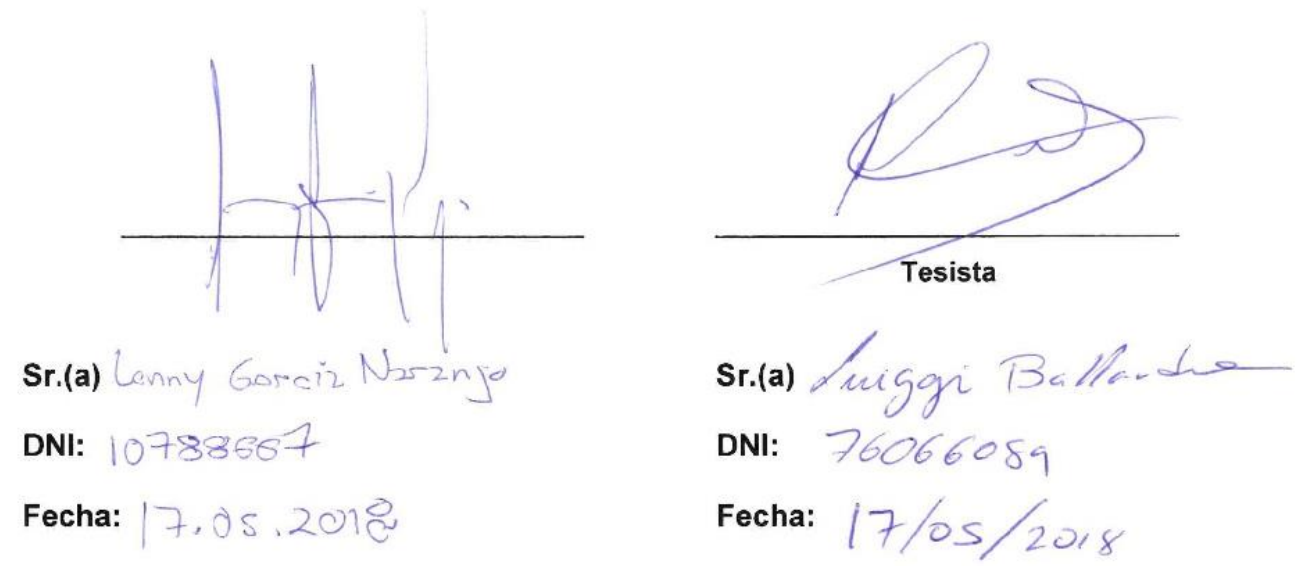

Figura 44: Carta de Consentimiento Informado Coordinador Académico de la carrera de Gestión Ambiental USIL. 


\section{ANEXO No 24}

\section{Encuesta Luiggi Ballardo}

B. Luiggi Ballardo <luiggiballardo.ev@gmail.com>

jue., 5 jul. 12:17 (Hace 2 días.)

para jpoggi v

Estimada Ing. Johanna Poggi

Buenas tardes. Mi nombre es Luiggi Ballardo, ex alumno de la universidad, y he elaborado, en el marco de mi tesis, una propuesta de Guia de Gestiòn Ambiental para USIL. En este sentido, vengo encuestando a tomadores de decisiòn y expertos en materia ambiental de la universidad sobre la necesidad de implementar esta propuesta de instrumento de gestion. Asimismo, conforme le manifestè el 17 de junio (fecha en la que usted me atendiò muy amablemente) estaria interesado en que usted pueda participar llenado la encuesta mencionada.

Cabe resaltar que conozco su limitada disponibilidad de tiempo, conforme me lo mencionò en la reuniòn. En caso usted disponga de tiempo para participar del llenado de la encuesta, se la estaria remitiendo por este medio a la brevedad posible. En caso no logre disponer del tiempo necesario, solicitaria por favor me lo haga saber por esta via.

Finalmente, agradecerle el feedback recibido en el espacio brindado en la reuniòn del 17 de mayo y por la oportunidad de poder contar con su opiniòn al respecto.

\section{Luiggi Ballardo Evangelista}

Teléfono: 887111826

Figura 45: Correo electrónico a la Directora de Ingeniería Ambiental - Solicitud de llenado de encuesta. 
ANEXO $\mathbf{N}^{\circ} 25$.

\section{Encuesta \\ "Guia de Gestión Ambiental USIL"}

La presente encuesta se realiza en el marco del Proyecto de Tesis "Guia de Gestión Ambiental para la Universidad San Ignacio de Loyola". Como requisito indispensable para iniciar la encuesta, el Encuestador debe entregar, en formato físico, la "Guia de Gestión Ambiental USIL" al Encuestado, para su análisis y revisión. El plazo máximo para el llenado de la Encuesta es de 7 dias calendarios.

Nombre del Encuestado: Dely 3 egama Choque

Cargo del Encuestado: Coord de la camena de Ing. Ambiental

Fecha de la encuesta: $25 / 05 / 2018$

Siendo 1: Totalmente desacuerdo; Siendo 2: Desacuerdo; Siendo 3: Ni acuerdo ni en desacuerdo; Siendo 4: De acuerdo; $y$, Siendo 5: Totalmente de acuerdo

\begin{tabular}{|c|c|c|c|c|c|}
\hline & \multicolumn{5}{|c|}{$\begin{array}{l}\text { Grado de } \\
\text { acuerdo }\end{array}$} \\
\hline \multicolumn{6}{|c|}{$\begin{array}{l}\text { 1. Por favor, indique su grado de acuerdo con las siguientes premisas sobre los beneficios de la } \\
\text { implementación de la Guia de Gestión Ambiental USIL. presentada. }\end{array}$} \\
\hline $\begin{array}{l}\text { a. Es una herramienta para la toma de decisiones en la planificación ambiental de } \\
\text { la universidad. }\end{array}$ & 1 & 2 & 3 & 4 & 5 \\
\hline $\begin{array}{l}\text { b. Fomenta la integración de la comunidad universitaria para mejorar el } \\
\text { desempeño ambiental de la universidad. }\end{array}$ & 1 & 2 & 3 & 4 & 5 \\
\hline $\begin{array}{l}\text { c. Marca el inicio para la implementación de un Sistema de Gestión Ambiental en } \\
\text { la universidad. }\end{array}$ & 1 & 2 & 3 & 4 & 兵 \\
\hline $\begin{array}{l}\text { d. Permite conocer los aspectos e impactos ambientales que posee la universidad } \\
\text { a causa de sus acciones, decisiones u omisiones. }\end{array}$ & 1 & 2 & 3 & 4 & $\sqrt[5]{1}$ \\
\hline $\begin{array}{l}\text { e. La correcta implementación de la Guia contribuirá a la mejora del desempeño } \\
\text { ambiental de la universidad. }\end{array}$ & 1 & 2 & 3 & 4 & 5 \\
\hline
\end{tabular}

2. Por favor, indique su grado de acuerdo con las siguientes premisas sobre la gestión ambiental actual en la universidad.

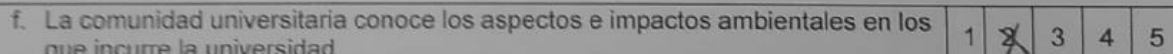
que incurre la universidad

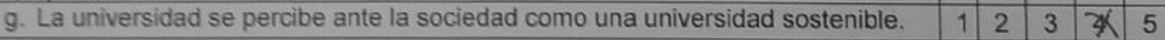

3. Por favor, indique su grado de acuerdo con las siguientes premisas sobre la participación actual del alumnado y tomadores de decisión en el accionar ambiental de la universidad.

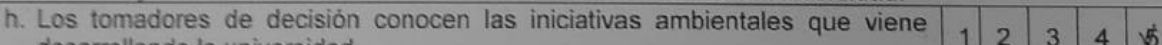
desarrollando la universidad.

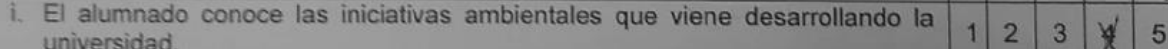
universidad.

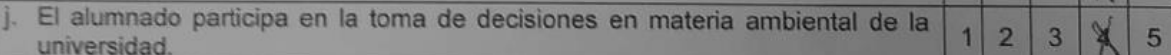

4. Por favor, indique su grado de acuerdo con las siguientes premisas sobre el capitulo "Propuesta de Sistema de Gestion Ambiental" de la Guia.

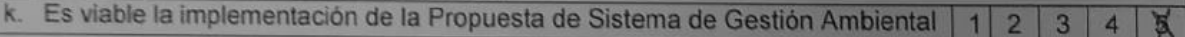

1. El capitulo precitado propone estrategias y acciones que deberian $\mid$\begin{tabular}{ll|l|l|l|l|}
\hline & 2 & 3 & 4 & 5
\end{tabular}

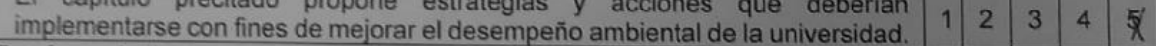

5. Por favor, indique su grado de acuerdo con las siguientes premisas sobre el capitulo "Educación Ambiental' de la Guia. m. Debe impartirse un curso ambiental obligatorio dentro de la malla curricular de
todas las carreras universitarias.

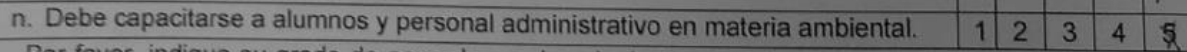

6. Por favor, indique su grado de acuerdo con las siguientes premisas sobre la implementación de la

"Guia de Gestión Ambiental USIL"

o. Contribuye al cumplimiento de los compromisos establecidos en la Política Integral de la universidad.

p. La creación del Comité Estudiantil Ambiental, conforme lo estipula la Guia, contribuirá a mejorar la planificación ambiental universitaria

q. Debe implementarse a futuro la Guia de Gestión Ambiental USIL

\begin{tabular}{|l|l|l|l|l|l|}
\hline 1 & 2 & 3 & 4 & 5 \\
\hline 1 & 2 & 3 & 4 & 5 \\
\hline 1 & 2 & 3 & 4 & 5 \\
\hline
\end{tabular}

Figura 46: Encuesta Coordinador Académico de la carrera de Ingeniería Ambiental USIL. 
ANEXO $\mathbf{N}^{\circ} 26$.

\section{CARTA DE CONSENTIMIENTO INFORMADO}

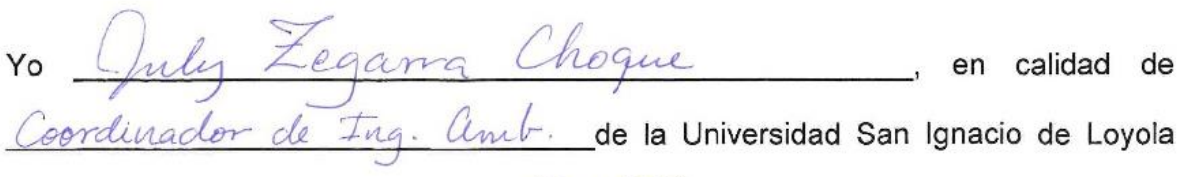

[USIL] y reconocido (a) con DNI N ${ }^{\circ} 40011788$; por medio de la presente dejo constancia que he contribuido con la Tesis "Guía de Gestión Ambiental para la Universidad San Ignacio de Loyola" [Investigación], cuyo autor es el Bachiller Luiggi Anthony Ballardo Evangelista [Tesista]; a través del Ilenado de la Encuesta "Guía de Gestión Ambiental USIL", desarrollado por el Tesista, en el marco de la presente investigación.

Adicionalmente se me informó que:

Mi participación en esta investigación es completamente libre y voluntaria, estoy en libertad de retirarme de ella en cualquier momento.

No recibiré beneficio personal de ninguna clase por la participación en este proyecto de investigación. Sin embargo, se espera que los resultados obtenidos permitan mejorar el desempeño ambiental de la universidad.

Hago constar que el presente documento ha sido leído y entendido por mí en su integridad de manera libre y espontánea.
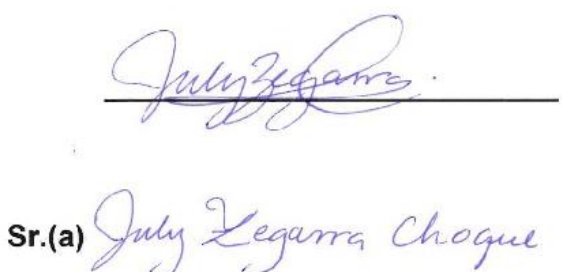

DNI: 40011788

Fecha: $17 / 05 / 18$

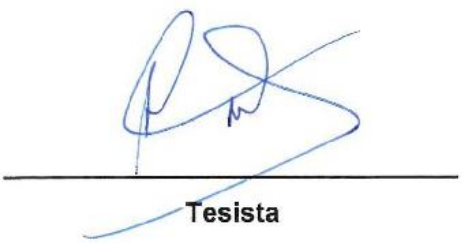

Sr.(a)

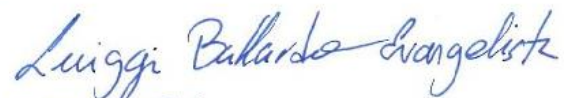

DNI: 76066089

Fecha:

Figura 47: Carta de Consentimiento Informado Coordinador Académico de la carrera de Ingeniería Ambiental USIL. 
ANEXO N ${ }^{\circ} 27$.

\section{Encuesta \\ "Guía de Gestión Ambiental USIL"}

La presente encuesta se realiza en el marco del Proyecto de Tesis "Guia de Gestión Ambiental para la Universidad San Ignacio de Loyola". Como requisito indispensable para iniciar la encuesta, el Encuestador debe entregar, en formato flsico, la "Guia de Gestión Ambiental USIL" al Encuestado, para su análisis y revisión. El plazo máximo para el llenado de la Encuesta es de 7 dias calendarios.

Nombre del Encuestado: Lisis Sartillair

Cargo del Encuestado: coordin $25 / 05 / 18$

Fecha de la encuesta

$$
\text { - }
$$

Siendo 1: Totalmente desacuerdo; Siendo 2: Desacuerdo; Siendo 3: Ni acuerdo ni en desacuerdo; Siendo 4: De acuerdo; $y$, Siendo 5: Totalmente de acuerdo

\begin{tabular}{|c|c|c|c|c|c|}
\hline & \multicolumn{5}{|c|}{$\begin{array}{l}\text { Grado de } \\
\text { acuerdo }\end{array}$} \\
\hline \multicolumn{6}{|c|}{$\begin{array}{l}\text { 1. Por favor, indique su grado de acuerdo con las siguientes premisas sobre los beneficios de la } \\
\text { implementación de la Guia de Gestión Ambiental USIL presentada. }\end{array}$} \\
\hline $\begin{array}{l}\text { a. Es una herramienta para la toma de decisiones en la planificación ambiental de } \\
\text { la universidad. }\end{array}$ & 1 & 3 & 4 & (5) & \\
\hline $\begin{array}{l}\text { la universidad. } \\
\text { b. Fomenta la integración de la comunidad universitaria para mejorar el } \\
\text { desempeño ambiental de la universidad. }\end{array}$ & 1 & 3 & (4) & 5 & \\
\hline $\begin{array}{l}\text { desempeño ambiental de la universıdad. } \\
\text { c. Marca el inicio para la implementación de un Sistema de Gestión Ambiental en } \\
\text { la universidad. }\end{array}$ & 1 & 23 & 4 & 5 & \\
\hline $\begin{array}{l}\text { la universidad. } \\
\text { d. Permite conocer los aspectos e impactos ambientales que posee la universidad } \\
\text { a causa de sus acciones, decisiones u omisiones. }\end{array}$ & 1 & 2 & 4 & 3 & \\
\hline $\begin{array}{l}\text { e. La correcta implementación de la Guia contribuirá a la mejora del desempeño } \\
\text { ambiental de la universidad. }\end{array}$ & 1 & 2 & 4 & & 5) \\
\hline \multicolumn{6}{|c|}{$\begin{array}{l}\text { ambiental de la universidad. } \\
\text { 2. Por favor, indique su grado de acuerdo con las siguientes premisas sobre la gestión ambiental actual } \\
\text { en la universidad. }\end{array}$} \\
\hline \begin{tabular}{l|l} 
f. La comunidad universitaria conoce los aspectos e impactos ambientales en los & 1 \\
que incurre la universidad &
\end{tabular} & $1 / 2$ & (2) 3 & 4 & 4 & 5 \\
\hline g. La universidad se percibe ante la sociedad como una universidad sostenible. 11 & \begin{tabular}{l|l}
12 \\
\end{tabular} & $2 \mathrm{C}_{3}$ & & 4 & 5 \\
\hline \multicolumn{6}{|c|}{$\begin{array}{l}\text { 3. Por favor, indique su grado de acuerdo con las siguientes premisas sobre la participación actual del } \\
\text { alumnado y tomadores de decisión en el accionar ambiental de la universidad. }\end{array}$} \\
\hline $\begin{array}{l}\text { h. Los tomadores de decisión conocen las iniciativas ambientales que viene } \\
\text { desarrollando la universidad. }\end{array}$ & 1 & $2 \mid 3$ & $3 \longdiv { 4 }$ & & 5 \\
\hline $\begin{array}{l}\text { i. El alumnado conoce las iniciativas ambientales que viene desarrollando la } \\
\text { universidad. }\end{array}$ & 1 & 2 & 3 & (4) & 5 \\
\hline $\begin{array}{l}\text { j. El alumnado participa en la toma de decisiones en materia ambiental de la } \\
\text { universidad. }\end{array}$ & 1 & 2 & (3) & 4 & 5 \\
\hline \multicolumn{6}{|c|}{$\begin{array}{l}\text { universidad. } \\
\text { 4. Por favor, indique su grado de acuerdo con las siguientes premisaş sobre el capitulo "Propuesta de } \\
\text { Sistema de Gestion Ambiental" de la Gula. }\end{array}$} \\
\hline k. Es viable la implementación de la Propuesta de Sistema de Gestión Ambiental & 1 & & (3) & 4 & 5 \\
\hline $\begin{array}{l}\text { I. El capitulo precitado propone estrateglas y acciones que deberian } \\
\text { implementarse con fines de mejorar el desempeño ambiental de la universidad. }\end{array}$ & 1 & 2 & 3 & (4) & 5 \\
\hline \multicolumn{6}{|c|}{$\begin{array}{l}\text { 5. Por favor, indique su grado de acuerdo con las siguientes premisas sobre el capítulo "Educación } \\
\text { Ambiental" de la Guía. }\end{array}$} \\
\hline $\begin{array}{l}\text { m. Debe impartirse un curso ambiental obligatorio dentro de'la malla curricular de } \\
\text { todas las carreras universitarias. }\end{array}$ & 1 & 2 & (3) & 4 & 5 \\
\hline n. Debe capacitarse a alumnos y personal administrativo en materia ambiental. & 1 & 2 & 3 & 4 & \\
\hline \multicolumn{6}{|c|}{$\begin{array}{l}\text { 6. Por favor, indique su grado de acuerdo con las siguientes premisas sobre la implementación de la } \\
\text { "Guia de Gestión Ambiental USIL" }\end{array}$} \\
\hline $\begin{array}{l}\text { o. Contribuye al cumplimiento de los compromisos establecidos en la Politica } \\
\text { Integral de la universidad. }\end{array}$ & 1 & 2 & 3 & 4 & \\
\hline $\begin{array}{l}\text { p. La creación del Comité Estudiantil Ambiental, conforme lo estipula la Guia, } \\
\text { contribuirá a mejorar la planificación ambiental universitaria. }\end{array}$ & 1 & 2 & 3 & 4 & \\
\hline q. Debe implementarse a futuro la Guila de Gestión Ambiental USIL & 1 & 2 & 3 & 4 & \\
\hline
\end{tabular}

Figura 48: Encuesta Coordinador Académico de la carrera de Ingeniería del Agua USIL. 
ANEXO $\mathbf{N}^{\circ} 28$.

\section{CARTA DE CONSENTIMIENTO INFORMADO}

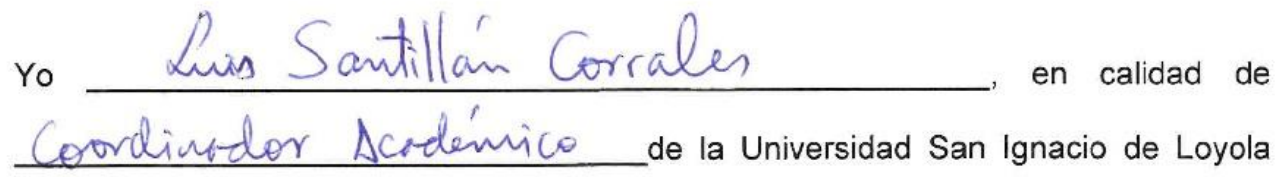

[USIL] y reconocido (a) con DNI No 07639041 ; por medio de la presente dejo constancia que he contribuido con la Tesis "Guía de Gestión Ambiental para la Universidad San Ignacio de Loyola" [Investigación], cuyo autor es el Bachiller Luiggi Anthony Ballardo Evangelista [Tesista]; a través del Ilenado de la Encuesta "Guía de Gestión Ambiental USIL", desarrollado por el Tesista, en el marco de la presente investigación.

Adicionalmente se me informó que:

Mi participación en esta investigación es completamente libre y voluntaria, estoy en libertad de retirarme de ella en cualquier momento.

$>$ No recibiré beneficio personal de ninguna clase por la participación en este proyecto de investigación. Sin embargo, se espera que los resultados obtenidos permitan mejorar el desempeño ambiental de la universidad.

Hago constar que el presente documento ha sido leído y entendido por mí en su integridad de manera libre y espontánea.

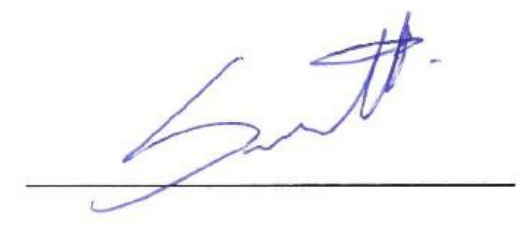

Sr.(a) Lisis Santillain Corrdes

DNI: $\quad 07639041$

Fecha: $\quad 17 / 05 / 18$

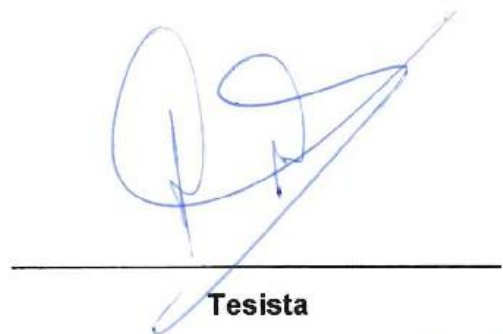

Sr.(a)

DNI:

Fecha:

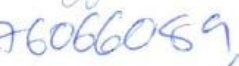

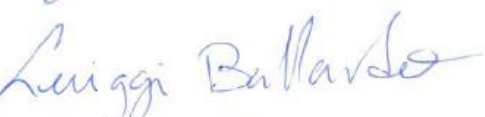

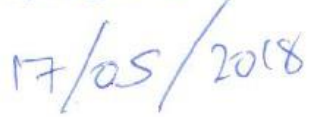

Figura 49: Carta de Consentimiento Informado Coordinador Académico de la carrera de Ingeniería del Agua USIL. 


\section{ANEXO N²9.}

\section{Resultados de la aplicación de encuestas.}

En el marco de la tabulación de resultados de la presente investigación, se consideran las siglas siguientes:

- VPRS: Vicepresidenta de Responsabilidad Social.

- VRID: Vicerrectora de Investigación y Desarrollo.

- CGAE: Coordinador Académico - Carrera Gestión Ambiental Empresarial.

- CIAM: Coordinador Académico - Carrera Ingeniería Ambiental.

- CIAG: Coordinador Académico - Carrera Ingeniería del Agua.

A continuación, se presenta la tabulación de resultados:

\section{Tabla 43}

Tabla resumen de resultados - Categoría de análisis.

\begin{tabular}{|c|l|}
\hline 1 & $\begin{array}{l}\text { Categoría de análisis: Beneficios de la implementación } \\
\text { de la Guía de Gestión Ambiental USIL. }\end{array}$ \\
\hline a & $\begin{array}{l}\text { Es una herramienta para la toma de decisiones en la } \\
\text { planificación ambiental de la universidad. }\end{array}$ \\
\hline b & $\begin{array}{l}\text { Fomenta la integración de la comunidad universitaria } \\
\text { para mejorar el desempeño ambiental de la universidad. }\end{array}$ \\
\hline c & $\begin{array}{l}\text { Marca el inicio para la implementación de un Sistema de } \\
\text { Gestión Ambiental en la universidad. }\end{array}$ \\
\hline d & $\begin{array}{l}\text { Permite conocer los aspectos e impactos ambientales } \\
\text { que posee la universidad a causa de sus acciones, } \\
\text { decisiones u omisiones. }\end{array}$ \\
\hline e & $\begin{array}{l}\text { La correcta implementación de la Guía contribuirá a la } \\
\text { mejora del desempeño ambiental de la universidad. }\end{array}$ \\
\hline
\end{tabular}

\begin{tabular}{|c|c|c|c|c|}
\hline VPRS & VRID & CGAE & CIAM & CIAG \\
\hline 3 & 5 & 5 & 5 & 5 \\
\hline 4 & 4 & 4 & 4 & 4 \\
\hline 2 & 5 & 4 & 5 & 3 \\
\hline 3 & 4 & 5 & 5 & 5 \\
\hline 3 & 5 & 5 & 5 & 5 \\
\hline
\end{tabular}

\begin{tabular}{|c|c|c|c|c|}
\hline TD & D & NA/ND & DA & TDA \\
\hline $0 \%$ & $0 \%$ & $20 \%$ & $0 \%$ & $80 \%$ \\
\hline $0 \%$ & $0 \%$ & $0 \%$ & $100 \%$ & $0 \%$ \\
\hline $0 \%$ & $20 \%$ & $20 \%$ & $20 \%$ & $40 \%$ \\
\hline $0 \%$ & $0 \%$ & $20 \%$ & $20 \%$ & $60 \%$ \\
\hline $0 \%$ & $0 \%$ & $20 \%$ & $0 \%$ & $80 \%$ \\
\hline
\end{tabular}




\section{Tabla 44}

Tabla resumen de resultados - Categoría de análisis.

\begin{tabular}{|l|l|}
\hline 2 & Categoría de análisis: Gestión ambiental actual USIL \\
\hline f & $\begin{array}{l}\text { La comunidad universitaria conoce los aspectos e } \\
\text { impactos ambientales en los que incurre la universidad. }\end{array}$ \\
\hline g & $\begin{array}{l}\text { La universidad se percibe ante la sociedad como una } \\
\text { universidad sostenible }\end{array}$ \\
\hline
\end{tabular}

\begin{tabular}{|c|c|c|c|c|}
\hline VPRS & VRID & CGAE & CIAM & CIAG \\
\hline 2 & 2 & 3 & 2 & 2 \\
\hline 4 & 3 & 4 & 4 & 3 \\
\hline
\end{tabular}

\begin{tabular}{|c|c|c|c|c|}
\hline TD & D & NA/ND & DA & TDA \\
\hline $0 \%$ & $80 \%$ & $20 \%$ & $0 \%$ & $0 \%$ \\
\hline $0 \%$ & $0 \%$ & $40 \%$ & $60 \%$ & $0 \%$ \\
\hline
\end{tabular}

\section{Tabla 45}

Tabla resumen de resultados - Categoría de análisis.

\begin{tabular}{|c|l|}
\hline 3 & $\begin{array}{l}\text { Categoría de análisis: Participación de partes } \\
\text { interesadas. }\end{array}$ \\
\hline h & $\begin{array}{l}\text { Los tomadores de decisión conocen las iniciativas } \\
\text { ambientales que viene desarrollando la universidad. }\end{array}$ \\
\hline i & $\begin{array}{l}\text { El alumnado conoce las iniciativas ambientales que } \\
\text { viene desarrollando la universidad. }\end{array}$ \\
\hline j & $\begin{array}{l}\text { El alumnado participa en la toma de decisiones en } \\
\text { materia ambiental de la universidad. }\end{array}$ \\
\hline
\end{tabular}

\begin{tabular}{|c|c|c|c|c|}
\hline VPRS & VRID & CGAE & CIAM & CIAG \\
\hline 3 & 4 & 4 & 5 & 4 \\
\hline 3 & 2 & 3 & 4 & 4 \\
\hline 2 & 2 & 3 & 4 & 3 \\
\hline
\end{tabular}

\begin{tabular}{|c|c|c|c|c|}
\hline TD & D & NA/ND & DA & TDA \\
\hline $0 \%$ & $0 \%$ & $20 \%$ & $60 \%$ & $20 \%$ \\
\hline $0 \%$ & $20 \%$ & $40 \%$ & $40 \%$ & $0 \%$ \\
\hline $0 \%$ & $40 \%$ & $40 \%$ & $20 \%$ & $0 \%$ \\
\hline
\end{tabular}


Tabla 46

Tabla resumen de resultados - Categoría de análisis.

4 Categoría de análisis: Propuesta de Sistema de

4 Gestión Ambiental

Es viable la implementación de la Propuesta de Sistema

de Gestión Ambiental.

El capítulo precitado propone estrategias y acciones que

I deberían implementarse con fines de mejorar el

desempeño ambiental de la universidad.

\section{Tabla 47}

Tabla resumen de resultados - Categoría de análisis

\begin{tabular}{|c|l|}
\hline 5 & Categoría de análisis: Educación Ambiental \\
\hline $\mathrm{m}$ & $\begin{array}{l}\text { Debe impartirse un curso ambiental obligatorio dentro de } \\
\text { la malla curricular de todas las carreras universitarias. }\end{array}$ \\
\hline $\mathrm{n}$ & $\begin{array}{l}\text { Debe capacitarse a alumnos y personal administrativo } \\
\text { en materia ambiental. }\end{array}$ \\
\hline
\end{tabular}

\section{Tabla 48}

Tabla resumen de resultados - Categoría de análisis

6 Categoría de análisis: Implementación de la propuesta de Guía de Gestión Ambiental USIL.

Contribuye al cumplimiento de los compromisos

- establecidos en la Política Integral de la universidad.

La creación del Comité Estudiantil Ambiental, conforme

p lo estipula la Guía, contribuirá a mejorar la planificación ambiental universitaria.

Debe implementarse a futuro la Guía de Gestión

Ambiental USIL.

\begin{tabular}{|c|c|c|c|c|}
\hline VPRS & VRID & CGAE & CIAM & CIAG \\
\hline 3 & 4 & 4 & 5 & 3 \\
\hline 3 & 5 & 4 & 5 & 4 \\
\hline
\end{tabular}

\begin{tabular}{|c|c|c|c|c|}
\hline TD & D & NA/ND & DA & TDA \\
\hline $0 \%$ & $0 \%$ & $40 \%$ & $40 \%$ & $20 \%$ \\
\hline $0 \%$ & $0 \%$ & $20 \%$ & $40 \%$ & $40 \%$ \\
\hline
\end{tabular}

\begin{tabular}{|c|c|c|c|c|}
\hline VPRS & VRID & CGAE & CIAM & CIAG \\
\hline 4 & 4 & 4 & 5 & 3 \\
\hline 4 & 4 & 4 & 5 & 5 \\
\hline
\end{tabular}

\begin{tabular}{|c|c|c|c|c|}
\hline TD & D & NA/ND & DA & TDA \\
\hline $0 \%$ & $0 \%$ & $20 \%$ & $60 \%$ & $20 \%$ \\
\hline $0 \%$ & $0 \%$ & $0 \%$ & $60 \%$ & $40 \%$ \\
\hline
\end{tabular}

\begin{tabular}{|c|c|c|c|c|}
\hline VPRS & VRID & CGAE & CIAM & CIAG \\
\hline 3 & 4 & 4 & 5 & 4 \\
\hline 3 & 2 & 3 & 4 & 4 \\
\hline 2 & 2 & 3 & 4 & 3 \\
\hline
\end{tabular}

\begin{tabular}{|c|c|c|c|c|}
\hline TD & D & NA/ND & DA & TDA \\
\hline $0 \%$ & $0 \%$ & $20 \%$ & $20 \%$ & $60 \%$ \\
\hline $0 \%$ & $0 \%$ & $0 \%$ & $60 \%$ & $40 \%$ \\
\hline $0 \%$ & $0 \%$ & $20 \%$ & $40 \%$ & $40 \%$ \\
\hline
\end{tabular}


ANEXO № 30 - Tabla 49.

\begin{tabular}{|c|c|c|c|c|}
\hline PROBLEMA & JUSTIFICACIÓN & OBJETIVOS & HIPÓTESIS & MÉTODO \\
\hline $\begin{array}{l}\text { ¿Qué tan de acuerdo } \\
\text { están las autoridades y } \\
\text { expertos en materia } \\
\text { ambiental de la } \\
\text { Universidad San } \\
\text { lgnacio de Loyola en } \\
\text { relación al diseño e } \\
\text { implementación de la } \\
\text { propuesta de Guía de } \\
\text { Gestión Ambiental, } \\
\text { instrumento que } \\
\text { contribuirá } \\
\text { cumplimiento de los } \\
\text { compromisos } \\
\text { ambientales } \\
\text { establecidos en la } \\
\text { Política Integrada de la } \\
\text { universidad? }\end{array}$ & $\begin{array}{l}\text { Se estima conveniente el } \\
\text { análisis del presente caso de } \\
\text { estudio, debido a que la } \\
\text { Universidad San Ignacio de } \\
\text { Loyola no cuenta en la } \\
\text { actualidad con un } \\
\text { instrumento de gestión } \\
\text { ambiental que establezca } \\
\text { criterios, lineamientos y } \\
\text { estrategias unificadas para la } \\
\text { ejecución de actividades y } \\
\text { procesos que contribuyan al } \\
\text { cumplimiento de los } \\
\text { objetivos ambientales } \\
\text { organizacionales y acciones } \\
\text { estratégicas establecidas en } \\
\text { la Política Integrada de la } \\
\text { universidad. Ambiental } \\
\text { Esta propuesta de Guía de } \\
\text { Gestión gestión } \\
\text { (instrumento de de } \\
\text { ambiental) es capaz de } \\
\text { orientar acciones del } \\
\text { personal administrativo, } \\
\text { docentes y alumnos a través }\end{array}$ & $\begin{array}{l}\text { Objetivo General: } \\
\text { Conocer el grado de acuerdo } \\
\text { de las autoridades y expertos } \\
\text { en materia ambiental de la } \\
\text { Universidad San Ignacio de } \\
\text { Loyola en relación al diseño e } \\
\text { implementación de la } \\
\text { propuesta de Guía de Gestión } \\
\text { Ambiental, instrumento que } \\
\text { contribuirá al cumplimiento de } \\
\text { los compromisos ambientales } \\
\text { establecidos en la Política } \\
\text { Integrada de la universidad. } \\
\text { Objetivos Específicos: } \\
\text { Desarrollar el Diagnóstico } \\
\text { Ambiental de la universidad } \\
\text { con el objetivo de mostrar una } \\
\text { vista actual de la gestión } \\
\text { ambiental en la universidad e } \\
\text { identificar aspectos e impactos } \\
\text { ambientales significantes y } \\
\text { priorizarlos. }\end{array}$ & $\begin{array}{l}\text { Pese a que la investigación } \\
\text { es netamente cualitativa } \\
\text { descriptiva, se ha } \\
\text { establecido una hipótesis de } \\
\text { trabajo. Según el autor } \\
\text { Carlos Muñoz Razo, en su } \\
\text { libro "Como elaborar y } \\
\text { asesorar una investigación } \\
\text { de Tesis" segunda edición, } \\
\text { año 2011, manifiesta lo } \\
\text { siguiente para el } \\
\text { establecimiento de hipótesis } \\
\text { en investigaciones } \\
\text { cualitativas: "Si bien se } \\
\text { establece una hipótesis de } \\
\text { trabajo, éstar no } \\
\text { necesariamenter se } \\
\text { comprueba con datos de } \\
\text { medición numérica o con } \\
\text { interpretación estadística. } \\
\text { Sin embargo, con los } \\
\text { resultados obtenidos es } \\
\text { posible interpretar y explicar } \\
\text { la realidad estudiada". }\end{array}$ & $\begin{array}{l}\text { Tipo de investigación: } \\
\text { Según el nivel de complejidad del estudio y el tipo de análisis al que se } \\
\text { somete la información recolectada, se concluye la realización de una } \\
\text { investigación descriptiva de análisis cualitativo, dado que se observa y } \\
\text { describe el estado actual de la gestión ambiental en la Universidad San } \\
\text { lgnacio de Loyola (fenómeno particular holístico); y con la información } \\
\text { obtenida, se diseña una propuesta de Guía de Gestión Ambiental } \\
\text { (instrumento de gestión ambiental) que contribuirá al cumplimiento de los } \\
\text { compromisos ambientales establecidos en la Política Integrada de la } \\
\text { universidad. } \\
\text { Finalmente, se realizarán encuestas, usando la escala de medición Likert, } \\
\text { con la finalidad de conocer el grado de acuerdo de autoridades y expertos } \\
\text { en materia ambiental de la universidad, en cuanto a la necesidad de } \\
\text { implementar la Guía de Gestión Ambiental propuesta. } \\
\text { La presente investigación estudia un fenómeno particular (estado actual de } \\
\text { la gestión ambiental en la universidad) y no busca la generalización de sus } \\
\text { resultados a una población determinada. } \\
\text { Diseño de la investigación: } \\
\text { Con la finalidad de cumplir con el objetivo general, se ha procedido a } \\
\text { diseñar los pasos siguientes, dividido en } 03 \text { etapas: } \\
\text { A. Elaboración del Diagnóstico Ambiental USIL } \\
\text { 1. Recopilación de información de las actividades en materia ambiental } \\
\text { que viene desarrollando la universidad, con la finalidad de conocer el } \\
\text { estado actual de la gestión ambiental en USIL. }\end{array}$ \\
\hline
\end{tabular}




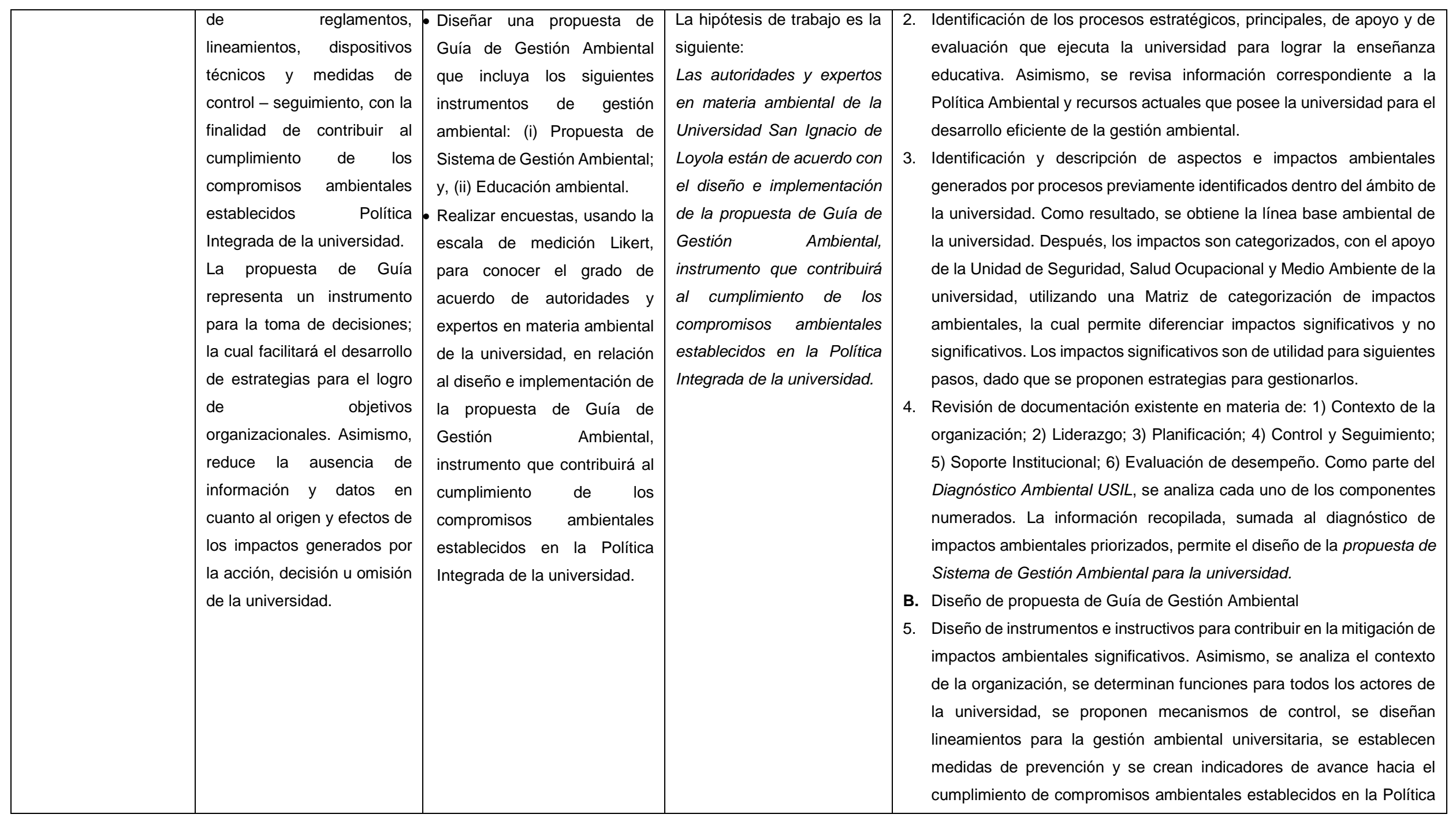




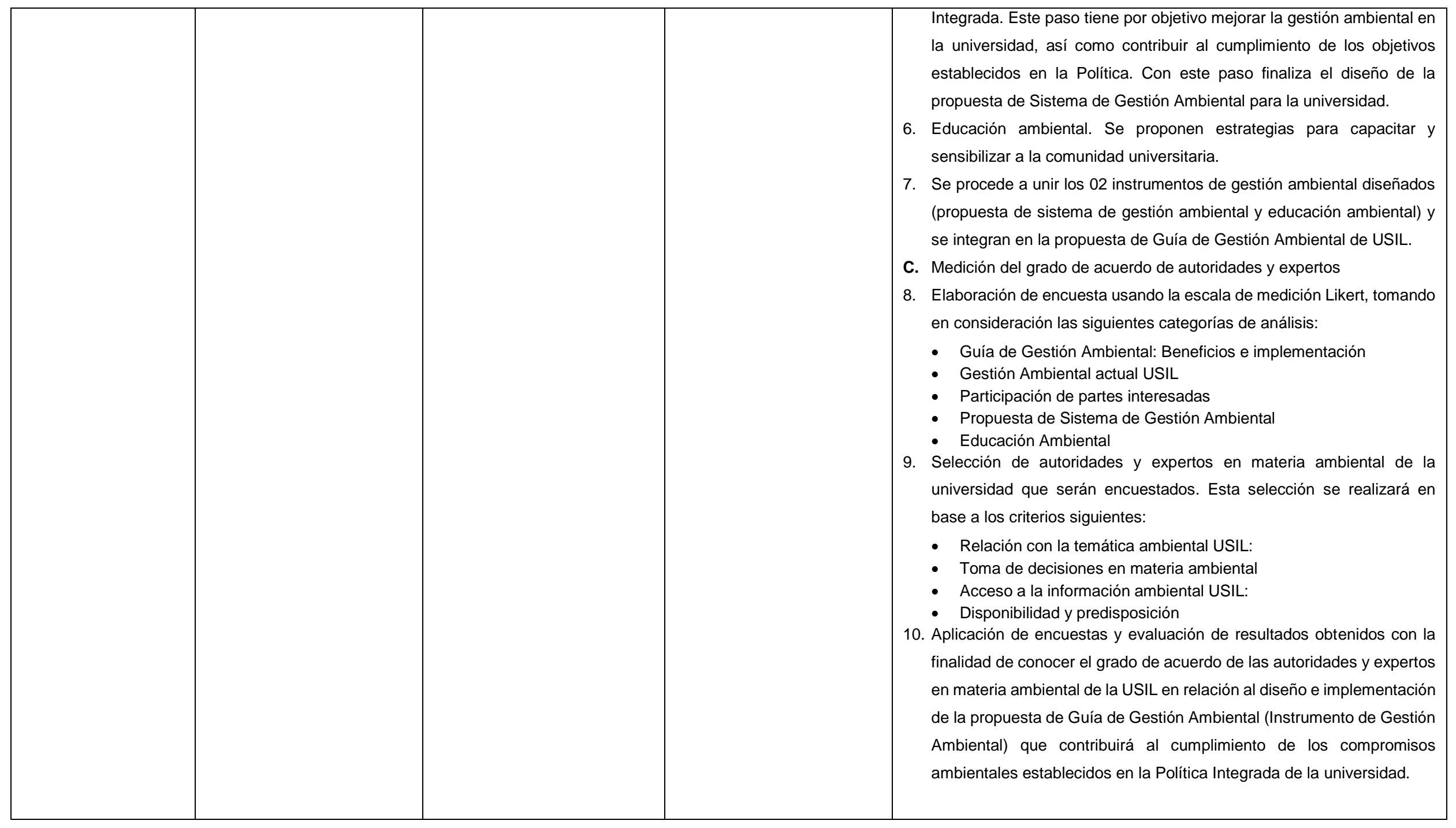


